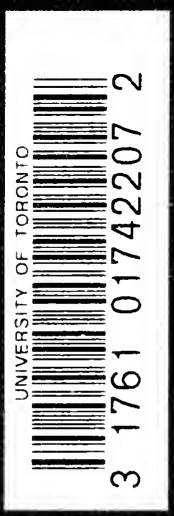



12166 
Digitized by the Internet Archive in 2007 with funding from Microsoft Corporation 
THE MAFULU MOUNTAIN PEOPLE OF BRITISH NEW GUINEA 


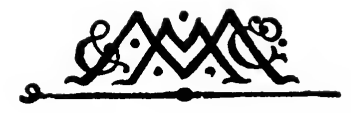
MACMILLAN AND CO., LIMITED LONDON - BOMBAY . CALCUTTA MELBOURNE

THE MACMILLAN COMPANY NEW YORK - BOSTON . CHICAGO

DALLAS . SAN FRANCISCO

THE MACMILLAN CO. OF CANADA, LTD. TORONTO 



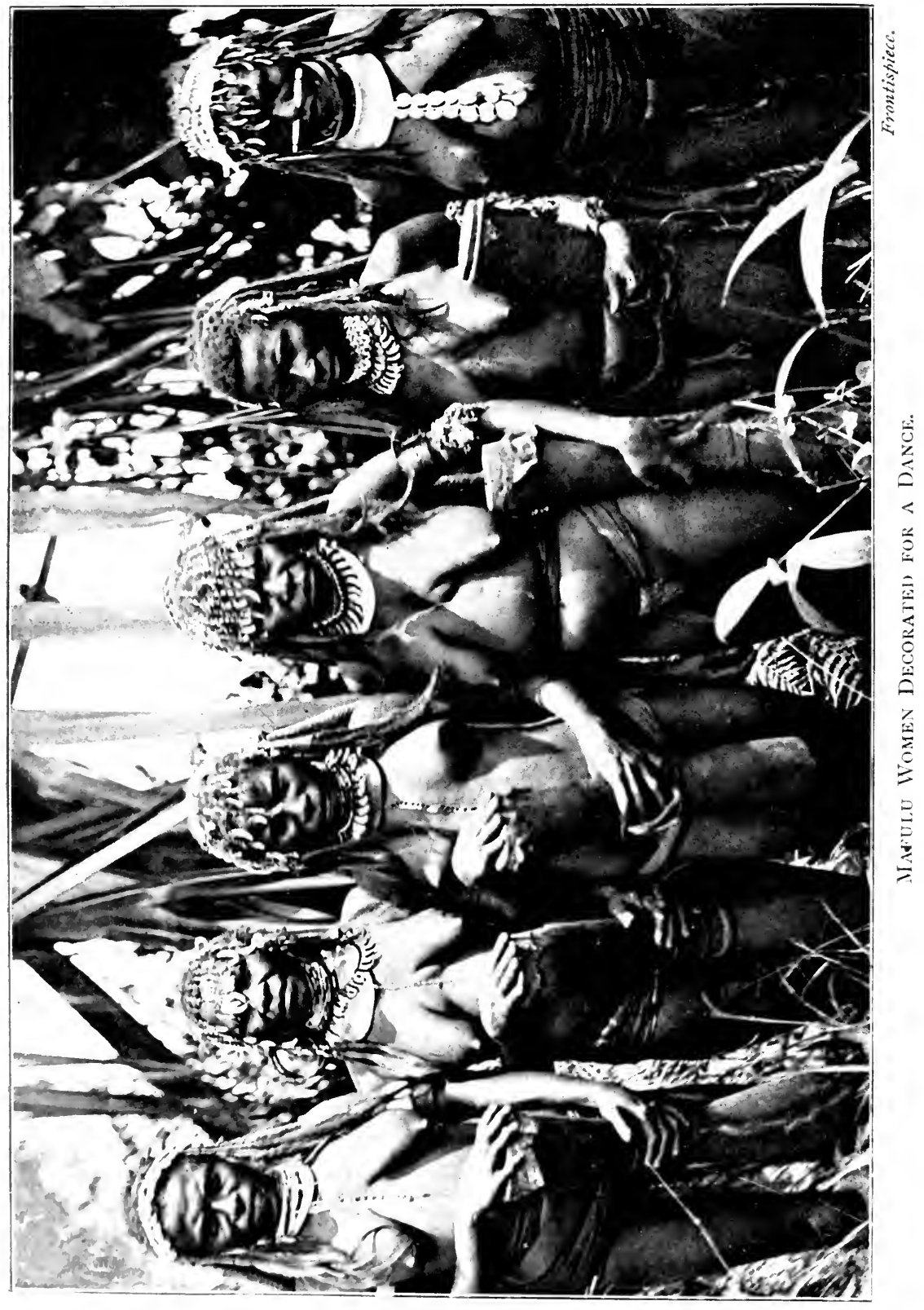




\section{THE MAFULU}

\section{MOUNTAIN PEOPLE OF BRITISH NEW GUINEA}

ROBERT W. WILLIAMSON

WITH AN INTRODUCTION

BY

A. C. HADDON, Sc.D., F.R.S.

WITH ILLUSTRATIONS AND MAP

MACMILLAN AND CO., LIMITED ST. MARTIN'S STREET, LONDON I 9 I 2 
COPYRIGHT

Richard Clay and Sons, Limited, BRUNSWICK STREET, STAMFORD STREET, S.E., AND BUNGAY, SUFFOLK.
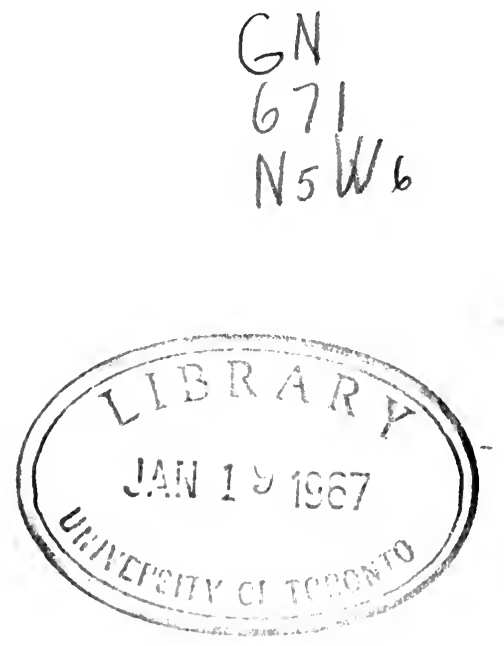


\section{PREFACE}

THIs book is the outcome of an expedition to British New Guinea in I9I0, in which, after a short stay among the people of some of the western Solomon Islands, including those of that old centre of the head hunters, the Rubiana lagoon, and a preparatory and instructive journey in New Guinea among the large villages of the Mekeo district, I struck across country by a little known route, via Lapeka, to Ido-Ido and on to Dilava, and thus passed by way of further preparation through the Kuni country, and ultimately reached the district of the Mafulu villages, of whose people very little was known, and which was therefore the mecca of my pilgrimage.

I endeavoured to carry out the enquiries of which the book is a record as carefully and accurately as possible; but it must be remembered that the Mafulu people had seen very few white men, except some of the Fathers of the Catholic Mission of the Sacred Heart, the visits of Government officials and once or twice of a scientific traveller having been but few and far between, and only short; that the mission station 
in Mafulu (the remotest station of the mission) had only been established five years previously; that the people were utterly unaccustomed to the type of questioning which systematic ethnological enquiry involves, and that necessarily there was often the usual hesitation in giving the required information.

I cannot doubt, therefore, that future enquiries and investigations made in the same district will bring to light errors and misunderstandings, which even with the greatest care can hardly be avoided in the case of a first attempt on new ground, where everything has to be investigated and worked up from the beginning. I hope, however, that the bulk of my notes will be found to have been correct in substance so far as they go.

I regret that my ignorance of tropical flora and fauna has made it impossible for me to give the names of many of the plants and animals to which I refer.

There are many people, more than I can mention here, to whom I owe my grateful thanks. Prior to my departure for the South Seas Dr. Haddon took great trouble in helping and advising me, and, indeed, I doubt whether I should have ventured upon my solitary expedition if I had not had his stimulating encouragement.

In New Guinea I had the never-failing hospitality and kindness of my good friend Monseigneur de Boismenu (the Bishop of the Mission of the Sacred Heart) and the Fathers and Brothers of the Mission. Among the latter I would specially mention Father Egedi and Father Clauser. Father Egedi (whose name is already familiar to students of New Guinea Ethnology) was my friend and travelling companion during a 
portion of my journeyings through the Mekeo and Kuni districts, and his Mekeo explanations proved invaluable to me when I reached my Mafulu destination. And dear good Father Clauser was a pillar of help in Mafulu. He placed at my disposal all his existing knowledge concerning the people, and was my intermediary and interpreter throughout all my enquiries. And finally, when having at some risk prolonged my stay at Mafulu until those enquiries were completed, I was at last compelled by the serious state of my health to beat a retreat, and be carried down to the coast, he undertook to do the whole of my photographing and physical measurements, and the care and skill with which he did so are evidenced by the results as disclosed in this book. ${ }^{1}$ I must also add that the frontispiece and plates $I 7,67,68,69$ and 70 are taken from previous photographs which Father Clauser kindly placed at my disposal. My remembrance of His Lordship the Bishop, and of the Reverend Fathers and the Brothers of the Mission will ever be one of affectionate personal regard, and of admiration of the spirit of herioc self-sacrifice which impels them to submit cheerfully to the grave and constant hardships and dangers to which their labour of love necessarily exposes them.

Since my return home Dr. Seligmann has given me immense help, advising me upon my notes, placing material at my disposal, and afterwards reading through a considerable portion of my manuscript. Mr. T. A.

1 The photographs of skulls, articles of dress and ornament, implements and weapons were made in London after my return. 
Joyce and Mr. J. Edge Partington helped me in arranging and dealing with the things which I had brought back to the British Museum. Dr. Keith examined and reported upon some skulls which I had obtained, and advised me upon my notes on physique. Dr. Stapf helped me in matters of botanical identification; Mr. S. H. Ray has given me the full benefit of his wide knowledge of South Pacific linguistics, and has written the appendices to the book. And, finally, Dr. Haddon has very kindly read through my proof sheets.

In conclusion, I would add that there is still an immense amount of detailed work to be done among the Mafulu people, and that the districts of the Ambo and Boboi and Oru Lopiku people, still further back among the mountains, offer an almost virgin field for investigation to anyone who will take the trouble to go there. 


\section{CONTENTS}

. PAGE

INTRODUCTION, BY DR. A. C. HADDON . . . . . . . xvii

\section{CHAPTER I}

INTRODUCTORY .

CHAPTER II

PHYSIQUE AND CHARACTER $. \quad . \quad$. . . . . . $\quad$. 17

CHAPTER III

DRESS AND ORNAMENT . . . . . . . . . . . 26

CHAPTER IV

DAILY LIFE AND MATTERS CONNECTED WITH IT . . . . 63

CHAPTER V

COMMUNITY, CLAN, AND VILLAGE SYSTEMS AND CHIEFTAINSHIP 82

CHAPTER VI

VILLAGES, EMONE, HOUSES AND MODES OF INTER-VILLAGE

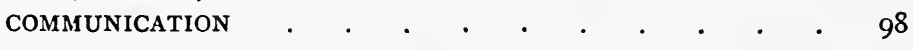

CHAPTER VII

GOVERNMENT, PROPERTY AND INHERITANCE . • . . . . II4

CHAPTER VIII

THE BHG FEAST 
CHAPTER IX

SOME OTHER CEREMONIES AND FEASTS

CHAPTER $\mathrm{X}$

MATRIMONIAL AND SEXUAL . 168

CHAPTER XI

KILLING, CANNIBALISM AND WARFARE . . . . . . 176

CHAPTER XII

HUNTING, FISHING AND AGRICULTURE . . . . . . 186

CHAPTER XIII

BARK CLOTH MAKING, NETTING AND ART

201

CHAPTER XIV

MUSIC AND SINGING, DANCING, AND TOYS AND GAMES

212

CHAPTER XV

COUNTING, CURRENCY AND TRADE

CHAPTER XVI

LANGUAGE

CHAPTER XVII

ILLNESS, DEATH AND BURIAL

240

CHAPTER XVIII

RELIGION AND SUPERSTITIOUS BELIEFS AND PRACTICES • $\quad 264$

CHAPTER XIX

NOTE ON THE KUNI PEOPLE

290

CHAPTER XX

CONCLUSION 


\section{APPENDIX I}

a GRammar of the FuYUge language.

\section{APPENDIX II}

NOTE ON THE AFOA LANGUAGE

APPENDIX III

NOTE ON THE KOVIO LANGUAGE

\section{APPENDIX IV}

A COMPARATIVE VOCABULARY OF THE FUYUGE, AFOA, AND KOVIO LANGUAGES ..$\quad$. . . . . . . . . . 336

\section{APPENDIX V}

NOTES ON THE PAPUAN LANGUAGES SPOKEN ABOUT THE HEAD WATERS OF THE ST. JOSEPH RIVER, CENTRAL PAPUA • • 345 



\section{LIST OF ILLUSTRATIONS}

PLATE

Mafulu Women Decorated for a Dance . . Frontispiece

I.-Kuni Scenery . . . . . . . . To face page

I 4

2.-Mafulu Scenery . . . . . . . . ",$\quad$ I4

3.-Skull A . . . . . . . . . . . .

4.-Skull C . . . . . . . . . . . ,

5.-Husband, Wife and Child . . . . . " , " 26

6.-Man and Two Women . . . . . . " , " ‘ 26

7, 8.-Man, Young Man and Boy . . . . " " 30

9.-Different Types of Men . . . . . . . " , " $\quad 34$

Io.-An Unusual Type . . . . . . . . " " ,

I I, 12.- Two Unusual Types . • • . . • " " " 42

13.-Fig. I. Section of Man's Perineal Band. Fig. 2.

Decoration near end of Woman's Perineal

Band. Fig. 3. Section of Woman's Perineal

Band. Fig. 4. Section of Man's or Woman's

Dancing Ribbon . . . . . . " " 46

14.-Fig. I. Belt No. I. Fig. 2. Belt No. 3. Fig. 3.

Belt No. 4 . Belt No. 5 (one end only). Fig. 2. Belt

15.-Fig. I. Belt No. 5 (one end only). Fig. 2. Belt

No. 6 (one end only). Fig. 3. Belt No. 7 . " " " 54

I6.-A General Group . . . . . . . " " 58

17.-A Young Chief s Sister decorated for a Dance . " , , " 62

18, 19.-Women wearing Illness Recovery Capes . " " " 66

20. -Fig. 1. Ear-rings. Fig. 2. Jew's Harp. Fig. 3. Hair Fringe . . . . . . . " , " , 70

2I.-Man, Woman and Children . . . . . " " " 74

22, 23.-A Little Girl with Head Decorations . . " , , , 78

24.-Figs. I, 2, 5, and 6. Women's Hair Plaits decorated with European Beads, Shells, Shell Discs, Dog's Tooth, and Betel Nut Fruit. Fig. 3. Man's Hair Plait with Cane Pendant. Fig. 4. Man's Hair Plait with Betel Nut Pendant . . . . . . . . " , " 42 
PLATE

25.-Fig. I. Leg Band. Figs. 2 and 4. Women's Hair Plaits decorated with Shells and Dogs' Teeth. Fig. 3. Bone Implement used (as a Fork) for Eating 26.-Group of Women 27.-A Young Woman 28. - Two Women 29. - Two Women 30.-Fig. I. Mourning String Necklace. Fig. 2. To face page 86 Comb. Fig. 3. Pig's Tail Ornament for Head. Fig. 4. Whip Lash Head Ornament.

Fig. 5. Forehead Ornament . 3I.-Necklaces 32.-A Necklace 33.-Necklaces . 34.-Fig. I. Armlet No. 5. Fig. 2. Armlet No. 4.

Fig. 3. Armlet No. 2. Fig. 4. Armlet No. I 35.-Woman wearing Dancing Apron . 36, 37.-Decoration of Dancing Aprons 38, 39.40,4 I. $42,43 .-$ 44.- - Head Feather Ornaments 45. 46.-Fig. I. Head Feather Ornament. Fig. 2. Back Feather Ornament 47.- Plaited Head Feather Frames 48. - Mother and Baby 49.-At the Spring 50.-A Social Gathering .

5I.-Fig. 1. Small Smoking Pipe. Fig. 2. Pig-bone Scraping Implement. Fig. 3. Stone Bark Cloth Beater. Fig. 4. Drilling Implement. Fig. 5. Bamboo Knife. Figs. 6 and 7. Lime Gourds

52.-Fig. 1. Wooden Dish. Figs. 2 and 3. WaterCarrying Gourds

53.-Fig. I. Bag No. 3. Fig. 2. Bag No. 4. Fig. 3. Bag. No. 6 .

54.-Village of Salube and Surrounding Country 55.-Village of Seluku, with Chief's Emone at End and Remains of Broken-down Burial Platform in Middle . 166

150 I 54 158 162 162

102

106

I 10

114

I 18

122

126

130

I34

I 38

142

146

54 58 
PLATE

57.-Village of Amalala (looking in other direction), with Secondary Emone at End . . .

58.-Village of Malala, with Secondary Emone at End To face page 190 and Ordinary Grave and Burial Platform of Chief's Child in Right Foreground

59.-Village of Uvande, with Chief's Emone at End . 6o.-Village of Biave, with Chief's Emone at End and Burial Platform of Chief's Child in Middle

6I.-Chiefs Emone in Village of Amalala

62.-Chief s Emone in Village of Malala . . .

63.-House in Village of Malala . . . . .

64.-House in Village of Levo, with Child's Excrement Receptacle to Left .

65.-Suspension Bridge over St. Joseph River . .

66.-Bridge over Aduala River

67.- Scene at Big Feast in Village of Amalala .

68.--Row of Killed Pigs at Big Feast at Village of Amalala

69.-Scene at Village of Seluku during Preparations for Big Feast . $. \quad . \quad . \quad . \quad . \quad$.

70.-Scene at Big Feast at Village of Seluku . . 71.-Young Girl Ornamented for Perineal Band Ceremony

72.- Feast at Perineal Band Ceremony

73.-Figs. I, 2, and 3. Points of War Spears. Fig. 4.

Point of War-Arrow. Fig. 5. Point of BirdShooting Arrow

74.-Fig. 1. Bow. Fig. 2. Shield (outside). Fig. 3. Shield (inside)

$\begin{array}{lll}, & , & \text { I94 } \\ , & \quad 198\end{array}$

\begin{tabular}{|c|c|c|}
\hline " & $"$ & 202 \\
\hline$"$ & " & 206 \\
\hline " & " & 206 \\
\hline ", & $"$ & 210 \\
\hline$"$ & ", & 210 \\
\hline$"$ & " & 214 \\
\hline " & ", & 214 \\
\hline$"$ & $"$ & - 218 \\
\hline " & " & 222 \\
\hline " & , & 226 \\
\hline$"$ & " & 230 \\
\hline$"$ & ", & 234 \\
\hline$"$ & ", & \\
\hline
\end{tabular}

75.-Fig. I. Club (pineapple type of head). Fig. 2. Club (disc type of head). Fig. 3. Drum.

Fig. 4. Adze

76. -Fishing Weir

77.--Planting Yams in Garden

78.-Collecting Sweet Potatoes in Garden

79.-Hammering Bark Cloth .

8o.- The Ine Pandanus

81.-Mafulu Network

82.-Funeral Feast (not of Chief). Guests assembled to commence Dance down Village Enclosure

83. - The same Funeral Feast. Guest Chief Dancing down Village Enclosure 
PLATE

84.-Platform Grave of Chief's Child at Back. Ordinary Grave in Front . . . . To face page

85.-Group of Platform Graves of Chiefs and their Relations . . . . . . . . " ,, 278

86.-Platform Grave of a Chief's Child . . . . " " " 278

87, 88. - The Gabe Fig Tree, in which Chiefs' Burial Boxes are placed and which is Generally Believed to be Haunted by Spirits

89. - The Remains of a Chief s Burial Platform which has collapsed, and beneath which his Skull and some of his Bones are interred Underground

90.-An mone to which are hung the Skulls and some of the Bones from Chiefs'.Burial Platforms which have Collapsed . . . . " " , 290

91.-A House with Receptacle for Child's Excrement Map . . . . . . . . . . . End of book

\section{ILLUSTRATIONS IN TEXT}

FIGURE

PAGE

1.--Leg band making (commencing stage) - . . . $\quad 55$

2.-Ancient Mortar . . . . . . . . . . . 75

3.-Illustrative Diagram of a Mufulu Community of Villages . 84

4.-Diagram of Front of Emone (Front Hood of Roof and Front Platform and Portions of Front Timbers omitted, so as to show Interior) . $. \quad . \quad . \quad . \quad . \quad . \quad . \quad . \quad 102$

5.-Diagram of Transverse Section across Centre of Emone . 105

6.-Diagrammatic Sketch of Apse-like Projection of Roof of Emone and Platform Arrangements . . . . . 107

7.-Diagram Illustrating Positions of People during Performance at Big Feast . . . . . . . . . . I4I

8. - Mafulu Net Making (Ist Line of Network) . . . . . 204

9. -Mafulu Net Making (2nd, 3rd, and 4th Lines of Network) . 205 10.-Mafulu Net Making (5th Line of Network, to which Rest of Net is similar in Stitch) . . . . . . . 


\title{
INTRODUCTION
}

\author{
By DR. A. C. HADDON
}

IT is a great pleasure to me to introduce $\mathrm{Mr}$. Williamson's book to the notice of ethnologists and the general public, as I am convinced that it will be read with interest and profit.

Perhaps I may be permitted in this place to make a few personal remarks. Mr. Williamson was formerly a solicitor, and always had a great longing to see something of savage life, but it was not till about four years ago that he saw his way to attempting the realisation of this desire by an expedition to Melanesia. $\mathrm{He}$ made my acquaintance in the summer of 1908 , and seeing that he was so keenly interested, I lent him a number of books and all my MS. notes on Melanesia; by the help of these and by the study of other books he gained a good knowledge of the ethnology of that area. In November, 1908, he started for Oceania for the first time and reached $\mathrm{Fiji}$, from which place he had intended to start on his expedition. Circumstances over which he had no control, however, prevented the carrying out of his original programme ; so he went to Sydney, and there arranged modified plans. He was on the point of executing these, when 
he was again frustrated by a telegram from England which necessitated his immediate return. It was a sad blow to him to have his long-cherished schemes thus thwarted and rendered abortive, but, undaunted, he set about to plan another expedition. Accordingly, in January, I9IO, he once more set sail for Australia as a starting place for the Solomon Islands and British New Guinea, and this time achieved success; the book which he now offers to the public is the result of this plucky enterprise. In justice to the author it should be known that, owing to climatic and other conditions, he was unwell during the whole of his time in New Guinea, and had an injured foot and leg that hurt him every step he took. The only wonder is that he was able to accomplish so large and so thorough a piece of work as he has done.

It is interesting to note the different ways by which various investigators have entered the field of Ethnology. Some have approached it from the literary or classical side, but very few indeed of these have ever had any experience in the field. The majority of field workers have had a previous training in sciencezoology not unnaturally has sent more recruits than any other branch of science. A few students have been lawyers, but so far as I am aware Mr. Williamson is the first British lawyer who has gone into the field, and he has proved that legal training may be a very good preliminary discipline for ethnological investigation in the field, as it gives invaluable practice in the best methods of acquiring and sifting of evidence. A lawyer must also necessarily have a wide knowledge of 
human nature and an appreciation of varied ways of thought and action.

It was with such an equipment and fortified by extensive reading in Ethnology, that $\mathrm{Mr}$. Williamson was prepared for his self-imposed task. Proof of his powers of observation will be found in the excellent descriptions of objects of material culture with which he has presented us.

I now turn to some of the scientific aspects of his book. Mr. Williamson especially set before himself the work of investigating some tribes in the mountainous hinterland of the Mekeo district. This was a most happy selection, though no one could have foreseen the especial interest of these people.

Thanks mainly to the systematic investigations of Dr. Seligmann and to the sporadic observations of missionaries, government officials and travellers, we have a good general knowledge of many of the peoples of the eastern coast of the south-eastern peninsula of New Guinea, and of some of the islands from the Trobriands to the Louisiades. The Ethnology of the fertile and populous Mekeo district has been mainly made known to us by the investigations of various members of the Sacred Heart Mission, and by Dr. Seligmann. What little we know of the Papuan Gulf district is due to missionaries among the coastal tribes, Mr. James Chalmers and Mr. W. Holmes. Dr. G. Landtman is at present investigating the natives of the delta of the Fly river and Daudai. The natives of the Torres Straits islands have also been studied as fully as is possible. But of the 
mountain region lying behind the Mekeo district very little indeed has been published; so Mr. Williamson's book fills a gap in our knowledge of Papuan ethnology.

We have as yet a very imperfect knowledge of the ethnological history of New Guinea. Speaking very broadly, it is generally admitted that the bulk of the population belongs to the Papuan race, a dark-skinned, woolly-haired people who have also spread over western Oceania ; but, to a greater or less extent, New Guinea has been subject to cultural and racial influences from all sides, except from Australia, where the movement has been the other way. Thus the East Indian archipelago has directly affected parts of Netherlands New Guinea, and its influence is to be traced to a variable degree in localities in the Bismarck archipelago, German New Guinea (Kaiser Wilhelm's Land), Western Oceania, and British New Guinea or Papua, as it is termed officially.

The south-eastern peninsula of New Guinea-or at all events the coastal regions-has been largely affected by immigrants, who were themselves a mixed people, and who came later at various times. It is to these immigrants that Mr. Ray and I applied the term Melanesian (Ray, S. H., and Haddon, A. C., "A Study of the Languages of Torres Straits," Proc. Roy. Irish Acad., 3rd ser., IV., 1897, p. 509). Early in 1894, Mr. Ray read a paper before the Anthropological Institute (Journ. Anth. Inst., XXIV., p. I 5), in which he adhered to our former discrimination of two linguistic stocks and added a third type of language composed 
of a mixture of the other two, for which he proposed the name Melano-Papuan. These languages, according to Mr. Ray, occur in the Trobriands, Woodlarks and the Louisiades, and similar languages are found in the northern Solomon Islands. For some years I had been studying the decorative art of British New Guinea, and from physical and artistic and other cultural reasons had come to the conclusion that the Melanesians of British New Guinea should be broken up into two elements : one consisting of the Motu and allied Melanesians, and the other of the inhabitants of the Massim district-an area extending slightly beyond that of Mr. Ray's Melano-Papuans ("The Decorative Art of British New Guinea," Cunningham Memoirs, X., Roy. Irish Acad., I 894, pp. 253-269). I reinforced my position six years later ("Studies in the Anthropogeography of British New Guinea," Journ. Roy. Geog. Soc., 1900, pp. 265, 414). Dr. Seligmann, in his valuable paper "A Classification of the Natives of British New Guinea" (Journ. Roy. Anth. Inst., XXXIX., 1909, pp. 246, 315 ) corroborated these views and designated the two groups of "Melanesians" as the Eastern and Western Papuo-Melanesians. The following year he published the great book to which $\mathrm{Mr}$. Williamson so frequently refers, and in which this classification is maintained, and these two groups together with the Papuans, are termed Papuasians.

The Motu stock of the Western Papuo-Melanesians have extended their dispersal as far as the Mekeo district, where they came into contact with other peoples. It has been shown that the true Papuans are 
a narrow-headed people, but there are some puzzling exceptions, the explanation of which is not yet ascertained. The Papuo-Melanesians contain a somewhat broad-headed element, and there is a slightly broad-headed population in the central range of the south-east peninsula, the extent of which has not yet been determined. The questions naturally arise: (I) Is the true Papuan a variable stock including both long- and broad-headed elements? or (2) Does the broad-headed element belong to an immigrant people? or, again (3) Is there an hitherto unidentified indigenous broad-headed race? I doubt if the time is ripe for a definite answer to any of these questions. Furthermore, we have yet to assign to their original sources the differences in culture which characterise various groups of people in New Guinea. Something has been clone in this direction, but much more has yet to be learnt.

So far I have not referred to a Negrito element in the Ethnology of New Guinea. From time to time we have heard rumours of pygmy people, and German travellers have recorded very short individuals in Kaiser Wilhelm's Land ; but it was not till the expedition to Netherlands New Guinea of the British Ornithological Union of I9IO-I I that a definite pygmy race was demonstrated. I think this can be no longer denied, and the observations made by German ethnologists show that the race in a more or less modified state is widely spread. Now Mr. Williamson, whose work in New Guinea was contemporaneous with that of the Netherlands New Guinea expedition, 
adduces evidence that this is also the case in British territory. It is worth recalling that de Quatrefages and Hamy (Crania Ethnica, I 882, pp. 207-210, 253256) distinguish a "Negrito-Papuan " and a "Papuan " element in the Torres Straits. This problem will be discussed in Vol. I. of the Reports of the Cambridge Expedition to Torres Straits. I feel little doubt that Mr. Williamson has shown strong evidence that the Mafulu and probably other adjacent mountain tribes are essentially a pygmy - that is to say a Negritopeople who have been modified to some extent by Papuan and possibly Papuo-Melanesian influence, both physical and cultural. $\mathrm{He}$ has marshalled his data with great skill, and has dissected out, as it were, the physical and cultural elements of the Negrito substratum. It only remains for other observers to study Negritos in other parts of New Guinea to see how far these claims can be substantiated. It is evident therefore that, apart from the valuable detailed information which Mr. Williamson has given us concerning a hitherto unknown tribe, he has opened up a problem of considerable interest and magnitude.

A. C. HADDON. 



\title{
THE MAFULU MOUNTAIN PEOPLE OF BRITISH NEW GUINEA
}

\author{
CHAPTER I \\ INTRODUCTORY
}

THE map appended to this volume is (with the exception of the red lines and red lettering upon it) a reproduction of a portion of the map relating to the explorations and surveys of Dr. Strong, Mr. Monckton and Captain Barton, which was published in the Geographical Journal for September, 1908, and the use of which has been kindly permitted me by the Royal Geographical Society. I have eliminated the red route lines which appear in the original map, so as to avoid confusion with the red lines which I have added. The unbroken red lines and the red lettering upon my map are copied from a map, also kindly placed at my disposal, which has been recently prepared by Father Fillodean of the Mission of the Sacred Heart, and these lines mark roughly what the Fathers of the Mission believe to be the boundaries of the several linguistic areas within the district covered by their map. It will be observed 
that some of these lines are not continued so as to surround and complete the definition of the areas which they indicate; but this defect is unavoidable, as the Fathers' map only covered a relatively small area, and even in that map the lines were not all carried to its margin. It will also be noticed that, though the Fathers introduce the two names Oru Lopiku and Boboi as being linguistically distinct, they have not indicated the boundary line between the two areas. Father Egedi, however, informed me that this boundary passes along the ridge of hills south of the Ufafa river as far as Mt. Eleia, and thence along the Ukalama river to the Kuni boundary. The Ukalama river is not shown in the Geographical Society's map; but I may say that it is shown in the Fathers' map as rising in Mt. Eleia, and flowing thence in a south-easterly direction, and so joining the St. Joseph river close to Dilava. The broken red line upon my map does not appear in the Fathers' map, but has been added by me to indicate what, I understand, the Fathers believe to be a continued boundary, so far as ascertained, of the Fuyuge linguistic area, called by them the Mafulu area, to which I am about to draw attention.

The term Mafulu is the Kuni pronunciation of Mambule, which is the name, as used by themselves, of the people who live in a group of villages within and near the north-westerly corner of the area of the Fuyuge-speaking people, whose Papuan language, so far as ascertained, appears, subject to local dialectal differences, to be the same, and may, I was informed, 
be regarded as one common language throughout the Fuyuge area.

The Fathers of the Mission have adopted the name Mafulu in a wider sense, as including all the people with whom they have come in contact of the Fuyugespeaking area; and, though my investigations, which form the subject-matter of this book, have been conducted only in the neighbourhood of Mafulu itself, I was assured that, so far as the Fathers have been able to ascertain, all these Fuyuge people not only have similar languages, but also are substantially similar in physique and in culture. My observations concerning the Mafulu people may therefore, if this statement is correct, be regarded as applying, not only to the inhabitants of the portion of the north-westerly corner of the Fuyuge area in which the Mafulu group of villages is placed, but to those of the whole of the north-westerly portion of the area, and generally in a greater or less degree of accuracy to those of the northerly and north-easterly parts of the area, and possibly the southerly ones also.

The boundaries of this Fuyuge-speaking area can hardly be regarded as definitely ascertained; and the discrepancies, even as regards the courses of the rivers and the positions of the mountains, which appear in the few available maps make it difficult to deal with the question. The area, so far as actually ascertained by the Fathers of the Mission, roughly speaking, covers, and seems to extend also some distance to the south or south-west of a triangle, the western apex of which is the junction of the river Kea with the 
river Aduala (a tributary of the St. Joseph), ${ }^{1}$ whose north-eastern apex is Mt. Albert Edward, and whose south-eastern apex is Mt. Scratchley. It includes the valley of the Aduala river and its streams (except those flowing into it from the north in the region of the western apex of the triangle) within its northern boundary, and the valley of the upper Vanapa river and its rivers and streams in the neighbourhood of its eastern boundary; but this eastern boundary has been found to extend also so as to include the upper valley of the river Chirima. How far the area extends to the south or south-west of the triangle above mentioned appears to be uncertain.

The linguistic area to the north of the Mafulu or Fuyuge people is that of the Ambo people, who are somewhat similar in appearance to the Mafulu, and whose language is also Papuan, and, though differing from the Mafulu language, is, I was told, somewhat similar to it in grammatical construction and as regards a few of its words. The area to the west is that of the

1 The Geographical Society's map used by me is somewhat confusing as regards the upper reaches of the St. Joseph or Angabunga river and the rivers flowing into and forming it. The Fathers' map makes the St. Joseph river commence under that name at the confluence, at a point a little to the west of $8^{\circ} 30^{\prime} \mathrm{S}$. Lat. and $147^{\circ} \mathrm{E}$. Long., of the river Alabula (called in one of its upper parts Loloipa), flowing from the north, and the river Aduala, flowing from Mt. Albert Edward in the north-east ; and this arrangement, which is practically in accord with a map appended to the British New Guinea Annual Report for June, 1900 , is, I think, probably the most suitable and correct one. The Aduala is the river the upper part of which is in the Geographical Society's map called Angabunga. The Fathers' map shows the river Kea flowing into the Aduala at a distance of about two miles above the confluence of the latter with the Alabula; but, according to the Report map, this distance is about 12 miles. 
Kuni people, whose language is Melanesian, but whose ordinary modes of life are, I was informed, more like those of the Mafulu than are those of the Papuanspeaking Ambo. The areas to the east and south cannot be so definitely stated, but are dealt with below.

As regards these Ambo people I may, in view of divergences of names which appear in maps, explain that Ambo is a contraction of Ambore, and is the name given to the people by their Mafulu neighbours, whilst Afoa is the name given to them by the Kuni people, and is adopted in the Geographical Society's map. ${ }^{1}$ As regards the Kuni people, their name is the one adopted by themselves.

Concerning the boundaries of the Fuyuge linguistic area as above indicated, and the people whose districts adjoin that area, I propose here to draw attention to four names, and to refer to some observations bearing on the subject of the probable Fuyuge boundary which are to be found in existing literature.

The term Kovio, though primarily the name of Mt. Yule, and properly applicable to the people living in the neighbourhood of that mountain, is now, I think, often used to express all the mountain tribes of the hinterland of the Mekeo and Pokau, and perhaps the Kabadi, districts. But the use of this name has not, I believe, been generally associated with any question of linguistics.

The area in the map which is called by the Fathers

1 Note the change from the Mafulu (Papuan) pronunciation Mambule to the Kuni (Melanesian) pronunciation Mafulu and the similar change from the Mafulu $A m b o$ to the Kuni $A j o a$. 
Boboi is occupied by people whose language, I was told by the Fathers, is Papuan, but is distinct from the languages of the Ambo and the Fuyuge areas.

Kamaweka is a name which appears in several of Dr. Seligmann's publications. It seems to have been originally used by Captain Barton to designate the natives of the district of which Inavaurene, to the north-east of the Mekeo plains, is the centre, but to have been afterwards regarded as a somewhat more general term; and I think Dr. Seligmann uses it in a very general sense, almost, if not quite, equivalent to the wide application above referred to of the term Kovio, and which might include the Papuanspeaking Boboi and Ambo people, and even perhaps the people of the northern Mafulu villages. ${ }^{1} \quad$ But here again the use of the name has, I think, no reference to linguistics.

If the Fathers' linguistic boundary lines are substantially correct, each of the two terms Kovio and Kamaweka, as now used, would appear to cover more than one linguistic area; and in any case these terms seem to have widened and to have become somewhat indefinite. It will be seen on reference to the map and to Father Egedi's information as to the Oru Lopiku and Boboi boundaries that both Mt. Yule and Inavaurene are within the area which the Fathers call Oru Lopiku, but that Inavaurene is not far from

${ }^{1}$ See Dr. Seligmann's "Hunterian Lecture" in the Lancet for February I7, 1906, p. 427 ; Seligmann and Strong in the Gengraphical Journal for March, 1906, pp. 233 and 236 ; also Dr. Seligmann's "Classification of the Natives of British New Guinea" in the Journal of the Royal Anthropological Institute for December, I909, p. 329. 
their Boboi area. I suggest that it would be convenient for the present, pending further investigation and delimitation on the spot, and until we know something of the difference between the languages of the Oru Lopiku and Boboi people, to adopt the term Kovio as a general name for, and confine it to, the two areas Boboi and Oru Lopiku; though for linguistic purposes the names Boboi and Oru Lopiku, which at present indicate very little to us, may eventually be accepted and come into general use.

The Koiari people of the foothills and lateral spurs behind the Motu area, also referred to from time to time in Dr. Seligmann's writings, must be eastern next door neighbours of the Fuyuge-speaking people, the western boundary of these Koiari being stated by him to be the Vanapa river, ${ }^{1}$ and they being in fact regarded by him as being the eastern neighbours of the natives of "the mountains inland of Mekeo Nara and Kabadi," " and being referred to by him as being the people from whose district the Kamaweka and Kuni are reached by "passing westward"-the word used is " eastward," but this is obviously a printer's error" in the mountains, keeping roughly parallel with the coast." 3

Turning to the question of the Fuyuge boundary, Dr. Strong says that tile Fuyuge people occupy the upper waters of the St. Joseph river, ${ }^{4}$ and he is quoted by Dr. Seligmann as having stated that the Afoa

1 Melanesians of British New Guinea, p. 29.

${ }^{2}$ Ibid. p. 31. ${ }^{3}$ Lancet, February 17, 1906, p. 427.

4 Geographical Journal for September, 1908, p. 274. 
language "is spoken in the villages on Mt. Pizoko and the northern slopes of Mt. Davidson," and that "the Afoa villages lie to the north of the Fuyugespeaking communities, stretching westward for an unknown distance behind Mt. Davidson." ${ }^{1}$ If the information given to me verbally by the Fathers of the Mission of the Sacred Heart and the red linguistic boundary lines roughly drawn by them, and introduced into my map, be correct, these statements require modification, for according to the Fathers the Mafulu or Fuyuge-speaking area does not include any part of the St. Joseph river, as its extreme north-westerly corner lies to the east of the junction-close to the boundary line between the Afoa (Ambo) and the Kuni areas-of the rivers Alabula and Aduala, and Mt. Pizoko is within the Fuyuge area, and not within that of the Afoa, and Mt. Davidson is within the Boboi area. I think that, though the Fathers' lines are admittedly not exact, they and the information supplied by the Fathers to me are likely to be more trustworthy in these respects, especially as regards boundaries near to the actual Mafulu villages, than the earlier statements of Dr. Strong, as they are the outcome of recent and careful investigation; and, as regards Mt. Pizoko, I may mention that Dr. Strong himself seems to have subsequently regarded that mountain as being within the Mafulu district, ${ }^{2}$ which brings it into the Fuyuge area.

The inclusion of the upper valley of the river

1 Melanesians of British New Guinea, p. 32.

2 British New Guinea Annual Report for June, 1906, p. 29. 
Chirima within the Fuyuge or Mafulu-speaking area is perhaps surprising, as this valley is separated from the general Fuyuge area by one of the southern ridges of Mt. Albert Edward, and more or less so by the ridges of $\mathrm{Mt}$. Stone Wigg and the Wharton range, and as the Chirima is a tributary flowing into the Mambare river, which is one of the great watercourses of Northern New Guinea. The Mafulu Fathers, however, had no doubt as to the correctness of the inclusion, which seems to open out the possibility of some, at all events, of the Fuyuge people having northern associations; and indeed Monseigneur de Boismenu told me that he believed that the Mafulu people were in touch with Northern New Guinea, and got some of their shell ornaments, or the shells from which they were made, from the northern coast.

It is interesting, therefore, to turn for the purpose of comparison to the report of Mr. Monckton's expedition to Mt. Albert Edward by way of the Upper Chirima valley in $1906^{1}$ and the illustrations accompanying it, with which I incorporate a description of the people of this valley given to Dr. Seligmann by Mr. Money, who was with Mr. Monckton. ${ }^{2}$

From these it appears that the Upper Chirima people are short in stature and sturdily built. Both sexes wear the perineal band, the front of which is made (I am not sure whether this applies to women as well as to men) to bulge out by padding. In some cases the men's hair is tied up in a bunch with string,

1 British New Guinea Annual Report for June 30, 1906, pp. 85 to 93.

2 Melanesians of British Nere Guinea, p. 33. 
and in others it is bound up in various styles with native cloth. Some of the men have their hair done up in small plaits over the forehead. All the above descriptions, except that of the padding of the band, are applicable to the Mafulu. Some of the Chirima houses have a curious apse-like roof projection over the front platform, which is a specially distinctive feature of a Mafulu house, and one with this projection figured by Mr. Monckton is indistinguishable from a typical Mafulu house. The Chirima people place the bodies of their dead on raised platforms, and apparently sometimes put the body of an infant on the platform erection of an adult, but below the latter. This also is a practice of the Mafulu; and, though the latter people confine platform burial (if such it may be called) to chiefs and their families and important persons, it is possible that some such limitation of the custom exists in the Chirima valley also, but did not come under Mr. Monckton's notice. A burial platform figured by him might well be a Mafulu burial platform, except that the curious cone-shaped receptacle for the child is a form for which I cannot vouch as regards the Mafulu. The Chirima have a special and peculiar form of netting, which Mr. Monckton's illustration shows to be identical with the special form of Mafulu netting. On the other hand, as regards the Chirima weapons, implements and utensils, a comparison of Mr. Monckton's verbal descriptions and figures with what I have seen in Mafulu, and describe in this book, leads me to the conclusion that, though many of these are similar to those of Mafulu, 
- some of them are different. As examples of this I may say that the drill implements of the Chirima people are very similar to, and their stone cloth-beaters appear to be identical with, those used by the Mafulu ; whilst on the other hand their war bows are much longer, ${ }^{1}$ and their method of producing fire seems to be totally different; also they apparently have bullroarers, which to the best of my knowledge are unknown among the Mafulu. Again some of the Chirima weapons, as figured by Mr. Monckton, disclose ideas of artistic design, including that of the curved line and a rude representation of a man, which I have not met with among the Mafulu. As regards this last point I draw attention to Mr. Monckton's figures of carving on a bow and on wooden clubs. I think, however, that in such matters as these local differences might well arise between people who are really more or less identical, especially if their respective districts are on opposite sides of the main mountain range of the country, and still more so if the people of one of the districts (in the present case I refer to the Chirima people) may perhaps have been subject to the influence of other people beyond them. As to this latter point, however, I should say that these Chirima people seem to be, so far as dress, ornaments, \&c., are concerned, much nearer to the Mafulu than they are to the natives of the Mambare river itself, as described by Sir William Macgregor. ${ }^{2}$ It is curious

1 Apparently bows and arrows are not found among the tribes of the Lower Mambare river (Annual Report for June, I897, Appendix C, p. 7.)

${ }^{2}$ Annual Report for June, I894, p. 32. 
also that the dogs of the Chirima people are not yellow dingoes, but are black and white, as is the case in Mafulu.

I notice that Dr. Seligmann suggests that these Chirima valley people are related to the natives of the neighbourhood of Mt. Yule, ${ }^{1}$ a statement which, though probably intended broadly, is in accord with the suggestion that they are connected with the Mafuluspeaking people.

The natives of Mt. Scratchley (apparently the eastern or south-eastern side), visited by Sir William Macgregor in 1896, appear from his description of them ${ }^{2}$ to show a few points of resemblance to the Mafulu people. In particular I refer to their "dark bronze" colour, to the wearing by women of the perineal band (to which, however, is added a mantle and "in most cases" a grass petticoat, which is not done in Mafulu), to the absence of tattooing or cicatrical ornamentation, to their "large earrings made out of tails of lizards covered by narrow strips of palm leaves dyed yellow" (which, though not correctly descriptive of the Mafulu earring, is apparently something like it), to their use of pigs' tails as ear ornaments, to their plaiting of the hair and the decoration of the plaited hair with teeth and shells, to their small charm bags and to the shortness of their bows. Also to the construction of their houses, with the roof carried down to the ground, with a fireplace about

1 Journal of the Royal Anthropological Institute for December, 1909, p. 329.

2 Annual Report for June, I897, Appendix C, p. 7. 
.2 feet wide extending down the centre of the building from one end to the other, and having an inclined floor on each side, and especially to the curious apselike roof projections in front of these houses (Dr. Haddon calls them "pent roofs" $)$, Sir William's figure of which is, like that of the Chirima villages, identical, or nearly so, with that of a Mafulu house. But SirWilliam's description of the physique of these Mt. Scratchley people and other matters make it clear, I think, that they belong to a type different from that of the Mafulu, though they must be next door neighbours of the Fuyuge-speaking people. Dr. Seligmann, in commenting upon this description of these people, expresses the opinion that they are Papuo-Melanesians. ${ }^{2}$

The natives in the region of $\mathrm{Mt}$. Musgrave and Mt. Knutsford, as described by Mr. Thomson, ${ }^{3}$ appear, at all events so far as dress is concerned, to be utterly different from the Mafulu.

Dr. Seligmann states that Dr. Strong has informed him that the southern boundary of the Fuyugespeaking area is the Kabadi country, ${ }^{4}$ and he had previously referred to Korona, immediately behind the Kabadi and Doura districts, as being within the area, ${ }^{5}$ and, indeed, the Geographical Society's map shows the Fuyuge area as at all events extending as far south as Korona. I do not know how far inland the Kabadi

1 Geographical Journal for October, 1900, p. 422.

2 Journal of the Royal Anthropological Institute for December, 1909, p. 330 .

${ }^{3}$ British New Guinea, p. 94.

4 Melanesians of British New Guinea, p. 32.

5 Journal of the Royal Anthropological Institute for December, 1909, p. 329 . 
and Doura people extend; but I may say that the Mafulu Fathers expressed grave doubt as to the extension of the Fuyuge area so far south as is indicated by the map.

If the Fuyuge area does in fact reach the Kabadi boundary, and if my notes on the Mafulu people are, as suggested, broadly descriptive of the natives of the whole Fuyuge area, there must be a very sudden and sharp differentiation, as the Kabadi people are apparently an offshoot from Mekeo, ${ }^{1}$ with apparently other Papuo-Melanesian blood (especially Roro) introduced. $^{2}$

The contour and appearance of the country in the actual Mafulu district of the Fuyuge area is strikingly different from that of the immediately adjoining Kuni country, the sharp steep ridges and narrow deep-cut valleys of the latter, with their thick unbroken covering of almost impenetrable forest, changing to higher mountain ranges with lateral ridges among them, and with frequent gentle undulating slopes and wider and more open valleys; while, interspersed with the forests, are small patches and great stretches of grass land, sometimes thinly covered or scattered with timber and sometimes quite open and devoid of trees. ${ }^{3}$ And this

1 Seligmann and Strong-Geographical Journal for March, 1906, p. 232.

2 Seligmann's Melanesians of British New Guinea, p. 27.

3 Dr. Strong has referred (Geographical Journal for September, 1908, p. 272) to the considerable areas of open grass country at the source of the St. Joseph river; and in his remarks which appeared in the Annual Report for June, 1906, p. 28, he referred to the same matter, and spoke of the valleys being for the most part less steep than those of the Kuni district. 
Plate I.

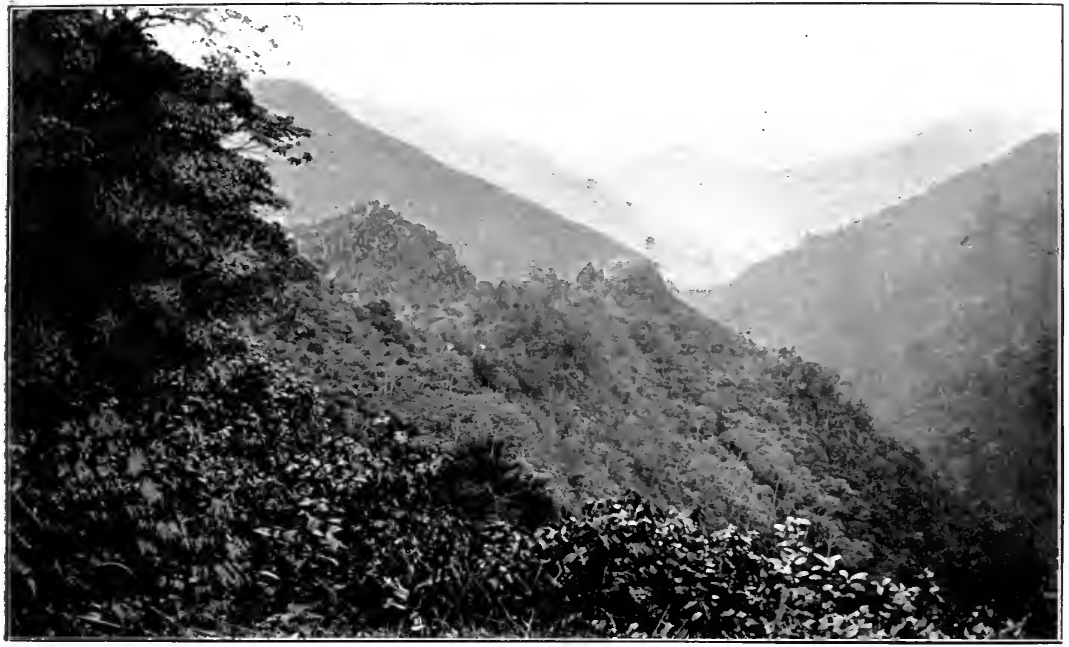

KUNI SCenery.

PIATE 2.

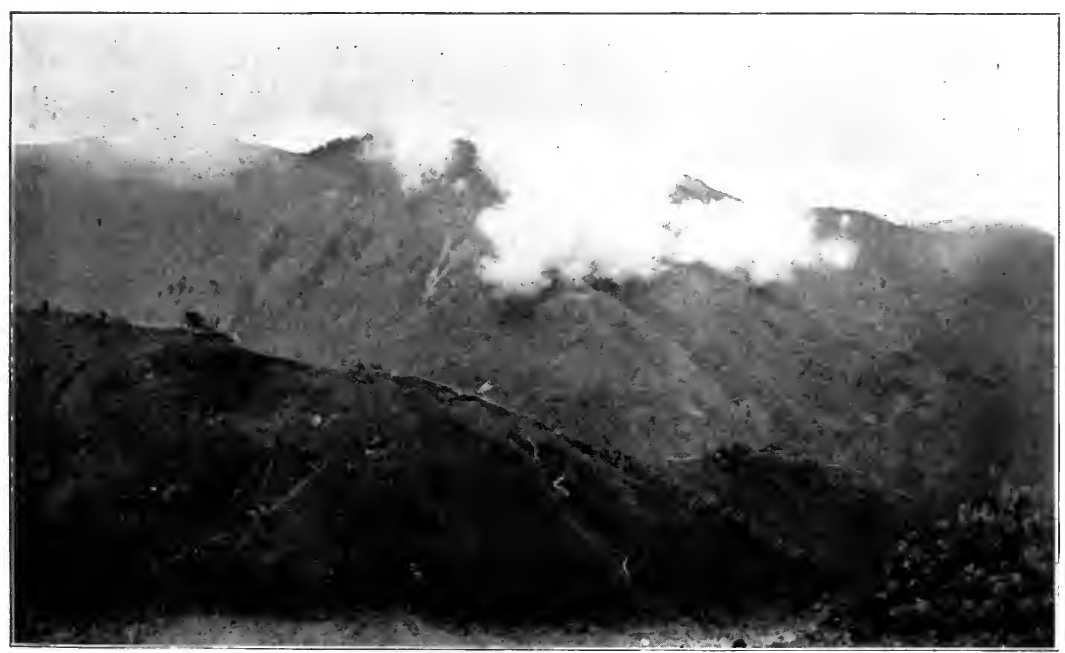

Mafulu Scenery. 

-condition continues, I was told, over the greater part of the triangular area above referred to.

Plates I and 2 give, I think, a fair illustration of what I mean, the steep contours and thickly wooded character of the foreground and nearer middle distance shown by Plate I being typical Kuni scenery, and the more open nature of the country displayed by Plate 2 and the comparative freedom from forest of its foreground being typical of the higher uplands of Mafulu. ${ }^{1}$

It will be noticed that the physical character of the Mafulu country is more favourable to continued occupation than is that of the Kuni country; and it is a fact that the Mafulu people are not so restless and ready to move as are the Kuni folk; and, even when they do migrate, it is generally to a spot comparatively near to their old villages.

The geological formation of the lower hills on which the actual Mafulu villages are placed and the intervening valleys is partly limestone; and I was told that limestone formation was also found further to the east.

Throughout this book I shall use the term "Mafulu" as including, not only the little group of villages near the north-westerly corner of the Fuyuge linguistic area actually known by that name, but also the other groups of Fuyuge villages in the north-

1 I must state that Plate 2 represents a scene taken from a spot near to Deva-deva, which, though close to what is regarded as the boundary between the Kuni and Mafulu areas, is in fact just within the former. The general appearance of the scenery is, however, distinctly Mafulu. 
western portion of that area ; and, as above indicated, it is believed by the Fathers of the Mission that I should be substantially correct if I included the whole of the northern and north-eastern, and probably the southern portions of the known part of that area, and possibly the entire area. 


\section{CHAPTER II}

PHYSIQUE AND CHARACTER

Physique.

The Mafulu people are of short stature, though perhaps a trifle taller than the Kuni.

They are as a rule fairly strong and muscular in build, the women in particular having very strongly developed thighs ; but, speaking generally, their limbs are more slender, and their general development is slighter, than is usually the case among the Roro and Mekeo people

They appear to be usually mesaticephalic, but to have a very marked tendency to brachycephaly.

Their noses seemed to me to be generally strong, and of prominent size, varying considerably in width of bridge, but usually having rather widely distending nostrils; and sometimes the width of the nose was equal to its length, or nearly so.

Referring to the above matters, the following are the results of twenty measurements of Mafulu men. These were obtained from men of upwards of six different communities or groups of villages, so as to avoid the possible misleading character of measurements made in only one village or group of villages, in which some family relationship between the persons 
measured might militate against the true average character of the figures obtained.

\begin{tabular}{|c|c|c|c|c|c|c|c|c|}
\hline No. & $\begin{array}{l}\text { Stature } \\
\text { in } \mathrm{cm} \text {. }\end{array}$ & $\begin{array}{l}\text { Length } \\
\text { of head } \\
\text { in } \mathrm{cm} \text {. }\end{array}$ & $\begin{array}{l}\text { Breadth } \\
\text { of head } \\
\text { in } \mathrm{cm} .\end{array}$ & $\begin{array}{l}\text { Cephalic } \\
\text { index. }\end{array}$ & $\begin{array}{c}\text { Cranial } \\
\text { index } \\
\text { (2 units } \\
\text { deducted } \\
\text { from ceph- } \\
\text { alic index). }\end{array}$ & $\begin{array}{l}\text { Nose } \\
\text { length } \\
\text { in } \mathrm{cm} \text {. }\end{array}$ & $\begin{array}{c}\text { Nose } \\
\text { breadth } \\
\text { in } \mathrm{cm} .\end{array}$ & $\begin{array}{l}\text { Nasal } \\
\text { index. }\end{array}$ \\
\hline I & 150 & $18 \cdot 5$ & $14 \%$ & 79.5 & $77 \cdot 5$ & $4^{\circ} 9$ & $4 \%$ & $89 \cdot 8$ \\
\hline 2 & 155 & 18.8 & $15^{\circ} \mathrm{I}$ & $80 \cdot 3$ & $78 \cdot 3$ & 4.8 & $4 \cdot 8$ & $1000^{\circ}$ \\
\hline 3 & 155 & 19.5 & 14.8 & $75^{\circ} 9$ & $73 \cdot 9$ & $5 \cdot 3$ & 43 & $8 \mathbf{I} \cdot \mathbf{I}$ \\
\hline 4 & I 57 & 18.5 & 154 & $83 \cdot 2$ & $8 I \cdot 2$ & 43 & 4.3 & $100^{\circ} 0$ \\
\hline 5 & I 53 & $180^{\circ}$ & $14^{\circ} 6$ & $77^{\circ} \cdot 2$ & $75^{\circ} 2$ & 4.8 & $4 \%$ & $9 I^{\circ} 7$ \\
\hline 6 & I 5 I & $18 \cdot 6$ & 14.3 & $76 \cdot 9$ & $74^{\circ} 9$ & $4^{\circ} 9$ & $3 \cdot 8$ & $77 \cdot 6$ \\
\hline 7 & I 5 I & 19.3 & $15^{\circ}$ & $78 \cdot 8$ & $76 \cdot 8$ & 54 & $4 \%$ & $8 \mathrm{I} \cdot 5$ \\
\hline 8 & 163 & 19.4 & 14.5 & $74 \%$ & 727 & $5 \cdot 6$ & 44 & $78 \cdot 6$ \\
\hline 9 & 162 & 18.8 & $15 \cdot 2$ & $80 \% 9$ & 78.9 & $5 \cdot 3$ & $4^{\circ} 0$ & 75.5 \\
\hline Io & 163 & 174 & $15 \cdot 1$ & $86 \cdot 8$ & 84.8 & 5.5 & $4^{\circ} 6$ & $83^{\circ} \cdot 6$ \\
\hline I I & 155 & $180^{\circ}$ & $14^{\circ} \mathrm{O}$ & $77 \cdot 8$ & $75 \cdot 8$ & $5 \cdot 3$ & $4 \%$ & $83^{\circ} 0$ \\
\hline I 2 & I 57 & $17 \%$ & $14^{\circ} 6$ & $83^{\circ} 9$ & $8 I^{\circ} 9$ & $4^{\circ} 6$ & $4^{\circ} 0$ & $87^{\circ} 0$ \\
\hline 13 & $15^{8}$ & 197 & 14.8 & $75^{\circ} \mathrm{I}$ & $73 \cdot I$ & $5 \cdot 3$ & $4 \div 3$ & $8 \mathrm{I} \cdot \mathrm{I}$ \\
\hline I 4 & 160 & $179^{\circ}$ & 144 & 80.4 & 78.4 & $5^{\cdot I}$ & $4 \div 3$ & $84: 3$ \\
\hline 15 & I 53 & $17 \%$ & 147 & $83 \cdot I$ & $8 I \cdot I$ & $5^{\circ} 2$ & $4 \cdot I$ & $78 \cdot 8$ \\
\hline 16 & 156 & $18 \cdot 5$ & 14.8 & $80 \cdot 0$ & $78 \cdot 0$ & 5.5 & 4.5 & $8 I \cdot 8$ \\
\hline 17 & 152 & $17 \%$ & $14 \%$ & $84^{\circ} 2$ & $82 \cdot 2$ & $5 \cdot 6$ & $4^{\circ}$ & $71^{\circ} 4$ \\
\hline 18 & I 54 & 18.6 & $14 \% 9$ & $80 \cdot I$ & $78 \cdot I$ & $5 \cdot 2$ & $4 \cdot 5$ & 86.5 \\
\hline 19 & I 50 & I 7.8 & $15^{\circ} 2$ & 85.4 & 83.4 & $4^{\circ} 9$ & 3.9 & $79^{\circ} 6$ \\
\hline 20 & 147 & 18.8 & 14.5 & $77 \cdot 1$ & $75^{\circ} \mathrm{I}$ & $4 \cdot 6$ & $3 \cdot 8$ & $82 \cdot 6$ \\
\hline
\end{tabular}

Analysing these figures, we get the following results :

\begin{tabular}{|c|c|c|c|c|c|}
\hline & & & Highest number. & Lowest number. & Average. \\
\hline $\begin{array}{l}\text { Stature }{ }^{1} \\
\text { Head length. } \\
\text { Head breadth } \\
\text { Cephalic index }{ }^{2} \\
\text { Cranial index } \\
\text { Nose length } \\
\text { Nose breadth } \\
\text { Nasal index }\end{array}$ & $\begin{array}{l}\cdots \\
\cdots \\
\cdots \\
\cdots \\
\cdots \\
\cdots \\
\cdots\end{array}$ & $\begin{array}{l}\cdots \\
\cdots \\
\cdots \\
\cdots \\
\cdots \\
\cdots \\
\cdots\end{array}$ & $\begin{array}{c}\text { I63 cm. }(64.2 \text { ins. }) \\
\text { I9.7 cm. } \\
15.4, \\
86.8 \\
84.8 \\
5.6 \mathrm{~cm} . \\
4.8, \\
100.0\end{array}$ & \begin{tabular}{|c}
$147 \mathrm{~cm} .(57 \cdot 9$ ins.) \\
$17.4 \mathrm{~cm}$. \\
14.0, \\
74.7 \\
72.7 \\
$4.3 \mathrm{~cm}$. \\
$3.8, "$ \\
71.4
\end{tabular} & 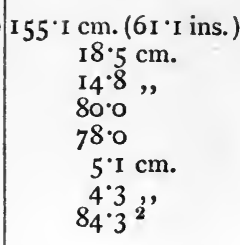 \\
\hline \multicolumn{6}{|c|}{ Number of cranial indices under 75} \\
\hline ," & & , & $\begin{array}{ll}, & \text { betwee } \\
, & \text { over } 80\end{array}$ & $\begin{aligned} & \\
& \end{aligned}$ & $\begin{array}{lll}(50 & , 1 & ) \\
(30 & , & )\end{array}$ \\
\hline
\end{tabular}

1 Dr. Strong's measurements of seven Mafulu men referred to by Dr. Seligmann (Journal of Royal Anthropological Institute, Vol. 39, 

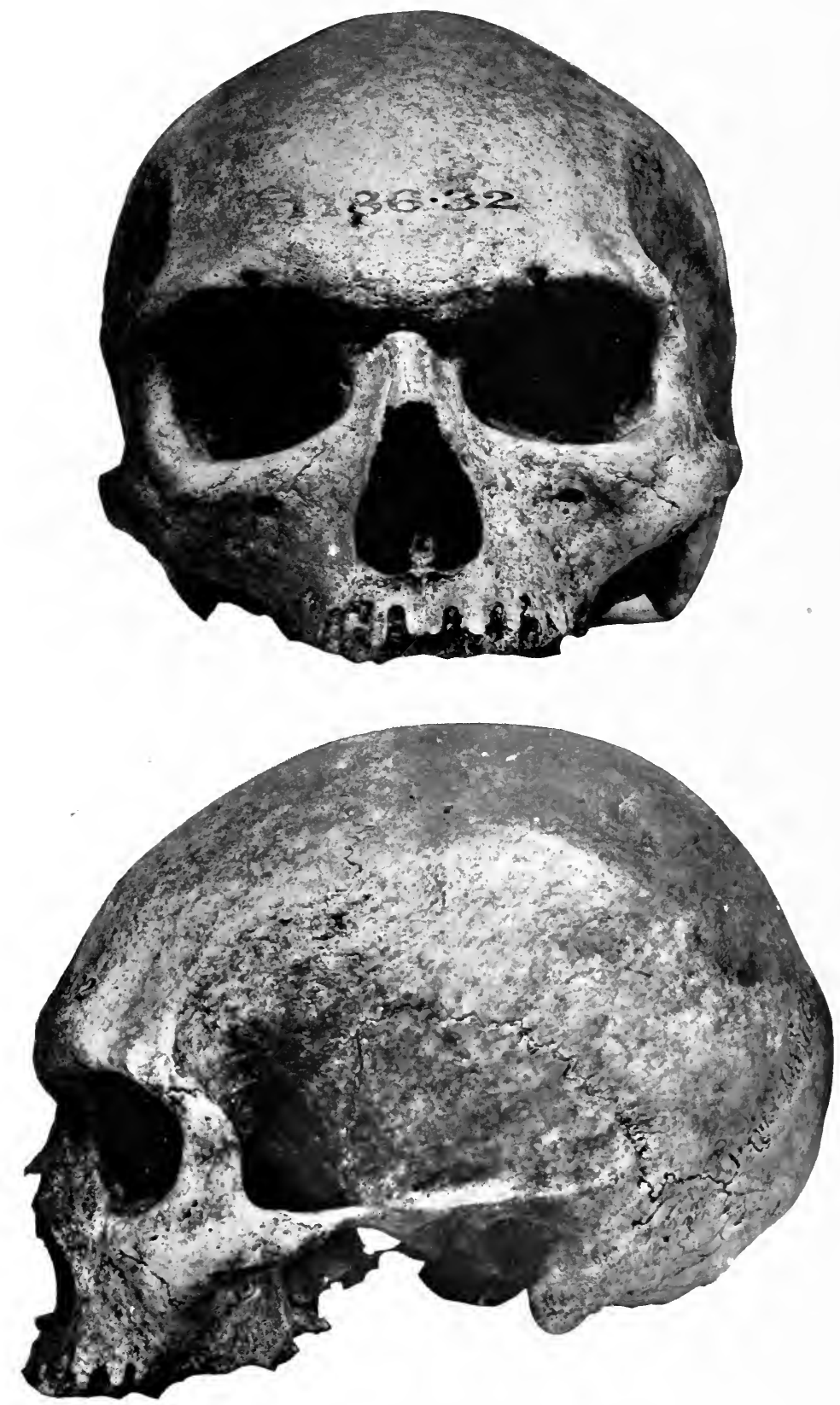

SkUte $A$. 

There are a few points in connection with these figures to which I would draw attention. The very short man (No. 20-height, I $47 \mathrm{~cm}$.) has a cranial index of $75^{\circ} \mathrm{I}$, on the border line between dolichocephaly and mesaticephaly. He has also a short nose $\left(4^{\circ} 6 \mathrm{~cm}\right.$.), and is one of the two with the narrowest noses $(3.8 \mathrm{~cm}$.). The very tall man (No. 8-height, I63 cm.) has a long head $(19.4 \mathrm{~cm}$.$) , and the$ lowest dolichocephalic cranial index of $72 \%$, and is one of two with the longest noses $\left(5^{\circ} 6 \mathrm{~cm}\right.$.). The other very tall man (No. 10-height, $163 \mathrm{~cm}$.) has one of the two shortest heads $(17.4 \mathrm{~cm}$.), and the highest brachycephalic cranial index of $84^{\circ} 8$, and has a long nose $(5.5 \mathrm{~cm}$.) The man (No. 2) whose nasal index is roo has the mesaticephalic cranial index of 78.3 (almost the average index). The other man (No. 4) whose nasal index is 100 has a head of exactly the average length $(18.5 \mathrm{~cm}$.) and the greatest breadth $(15 \% \mathrm{~cm}$.$) , and the brachycephalic cranial$ index of $8 \mathrm{I}^{\circ} 2$. The man (No. I7) with the lowest nasal index of $71^{\circ} 4$ has a very short head $(17.7 \mathrm{~cm}$.), and the brachycephalic cranial index of $82 \cdot 2$.

The following tables, however, illustrate the fact that the measurements of these twenty men do not appear to indicate, as regards them, any marked

p. 329) showed an average stature of $59 \frac{1}{2}$ inches, and an average cephalic index of $80^{\circ} 0$. It will be noticed that my figures show a somewhat higher average stature, but that my average cephalic index is the same. Dr. Seligmann here speaks of the Mafulu as being almost as short as the men of Inavaurene, and even more round-headed.

2 This is the index calculated on average lengths and breadths. The average of the indices is $83^{\circ} 8$, the difference arising from the omission in working out of each index of second points of decimals. 
connection between stature, cranial index, and nasal index.

Order in stature (beginning with the shortest) :

$$
\begin{aligned}
& 20-I-I 9-6-7-I 7-5-15-\text { I } 8-2-3-\text { I I } \\
& \text {-I6-4-I } 2-13-\text { I } 4-9-8-\text { IO. }
\end{aligned}
$$

Order in progress upwards of cranial indices :

$$
\begin{aligned}
& 8-\mathrm{I}-3-6-20-5-\mathrm{II}-7-\mathrm{I}-\mathrm{I} 6-\mathrm{I} 8-2- \\
& \text { I } 4-9-\mathrm{I} 5-4-\mathrm{I} 2-\mathrm{I} 7-\mathrm{I} 9-\mathrm{IO} .
\end{aligned}
$$

Order in progress upwards of nasal indices :

$$
\begin{aligned}
& \text { I } 7-9-6-8-\mathrm{I} 5-\mathrm{I} 9-3-\mathrm{I} 3-7-\mathrm{I} 6-2 \mathrm{O}-\mathrm{II} \\
& \text { - IO - I } 4-\mathrm{I} 8-\mathrm{I} 2-\mathrm{I}-5-2-4 \text {. }
\end{aligned}
$$

\begin{tabular}{|c|c|c|c|c|c|}
\hline Skull & $\begin{array}{l}\text { Length } \\
\text { in } \mathrm{cm} \text {. }\end{array}$ & $\begin{array}{l}\text { Breadth } \\
\text { in } \mathrm{cm} .\end{array}$ & $\begin{array}{l}\text { Height } \\
\text { in } \mathrm{cm} \text {. }\end{array}$ & $\begin{array}{c}\text { Cranial } \\
\text { Index. }\end{array}$ & $\begin{array}{l}\text { Proportion of } \\
\text { height to } \\
\text { length. }\end{array}$ \\
\hline $\begin{array}{lll}A & \ldots & \ldots \\
B & \ldots & \ldots \\
C & \ldots & \ldots\end{array}$ & $\begin{array}{l}17 \cdot 6 \\
18 \cdot 2 \\
17 \cdot 3\end{array}$ & $\begin{array}{l}144^{\circ} \\
14.1 \\
12 \cdot 7\end{array}$ & $\begin{array}{l}12 \cdot 2 \\
13 \cdot 2 \\
12 \cdot 5\end{array}$ & $\begin{array}{l}79 \cdot 5 \\
77.5 \\
73.4\end{array}$ & $\begin{array}{l}69 \cdot 3 \\
72 \cdot 5 \\
72 \cdot 3\end{array}$ \\
\hline
\end{tabular}

I brought home three Mafulu skulls, which Dr. Keith kindly had measured at the Royal College of Surgeons, with the following results ${ }^{1}$ :-

It will be observed that the lowest of these three cranial indices is a trifle higher than the lowest of those of the head measurements, that the highest of them is much lower than the highest of those of the head measurements, and that their average $(76.8)$ is a little below the average of those of the head measurements.

Dr. Keith had further measurements made of these

1 Dr. Keith thinks that they are all skulls of males. They are now in the College Museum, and are numbered 1186.32, 1186.33 and 1186.34 in the College Catalogue. 
skulls from the point of view of prognathism and characters of noses and orbits, with the following results :

\begin{tabular}{|c|c|c|c|c|c|c|}
\hline Skull. & $\begin{array}{l}\text { Basi-nasal } \\
\text { length. }\end{array}$ & $\begin{array}{l}\text { Basi- } \\
\text { alveolar } \\
\text { length. }\end{array}$ & $\begin{array}{l}\text { Height of } \\
\text { nose. }\end{array}$ & $\begin{array}{c}\text { Width of } \\
\text { nose. }\end{array}$ & $\begin{array}{l}\text { Height of } \\
\text { orbit. }\end{array}$ & $\begin{array}{c}\text { Width of } \\
\text { orbit. }\end{array}$ \\
\hline $\begin{array}{ll}A \ldots & \ldots \\
B \ldots & \ldots \\
C \ldots & \ldots\end{array}$ & $\begin{array}{l}98 \mathrm{~mm} . \\
99 ", \\
97,\end{array}$ & $\begin{array}{c}102 \mathrm{~mm} . \\
96 \quad, \\
102, "\end{array}$ & $\begin{array}{l}48 \mathrm{~mm} . \\
49, " \\
47, "\end{array}$ & $\begin{array}{l}26 \mathrm{~mm} . \\
25, " \\
26, "\end{array}$ & $\begin{array}{l}40 \mathrm{~mm} . \\
42 \quad, \\
38,\end{array}$ & $\begin{array}{l}35 \mathrm{~mm} . \\
35 \quad, \\
34,\end{array}$ \\
\hline
\end{tabular}

Dr. Keith, referring to these skulls, says that they disclose relatively small brains, the cranial capacity of A being $\mathrm{I}, 230$ c.c., that of $\mathrm{B}$ being $\mathrm{I}, 33 \mathrm{O}$ c.c., and that of $\mathrm{C}$ being I, I 30 c.c. He compares these figures with the average cranial capacity of the male European, which he puts at I, 500 c.c.

The eyes of the Mafulu people are dark brown and very bright. I never saw among them those oblique eyes, almost recalling the Mongolian, which, according to Dr. Seligmann, are found, though rarely only, on the coast, ${ }^{1}$ and of which I saw many instances among the Kuni. people.

Their lips are usually not so thick as are those of the Mekeo and Roro people, and are generally finer and more delicate in shape.

In view of their Papuan language I kept a sharp look out for the curious backward sloping foreheads and projecting brow ridges and Jewish-looking noses which are so often found among the Western Papuans; but, although I saw a few examples of these, they were rare, and I did not observe any 
noticeable tendency in these directions in the faces of the people generally. ${ }^{1}$

A curious characteristic with them is the big toe, which is usually much developed, and projects outwards at a larger angle than is the case with the Roro and Mekeo people, and is much used for holding on to roots, \&c., whilst travelling along their rough mountain paths.

Their general colour is a dark sooty brown, a trifle darker, perhaps, than that of the Kuni people, and contrasting forcibly with the varying shades of chocolate which you find among the Roro and Mekeo people. They are smooth-skinned.

Their hair is frizzly, and generally dark brown, often quite dark, almost even approaching to black, and sometimes perhaps quite black. But it is frequently lighter; and indeed I was often, when observing men's hair lit up by sunshine, impressed by the fact that its brown colour was not even what we should in Europe call dark. ${ }^{2}$ I often saw marked variations in the depth of hair colour on the head of the same individual. I saw no examples of the comparatively straight or curly type of hair which is found in the Pokau district and elsewhere. ${ }^{3}$

1 Dr. Haddon refers (Geographical Journal, Vol. 16, p. 29I) to the finding by the Mission Fathers of "another type of native, evidently an example of the convex-nosed Papuan," in the upper waters of the Alabula river. I gather from the habitat of these natives that they must have been either Ambo or Oru Lopiku. I should be surprised to hear that the Semitic nose was common in either of those areas.

2 Dr. Seligmann, in speaking of the Koiari people, refers to an occasional reddish or gingery tinge of facial hair (Melanesians of British New Guinea, p. 29). I never noticed this among the Mafulu.

3 Since writing the above, I have learnt that some of the dwarf people 
Plate 4.
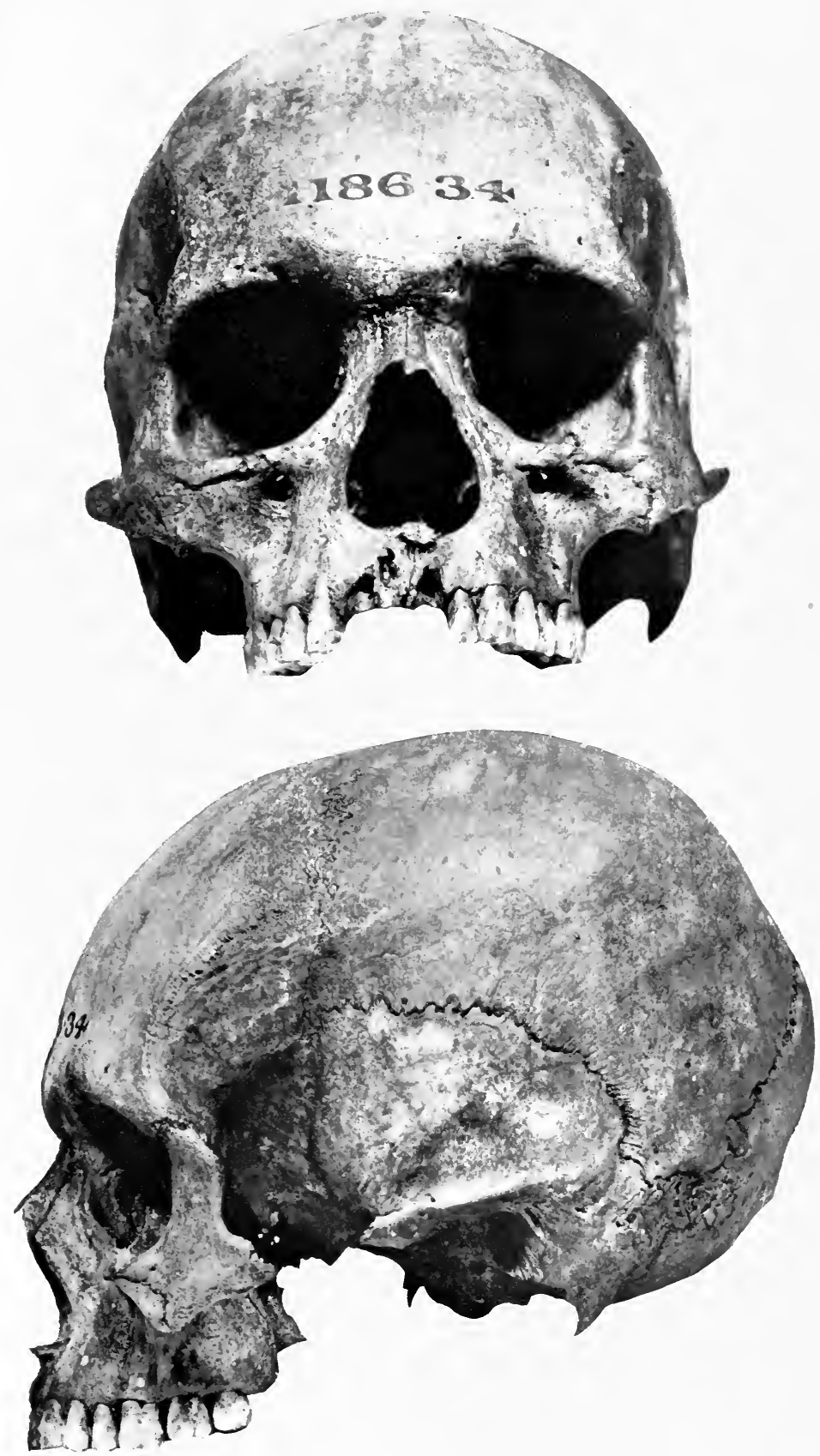

Skult, C. 

Plate 3 gives front and side views of the mesaticephalic (almost brachycephalic) skull A and Plate 4 gives similar views of the dolichocephalic skull C. All the photographs were made as nearly as possible exactly half the sizes of the originals; but the photographer has made the front view of skull A about an eighth of an inch too narrow (with, of course, a corresponding deficiency in height), so that the tendency to roundness of this skull is not quite sufficiently shown, and the proportion of its height to its length is reduced, in the plate. I am not a craniologist, and so I do not attempt to discuss the more detailed points of interest which arise in connection with these skulls.

A good idea of the somewhat varying characters of the general physiques and features of the people will be obtained from my plates; but there are a few of these plates which I may mention here.

The people shown in Plates 5, 6, 7, 8, 9 and $\mathrm{I} 6$ may, I think, be regarded as fairly typical, and I would draw attention to the somewhat Melanesian tendency of feature which is disclosed by the faces of the man in Plate 6, the young man in the middle in Plate 7 and the fourth and sixth men from the left in Plate 9; also to the great diversity shown in Plate 9. The man shown in Plate Io, with his thick and strong muscular found by the expedition into Dutch New Guinea organised by the British Ornithologists' Union had brown hair-Mr. Goodfellow tells me that "the hair of some of the pygmies was decidedly dark brown"; and Dr. Wollaston gives me the following extract from his diary for March I, I9I I, relating to twenty-four pygmies then under observation:- " Hair of three men distinctly not black, a sort of dirty rusty brown or rusty black colour-all others black-haired." 
development, is of a type which is occasionally seen, but which is, I believe, unusual. The two men figured in Plates I I and I 2 are, I think, specially interesting. The one to the right, with his somewhat backward sloping forehead, and slightly arched nose, shows a distinct tendency towards the type of the Western Papuan, to which I have already referred. The other one is in general shape of head and appearance of features not unlike some of the dwarf people found by the recent expedition into Dutch New Guinea (see the man to the left in Plate 4 of the page of illustrations in The Illustrated London Neres for September 2, I9II), and indeed there is almost an Australian tendency in his face. It is noticeable that he has a beard and moustache, which is quite unusual among the Mafulu. A somewhat similar type of face may be noticed in one or two of the other plates.

\section{Character and Temperament.}

It is difficult to speak with any degree of definiteness on this question. It must be borne in mind that the Mafulu people have been very little in touch with white people, the missionaries, who have only been there since 1905, and on rare occasions a Government official or scientific traveller, being almost the only white men whom the bulk of them have ever seen; and they have been but slightly affected by the outside influences which for some years past have been constantly brought to bear upon the natives of the adjoining coast line and the people of the Mekeo plains; so that comparisons of these people with their more up-to-date 
neighbours as regards their relative natural characters may well be in some respects misleading.

Subject, however, to this caution I would say that they are lazy and easy-going (though not so much so as the Roro and Mekeo people), lively, excitable, cheerful, merry, fairly intelligent (this being judged rather from the young people), very superstitious, brave, with much power of enduring pain, cruel, not more revengeful perhaps than is usual among uncivilised natives, friendly one with another, not quarrelsome, but untrustworthy and not over-faithful even in their dealings with one another, though honest as regards boundaries and property rights and in the sense of not stealing from one another within their own communities (this being regarded as a most shameful offence), and of very loose sexual morality.

A difference between them and the Mekeo and Roro natives is that they appear to be not so conservative as the latter, being more ready to abandon old traditions and adopt new ideas; though this characteristic is one which shows itself in the young people rather than in the elders with their formed habits. 


\section{CHAPTER III}

DRESS AND ORNAMENT

\section{Dress.}

THE perineal band, made of bark cloth, is the one article of dress which is universally worn by both men and women.

These bands are made by both men and women, but are coloured by men only. They are commonly unstained and undecorated; but some of them, and especially those worn for visiting and at dances, are more or less decorated. Some that I have noticed are stained in one colour covering the whole garment; others in two colours arranged in alternate transverse bands, sometimes with narrow spaces of unstained cloth between; and again others have bands of one colour alternating with bands of unstained cloth. Some are decorated with lines or groups of lines of one colour, or alternating lines or groups of lines of two colours, painted transversely across the cloth. Others, while simply stained in one colour or stained or decorated in one of the ways above described, have another simple terminal design near the end of the garment.

The men's bands are usually small and narrow, as 

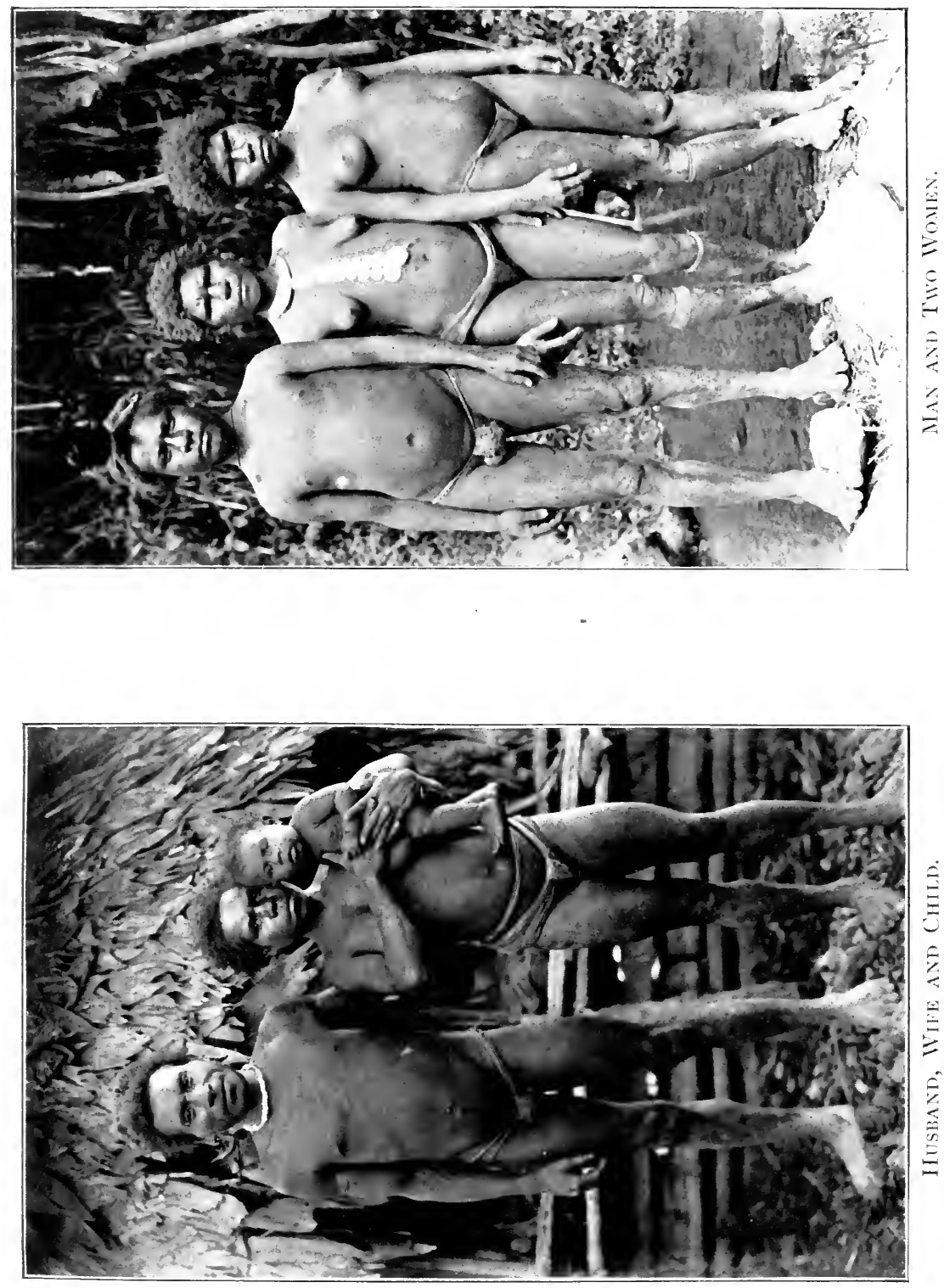

compared with those worn by the Roro and Mekeo people; and the women's bands seemed to me to be generally even narrower than those of the men, particularly in front. Men's bands, which I have measured, were about 6 inches wide at one end, narrowing down to about 3 inches at the other; and the widths of women's bands were 4 or 5 inches or less at one end, narrowing down to about 2 inches at the other. But the bands of both men and women, especially those of the latter, often become so crumpled up and creased with wear that the portion passing between the legs dwindles down to about an inch or less in width. One is tempted to think, as regards both men and women, that, from the point of view of covering, the bands might be dispensed with altogether. This remark applies still more strongly to the case of young boys and unmarried girls, including among the latter big full-grown girls, who are in fact fully developed women, whose bands can hardly be regarded as being more than nominal, and who, especially the girls and young women, and even sometimes married women who are nursing their babies, can really only be described as being practically naked.

Plate 13 (Figs. 1, 2, and 3) illustrates the staining and decoration of perineal bands. ${ }^{1}$ Fig. I is a section

1 This plate and the plates of dancing aprons were produced by first drawing the objects, and then photographing the drawings. It would have been more satisfactory if $I$ could have photographed the objects themselves. But they were much crumpled, and I was advised that with many of them the camera would not indicate differences of colour, and that in one or two of them even the design itself would not come out clearly. 
of a man's band about 6 inches wide. The transverse lines, which extend along the whole length of the band, are in alternate groups of black and red. The background is unevenly stained yellow behind the black lines; but the background behind the red lines and the spaces intervening between the groups of lines are unstained. Fig. 2 is the pattern near the end of a woman's band about 5 inches wide. The lines are coloured red. There is no pattern on the rest of the band; but the whole of the band, including the background of the pattern, is stained yellow. Fig. 3 is a section of a woman's band about $2 \frac{1}{2}$ inches wide. The colouring is in alternate bands of red and yellow with irregular unstained spaces between.

I was struck with the gradual reduction of the women's dress as I travelled from the coast, with its Roro inhabitants, through Mekeo, and thence by Lapeka and Ido-ido to Dilava, and on by Deva-deva to Mafulu. The petticoats of the Roro women gave way to the shorter ones of Mekeo, and these seemed to get shorter as I went further inland. Then at Lapeka they were still shorter. At Ido-ido, which is Kuni, the petticoats ceased, and there was only the perineal band. Then, again, at Dilava (still Kuni) this band was narrower, and at Deva-deva, and finally at Mafulu, it was often, as I have said, almost nominal.

I was told that the age at which a boy usually begins to wear his band is about 10 or 12 , or in the case of a chief's son 16 or 17 ; but that girls assume their bands at a somewhat earlier age, say at 7 or 8 . 
So far as my personal observation went I should have thought that the usual maximum age of nakedness for both boys and girls was rather younger, and I never saw a naked boy of an age anything like 16.

The assumption of the perineal band is the subject of a ceremony which will be dealt with hereafter.

Caps are very often worn by men, but not by women or children. These are simply pieces of plain unstained bark cloth about 9 inches wide, which are coiled and twisted on the head. The result is often a shapeless mass; but there are methods of arranging the cloth in definite ways which produce describable results. Sometimes the cloth is merely coiled several times around the head, so as to produce a tall thin turban-shaped band, the crown of the head being left uncovered. Often this plan is extended by turning the end of the cloth over, so as to cover the top of the head, thus producing in some cases a result which resembles a fez, and in other cases one which looks more like a tight skullcap. Again the cap often has its centre terminating in an end or tassel hanging over, thus making it look like a cap of liberty; and yet again I have seen the cap look almost like the square paper caps often worn by certain artisans at home. These caps are seen in several of the plates.

Abdominal belts are commonly worn by both men and women, but not as a rule by children. There are several distinct forms of these :-

(I) A thick strong dark-coloured belt (Plate I4, Fig. I) made of tree bark; made and worn by men only. The belt is about 3 or more inches wide and is often so 
long that it passes twice round the body, the outer end being fastened to the coil beneath it by two strings. This form of belt is sometimes ornamented with. simple straight-lined geometric patterns carved into the belt, but it is never coloured. The process of manufacture is as follows: they cut off a strip of bark large enough for one, two, three, or four belts, and coil it up in concentric circles, like the two circles of the belt when worn. They then place it so coiled into water, and leave it there to soak for a few days, after which they strip off the outer part, leaving the smooth inner bark, which they dry, and finally cut into the required lengths, to which they add the attachment strings made of native fibre.

(2) A belt made of a material looking like split cane and thin strips from the fibre of what I was told was a creeping plant ${ }^{1}$; made and worn by men only. The latter material is obtained by splitting the fibre into thin strips. These strips and the strips of split cane-like material are rather coarse in texture. The former are of a dull red-brown colour (natural, not produced by staining) and the latter are stone-yellow. The two are plaited together in geometric patterns. The width of the belt is about 2 inches. It only passes

1 Dr. Stapf, to whom I showed one of the armlets, No. 4, the materials of which are said to be the same as those used for this belt, said that the split cane-like material is a strip from the periphery of the petiole or stem of a palm, and that the other material is sclerenchyma fibre from the petiole or rhizome of a fern, and not that of a creeping plant. I may say that I felt a doubt at the time as to the complete accuracy of the information given to me concerning the vegetable materials used for the manufacture of various articles, and there may well be errors as to these. 


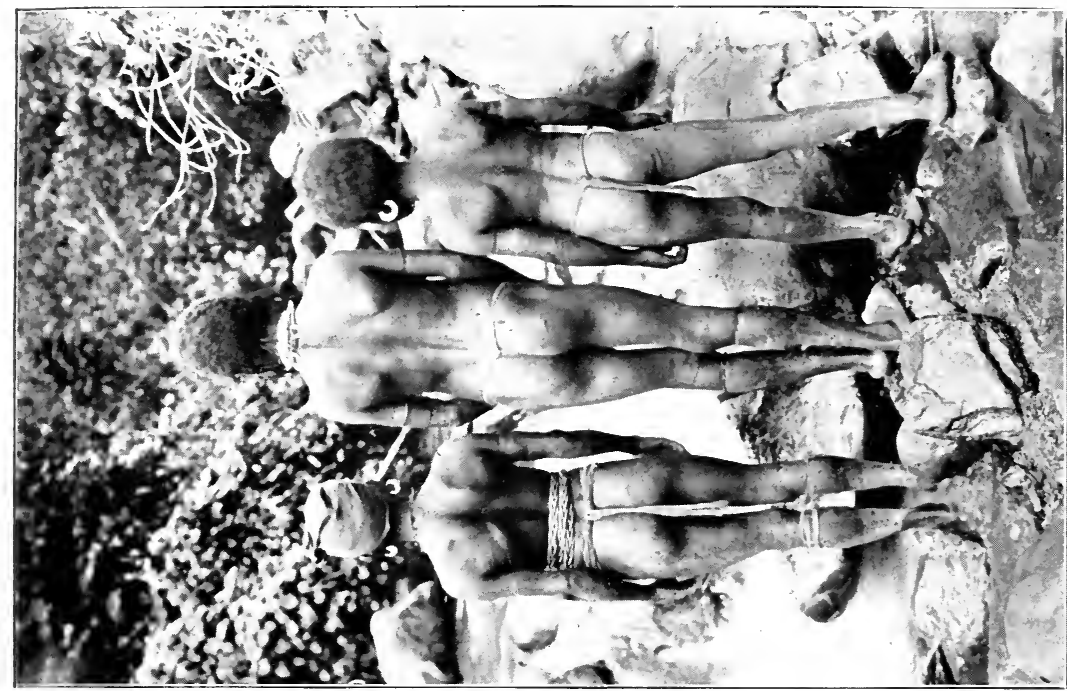

$\frac{1}{3}$

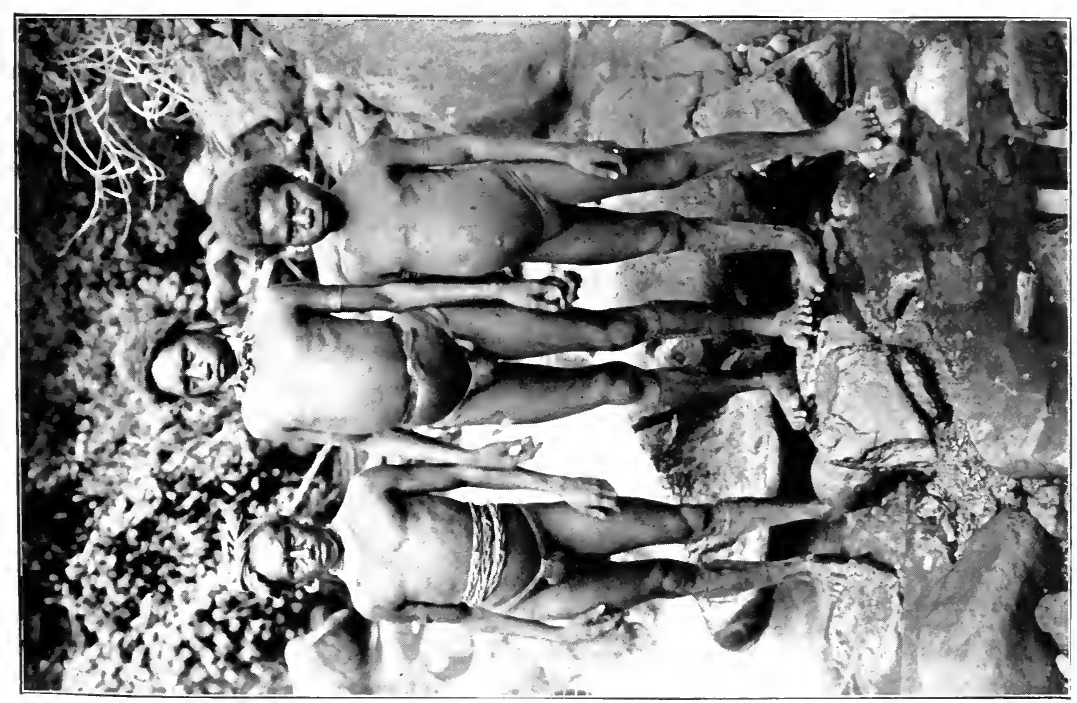



once round the man's body; and the plaiting is finished with the belt on the body, so that it can only afterwards be removed by unplaiting or cutting it off.

(3) A belt (Plate I4, Fig. 2) made of stone-yellow unsplit cane; made and worn by both men and women. This is the simplest form of belt, being merely a strip of cane intertwined (not plaited) so as to form a band about half an inch wide, and left the natural colour of the cane. Both men and women, when short of food, use this belt to reduce the pain of hunger, by tightening it over the stomach. It is, therefore, much worn during a period of restricted diet prior to a feast. Women also use it, along with their other ordinary means, to bring about abortion, the belt being for this purpose drawn very tightly round the body. Often two, or even three, such belts are worn together.

(4) A belt (Plate 14, Fig. 3) made of coarse, sometimes very coarse, stone-yellow split cane or cane-like material; made and worn by men only. This belt is left the natural colour of the material, which is plaited so as to form a band from half an inch to 2 inches broad, the two ends of which are bound together with cane. It also, like No. 2, is finished on the body. A man will often wear two or three of these belts together.

(5) A belt (Plate I 5, Fig. I) made out of the inner fibre of a creeping plant ${ }^{1}$; made and worn by men

1 Dr. Stapf, to whom I showed one of these belts, says that it is made of the separated woody strands from the stem of a climbing plant (possibly one of the Cucurbitaceae or Aristolochiaceae). 
only. The fibre threads used for this belt are very fine, so the plaiting is minute, instead of being coarse like that of No. 2 ; but it is generally done rather loosely and openly. The belt is usually about 2 inches wide or a trifle less and is often plaited in slightly varying geometric patterns. It is not stained in manufacture, but the natural stone-grey colour of the fibre soon becomes tinted as the result of wear and the staining of the wearer's body, and in particular it often becomes an ornamental red. This belt also is finished on the man's body.

(6) A belt (Plate 15, Fig. 2) made of the inner fibre of what I was told was another creeping plant ${ }^{1}$ and the stem of a plant which I believe to be one of the Dendrobiums ${ }^{2}$; made and worn by men only. The fibres of the former plant are stained black; the reedy stems of the other plant are put in short bamboo stems filled with water, and then boiled. They are then easily split up into flattish straws, and become a colour varying from rather bright yellow to brown. For making the belt these two materials, looking rather like black and bright yellow straw, are plaited together in various geometrical patterns. The width of the belt is 2 inches, or a trifle more. It is tied at the ends with fibre string.

(7) A rather special form of belt (Plate I 5, Fig. 3)

1 Dr. Stapf, having inspected one of the belts, thinks this material is composed of split strips of sclerenchyma fibre from the petiole or rhizome of a fern, and not that of a creeping plant.

2 Dr. Stapf, to whom I showed a written description which I had made of the plant, and who has also examined the belt, is of opinion that it belongs to the Diplocaulobium section of Dendrobium. 
used mainly for visiting and dancing ; made and worn by both men and women. The belt is made out of a hank of loose separate strands between 4 and 5 feet long, tied together with string or bark cloth at two opposite points, so as to form a belt of between 2 feet and 2 feet 6 inches in length. For better description I would liken it to a skein of wool, as it looks when held on the hands of one person for the purpose of being wound off into a ball by someone else, but which, instead of being wound off, is tied up at the two points where it passes round the hands of the holder, and is then pulled out into a straight line of double the original number of strands, and so forms a single many-stranded belt of 2 feet or more in length. It is fastened round the waist with a piece of bark cloth attached to one of the points where the hank has been tied up. ${ }^{1}$

The number of strands is considerable. Belts examined by me and counted gave numbers varying from eighteen to thirty-five, and the number of strands of the belt round the body would be double that. Each strand is made of three parts plaited together, and is one-eighth of an inch or less in width. Various materials, including all the materials used for armlets (see below), are employed for making these belts,

1 I have examined at the British Museum a belt made by the dwarf mountain people found by the recent expedition organised by the British Ornithologists' Union. This belt is made in hank-like form, remarkably similar to that of my Mafulu belt No. 7, though in other respects it differs from the latter, and it is much smaller. The only other thing of similar hank-like form which I have been able to find at the Museum is a small belt or head ornament (it is said to be the latter) made by Sakai people of the Malay Peninsula. 
some for one and some for another. Sometimes a belt has its strands all plaited out of one material only, in which case the belt will be all of one colour. Sometimes its strands are plaited out of two different coloured materials. There is no colouring of the belt, except that of its strands.

Belt No. I, as worn, is seen in Plates 9 and I I. Belt No. 3 is worn by the man at the extreme right in Plate I6. It is worn by many of the women figured in the plates, and several of them have two belts. One of the women figured in Plates i 8 and 19 has three of them. Belt No. 4 is worn by one of the men figured in Plates 7 and 8 (he has three of them). Belt No. 7 is worn by one or two of the women figured in the frontispiece, the one to the extreme right having a many-stranded belt, and it is excellently illustrated in Plate 17.

Capes made of bark cloth are made and worn by men and women. They are only put on after recovery from an illness by which the wearer has been laid up, including childbirth. The cape is simply a plain long narrow piece of undyed bark cloth. The corners of one end are fastened together, and the whole of that end is bunched up into a sort of hood, which is placed over the head, whilst the rest of the cloth hangs down as a narrow strip behind. The cape in no way covers or conceals any part of the body when viewed from the front or side. It is only worn for a few days; but whilst wearing it the wearer discards all, or nearly all, his or her ornaments. I could learn no reason for the custom. Plates is and I9 


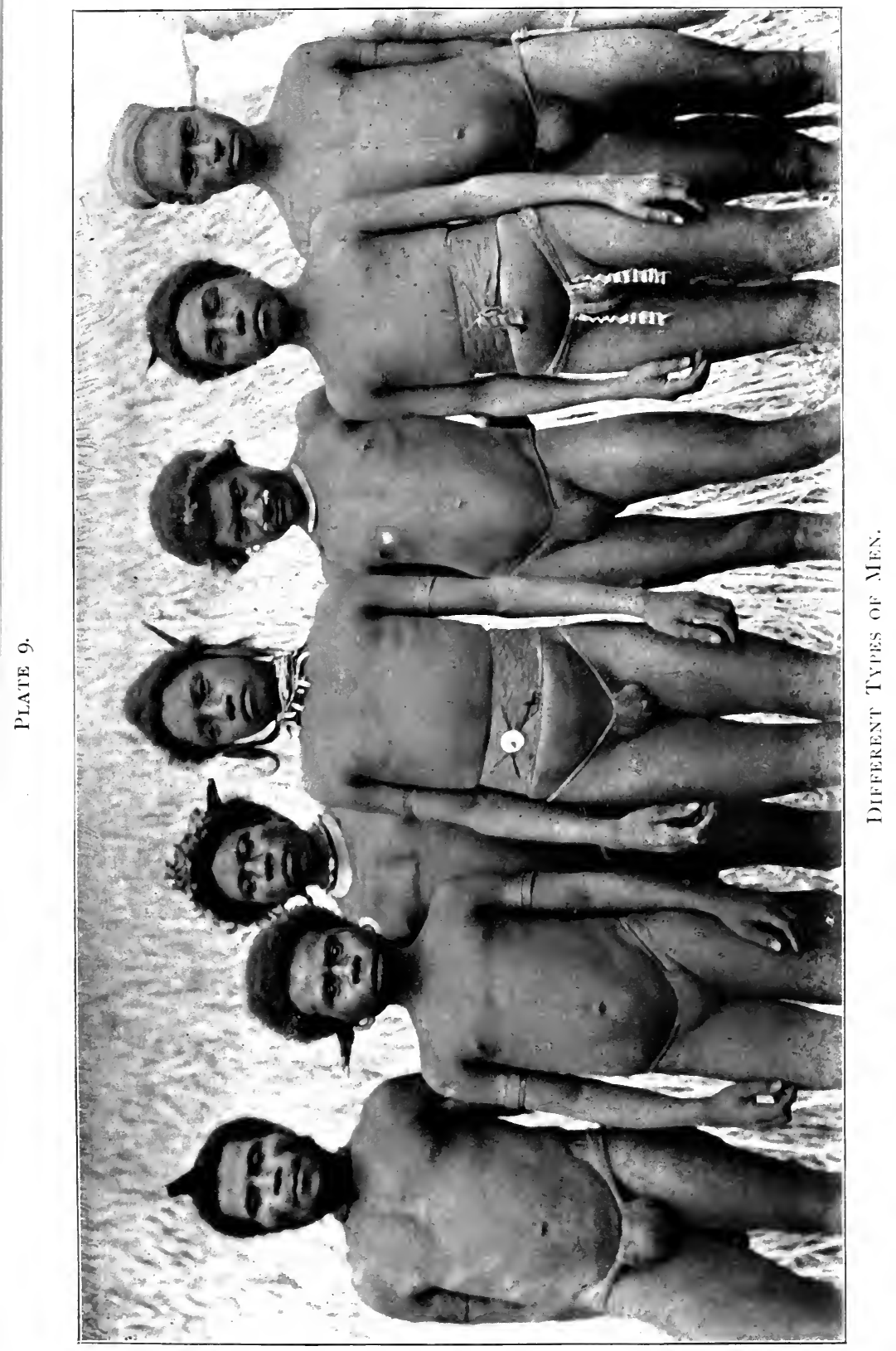



show these capes, and the way in which they are worn.

Mourning strings (Plate 30, Fig. I) are made and worn by both men and women. These are plain undecorated necklaces varying much in size and appearance; sometimes they are made of undyed twisted bark cloth, and vary in thickness from onesixteenth of an inch to an inch; sometimes they are only made of string, and are quite thin. There is always an end or tassel to the necklace, made out of the extremities of the neck part, and hanging in front over the chest; and, if the necklace is of string, and not of bark cloth, some bark cloth is twisted round this tassel. This sign of grief is after a death worn by the widow or widower or other nearest relative (male or female) of the deceased; and at times two people of equal degree of relationship will both wear it. It is worn until the formal ending of the mourning. The woman to the extreme right in Plate 26 is wearing one of these.

Widows' vests. These are mourning garments, only worn by the widows of chiefs. The garment, which is made by women, is a vest made of string network (like a string bag), the mesh of which is the special Mafulu mesh, which will be described hereafter, and it is not coloured. It is plainly and simply made, with openings at the top for the neck, and at the sides for the arms (no sleeves), and coming down to about the waist, without any other opening either in front or at the back. This garment is also worn until the formal end of the period of 
mourning. ${ }^{1} \quad$ I was unable to secure a picture of one of these.

There is no special dress for chiefs to distinguish them from other people.

European calico clothing has not been adopted by these people, even in the district where they are in touch with the missionaries. Indeed I may say that the people, happily for their own health, show no inclination to wear more clothing; and no doubt as a result of their conservatism in this respect they escape many a fatal cold and attack of pneumonia, and the spread of infectious skin diseases is somewhat reduced. I may also add that the Bishop and Fathers of the Mission do not attempt, or seem to desire, to urge the people who come under their influence to endanger their health and their lives for the sake of conforming to views as to clothing which have played such havoc with tropical natives in many parts of the globe. ${ }^{2}$

\section{Physical Body Decoration, \&c.}

Tattooing and body-scarring are not practised by either men or women among the Mafulu.

Depilation. When a young man's beard begins to grow, the hairs of the beard and moustache and eye-

1 Chalmers describes a young woman in the foot hills behind Port Moresby who "had a net over her shoulders and covering her breasts as a token of mourning" (Work and Adventures in New Guinea, p. 26). Compare also the Koita custom referred to by Dr. Seligmann (Melanesians of British New Guinea, p. 164) for a widow to wear two netted vests. The same custom is found at Hula.

2 See reference to this question in the Annual Report for June, I906, p. I3. 
brows are extracted. No other depilation is practised by men, and none whatever by women; and none of them shave any part of the body. The depilation is effected with two fibre threads twisted round each other, the hair to be extracted being inserted between the threads. Anyone can do this, and there is no ceremony connected with it.

Nose-piercing. The septa of the noses of both men and women are pierced at or after the age of 15 or I 8, and either before or after marriage. This is done for men by men, and for women by women. There is no special person whose duty it is to do it, but he or she must be one who knows the incantations which are required. There is no restriction as to diet or otherwise placed upon the operator prior to the operation, but there is a day's food restriction imposed upon the person whose nose is to be pierced.

Two instruments are used for the operation, one being a piercing instrument made of pig bone and sharpened, and the other being a small wooden plug, also sharpened. The operator first visibly, but silently, engages in two incantations, during the former of which he holds up the thumb and first finger of his right hand, and during the latter of which he holds up the two instruments. He then with the thumb and first finger of his right hand holds the septum of the nose of the person to be operated upon, whom I will call the "patient," and with the left hand pierces the septum with the bone instrument. $\mathrm{He}$ next inserts the wooden plug into the hole, so as to make it larger, and leaves the plug there. Then 
he takes a blade of grass, which he also inserts through the hole, by the side of the plug, and, holding the grass by the two ends, he makes it rotate round and round the plug. This is a painful process, which frequently causes tears and cries from the patient. He then probably goes through the same process with various other patients, as it is the custom to operate on several persons at the same time.

The patients are then all lodged in houses built for the purpose, one house being for men and one for women. These are not houses which are kept permanently standing, but are specially built on each occasion on which the nose-boring operation is going to be performed. A great swelling of the patients' noses develops, and this spreads more or less over their faces. The patients are confined in the special houses until the holes in their noses are large enough and the wounds are healed. During this confinement each patient has himself to do what is requisite to further enlarge the hole by the insertion into it from time to time of pieces of wood and by putting in rolled up leaves and pushing pieces of wood inside these leaves. During all this period he is not allowed to come out of the house, at all events not so as to be seen, and his diet is confined to sweet potato, cooked in a certain way. The cooking for all the patients, men and women, is done by the woman nose-piercing operator, assisted by other women. The potatoes are wrapped up in leaves (usually banana), each potato being generally wrapped up separately in one or more leaves; and, when so wrapped up, they are 


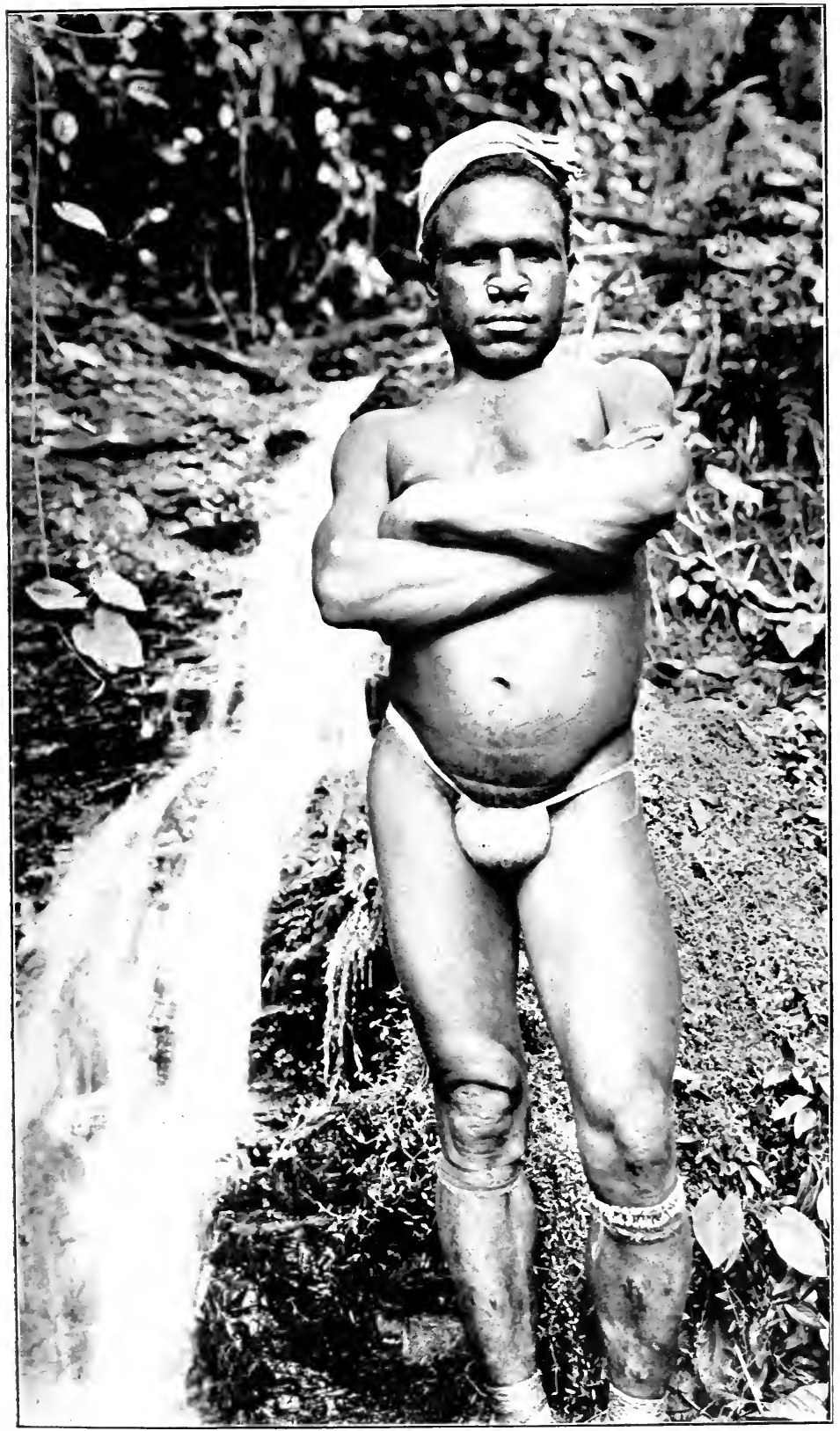

An Unusual Trie. 

cooked in red-hot ashes, and then taken to the houses where the patients are.

When the hole in any patient's nose has reached the requisite size, and the wound is healed, he inserts a large croton leaf ${ }^{1}$ into the hole; he may then come out and return to his own house, retaining the croton leaf in his nose. He must next occupy himself in searching for a black non-poisonous snake about I 2 or I 8 inches long, which is commonly found in the grass. I cannot say what snake this is, but I am advised that it is probably Tropidonotus mairii. Its native name is fal' $u l$ ' obe, which means "germ of the ground." Until he finds this snake he must keep the croton leaf in his nose, and is still under the same restriction as to food, which is cooked in the same way and by the same persons as before. On finding the snake, he secures it alive, removes the croton leaf from the hole in his nose, and inserts into it the tail end of the living snake; then, holding the head of the snake in one of his hands, and the tail in the other, he draws the snake slowly through the hole, until its head is close to the hole. He then lets the head drop from his hand, and with a quick movement of the other hand draws it through the nose, and throws the snake, still living, away. ${ }^{2}$ This

1 I shall from time to time have to refer to the croton, and in doing so I am applying to the plant in question the name commonly given to it ; but Dr. Stapf tells me that the plant so commonly called is really a codiœum.

2 The Rev. Mr. Dauncey, of the L.M.S. station at Delena (a Roro village on the coast) told me that in his village it is a common thing for a native to pick up a small white snake about 12 inches long, and pass it through the hole in his nose ; and that the Pokau people sometimes pass 
completes the nose-piercing; but there still rests upon the patient the duty of going to the river, and there catching an eel, which he gives to the people who have been feeding him during his illness.

The nose-piercing is generally done at one of the big feasts; and, as these are rare in any one village, you usually find in the villages many fully-grown people whose noses have not been pierced; though as to this I may say that nose-piercing is more generally indulged in by chiefs and important people and their families than by the village rank and file. It commonly happens, however, that a good many people have to be done when the occasion arises. Each person to be operated upon has to provide a domestic pig for the big feast. I have been unable to discover the origin and meaning of the nose-piercing ceremony. ${ }^{1}$

Ear-piercing is done to both men and women, generally when quite young, say at seven or twelve years of age. Both the lower and the upper lobes are pierced, sometimes only one or the other, and sometimes both; but the lower lobe is the one more commonly pierced. They can do it themselves, or can get someone else to do it. There is no ceremony. The

the tip of the tail of a larger black snake into these holes, the intention of both practices being to keep the hole open. In neither of these cases is the practice a part of an original ceremony connected with nosepiercing, such as that of Mafulu; but it may well be that all the practices have superstitious origins.

1 There is apparently no corresponding ceremony among the Koita natives (Seligmann, Melanesians of British New Guinea, p. 72), nor among the Roro people (Id., p. 256), and I do not believe there is any such in Mekeo. 
piercing is done with the thorn of a tree, and the hole is afterwards gradually widened by the insertion of small pieces of wood. They never make large holes, or enlarge them greatly afterwards, as the holes are only used for the hanging of pendants, and not for the insertion of discs. After the piercing the patient must, until the wound is healed, abstain from all food except sweet potato; but there is no restriction as to the way in which this food is to be cooked, or the person who is to cook it. There is as regards earpiercing no difference between the case of chiefs' children and those of other people.

Body-staining is usual with both men and women, who do it for themselves, or get others to help them. There is no ceremony in connection with it. The colours generally adopted are red, greyish-yellow and black. The red stain is procured from an earth, which is obtained from the low countries; but they themselves also have an earth which is used, and produces a more bronzy red. The yellow stain is also got from an earth. All these coloured earths are worked into a paste with water, or with animal fat, if they can get it. I think they also get a red stain from the fruit of a species of Pandanus; but I am not quite clear as to this. The black stain is obtained from crushed vegetable ashes mixed with fat or water. The staining of the face is usually of a simple character. It may cover the whole face all in one colour or in different colours, and often one side of the face is stained one colour, and the other side another colour. They also make stripes and spots or 
either of them of any colour or colours on any part of the face. The red colour (I think especially that obtained from the Pandanus fruit) is also often applied in staining the whole body, this being especially done for dances and visiting; though a young dandy will often do it at other times. The black is the symbol of mourning, and will be referred to hereafter.

Hairdressing may be conveniently dealt with here. The Mafulu hairdressing is quite simple and rough, very different from the big, spreading, elaborately prepared and carefully combed mops of Mekeo. This is a factor which a traveller in this part of New Guinea may well bear in mind in connection with his impedimenta, as he has no difficulty in getting the Kuni and Mafulu people to carry packages on their heads, which the Mekeo folk are unwilling to do.

The modes in which the men dress their hair, so far as I was able to notice, may be roughly divided into the following categories:- $(a)$ A simple crop of hair either cut quite close or allowed to grow fairly long, or anything between these two, but not dressed in any way, and probably uncombed, unkempt and untidy. This is the commonest form. (b) The same as $(a)$, but with a band round the hair, separating the upper part of it from the lower, and giving the former a somewhat chignon-like appearance. (c) The hair done up all over the head in three-stranded plaits a few inches long, and about an eighth of an inch thick, having the appearance of short thick pieces of string. (d) The top of the head undressed, but the sides, and sometimes the back, of the head done up in plaits like $(c)$. (e) A 

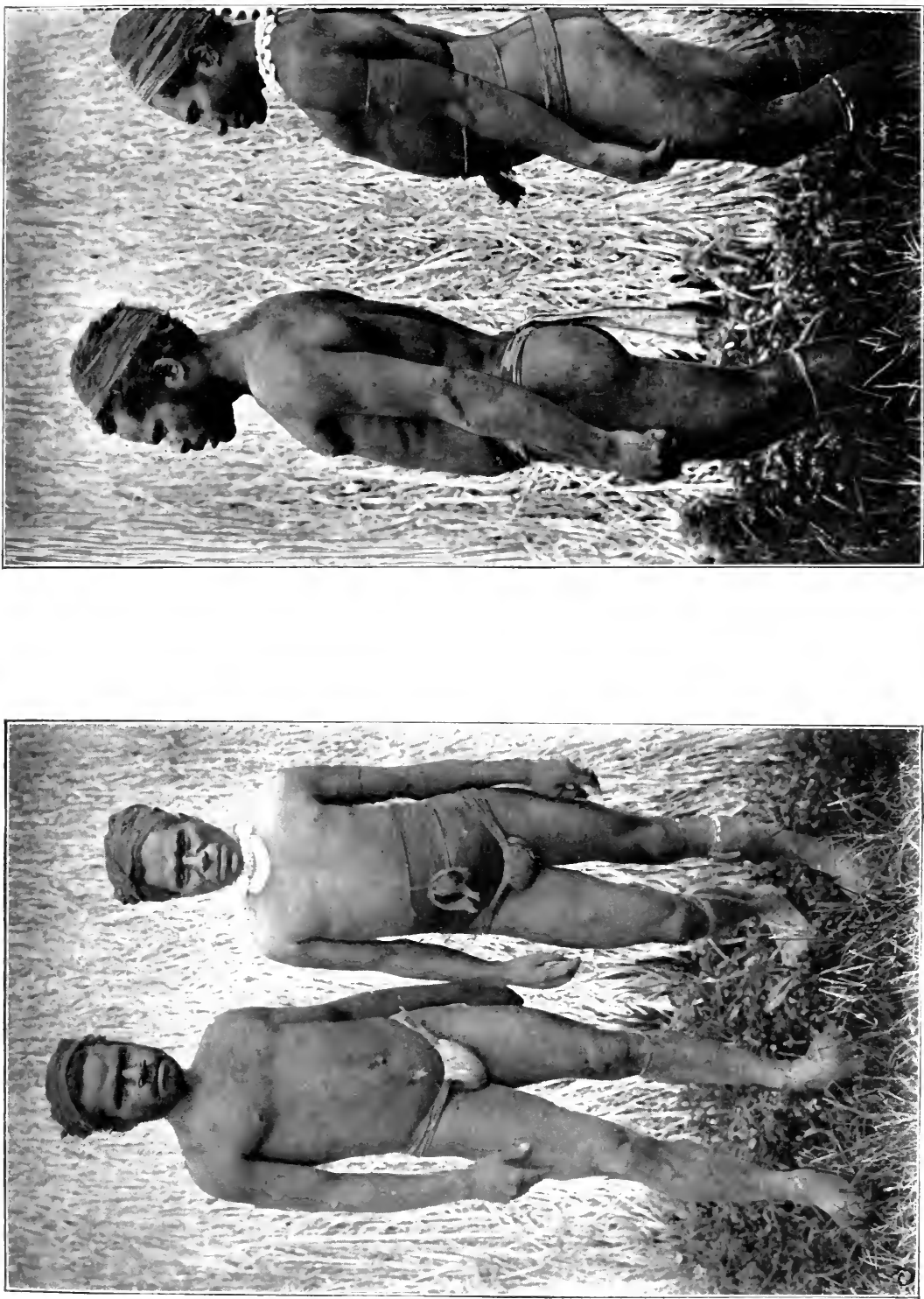

manufactured long shaped fringe of hair, human, but not the hair of the wearer (Plate 20, Fig. 3), is often worn over the forehead, just under the wearer's own hair, so as to form, as it were, a part of it, pieces of string being attached to the ends of the fringe and passed round the back of the head, where they are tied. These fringes are made by tying a series of little bunches of hair close to one another along the double string, which forms the base of the fringe. Specimens examined by me were about $\mathrm{I} 2$ inches long and $\mathrm{I} \frac{1}{4}$ inches wide (this width being the length of the bunches of hair), and contained about twenty bunches. It is usual to have two or three of these strings of bunches of hair tied together at the ends, thus making one broad fringe. These fringes are often worn in connection with styles $(c)$ and $(d)$ of hairdressing; but I never noticed them in association with $(a)$ and $(b)$.

I was told that men who have become bald sometimes wear complete artificial wigs, though I never saw an example of this.

The hairdressing of the women seemed to be similar to that of the men, except that I never saw the chignon-producing band, that they do not wear fringes, and that the entire or partial plaiting of the hair is more frequently adopted by them than it is by the men. I do not know whether the women ever indulge in entire wigs.

Method $(a)$ is seen in many of the plates. Method (b) is illustrated, though not very well, in Plate 9 (the fourth and fifth man from the left) and in Plate $2 \mathrm{I}$ (the young man to the left, behind). Method (c) is adopted 
by four of the women in the frontispiece, by some of the women in Plate 16 , by the woman in Plate 17 , and by the little girl in Plates 22 and 23. Method $(d)$ is well illustrated by the second woman from the right in the frontispiece.

The cutting of the hair of both men and women is effected with sharp pieces of stone of the sort used for making adze blades, or with sharp pieces of bamboo or shell.

Infant deformation is not practised in any form by the Mafulu people; nor do they circumcise their children.

\section{Ornaments.}

The string-like plaits in which men and women arrange their hair, and especially those of the women, are often decorated with ornaments. Small cowrie and other shells, or native or European beads, or both, are strung by women on to these plaits, sometimes in a line along all or the greater part of the length of the plait, sometimes as a pendant at the end of it, and sometimes in both ways; and any other small ornamental object may be added. Dogs' teeth are also used by both men and women in the same way; but these are, I think, more commonly strung in line along the plaits, rather than suspended at the ends of them. Both men and women wear suspended at the ends of these plaits wild betel-nut fruit, looking like elongated acorns; and men, but not women, wear in the same way small pieces of cane, an inch or two long, into which the ends of the plaits are inserted. 
All these forms of decoration may be found associated together. They are in the case of men usually confined to the plaits at the sides, being also often attached to the side ends of the artificial fringes; but they are sometimes used for the back of the head also. The women often wear them also at the top of the head, and in wearing them at the sides sometimes have them hanging in long strings reaching to the shoulders.

Plate 24 (Figs. I, 2, 5, and 6) and Plate 25 (Figs. 2 and 4) are ornamented plaits cut off the heads of women. The ornaments shown include beads, shells, discs made out of shells, dogs' teeth and betel-nut fruit: Plate 24 (Figs. 3 and 4 ) are ornamented plaits cut off the heads of men, one of them having a cane pendant, and the other a pendant of betel-nut.

The appearance of these things, as worn, is seen in Plates 16, 26, 27, 28 and 29 (the habit of wearing a single dog-tooth at each side of the head, as shown by 27 , being a common one, and 28 showing the equally common habit of wearing a couple of betel-nuts at each side). Their appearance, when worn in abundance for a festal dance, is excellently shown in the frontispiece and in Plate 17 ; and the little girl in Plates 22 and 23, though too young to be a dancer, is decorated for an occasion.

Pigs' tails are a common head decoration for women, and are also worn, though not so frequently, by men. These tails are covered with the natural hair of the tail, and are brown-coloured. They are suspended by strings passing round the crown of 
the head or from the plaits at the sides of the head. They are generally only about 6 inches long; but sometimes the ornaments into which they are made are much longer, and I have seen them worn by women hanging down as far as the level of the breast. These pigtails are sometimes worn hanging in clusters of several tails. They are also often, in the case of women, decorated with shells, beads, dogs' teeth, etc., which are attached like tassels to their upper ends. ${ }^{1}$

Plate 30, Fig. 3 shows a pigtail ornament for hanging over the head, with the tails suspended on both sides and strings of beads and dogs' teeth hanging from the upper ends of the tails. The ornament is worn by the middle man in Plate 9 and by the little girl figured in Plates 22 and 23 , and it is seen more extensively worn by women decorated for dancing in the frontispiece and in Plate 17 , and by the girl in Plate $7 \mathrm{I}$.

A peculiar and less usual sort of head ornament (Plate 30, Fig. 4), worn by both men and women, is a cluster of about a dozen or less of bark cloth strings, about $\mathrm{I} \frac{1}{2}$ feet long, fastened together at the top, and there suspended by a string tied round the top of the head, so as to hang down like the lashes of a several-thonged whip over the back. The individual strings of the cluster are quite thin, but they

1 I do not think these pigtails are used as ornaments by the Roro and Mekeo people, though Dr. Seligmann says that a Koita bridegroom wears them in his ears on his wedding day (Melanesians of British New Guinea, p. 78). 


\section{Plate I3.}

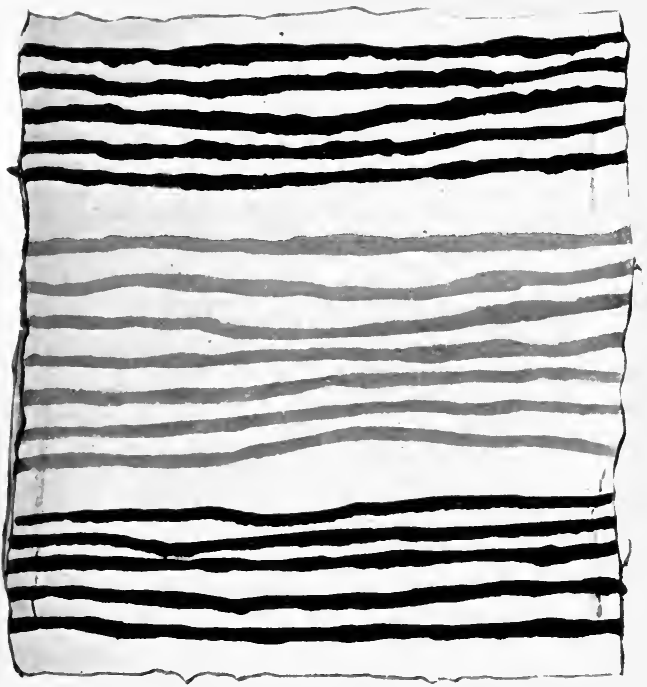

2

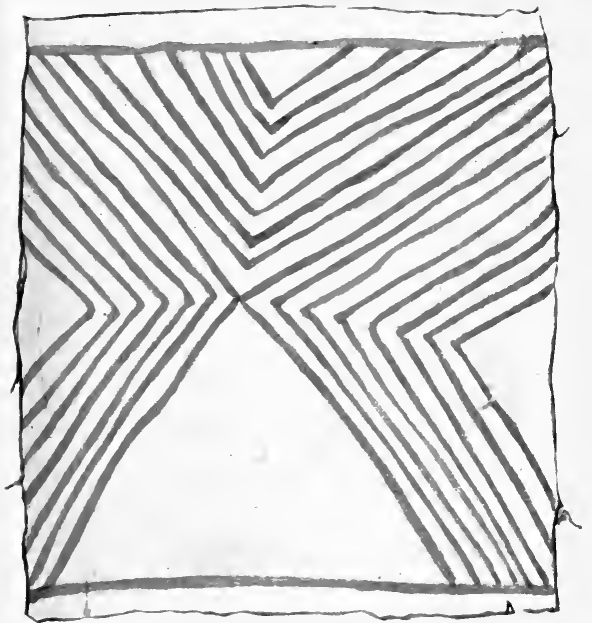

3

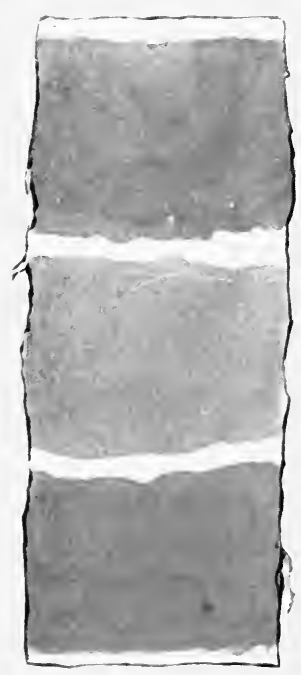

4

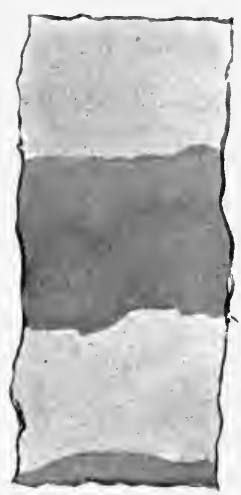

Fig. i. Section of Man's perineal Bayd.

, 2. Decoration near find of Woman's Perineal Bayd.

, 3. Section of Woman's Perineal. Bani).

, 4. Section of Man's or Woman's Dancing Ribbon. 

are decorated with the yellow and brown straw-like material above referred to in connection with abdominal belt No. 6 (being prepared from the same plant, apparently Dendrobium, and in the same way), the material being twisted in a close spiral round the strings, and making them look, when seen from a short distance off, like strings of very small yellow and brown beads, irregularly arranged in varying lengths of the two colours, shading off gradually from one to the other. Even when so bound round, these strings are only about $\frac{1}{16}$ to $\frac{1}{8}$ of an inch thick.

The Mafulu comb (Plate 30, Fig. 2) differs in construction from the wooden combs, all made in one piece, which are commonly used in Mekeo. It is made of four, five, or six thin pieces of wood, which are left blunt at one end, but are sharpened to points at the other. These are bound together with straw-like work, sometimes beautifully done, the binding being nearly always near to the blunt ends, though it is sometimes almost in the middle. $^{1} \quad$ The combs so made are flat, with the blunt ends converging and generally fastened together, and the long sharp ends, which are the ends to be inserted into the hair, spreading outwards. The bound-up blunt ends are in fact a point, or, say, half an inch or less (occasionally more) across. The spread of the sharp ends varies from $\mathrm{I}$ to 2 inches or more. The

1 Dr. Stapf, to whose inspection I have submitted two of these combs, said they were made of palm-wood-split and shaped pieces from the periphery of the petiole or stem of a palm-and that the material used for binding the teeth of the combs together was sclerenchyma fibre from the petiole or rhizome of a fern. 
straw-like binding may be light or dark brown, or partly one and partly the other. Sometimes only the two outside prongs meet together at the blunt end, and the inner prongs do not extend much, or at all, beyond the upper edge of the straw-like work binding. The fastening together of the blunt converging tips is done sometimes with native thread just at the tips, and sometimes with a little straw work rather further down; occasionally it is missing altogether. The comb figured is not so converging at the blunt ends or so spreading at the sharp ends as is usual, and its blunt ends are not bound together. These combs are only worn by men; they are commonly worn in front, projecting forwards over the forehead, as is done in Mekeo; but they are also worn at the back of the head, projecting sideways to either right or left. A feather (generally a white cockatoo feather), or sometimes two feathers, are often inserted into the straw-like work of the comb, so as to stand up vertically when the comb is worn, and there wave, or rather wag, backwards and forwards in the wind. I could not learn any significance in these feathers, such as applies to many of the upright head feathers worn by the young men of Mekeo. The comb is worn by several of the men figured in Plate 9, one of them wearing it in front and the others having it standing out sideways at the back.

The almost universal type of earring (Plate 20, Fig. I), varying from 2 to 3 inches in circumference, is made out of the tail of the cuscus. The ring is made by removing the hair from the animal's tail, 
drying the tail, and fastening the pointed end into or on to the blunt cut-off stump end, tying them firmly together. The ring is then bound closely round with the yellow and brown material (Dendrobium) of belt No. 6 ; but a space of 1 or 2 inches is generally left uncovered at the part where the two ends of the tail are fastened together. The simplest form is a single earring, which passes through the hole in the ear; but I have seen two rings hanging to the ear ; and frequently a second ring is hung on to the first, and often a third to the second, and sometimes a fourth to the third; or perhaps, instead of the fourth ring, there may be two rings hanging to the second one. In fact, there are varieties of ways in which the fancy of the wearer and the number of rings he possesses will cause him to wear them. They are worn by both men and women. ${ }^{1}$ They may be seen in several plates, but unfortunately are not very clear. The most distinct are, I think, those worn by the second woman from the left in Plate 26 and the woman on the left in Plate 28. The second woman from the left in the frontispiece has two of them hanging from her right ear.

Pigs' tails, similar to those worn from the hair, are also worn by both men and women, especially the latter, suspended from the ears; and here again they vary much in length, and are often decorated with tassel-like hanging ornaments of shells, beads, etc.

Forehead ornaments (Plate 30, Fig 5) are made by

1 These earrings are, I think, sometimes found in Mekeo; but they have all come from the mountains. 
men and worn by them at dances. This ornament is a band, very slightly curved, which is worn across the forehead, just under and surrounding the basis of the dancing feathers. It is generally about 16 inches long and between 4 and 5 inches broad in the middle, from which it narrows somewhat towards the ends. Its manufacture consists of a ground basis of the material of belt No. 5, into which are interplaited in geometric patterns the two black and yellow and brown materials which are used for belt No. 6. It is fixed on to the forehead by means of strings attached to its two ends, and passing round, and tied at the back of, the head.

Nose ornaments. These are straight pencil-shaped pieces of shell, generally about 6 inches long, which are passed through the hole in the septum of the nose. They are only worn at dances and on special occasions; but the people from time to time insert bits of wood or cane or bone or some other thing into the hole for the purpose of keeping it open. There are temporary pegs in the noses of the fifth man to the left in Plate 9 and the man in Plate Io. The nose ornament is worn by the woman to the extreme right in the frontispiece.

Necklaces and straight pendants, suspended from the neck and hanging over the chest, are common, though they are not usually worn in anything approaching the profusion seen in Mekeo and on the coast. These are made chiefly of shells of various sorts (cut or whole), dogs' teeth and beads, as in Mekeo. The shells include the cowries and the small closely packed overlapping cut shells so generally 
Plate 14.

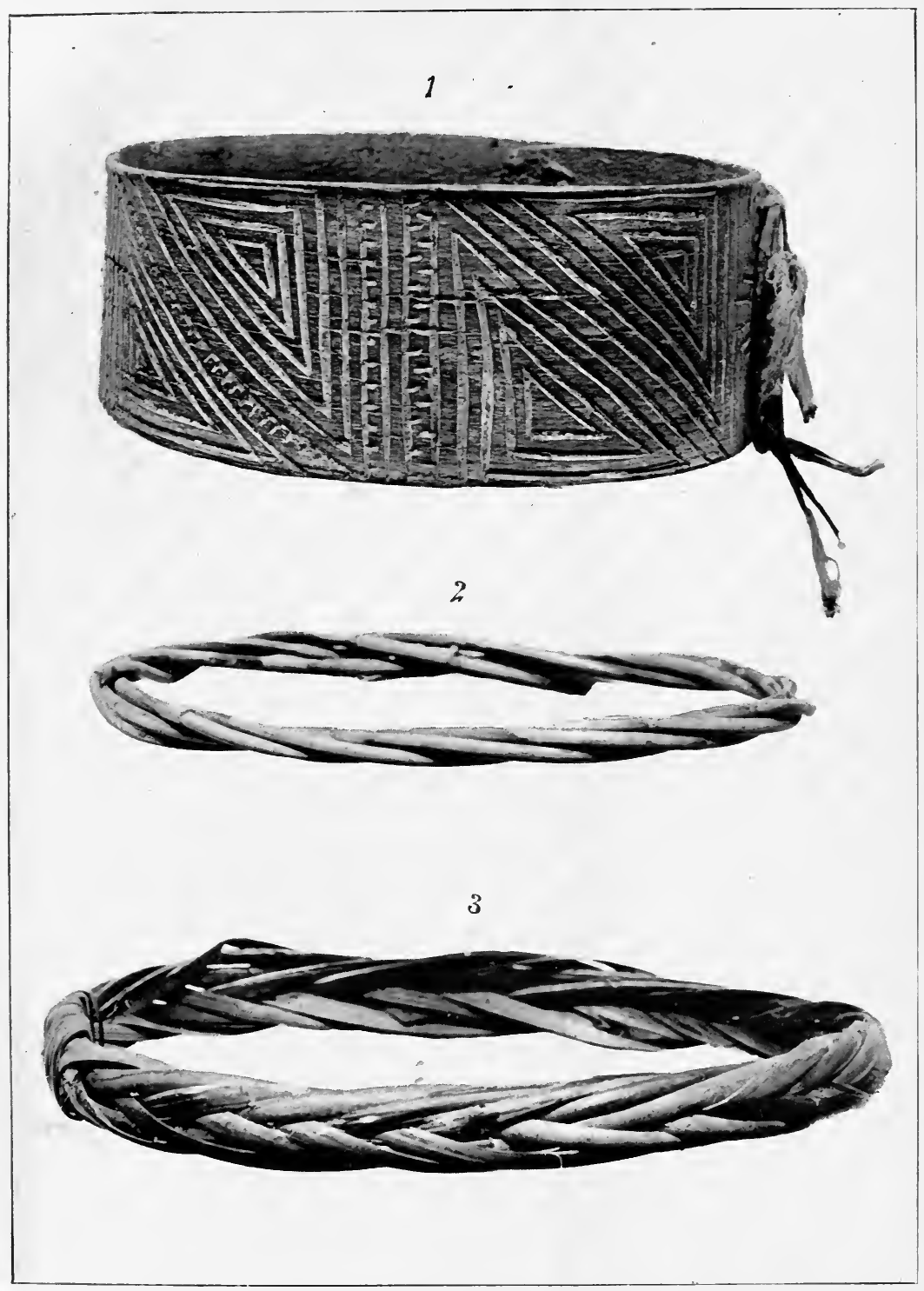

Fig. I. Belt No. I.

, 2. do. , 3 .

, 3. do. , 4 . 

used in Mekeo for necklaces, and the flat disc-like shell sections, which are here, as in Mekeo, specially used for straight hanging pendants; also those lovely large crescent-shaped discs of pearl shell, which are well known to New Guinea travellers. The shells are, of course, all obtained directly or indirectly from the coast; in fact, these are some of the chief articles for which the mountain people exchange their stone implements and special mountain feathers, so the similarity in the ornaments is to be expected; but it is only within a quite recent time that the pearl crescents have found their way to Mafulu. I do not propose to describe at length the various forms of shell ornament, as they are very similar to, and indeed I think practically the same as, those of Mekeo. Some of the necklaces are figured in Plates 31,32 and 33 , and they are worn by many of the people figured in other plates, especially the frontispiece and Plate I7. Straight pendant ornaments are seen in the frontispiece and in Plates 6, 17, 26 and others. The crescentshaped pearl ornaments are seen in the frontispiece and in Plates 6, 7, 16, 28 and others, a very large one being worn by the little girl in Plate $7 \mathrm{r}$.

There is, however, one shell necklace which is peculiar to the mountains, and, I think, to Mafulu (I do not know whether the Kuni people also wear it), where it is worn as an emblem of mourning by persons who are relatives of the deceased, but who are not sufficiently closely related to him to stain themselves with black during the period of mourning. This necklace is made of white cowrie shells varying in size 
from half an inch to an inch long, each of which has its convex side ground away, so as to show on one side the untouched mouth of the shell and on the other an open cavity. The shells are strung, sometimes closely and sometimes loosely, on to a double band of thin cord. Specimens of this type of necklace measured by me varied in length from 36 inches (with 97 shells) to 20 inches (with 38 shells). It is worn until the period of mourning is formally terminated. The middle necklace in Plate 33 is a mourning shell necklace, and it is seen on the neck of the woman to the right in Plate 29.

Pigs' tail ornaments similar to those already described are also worn suspended by neck-bands over the chest.

Armlets and wrist-bands are worn by both men and women, and more or less by children, including quite young ones, at the higher end of the upper arm and just above the wrist. They are made by men only, and vary in width from half an inch to 5 or 6 inches, the wider ones being generally worn on the upper arm. There are several common forms of these: (I) The more usual form (Plate 34, Fig. 4) is made of the thin and finely plaited stone-grey material described in abdominal belt No. 5, and is made in the same way, subject to the difference that the plaiting is more closely done. Measured specimens of this armlet varied in width from $I$ to $2 \frac{1}{4}$ inches, and displayed different varieties of diagonal twill stitch. (2) Another common form (Plate 34, Fig. 3) is made of the coarser-plaited black and yellow and brown 
materials described concerning No. 6 belt, and is made in the same way. Specimens of this armlet varied in width from $I$ to 5 inches. (3) There is another form which in fineness of material and plait is between Nos. I and 2. I was told that this is made out of another creeping plant, and is left in its own natural unstained colour, which, however, in this case is a dull brown red. (4) Another form (Plate 34, Fig. 2) is made of the coarse dull red-brown and stoneyellow materials described with reference to belt No. 2, and is made in the same way. A specimen of this armlet was $2 \frac{1}{4}$ inches wide. (5) Another form (Plate 34, Fig. I) is in make something like No. 4 , but the two materials used are the stone-yellow material of belt No. 2 and the black material of belt No. 6, and the plaiting materials are much finer in thickness than are those of armlet No. 4. Specimens of this armlet varied in width from $\frac{3}{4}$ to $I \frac{1}{4}$ inches. (6) The beautiful large cut single-shell wrist ornament, commonly worn on the coast and plains, whence the Mafulu people procure it. Armlets will be seen worn by many of the people figured in the plates.

There is no practice of putting armlets on young folk, and retaining them in after life, so as to tighten round and contract the arm.

Leg-bands (Plate 25, Fig. I) and anklets are worn by both men and women, and also by children, just below the knee and above the ankle.

There is a form of plaited leg-band somewhat similar in make to armlet No. 5, and between half-aninch and an inch in width, though the colour of this 
leg-band is a dull brown. But the usual form of legband and anklet is made by women only out of thread fibre by a process of manufacture quite distinct from the stiff plait work adopted for some of the belts and for the armlets. They make their thread out of fine vegetable fibre as they proceed with the manufacture of the band, rolling the individual fibres with their hands upon their thighs, and then rolling these fibres into two-strand threads, and from time to time in this way making more thread, which is worked into the open ends of the then working thread as it is required-all this being done in the usual native method.

I had an opportunity of watching a woman making a leg-band, and I think the process is worth describing. She first made a thread 5 or 6 feet long by the method above referred to, the thread being a two-strand one, made out of small lengths about 5 or 6 inches long of the original fibre, rolled together and added to from time to time until the full length of 5 or 6 feet of thread had been made. The thread was of the thickness of very coarse European thread or exceedingly fine string. She next wound the thread into a triple loop of the size of the proposed leg-band. This triple loop was to be the base upon which she was to make the leg-band, of which it would form the first line and upper edge. It was only about II inches in circumference, and thus left two ends, one of which (I will call it "the working thread") was a long one, and the other of which (I will call it "the irside thread") was a short one. Both these threads 


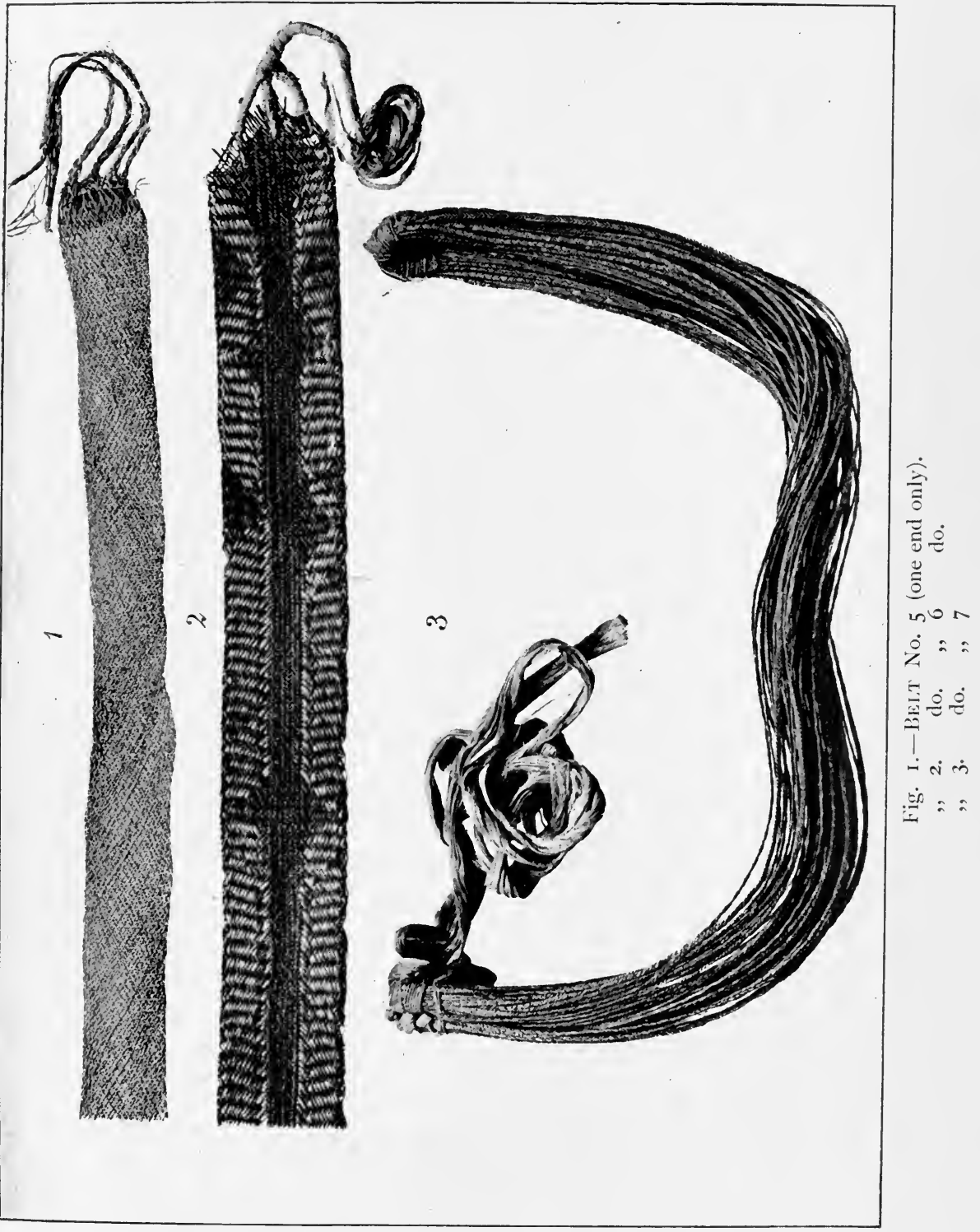



hung down together from the same point (which I will call "the starting point"). She then, commencing at the starting point, worked the working thread round the triple base by a series of interlacing loops in the form shown (very greatly magnified) in Fig. I ;

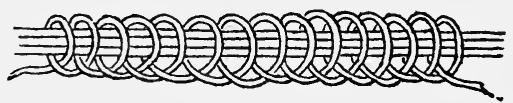

Fig. I. -Leg-BANd MAKING (COMmencing StAGe).

but the loops were drawn quite tight, and not left loose, as, for the purpose of illustration, I have had to make them in the figure. This process was carried round the base until she had again reached the starting point, at which stage the base, with its tightly drawn loop work all around it, was firm and strong, and there were still the two ends of thread hanging from the starting point. Here and at subsequent stages of the work she added to the lengths of these two ends from time to time in the way above described when they needed it, and the two ends of thread were therefore always present. Then began the making of the second line. This was commenced at the starting point, from which the two ends of thread hung, and was effected by a series of loops made with the working thread in the way already described, except that these loops, instead of passing round the whole of the base line, passed through holes which she bored with a thorn, as she went on, in the extreme bottom edge of that line, and also that, in making this second line, she passed the inside thread through each loop before she drew the latter tight; so that the 
second line was itself composed of a single internal thread, around which the loops were drawn. The second line was continued in this way until she again reached the starting point (but, of course; one line lower down), from which the two ends of thread hung down as before. The third and following lines were made by a process identical with that of the second one, the holes for each line being pricked through the bottom of that above it. I did not see the completion of the band, but I may say that the final line is similar to the second and subsequent ones, and is not a triple-threaded line like the first one. It was amazing to see this woman doing her work. She was an old woman, but she did the whole of the work with her fingers, and she must have had wonderful eyesight and steadiness of hand, as she made the minute scarcely visible prick holes, and passed the end of her working thread through them, with the utmost apparent ease and quickness.

The band thus produced is of very small, close, fine work, and is quite soft, flexible and elastic, like European canvas, instead of being stiff and hard, like the plaited belts and armlets. The band is generally about an inch (more or less) in width. It is not dyed or coloured in any way, but is often decorated with beads, which are worked into the fabric in one or more horizontal lines, but as a rule, I think, only at irregular intervals, and not in continuous lines. These bands and anklets are seen in many of the plates. In Plates IO, II and I 2 the bead decorations are seen. 
Dancing aprons are made out of bark cloth by both men and women, but coloured by men only. The apron, which is worn at dances by women only, is about 6 to 12 inches wide. It is worn, as shown in Plate 35, in front of the body, being passed over the abdominal belt or a cord so as to hang over it in two folds, one behind the other; and the front fold, which is the part which shows (the back fold being more or less concealed), and is generally I 8 inches to 2 feet in length, has at its base a fringe made by cutting the end of the cloth up into strips, equal or unequal in width, the number of which may be only six or less, or may be fifteen or twenty. The front fold is often wholly or partly stained, the colour of the stain being usually yellow, and is always more or less covered with a decorative design, the colours of which are usually black and red. The back fold is generally stained yellow, but never has any design upon it. The fringe is also usually stained yellow, and is without design, except occasionally perhaps a few horizontal lines of colour.

I may say here, as regards these colours, that, so far as my observation went, the colours of the decorative patterns were always black and red, and the general staining was always yellow; and indeed the lastmentioned colour does not show up against the natural colour of the cloth sufficiently clearly to adapt it for actual design work. I am not, however, prepared to say that this allocation of the colours is in fact an invariable one; and, as I know that red is used for general staining of perineal bands and dancing 
ribbons, it is possible that it, as well as yellow, is used for aprons.

Numerous variations of design are to be found in these garments; and indeed I may say that it is in these and in the feather head decorations that the Mafulu people mainly indulge such artistic powers as they possess.

Plates 36 to 43 are examples of decoration of the front folds of these dancing aprons ${ }^{1}$; and I give the following particulars concerning them, first stating that, subject to what may appear in my particulars, the darker lines and spots represent black ones in the apron, and the lighter ones represent red ones.

\begin{tabular}{|c|c|c|}
\hline Plate. & $\begin{array}{l}\text { Average } \\
\text { width of } \\
\text { apron in } \\
\text { inches. }\end{array}$ & Notes on ground staining and other matters. \\
\hline 36 & $6 \frac{1}{2}$ & $\begin{array}{l}\text { Background of design unstained, but back fold of apron } \\
\text { and fringe stained vellow. }\end{array}$ \\
\hline $37^{2}$ & $7 \frac{3}{4}$ & Ditto ditto ditto \\
\hline 38 & 51 & $\begin{array}{l}\text { Only a little irregular yellow staining behind the design. } \\
\text { Back fold of apron and fringe stained yellow. }\end{array}$ \\
\hline 39 & 6 & $\begin{array}{l}\text { Background of design (except fringe part) unstained, } \\
\text { but back fold of apron and fringe stained yellow. }\end{array}$ \\
\hline 40 & 7 & $\begin{array}{l}\text { Background of upper (zig-zag) part of design unstained, } \\
\text { but that of lower (rectangular) part and whole of back } \\
\text { fold of apron and fringe stained yellow. }\end{array}$ \\
\hline $4 \mathrm{I}$ & $10 \frac{1}{2}$ & $\begin{array}{l}\text { Faintly tinted broad horizontal and vertical lines and } \\
\text { triangles in figure represent yellow stain. No other } \\
\text { staining in the apron. }\end{array}$ \\
\hline 42 & $6 \frac{3}{4}$ & $\begin{array}{l}\text { Background of design unstained, but back fold end of } \\
\text { apron and fringe stained yellow. }\end{array}$ \\
\hline 43 & $6 \frac{3}{4}$ & $\begin{array}{l}\text { No background staining in the apron. The smallness of } \\
\text { the amount of decoration and the substitution of two } \\
\text { tails for a fringe are, I think, unusual. }\end{array}$ \\
\hline
\end{tabular}

1 See note on p. 27 as to the way in which these plates have been produced.

2 Only the two ends of the pattern have been copied, the intermediate part being the same throughout, as is shown. 


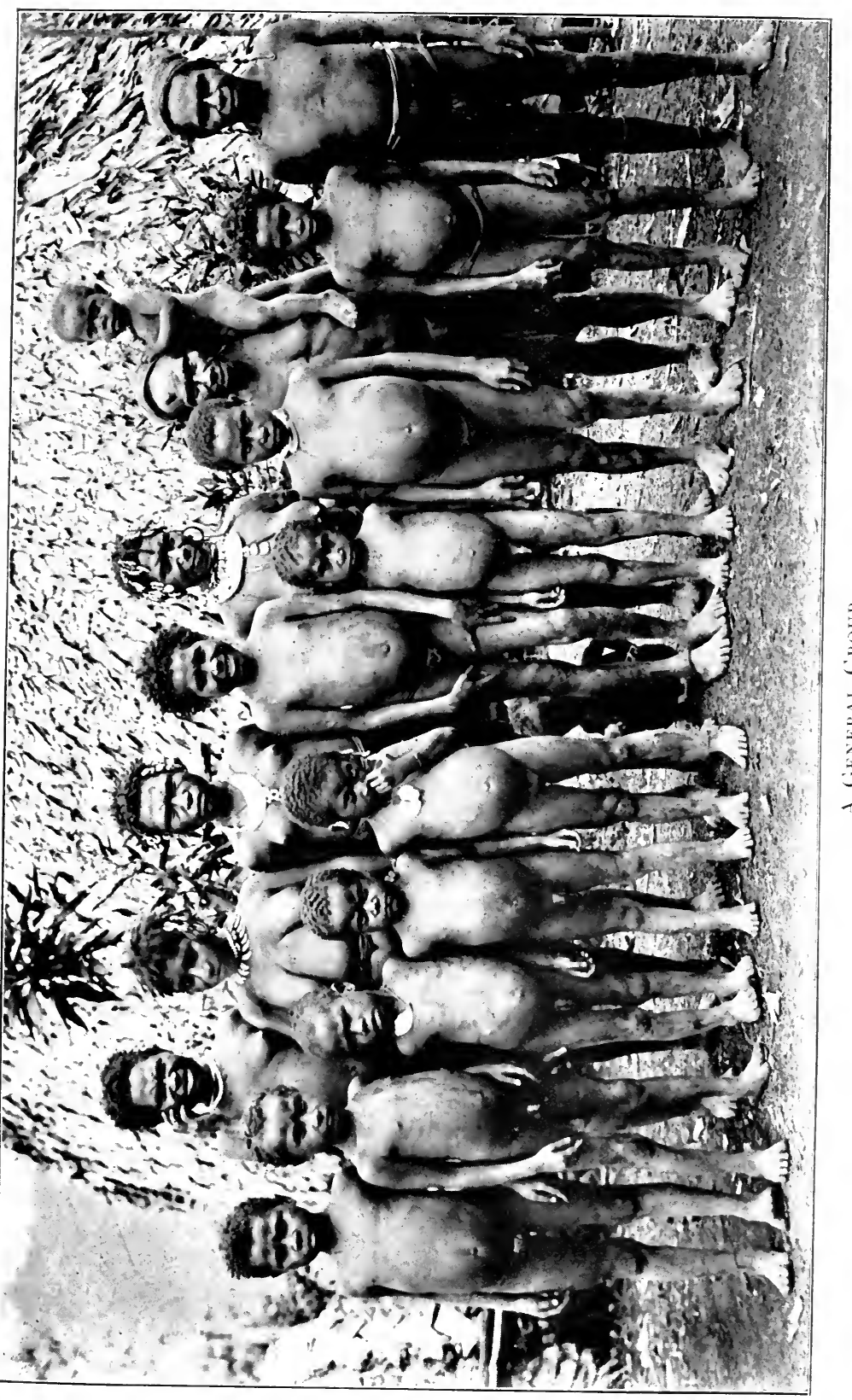



Dancing ribbons are made out of bark cloth by both men and women, but are coloured by men only. These are worn by both men and women at dances, the ribbons hanging round the body from the abdominal belt or a cord, three or four or five of them being worn by one person, and one of these commonly hanging in front. They are generally 2 or 3 inches wide and about 4 feet long, but a portion of this length is required for hitching the ribbon round the belt. I think their ornamentation is confined to staining in transverse bands of alternating colour or of one colour and unstained cloth. Plate I3, Fig. 4, illustrates the colouring of two ribbons (each 2 inches wide), the alternation in one case being red and yellow, and in the other red and unstained cloth; and the men figured in Plate 70 are wearing ribbons, though they are not very clearly shown in the plate.

The feather ornaments for the head, and especially those worn at dances, and the feather ornaments worn on the back at dances present such an enormous variety of colours and designs that it would be impossible to describe them here without very greatly increasing the length of the book. The ornaments are often very large, sometimes containing eight or ten or even twelve rows of feathers, one behind another. They can usually be distinguished from those made by the Mekeo people by a general inferiority in design and make of the ornament as a whole, the Mafulu people having less artistic skill in this respect than the people of the lowlands. The ornaments include feathers of parrots, cockatoos, hornbills, 
cassowaries, birds of paradise, bower birds and some others. One never or rarely sees feathers of seabirds, or waterfowl, or Goura pigeons (which, I was told, are not found among the mountains), as the Mafulu people in their trading with the people of the plains take in exchange things which they cannot themselves procure, rather than feathers, which are so plentiful with them.

The black cassowary feather is important in Mafulu as being the special feather distinction of chiefs ; but, though chiefs are as a rule possessed of more and better ornaments than are the poorer and unimportant people, they have no other special and distinctive ornament.

Plates 44 and 45 illustrate some of these head feather ornaments. Plate 44, Fig. I, shows an ornament made out of the brown fibrous exterior of the wild betel-nut, black pigeon feathers and white cockatoo feathers, the betel fibre and black pigeon feathers being, I was told, only used in the mountains. Plate 44, Fig. 2, shows one made out of brown feathers of young cassowary, white cockatoo feathers and red-black parrot feathers. Plate 44, Fig. 3, shows one made out of bright red and green parrot feathers. Plate 45, Fig. I, shows one made out of black cassowary feathers, white cockatoo feathers, red parrot feathers and long red feathers of the bird of paradise. Plate 45, Fig. 2, is made of cassowary feathers only. This ornament is worn in front of the head, over the forehead, and is specially worn by chiefs.

Plate 46, Fig. I, shows a head feather ornament which is peculiar to the mountains. The crescent- 
shaped body of the ornament, which is made of short feathers taken from the neck of the cassowary, is worn in front over the forehead, and the cockade of hawk feathers stands up over the head.

Plate 46, Fig. 2, shows a back ornament of cassowary feathers which is specially intended to be worn by chiefs at dances. The custom is to have from five to twelve of these ornaments hanging vertically side by side, suspended to a horizontal stick, which is fastened on the chief's back at the height of the shoulders, so that the feathers hang like a mantle over his back. The mode in which feather ornaments for the back are hung on sticks is seen in Plate 70 , where a stick with pendant ornaments is being held by two boys in front.

Plaited frames (Plate 47) are worn by men in connection with these head feather ornaments. These frames are flat curved bands, rigid or nearly so, generally forming half or nearly half a circle of an external diameter of about 9 inches, and being about $\mathrm{I}$ inch in width. They are worn at dances and on solemn occasions. They are placed round the top of the forehead, not vertically, but with their upper edges sloping obliquely forward, and have at their ends strings, which pass over the ears and are tied at the back of the head. These frames help to support the feather ornaments, and prevent them from falling down over the face. They are made by men only. A groundwork of small split cane or other material runs in parallel curved lines from end to end, single pieces of the material being generally doubled back at the 
ends so as to form several lines; and this is strengthened and ornamented by interplaiting into it either split cane or some other material obtained from the splitting of the inside fibre of a plant in the way previously referred to. There are varieties of material and of pattern worked up in different designs of interplaiting. Some of the materials are uncoloured or merely the natural colour of the material, and others are in two colours, generally brown or reddish-brown and yellow. These frames display a considerable amount of variety of artistic design.

The feather erections used at special and important dances, and especially those worn by chiefs, are enormous things, towering 6 or 12 feet above the wearer's head, and are generally larger than those of Mekeo. They are held in a framework, which has an inverted basket-shaped part to rest on the head, and downward pointing rods, which are tied to the shoulders. The frames are to a great extent similar to those of Mekeo, but, having a larger burden to bear, they are more strongly made. These feather erections and their frames are seen in Plate 70.

Here, as in other parts of New Guinea, both men and women, but especially men, love to decorate themselves with bright flowers and leaves and grasses, these being worn in the hair and in bunches stuck into their belts, armlets and leg-bands, and indeed in any places where they can be conveniently fastened.

It is not the practice with the Mafulu for mothers to wear the umbilical cords of any of their children, though apparently the Kuni people do so. 


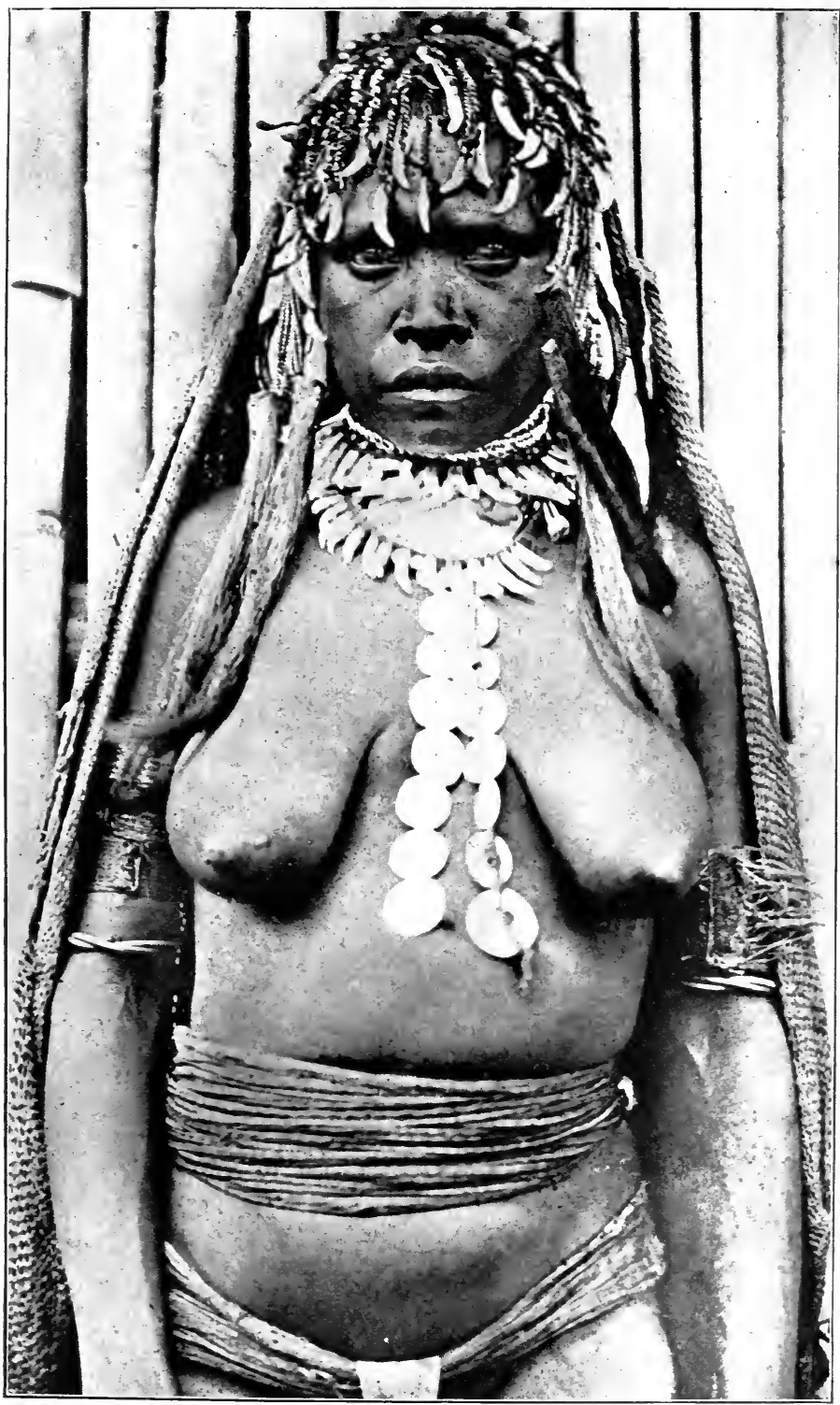

A Young Chiff's Sister decoratei for a Dance. 



\section{CHAPTER IV}

DAILY LIFE AND MATTERS CONNECTED WITH IT

\section{Daily Life.}

THE early morning finds the wife and young children and unmarried daughters in the house. The husband has been sleeping either there or in the emone (clubhouse), but most probably the latter. The unmarried sons are in the emone, except any very young ones, who have not been formally admitted to it in a way which will be hereafter described. The women cook the breakfast for the whole family inside the house at about six or seven o'clock, and then take the food of the men to the emone. After breakfast most of the men and women go off to the gardens and the bush. The women's work there is chiefly the planting of sweet potatoes, taro and other things, and cleaning the gardens; and in the afternoon they get food from the gardens and firewood from the bush, all of which they bring home to the village; also they have to clear off the undergrowth from newly cleared bush. The men's work is mainly the yam and banana and sugar-cane planting, each in its season, and the cutting down of big trees and making fences, if they happen 
to be opening out new garden land. They also sometimes help the women with their work. Or they may have hunting expeditions in the bush, or go off in fishing parties to the river. In all matters the men of Mafulu, though lazy, are not so lazy as those of Mekeo and the coast. In the middle of the day the women cook the meal for everyone in the gardens, this being done on the spot, and there they all eat it. At three, four, or five o'clock all the people of the village have returned to it, except perhaps when they are very busy taking advantage of good weather for making new clearings or other special work. In the evening they have another meal cooked in the village. At every meal in the village the pigs have to be fed also, these sharing the food of the people themselves, or feeding on raw potatoes. Unless there is dancing going on, or they are tempted by a fine moonlight night to sit out talking, the people all terminate their routine day by going to bed early.

As regards the daily social conduct of the people among themselves, I was told that the members of a family generally live harmoniously together (subject as regards husbands and wives to the matters which will be mentioned later), that children are usually treated kindly and affectionately by their parents, and that there is very little quarrelling within a village; and what I saw when I was among the Mafulu people certainly seemed to confirm all this.

There are various detailed matters of daily life which will appear under their appropriate headings; but I will here deal with a few of them. 


\section{Food.}

The vegetable foods of the Mafulu people are sweet potato and other plants of the same type, yam and other foods of the same type, taro and other foods of that type, banana of different sorts, sugar-cane, a kind of wild native bean, a cultivated reed-like plant with an asparagus flavour (what it is I do not know), several plants of the pumpkin and cucumber type, one of them being very small, like a gherkin, fruit from two different species of Pandanus, almonds, the fruit of the malage (described later on), and others, both cultivated and wild. The sugar-cane is specially eaten by them when working in the gardens. ${ }^{1}$

Their animal food consists of wild pig and, on occasions, village pig, a small form of cassowary, kangaroo, a small kind of wallaby, kangaroo rat, "iguana," an animal called gaivale (I could not find out what this is), various wild birds, fish, eels, mice, a large species of snake and other things.

Their staple drink is water, but when travelling they cut down a species of bamboo, and drink the watery fluid which it contains. After boiling any food in bamboo stems they drink the water which has

1 I am unable to state the various forms and varieties of these vegetables, but I give the following native names for plants of the yam, taro, and sweet potato types:-Yams include tsiolo, avanve, buba, aligarde, vaule, vonide, poloide and ilavuide. Taros include auvari, elume, lupeliolu, kamulepe, ivuvana and fude. Sweet potatoes include asi, bili, dube, saisasumulube and amb' $u$ tolo (this last name means "ripe banana," and the reason suggested for the name is that the potato tastes rather like a ripe banana). 
been used for the purpose, and which has become a sort of thin flavoured soup.

Betel-chewing is apparently not indulged in by these people as extensively as it is done in Mekeo and on the coast; but they like it well enough, and for a month or so before a big feast, during which period they are under a strict taboo restriction as to food, they indulge in it largely. The betel used by them is not the cultivated form used in Mekeo and on the coast, but a wild species, only about half the size of the other; and the lime used is not, as in Mekeo and on the coast, made by grinding down sea-shells, but is obtained from the mountain stone, which is ground down to a powder. The gourds (Plate 5I, Figs. 6 and 7) in which the lime is carried are similar to those used in Mekeo, except that usually they are not ornamented, or, if they are so, the ornamentation is only done in simple straight-lined geometric patterns. The spatulae are sometimes very simply and rudely decorated. The people spit out the betel after chewing, instead of swallowing it, as is the custom in Mekeo.

\section{Cooking and Eating and their Utensils.}

They have no cooking utensils, other than the simple pieces of bamboo stem, which they use for boiling.

Their usual methods of cooking are roasting and boiling.

Roasting is usually effected by making a fire, letting 

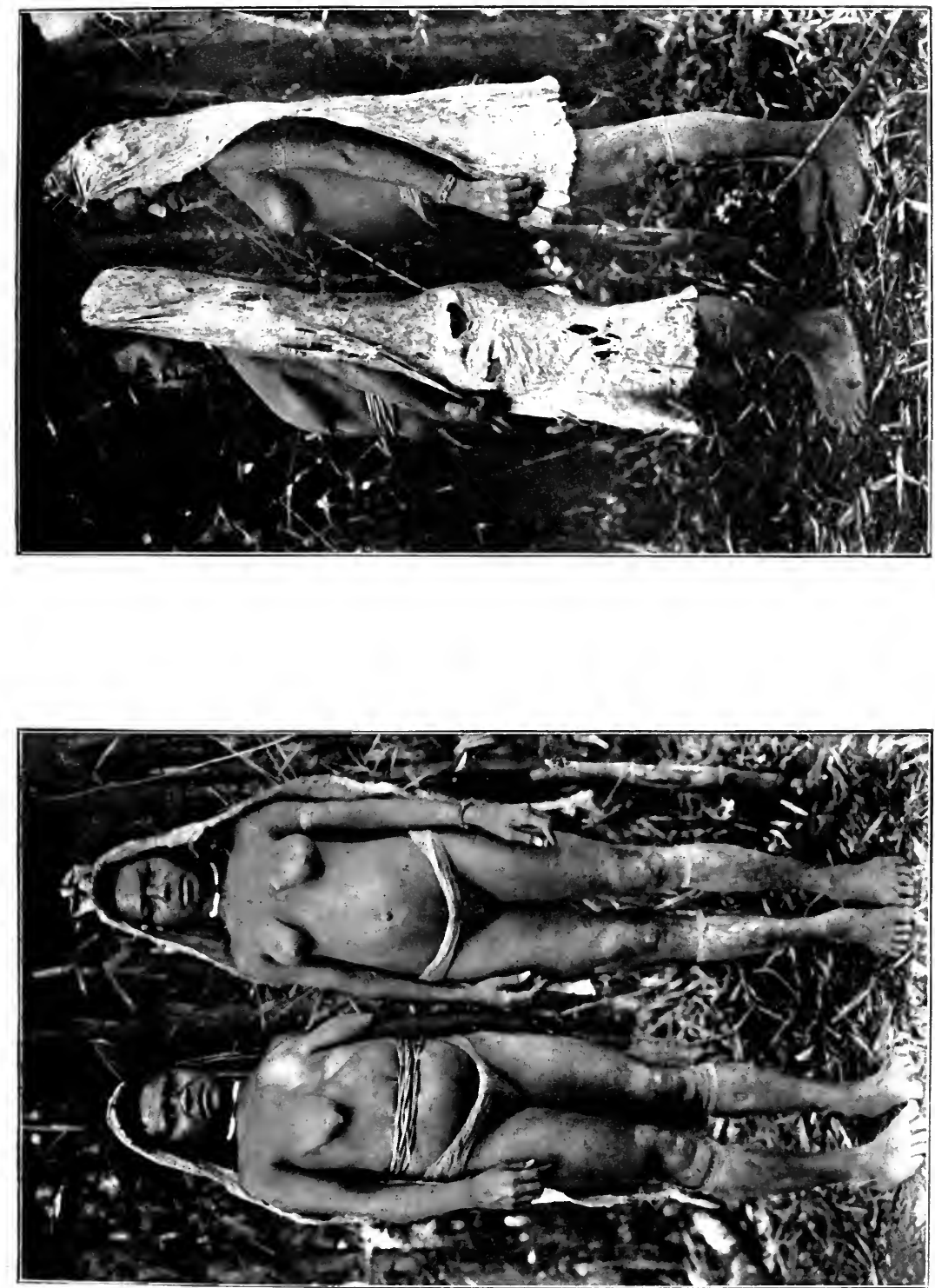

it die down into red-hot ashes, and then putting the food without wrap or covering into the ashes, turning it from time to time. They also roast by holding the food on sticks in the flame of the burning fire, turning it occasionally. Stone cooking is adopted for pig and other meats. They make a big fire, on the top of which they spread the stones; when the stones are hot eniough, they remove some of them, place the meat without wrap or covering on the others, then place the removed stones on the meat, and finally pile on these stones a big covering of leaves to keep in the heat. Stone cooking in the gardens is done in a slightly different way; there they dig in the ground a round hole about I foot deep and from $1 \frac{1}{2}$ to 2 feet in diameter, and in this hole they make their fire, on which they pile their stones; and the rest of the process is the same as before. This hole-making process is never adopted in the village. The only reason for it which was suggested was that the method was quicker, and that in the gardens they are in a hurry. Of course, holes of this sort dug in the open village enclosure would be a source of danger, especially at night.

Boiling is done in pieces of bamboo about 4 inches in diameter and about 15 or 18 inches long. They fill these with water, put the food into them, and then place or hold the bamboo stems in a slanting position in the flames. This method is specially used for cooking sweet potatoes, but it is their only method of boiling anything. Water, which they keep stored and carry in bamboo receptacles and hollow pumpkins, is boiled in bamboo stems in the same way. The bamboo 
storage vessels are generally from 2 to 5 feet long, the intersecting nodes, other than that at one end, having been removed. The pumpkins (Plate 52, Figs. 2 and 3 ) are similar to those used by the Roro coast people and in Mekeo, except that the usual form, instead of being rather short and broad with a narrow opening, is longer and narrower, some of them being, say, 3 feet long, and often very curved and crooked in shape.

Their only eating utensils are wooden dishes and small pieces of wood, or sometimes of cassowary or kangaroo bone, which are used as forks, and pieces of split bamboo, which are used for cutting meat; but these latter are used for other purposes, and rather come within the list of ordinary implements, and will be there described. They also use prepared pig-bones as forks; but these again are largely used for other purposes, and will be described under the same heading.

The dishes (Plate 52, Fig. I) are made out of the trunk of a tree called ongome. The usual length of a dish, without its handles, is between $I$ and 2 feet; its width varies from 9 inches to I foot, and its depth from 3 to 6 inches. It is rudely carved out of the treetrunk, ${ }^{1}$ the work being done with stone adzes-unless they happen to possess European axes-and it generally has a handle at one or both ends. It is not decorated with carving in any way. The common form of handle is merely a simple knob about 3 inches long and $1 \frac{1}{2}$ inches wide. But it is sometimes less

1 Dr. Stapf says the wood is that of a rather soft-wooded dicotyledonous tree (possibly urticaceous). 
simple, and I have a dish one of the handles of which is divided into two projecting pieces about $7 \frac{1}{2}$ inches long and joined to each other at the end. The handle is always carved out of the same piece of wood as is the dish; never made separately and afterwards attached. The wooden forks are simply bits cut from trees and sharpened at one end, and they are without prongs. Their use is only temporary, and they are not permanently stored as household utensils. The cassowary and kangaroo bone implements (Plate 25, Fig. 3) are also merely roughly pointed unpronged pieces of bone, and otherwise without special form. When eating en famille they do not always use these pointed wooden and bone sticks, but very commonly take the food out of the dish with their hands only; but if the family had guests with them they would probably use the sticks more, and their hands less. The men and women often eat together, sitting round the dish and helping themselves out of it, though, if there are too many to do this conveniently, pieces will be handed out to some of them.

\section{VARIOUS IMPLEMENTS.}

Besides the cooking and eating implements above described and other things, such as weapons of war and of hunting and fishing, and implements for manufacture, agriculture and music, which will be dealt with under their own headings, there are a few miscellaneous things which may be conveniently described here.

Bamboo, knives (Plate 5I, Fig. 5). These are 
simple strips made out of a special mountain form of bamboo, and are generally 8 to ro inches long and about I inch wide. One edge is left straight for its whole length, and the other is cut away near the end, very much as we cut away one side of a quill pen, so as to produce a sharp point. The side edge which is used for cutting is the one which is not cut away at the end; and when it gets blunt it is renewed by simply peeling off a length of fibre, thus producing a new edge, bevelled inwards towards the concave side of the implement, and making a hard and very sharp fresh cutting edge. The point can of course be sharpened at any time in the obvious way.

Pig-bone implements (Plate 5I, Fig. 2). These are the implements which are often used as forks, but they have straight edges also with which they are used as scraping knives, and they are utilised for many other purposes. The implement, which is, I think, similar to what is commonly found in Mekeo and on the coast, is made out of the leg-bone of a pig, and is generally from 5 to 8 inches long. One side of the bone is ground away, so as to make the implement flattish in section, one side (the outside unground part of the bone) being somewhat convex, and the other (where the bone has been ground away) being rather concave. Some of the joint end of the bone is left to serve as a handle; and from this the bone is made to narrow down to a blunt, rather flattish and rounded point, somewhat like that of a pointed paper-cutter. The side edge is used for scraping, and the point for sticking into things. 
Piate 20.

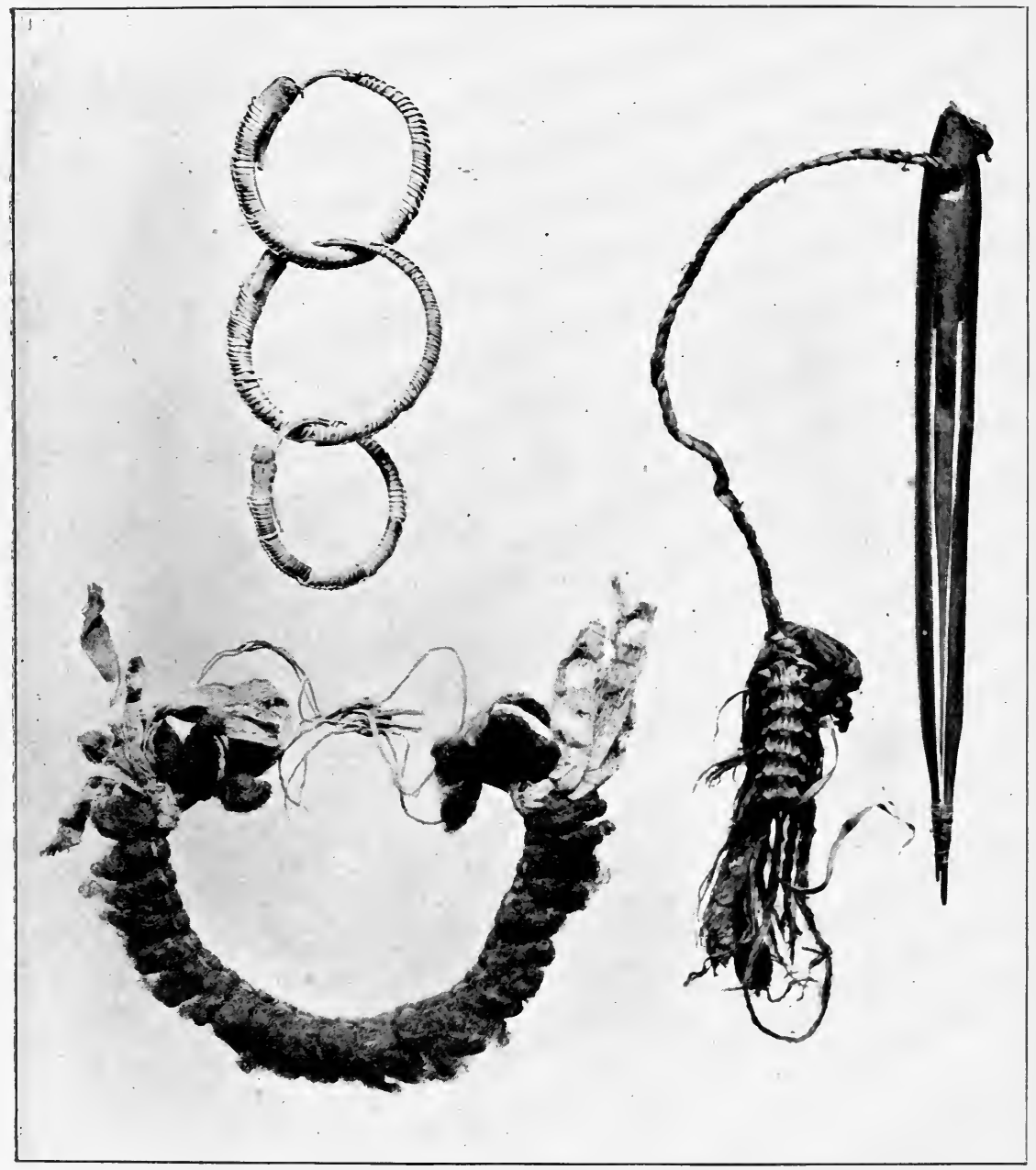

Fig. I.-EAR-RINGS.

, 2. -JEW'S HARP.

, 3.-IIAIR Fringe. 

Smoking pipes are in the ordinary well-known form of Mekeo and the coast, being made of sections of bamboo stem in which the natural intersecting node near the mouthpiece end is bored and the node at the other end is left closed, and between these two nodes, near to the closed one, is a flute-like hole, in which is placed the cigarette of tobacco wrapped up in a leaf. They are, however, generally not ornamented; or, if they are so, it is merely in a simple geometric pattern of straight lines. I obtained one pipe (Plate 5I, Fig. I) of an unusual type, being much smaller than is usual. A special feature of this pipe is its decoration, which includes groups of concentric circles. This is the only example of a curved line which I ever met with among the Mafulu villages, and it is probable that it had not been made there.

Boring drills (Plate $5 \mathrm{I}$, Fig. 4) are also similar to those of Mekeo and the coast, except that there the fly-wheel is, I think, usually a horizontal circular disc, through the centre of which the upright shaft of the implement passes, whereas in the Mafulu boring instrument the fly-wheel, through which the shaft passes, is a rudely cut flat horizontal piece of wood about 9 or Io inches long, 2 inches broad, and half an inch or less thick, and also that in Mafulu the native point, made out of a pointed fragment of the stone used for making club-heads, adze blades and cloth-beaters, is not generally replaced by a European iron point, as is so commonly the case in Mekeo and near the coast. These drills are used for boring dogs' teeth and shells and other similar hard- 
substanced things, but are useless for boring articles of wood or other soft substances, in which the roughly formed point would stick. ${ }^{1}$

Fire-making. This is a question of process, rather than of implement, but may be dealt with here. To produce fire, the Mafulu native takes two pieces of very dry and inflammable wood, one larger than the other, and some dry bark cloth fluff. He then holds the smaller piece of wood and the fluff together, and rubs them on the larger piece of wood. After four or five minutes the fluff catches fire, without bursting into actual flame, upon which the native continues the rubbing process, blowing gently upon the fluff, until the two pieces of wood begin to smoulder, and can then be blown into a sufficient flame for lighting a fire.

Carrying bags. These are all made of network. I shall say something about the mode of netting and colouring them hereafter, and will here only deal with the bags and their use. They are of various sizes. (I) There are the large bags used by women for carrying heavy objects, such as firewood, vegetables and fruit, which they bring back to the village on their return in the afternoon from the gardens and bush. These bags are carried in the usual way, the band over the opening of the bag being passed across the front of the head above the forehead, and the bag hanging over the back behind. They are curved in

1 The Chirima boring instrument figured by Mr. Monckton (Annual Report for June 30, 1906) is rather of the Mafulu type, but in this case the fly-wheel, instead of being a flat piece of wood, appears to be made of a split reed bound on either side of the upright cane shaft. 
shape, the ends of the bag being at both its top and bottom edges higher than are the centres of those edges, so that, when a bag is laid out flat, its top line is a concave one and its bottom line is a convex one. The network at the two ends of the top line is continued into the loop band by means of which the bag is carried. The usual dimensions of one of these bags, as it lies flat and unstretched on a table (the measurements being made along the curved lines) are as follows-top line about 2 feet, bottom line about 3 feet, and side lines about $\mathrm{I} 8$ inches. But when filled with vegetables, firewood, etc., they expand considerably, especially those made of "Mafulu network," of which I shall speak hereafter. These bags are uncoloured. (2) There are similar, but somewhat smaller, bags, in which the women carry lighter things, and which in particular they use for carrying their babies. They frequently carry this bag and the larger one together; and you will often see a woman with a big bag heavily laden with vegetables or firewood or both, and another smaller bag (perhaps also slung behind over the top of the big one, or hanging from her head at her side, or over her breast), which contains her baby, apparently rolled up into a ball. These bags also are uncoloured. (3) There are other bags, similar perhaps in size to No. 2, used for visiting and at feasts, dances and similar occasions, and also sometimes used for carrying babies. The top line of one of these is generally about 2 feet long, the bottom line a trifle longer, and the side lines about I foot. These are coloured in decorative patterns. (4) There 
are small bags of various sizes carried by men slung over their shoulders or arms, and used to hold their betel-nut, pepper and tobacco and various little implements and utensils of daily life. These are sometimes uncoloured and sometimes coloured. There are the very small charm bags, only about 2 inches or a trifle more square, which are used by both men and women (I think only the married ones) for carrying charms, and are worn hanging like lockets from the neck. They are sometimes coloured.

Plate 53 gives illustrations of three of these bagsFig. I being a woman's ornamented bag No. 3, and Fig. 2 being a man's ornamented bag No. 4 ; but this last-mentioned bag is rather a large one of its type, the usual difference in size between Nos. 3 and 4 being greater than the two examples figured would suggest. The patterns of both these bags, and especially of the larger one, are more regular than is usually the case. The bag shown in Fig. 3 will be dealt with hereafter under the heading of netting.

As regards women, the carrying of bags, either full or empty, hanging over their backs is so common that one might almost regard the bag as an additional article of dress. I may say here in advance of my observations on netting that the distinctive features of Mafulu bags, as compared with those made in Mekeo and on the coast, are the special and peculiar form of netting which is commonly adopted for some of them and the curious lines of colouring with which they are often ornamented.

Hammocks are commonly used in the houses and 


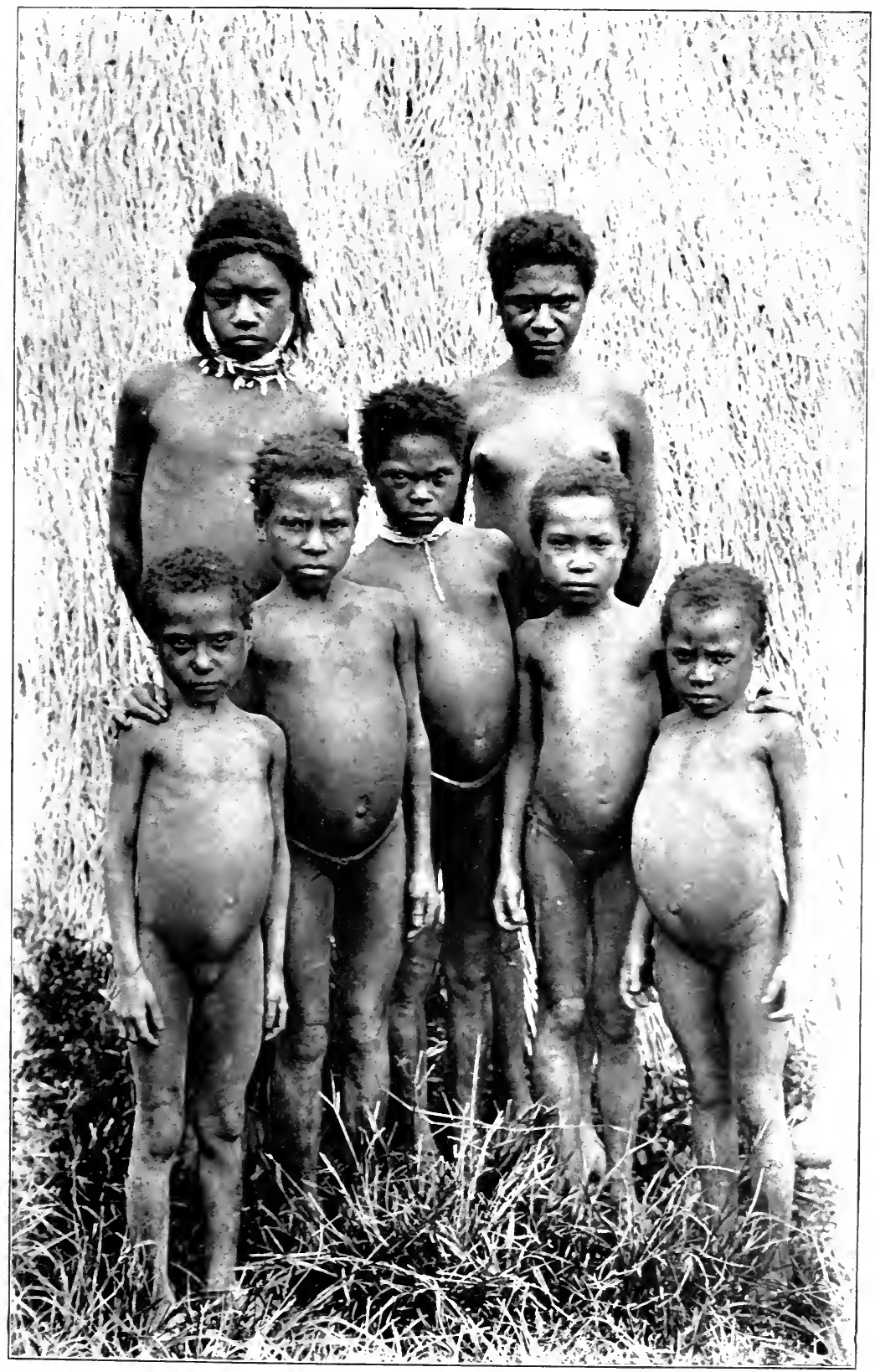

Max, Womax, ANo Childeri. 

emone for sleeping. ${ }^{1}$ These also are made of network and will be referred to later. The distinctive feature of network mentioned in relation to bags applies to these also, but not that of colouring.

Pottery is not made or used in Mafulu.

I may perhaps refer here to what I imagine to be an ancient stone mortar, which I found at Mafulu, and which I have endeavoured to show in Fig. 2. A portion of the upper part of the original was broken away, and I regret that I did not try to sketch it just as it was, instead of adopting the easier course of following what had been the original lines. I am also sorry that its great

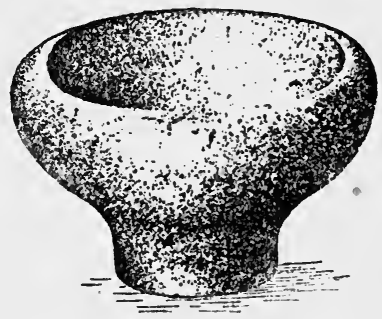

Fig. 2.-Ancient Mortar. weight made it impossible for me to bring it down with me to the coast, ${ }^{2}$ and that by an oversight I did not secure a photograph of it. The vessel was well and evenly shaped. It had perfectly smooth surfaces, without any trace of cutting or chipping, and must have been made by grinding. It was devoid of any trace of decoration. Its top external diameter was about I 2 inches, its height, when standing upright on its base, was about 8 inches, and the thickness of the bowl at the lip

1 Hammocks are also used in the plains and on the coast, but only, I think, to a very limited extent ; whereas in the mountains, of at all events the Mafulu district, they are used largely.

${ }^{2}$ I had a considerable quantity of impedimenta, and unfortunately my condition made it necessary for me to be carried down also ; and I had great difficulty in getting enough carriers. 
about I inch. I was told that similar things are from time to time found in the district, generally on the ridges, far away from water. A Mafulu chief said that the Mafulu name for these things is idagafe. The natives have no knowledge of their origin or past use, the only explanation of the latter which was suggested being that they were used as lookingglasses by looking into the scummy surface of the water inside them. ${ }^{1}$

European things. The Mafulu people are now beginning, mainly through the missionaries of the Sacred Heart, and also through their contact with Mekeo and other lowland tribes, to get into touch with European manufactures. Trade beads, knives, axes, plane irons (used by them in place of stone blades for their adzes), matches and other things are beginning to find their way directly and indirectly into such of the villages as are nearest to the opportunities of procuring them by exchange or labour.

\section{Domestic Animals.}

Dogs may occasionally, though only rarely, be seen in the villages, but these are small black, brownishblack, or black and white dogs with very bushy tails, and not the yellow dingo dogs which infest the villages of Mekeo; and even these Mafulu dogs are, I was told, not truly a Mafulu institution, having been obtained by the people, I think, only recently from their Kuni neighbours. A tame cockatoo may also

1 Compare the differently shaped mortar found in the Yodda valley and described and figured in the Annual Report for June, I904, p. 31 . 
very occasionally be seen, and even, though still more rarely, a tame hornbill. There are no cocks and hens.

The universal domestic animal of the Mafulu, however, is the pig, and he is so important to them that he is worthy of notice. These pigs are "village" pigs, which, though naturally identical with "wild" pigs-being, in fact, wild pigs which have been caught alive or their descendants - have to be distinguished from wild pigs, and especially so in connection with feasts and ceremonies.

Village pigs are the individual property of the householders who possess them, there being no system of community or village ownership; and, when required for feasts and ceremonies, each household has to provide such pig or pigs as custom requires of it. They are bred in the villages by their owners, and by them brought up, fed and tended, the work of feeding and looking after them being the duty of the women. No distinguishing ownership marks are put upon the pigs, but their owners know their own pigs, and still more do the pigs know the people who feed them; so that disputes as to ownership do not arise. The number of pigs owned by these people is enormous in proportion to the size of their villages, and I was told that a comparatively small village will be able at a big feast to provide a number of village pigs much in excess of what will be produced by one of the big Mekeo villages.

These village pigs often wander away into the bush, and may disappear from sight for months; but 
they nevertheless still continue to be village pigs. If, however, they are not seen or heard of for a very long time (say six months), they are regarded as having become wild pigs, and may be caught and appropriated as such. It is usual with village pigs to clip or shorten their ears and tails, or even sometimes to remove their eyes, so as to keep them from wandering into the gardens. ${ }^{1} \quad$ But even a village pig thus marked as such would be regarded as having become a wild pig if it had disappeared for a very long time.

Village pigs (as distinguished from wild pigs) are, as will be seen below, never eaten in their own village on ceremonial occasions, or indeed perhaps at all, being only killed and cut up and given to the visitors to take away and eat in their own villages.

\section{Etiquette.}

These simple people do not appear to have many customs which come under the heading of etiquette, pure and simple.

A boy must soon, say within a few weeks, after he has received his perineal band leave the parental home, and go to live in the emone; but this rule only refers to his general life, and does not prohibit him from ever entering his parents' house. If he receives his band when he is very young, this rule will not begin to operate until he is ten or twelve years old. $\mathrm{He}$ is in no case under any prohibition from being in

1 The practice of destroying the pigs' eyes in the Kuni district is referred to in the Annual Report for June, I900, p. 6I. 

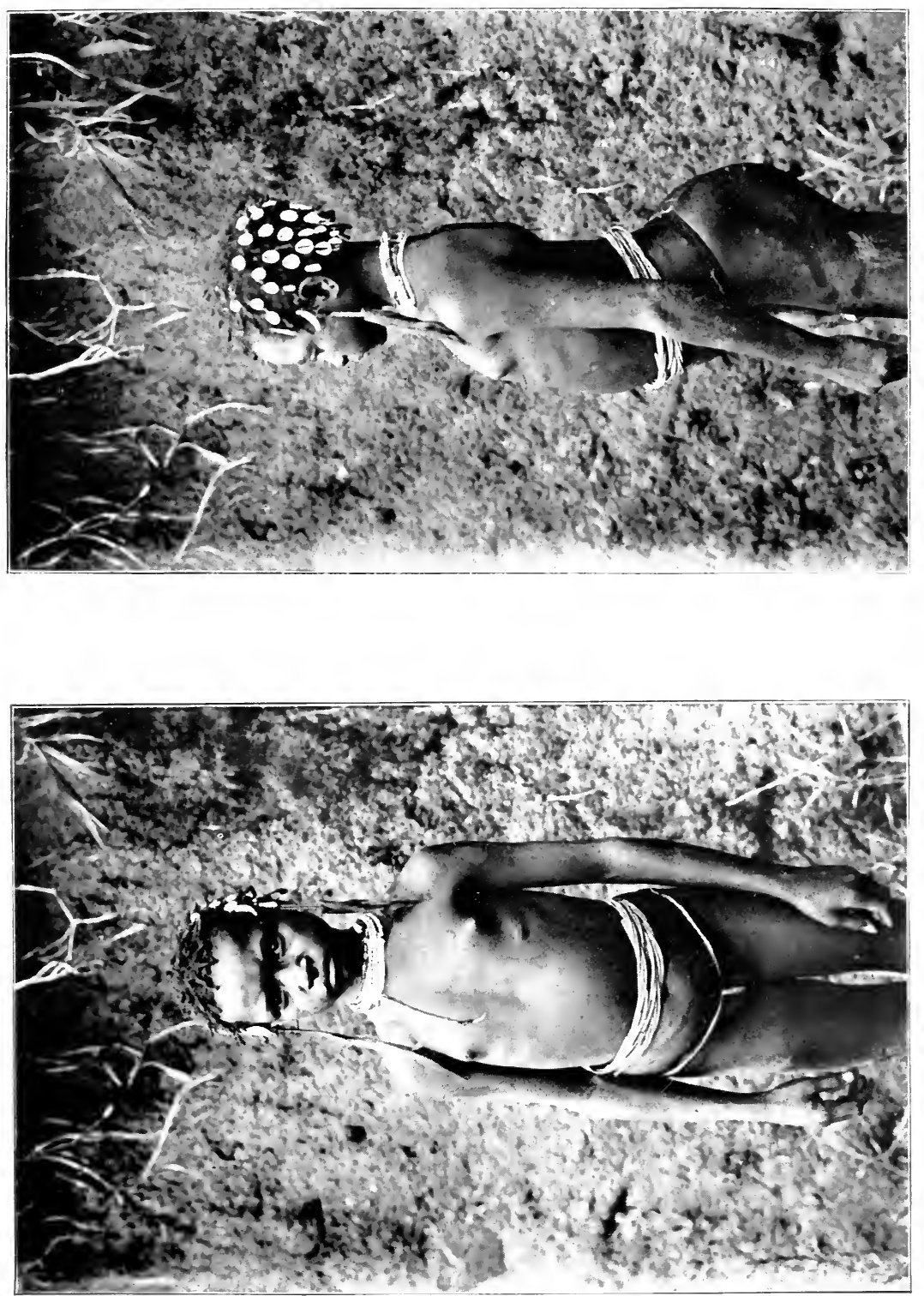

or crossing the village enclosure. A girl is allowed to enter the emone, though she may not sleep there, prior to receiving her band, but after that she must never enter it.

A young unmarried man, who has arrived at the marriageable age, must not eat in the presence of women. He can eat in the bush, or inside the emone, but he must not eat on the platform of the emone, where women might see him. There appear to be no other customs of mutual avoidance, as, for example, that between son-in-law and mother-in-law, and with reference to other marriage relationships, such as are found in some of the Solomon Islands; and among various other primitive races.

Children and unimportant adults must always pass behind a chief, not in front of him, and when a chief is speaking, everyone else, old and young, must be silent.

Young men and girls associate and talk freely together in public among other people, but no young man would go about alone with a girl, unless he was misconducting himself with her, or wished to do so.

Visiting is purely friendly and social, and there is no personal system of formal and ceremonial visiting, except as between communities or villages.

There do not appear to be any forms of physical salutation, but there are recognised ways in which men address one another on meeting and parting. If $A$ and B meet in the bush, A may say to B, "Where do you come from?", and B will answer, "I come from_-." A may then say, "Where are you 
going to ?", and B will reply to this. Then B may put similar questions to A, and will be similarly answered. These questions are not necessarily asked because the questioner is really anxious for information, but are in the nature of a formality, - the equivalent of our "How do you do?" The system of asking and answering these questions, though well recognised as a social form, is not in practice strictly adhered to. Also $\mathrm{A}$, on coming to a village and finding $\mathrm{B}$ there, and wishing to salute him, will call him by name, and $B$ will then call $A$ by name. Then $A$ will say, "You are here," and B will reply, "I am here." This form is more strictly carried out than is the other one. Then when A leaves he will say to B, "I am going," and B will answer, "Go." Then B will call $A$ by his name, and A will call B by name, and the formality is finished. If $A$, being very friendly with $B$, comes to his village to see him, on A's departure B, and probably B's family, will accompany A out of the village, and will stand watching his departure until he is about to disappear round the corner of the path; and then they will call out his name, and he will respond by calling out B's name.

Gestures may perhaps be included under this heading, though there is apparently but little to be said about the matter. When a question is asked, an affirmative reply is indicated by nodding the head, and a negative one by shaking it; and, though I asked if this was not probably the result of association with people who had been among white men, I was told 
that it was not so. A negative answer is also often expressed by shrugging the shoulders, and a kind of grimace with the lips. The nodding of the head to a negative question, such as "Are you not well?" signifies assent to the negative, that is, that he is not well, and so vice-versa with the shaking of the head. 


\section{CHAPTER V}

COMMUNity, CLAN, AND VIllaGE SYSTEMS AND CHIEFTAINSHIP

\section{Communities, Clans, and Villages.}

THE native populations of the Mafulu area are scattered about in small groups or clusters of villages or hamlets ; and, as each cluster of villages is for many purposes a composite and connected whole, I propose to call such a cluster a "community." Friendships, based on proximity and frequent intercourse and intermarriage, doubtless arise between neighbouring communities, but otherwise there does not appear to be any idea in the minds of the people of any general relationship or common interest between these various communities of the area. Each community regards the members of every other community within the area as outsiders, just as much so as are, say, the Ambo people to the north and the Kuni people to the west. If a community, or group of communities together, were the subject of an attack from either Ambo or Kuni natives, each of these being people whose language is different-as regards the Kuni utterly different-from that of the Mafulu, there would appar- 


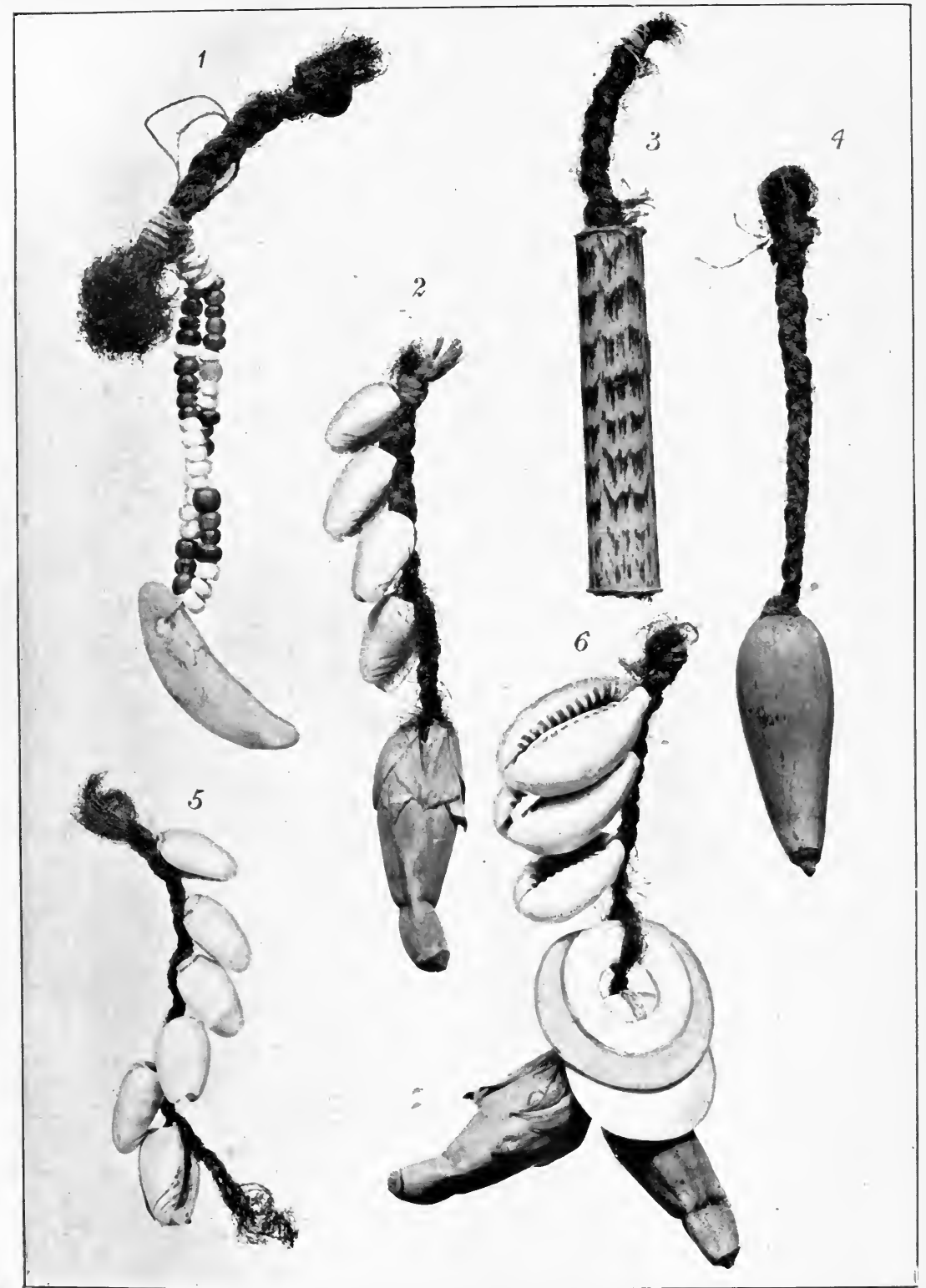

Figs. I, 2, 5, and 6. -Wonen's fiAir PlaIts decorated With European Beads, Shellas, Sheill Discs, Dog's Tooth, and Betel Nut Fruit.

Fig. 3. - Man's Haik Plait with Cane Pendant.
, 4 .
do.
do.
, Betel Nut Pendant. 

CH. v COMMUNITY, CLAN, VILLAGE SYSTEMS 83 ently be no thought of other Mafulu-speaking communities, as such, coming to assist in repelling the attack. Hence in dealing with the question of intervillage relationship, I have to fix my mind mainly upon the community and its constituent parts.

Concerning the situation as between one community and another, as they regard themselves as quite distinct and unrelated, the only question which seems to arise is that of the ownership of, and rights over, the intervening bush and other land. The boundaries between what is regarded as the preserve of one community, within which its members may hunt and fish, clear for garden purposes, cut timber, and collect fruit, and that of an adjoining community are perfectly well known. The longitudinal boundaries along the valleys are almost always the rivers and streams, which form good boundary - marks; but those across the hills and ridges from stream to stream are, I was told, equally defined in the minds of the natives, though no artificial boundary marks are visible. These boundaries are mutually respected, and trouble and fighting over boundary and trespass questions are, I was told, practically unknown, the people in this respect differing from those of Mekeo.

A community comprises several villages, the number of which may vary from, say, two to eight. But the relationship between all the villages is not identical. There is a clan system, and there is generally more than one clan in a community. Often there are three or more of such clans. Each clan, however, has its own villages, or sometimes one village only, within 
the community, and two clans are never found represented in any one village, ${ }^{1}$ or any one clan spread over two or more communities.

Fig. 3 is a diagrammatic illustration of a typical Mafulu community, the circles representing villages of one clan, the squares those of another clan, and the triangle being the sole village of a third clan.

I have said that the entire community is for many

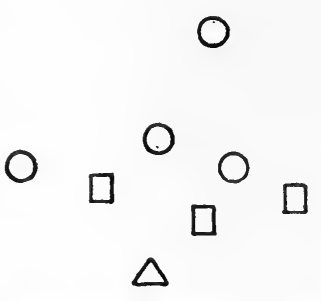
purposes a composite whole. In many matters they act together as a community. This is especially so as regards the big feast, which I shall describe hereafter. It

$\mathrm{O}=$ Villages of clan $A$. is so also to a large extent $\square=$ Villages of Clan $B$. in some other ceremonies

\section{$\Delta=$ only Village of Clan $C$.}

Fig. 3.-Illustrative Diagram

of a Mafulu Community of Villages. and in the organisation of hunting and fishing parties and sometimes in fighting. And the community as a whole has its boundaries, within which are the general community rights of hunting, fishing, etc., as above stated.

But the relationship between a group of villages of any one clan within the community is of a much closer and more intimate character than is that of the community as a whole. These villages of one clan

1 This is subject to the qualification which arises from the fact (stated below) that a member of one clan who migrates to a village of another clan retains his imbele relationship to the members of his own old clan, although he has by his change of residence obtained a similar relationship to the members of the clan in whose village he has settled. 
have a common amidi or chief, a common emone or clubhouse, and a practice of mutual support and help in fighting for redress of injury to one or more of the individual members; and there is a special social relationship between their members, and in particular clan exogamy prevails with them, marriages between people of the same clan, even though in different villages, being reprobated almost as much as are marriages between people of the same village.

The Mafulu word for village is emi, but there are no words signifying the idea of a community of villages and that of a group of villages belonging to the same clan within that community. As regards the latter there is the word imbele, but this word is used to express the intimate social relationship existing between the members of a clan, and not to express the idea of an actual group of villages. Communities and villages have geographical names. The name adopted for a community will probably be the name of some adjoining river or ridge. That adopted for a village will probably be the name of the exact crest or spot on which it is placed, the minuteness of the geographical nomenclature here being remarkable. Clan-groups of villages, forming part of a community, have, as such, no geographical names, but a member of one such group will distinguish himself from those of another group by saying that he is a man of _- giving the name of the chief of the clan occupying the group.

I was assured that, when there are two or more villages of a clan with a common chief and emone, they have originally been one village which has split up, an 
event which undoubtedly does in fact take place; while on the other hand the several villages of a clan, presumably the outcome of a previous splitting-up of a single village, will sometimes amalgamate together into one village, which thus becomes the only village of the clan. But two villages of different clans could never amalgamate in this way. The following are examples of these village changes :-

Near to the Mafulu Mission station is a community called Sivu, which includes seven villages occupied by three clans, as follows ${ }^{1}:-$

I. Voitele . . .

2. Amalala . . Belonging to a clan whose

3. Kodo-Malabe . $\{$ chief, Jaria, lives at Amalala,

4. Motaligo. . . where the clan emone is.

(Belonging to a clan whose chief, Gito-iola, lived at Malala, where the clan

5. Malala . . emone is. (He has recently

6. Gelva. . . $\{$ retired in favour of his eldest son, Anum' Iva, who is the present chief, and also lives there.)

(Being the only village of a clan whose chief, Baiva, has recently died. His eldest son, who has succeeded him, is an infant. There is no regency.

1 See Annual Report for June, I9ro, which on p. 5 speaks of "several villages round about the Mission, known as Sivu." 


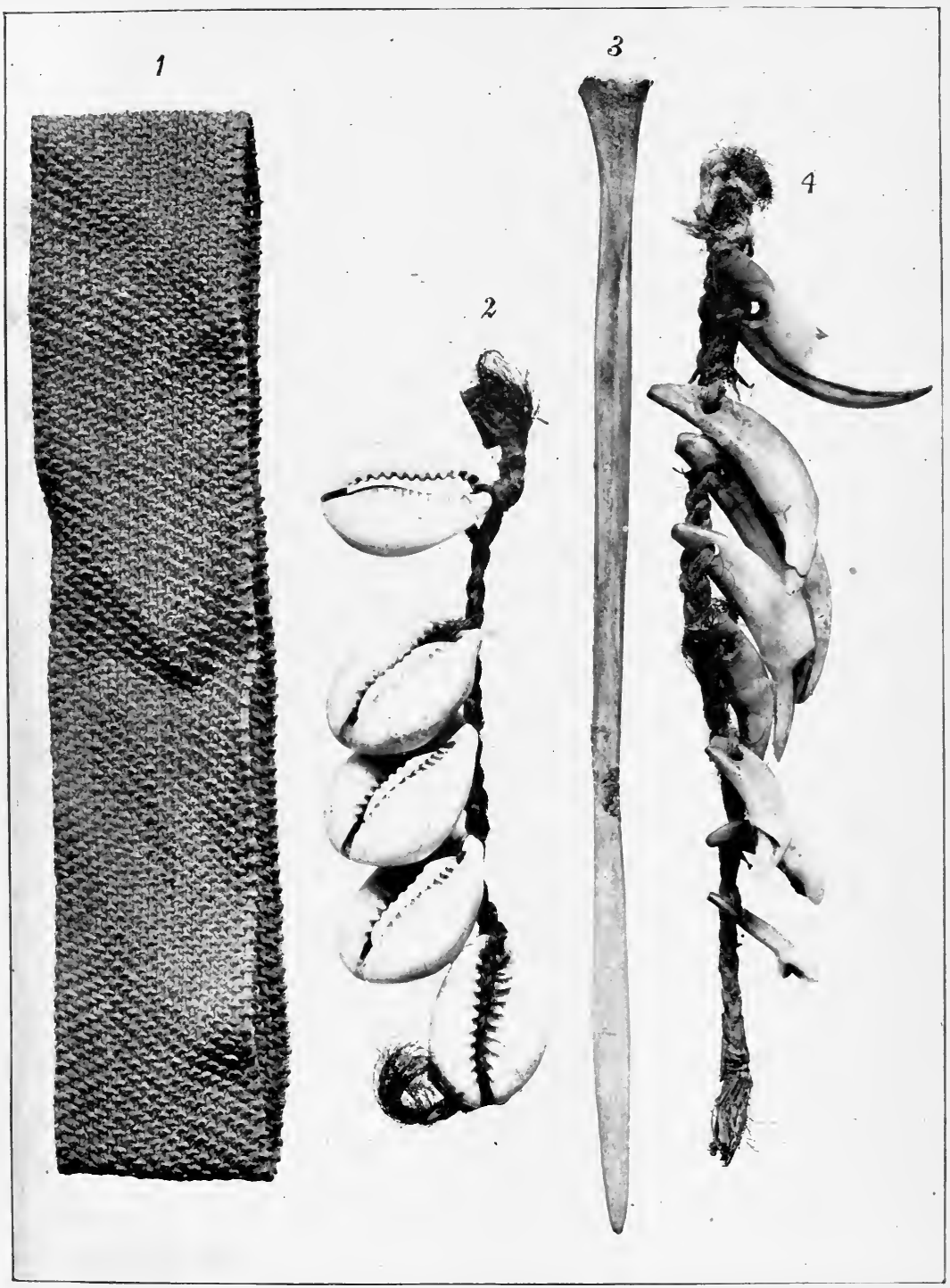

Fig. I. - LEg BAND.

Figs. 2 and 4.-Women's Hair Plaits decorated with Shells and Dogs' Teeth. Fig. 3.-Bone Implement used (as a Fork) For Eating. 

Also near the Mission station is a community called Alo, which includes four villages occupied by two clans, as follows :-

I. Asida. . . (Belonging to a clan whose 2. Kotsi. . . $\{$ chief, Amo-Kau, lives at

3. Ingomaunda. . Asida, where the emone is.

4. Uvande. $\therefore\left\{\begin{array}{l}\text { Being the only village of a } \\ \text { clan whose chief is Iu- } \\ \text { Baibe. }\end{array}\right.$

Referring to these villages, in the year 1899 the clan now occupying the four villages Voitele, Amalala, Kodo-Malabe and Motaligo had only a single village, Kaidiabe, the clan's chief being the above-mentioned Jaria. Then there was a Government punitive expedition, following the attack of the natives upon Monseigneur de Boismenu (the present Bishop of the Mission of the Sacred Heart in British New Guinea) and his friends, who were making their first exploration of the district, in which expedition a number of natives, including the brother of the chief, were killed. After that the village was abandoned, and the three villages of Voitele, Amalala and Motaligo arose in its place. Subsequently after a big feast, which was held at Amalala in the year 1909, that village put out an offshoot, which is the present village of Kodo-Malabe. Also in the year 1909 the village of Uvande was represented by seven villages, all belonging to one clan under the chieftainship of Iu-Baibe, the names of which were Ipolo, Olona, Isisibei, Valamenga, Amada, Angasabe and Amambu ; 
but after the feast above mentioned the people of that clan all abandoned their villages, and joined together in forming the present village of Uvande.

The chief, that is the true chief, of a clan has his house in one of the villages of the clan, and if, as sometimes occurs, he has houses in two or more of these villages, there is one village in which is what is regarded as his usual residence, and this is the village in which is the emone of the clan.

As regards the relative predominance of the various clans of a community and their respective chiefs in matters affecting the whole community (e.g., the arranging and holding of a big feast), there is no rule or system. The predominance will probably, unless there be a great disparity in the actual size or importance of the clans, and perhaps even to a certain extent notwithstanding such a disparity, fall to the clan whose chief by his superior ability or courage or force of character, or perhaps capacity for palavering, has succeeded in securing for himself a predominating influence in the community.

The word imbele and certain other words are used to designate the closeness or otherwise of the connection between individuals. Imbele signifies the close connection which exists between members of one clan, and a man will say of another member of his clan that he is his imbele. The word bilage signifies a community connection, which is recognised as being not so close as a clan connection; and a man will say of another, who is outside his own clan, but is a member of his own community, that he is his bilage. 
The expression a-gata signifies absence of any connection, and a man will refer to a member of another community, Mafulu, Kuni, Ambo, or anything else (there is no distinction between these in the use of the term) as being a-gata, thereby meaning that he is an outsider.

This brings me to the question of the use by me of the term "clan" to designate the intimate association above referred to. To begin with, there is a considerable difference between the situation produced by the clan system, if it may be regarded as such, of Mafulu and that of, say, Mekeo, where one finds several clans occupying one village, and where members of one clan may be scattered over several more or less distant villages; though this latter difference might perhaps arise in part from natural geographical causes, the flat lowlands of the Mekeo people being highly favourable to inter-village communication over their whole areas, and to the holding of their recognised and numerous markets, whilst it may almost be assumed that such intercommunication would be more restricted, at all events in days gone by, among the Mafulu inhabitants of the mountains.

Then again in Mafulu there are no clan badges, nor are there any realistic or conventional representations of, or designs which can to my mind be possibly regarded as representing, or having had their origin in the representation of, animals, birds, fishes, plants, or anything else. As regards this, however, it may be mentioned that the Mafulu people are very primitive and undeveloped, and have not in their art 
any designs which could readily partake of this imitative character, their artistic efforts never producing curves, and indeed not going beyond geometric designs composed of straight lines, rectangular and zig-zag patterns and spots.

Also I was unable to discover the faintest trace of any idea which might be regarded as being totemistic, or having a totemistic origin. In particular, although enquiry was made from ten independent and trustworthy native sources, I could not find a trace of any system of general clan taboo against the killing or the eating of any animal, bird, fish, or plant. It is true that there are various temporary food taboos associated with special conditions and events, and that there are certain things the eating of which is regarded as permanently taboo to certain individuals; but the former of these restrictions are general and are not associated with particular clans or communities, and the latter restrictions relate separately to the individuals only, and apparently are based in each case on the fact that the food has been found to disagree with him; though whether the restriction is the result of mere common sense based upon individual experience, or has in it an element of superstition as to something which may be harmful to the individual concerned, is a point upon which I could not get satisfactory explanation.

Again, still dealing with the question of totemism, I may say that the community and village names (as already stated, there are no clan names) do not appear to be referable to any possible totemistic objects. There 


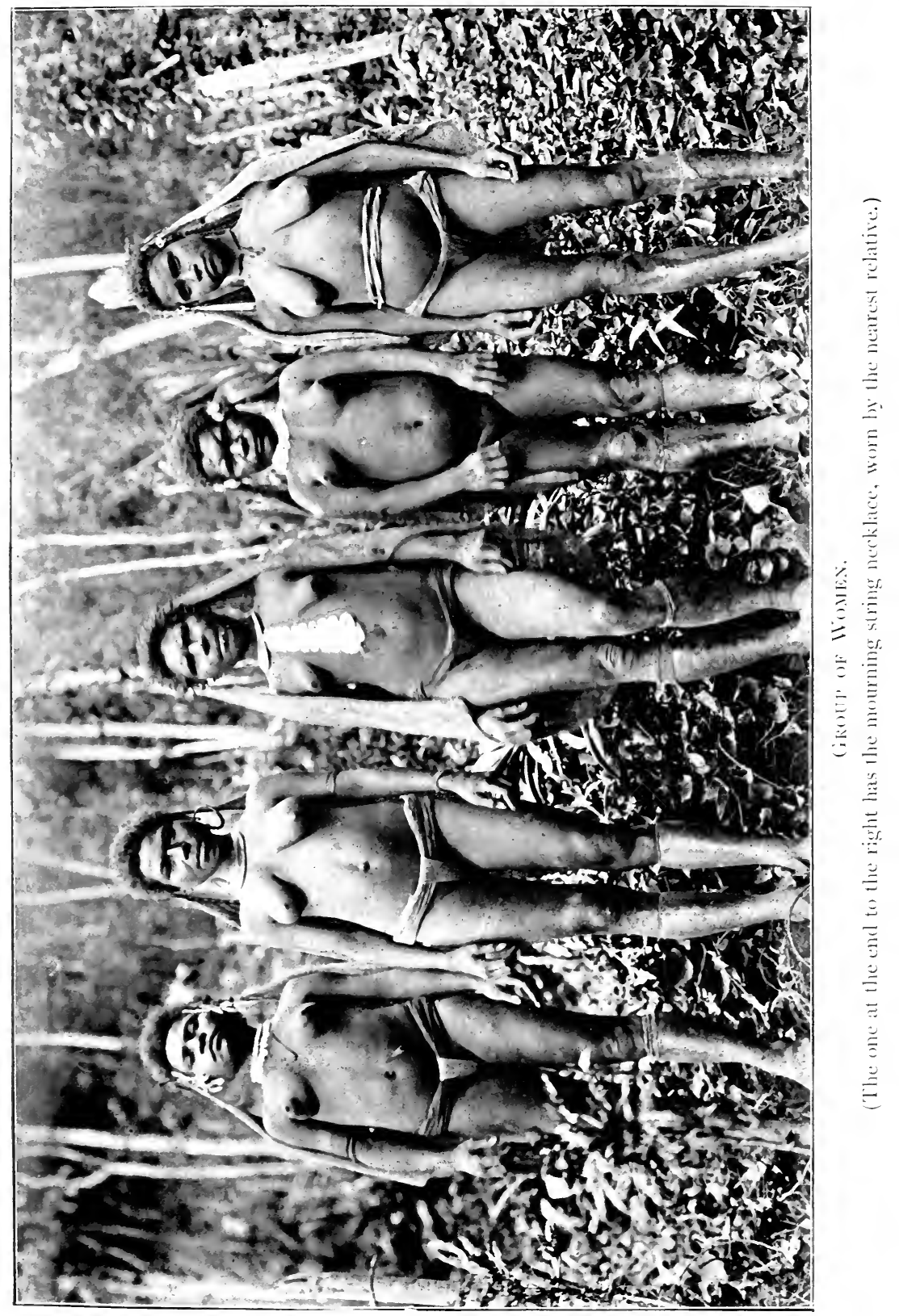



is no specific ancestor worship, in connection with which I could endeavour to trace out an association between that ancestor and a totemistic object, and there is no special reverence paid to any animal or vegetable, except certain trees and creepers, the fear of which is associated with spirits and ghosts generally, and not with ghosts of individual persons, and except as regards omen superstitions concerning flying foxes and fireflies, which are general and universal among all these people, and except as regards the possible imitative character of the Mafulu dancing, which, if existent, is probably also universal.

Moreover, I was told that now, at any rate, the people regard their imbele or clan relationship as a social one, as well as one of actual blood, a statement which is illustrated by the fact that, if a member of one clan leaves his village to reside permanently in a village of another clan, he will regard the members of the latter clan, and will himself be regarded by them, as being imbele, although he does not part with the continuing imbele connection between himself and the other members of his original clan.

On the other hand the association between members of a clan is exceedingly close, so much so that a serious injury done by an outsider to one member of a clan (e.g., his murder, or the case of his wife eloping with a stranger and her family refusing to compensate him for the price which he had paid for her on marriage) is taken up by the entire clan, who will join the injured individual in full force to inflict retribution; and, as already stated, the members of a clan 
share in one common chief and one common emone, intermarriage between them is regarded as wrong, and apparently each group of villages occupied by a single clan has in origin been a single village, and may well have a common descent. I think, therefore, that $I$ am justified in regarding these internal sections of a community as clans.

\section{Chiefs, Sub-chiefs and Notables AND THEIR EMONE}

At the head of each clan is the amidi, or chief of the clan. $\mathrm{He}$ is, and is recognised as being, the only true chief.

He is the most important personage of his clan, and is treated with the respect due to his office; but, though he takes a leading part in all matters affecting the clan, he is not a person with any administrative or judicial functions, and he has no power of punishment or control over the members of the clan. In public ceremonial matters of importance, however, he has functions which rest primarily upon him alone, and he does, in fact, always perform these functions in his own village; and on the occasion of a big feast (as to which see below), he does so in whatever village of the clan that feast may be held.

The chief lives in one of the villages of the clan, but may have houses in other villages of that clan also. In the village in which he mainly resides is his emone or club-house, which is the only true emone of the clan; and for the upkeep and repair of this he 
is responsible. This is the ceremonial emone in his own village, and is always the one used in connection with the ceremony of a big feast in any village of the clan; and, if the feast be held in a village other than that in which is his then existing emone, another one is built in that village in lieu of his former one in the other village.

There is not in connection with these chiefs and their ceremonies any distinctive difference in importance between the right and the left as regards the positions occupied by them on the emone platform or the structure of the emone, such as is found among the Roro people.

Next in rank to the chief, and at the head of each village of the clan, there is a sub-chief, or em' $u$ babe, this term meaning "father of the village." $\mathrm{He}$ is not regarded as a true chief, but he is entitled, and it is his duty, to perform in his own village all the functions of the chief, except those connected with the big feast. He and the similar sub-chiefs of the other villages of the clan are the persons who take the prominent part in supporting the chief in any ceremonial function concerning the whole clan in which the latter may be engaged, and in particular at the big feast. The $e m^{\prime} u$ oabe is usually a relative of the chief, and at all events is an important personage. $\mathrm{He}$ also has in his own village his emone, which is the principal emone of that village, and is used for all ceremonial functions in that village except the big feast, but it is not regarded as being a true emone. The chief holds in his own village of residence both 
his office of amidi and that of em' $u$ babe, there being no other person holding the latter office in that village.

Next in rank to the sub-chiefs come a number of ake baibe, which means "great men." These are the leading people-the aristocracy-of the clan. There are no distinctive social grades of rank among them. Their number is often very large in proportion to the total number of male inhabitants of a village; indeed sometimes almost every member of a village will claim to belong to this class. These people are in no sense office-bearers, and have no special duties to perform, though on a ceremonial occasion they are entitled to have their importance borne in mind. Each of them also is entitled to have an emone (here again not a true emone) in his village, but in fact their numbers often make this practically impossible, and you rarely see more than two or three emone in one village.

The above are all the chiefs and notables of the clan. There is no such thing as a war chief.

Aristocracy in its various forms is not a condition to which a man attains on getting older-it is attained by inheritance.

The office of the chief is hereditary in the male line by strict rules of descent and primogeniture. On the death of a chief his office descends to his eldest son, or if that son has died leaving children, it descends to the eldest son of that son, and so on for subsequent generations. Failing the eldest son or male issue in the male line of the eldest son, the office devolves upon the late chief's second son or his male issue in the 


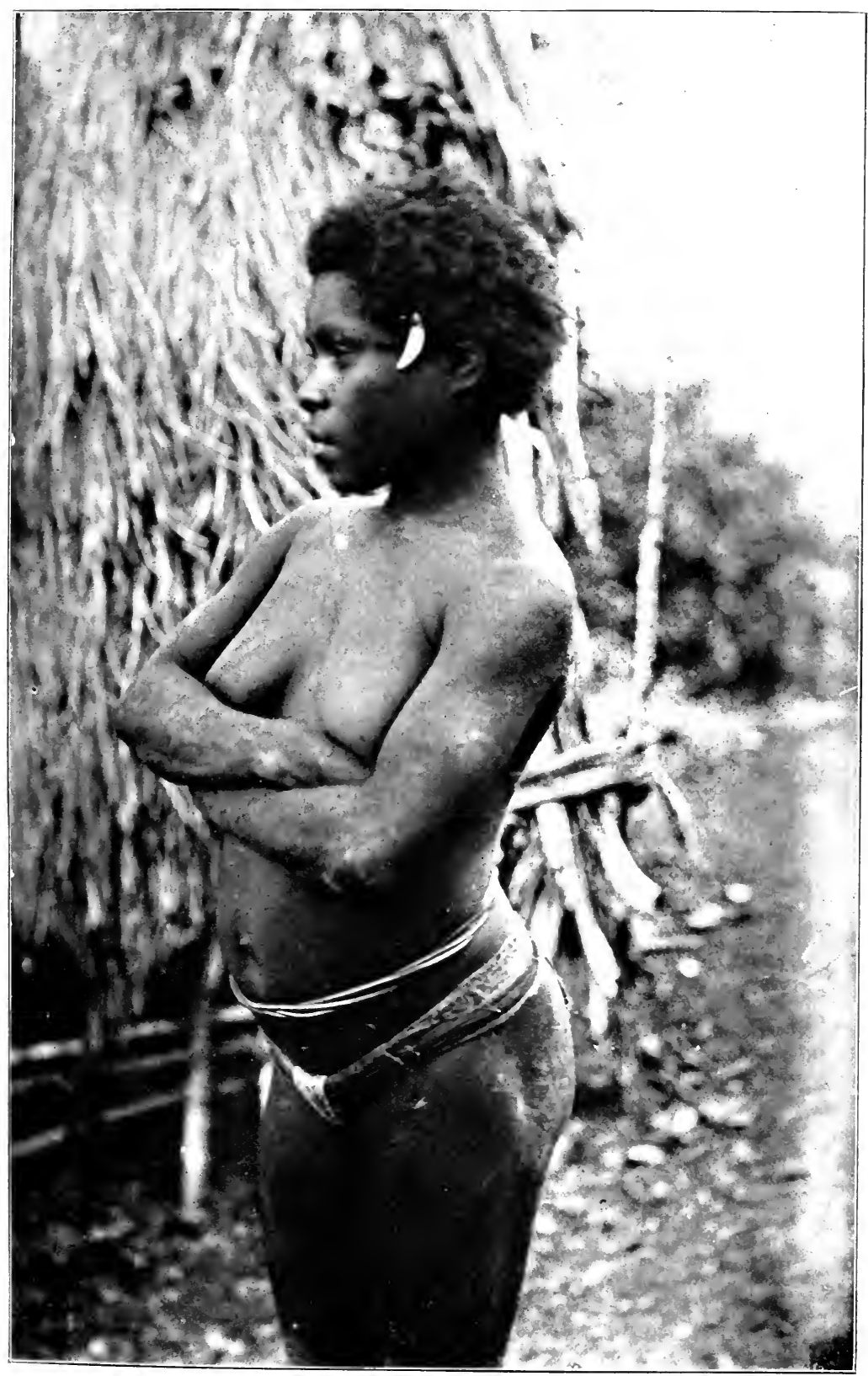

A Young Womax. 

male line. And so on for other sons and their issue. Failing such male issue the office passes to a collateral relation of the late chief on his father's side (e.g., the late chief's next eldest brother or that brother's son, or the late chief's second brother or that brother's son), the ascertainment of the devolution being based upon a general principle of nearest male relationship in the male line and primogeniture. ${ }^{1}$

The chief holds his office for life, but he may in his lifetime resign it in favour of the person entitled to succeed him, and this in fact often occurs. He cannot, however, on the appointment of his successor still continue in office himself, so as to create a joint chieftainship, as is done in Mekeo. He, as chief, is subject to no special taboo, and there is no qualification for office, other, of course, than hereditary right; but no chief can perform the functions of his office, or build for himself an emone, until he has married. There is no ceremony on the chief's accession to office on the death of his predecessor; but there is a ceremony (to be described hereafter) on a chief's abdication in favour of his successor. Cases have, I was told, occurred in which a man has in one way or another forced himself into the position of chief, though not qualified by descent, and has thus become a chief, from whom subsequent chieftainship descent has been traced, but I could learn nothing of the circumstances

1 Compare the Koita system, under which under certain conditions the son of a chiefs sister might succeed him (Seligmann, Melanesians of British New Guinea, p. 52). Such a thing could not take place among the Mafulu. 
under which this had occurred. Also it has happened that, when a chief has been weak, and has not asserted his position, a sub-chief has more or less usurped his power and influence, without actually upsetting his chieftainship or supplanting him in his performance of ceremonial duties.

If the chief on acquiring office by inheritance is a child, or not qualified to act (e.g., unmarried), he is nevertheless chief; but some person will usually act as his guardian, and perform his functions for him until he has qualified. This person will probably be one of the young chief's eldest male paternal relations (e.g., the eldest living brother of the last previous chief), and will presumably be a person of consequence; but he will not necessarily be one of the sub-chiefs.

All the above observations concerning the hereditary nature of a chief's office and subsequently explained matters apply also to the case of a sub-chief, except that there is no ceremony on his resigning office in favour of his successor, and that the usurpation of the office of a sub-chief, of the occurrence of which I found no record, would perhaps be more difficult of accomplishment. In the event of a village throwing off an offshoot village, or itself splitting up into two villages, the then existing sub-chief of the original village would continue his office in it or, in case of a division, in one of the villages resulting from the split, and the other village would have for its sub-chief some one of the ake-baibe of the original village, probably the one who was most active in organising the split. On the other hand, if several villages united into one, one 
only of their sub-chiefs could be sub-chief of the village arising from the amalgamation, and the others would sink to the rank of ake-baibe.

The observations concerning the hereditary nature of a chief's rank also apply to the ake-baibe. I have no information concerning them on the other points; but these are not so important as regards these people, who have no official position and have no duties to perform.

There are, as will be seen hereafter, a number of persons who are employed from time to time to perform various acts and functions of a ceremonious or superstitious character, notably the man who has the important duty of killing pigs at feasts ; but these men are not by virtue of their offices or functions either chiefs or sub-chiefs, or even notables or important personages. It is in each case a matter of the specific personal power which the man is believed to possess. Any of them might happen to be an important personage, and the pig-killer, whose office is a prominent one, would probably be one; though in his case muscular strength would, I understand, be an important element of qualification. ${ }^{1}$

1 I do not know how far this pig-killer may be compared with the Roro ovia akiva, or chief of the knife, referred to by Dr. Seligmann (Melanesians of British New Guinea, p. 219). The Mafulu pig-killer cannot be regarded as being even a quasi-chief, and his office is not hereditary. It is noticeable also that he is the man who kills the pigs, whereas the ovia akiva only cuts up the bodies after the pigs have been killed by someone else. 


\section{CHAPTER VI}

VILLAGES, EMONE, HOUSES AND MODES OF INTERVILLAGE COMMUNICATION

\section{Villages and their Emone and Houses.}

The Mafulu villages are generally situated on narrow plateaux or ridges, sloping down on each side; but the plateaux are not usually so narrow, nor the slopes so steep, as are those of the Kuni district, and the villages themselves are not generally so narrow, as the contour of the country does not involve these conditions to the same extent. Also the Mafulu villages are on the lower ridges only, and not on the high mountains; but the actual elevations above sea-level of these lower ridges are, I think, generally higher than those of the top ridges of the Kuni. Plate 54 shows the position and surroundings of the village of Salube (community of Auga), and is a good representative example, except that the plate does not show any open grassland.

The villages are, or were, protected with stockades and with pits outside the stockades, and sometimes with platforms on trees near the stockade boundaries, from which platforms the inhabitants can shoot and 


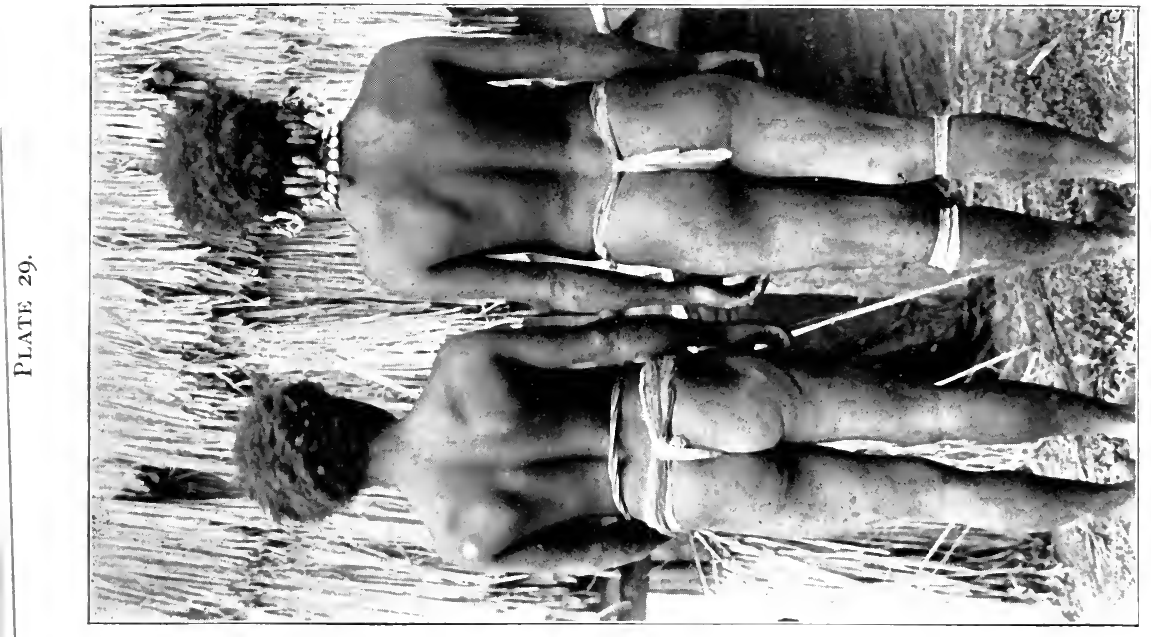

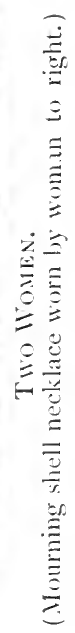

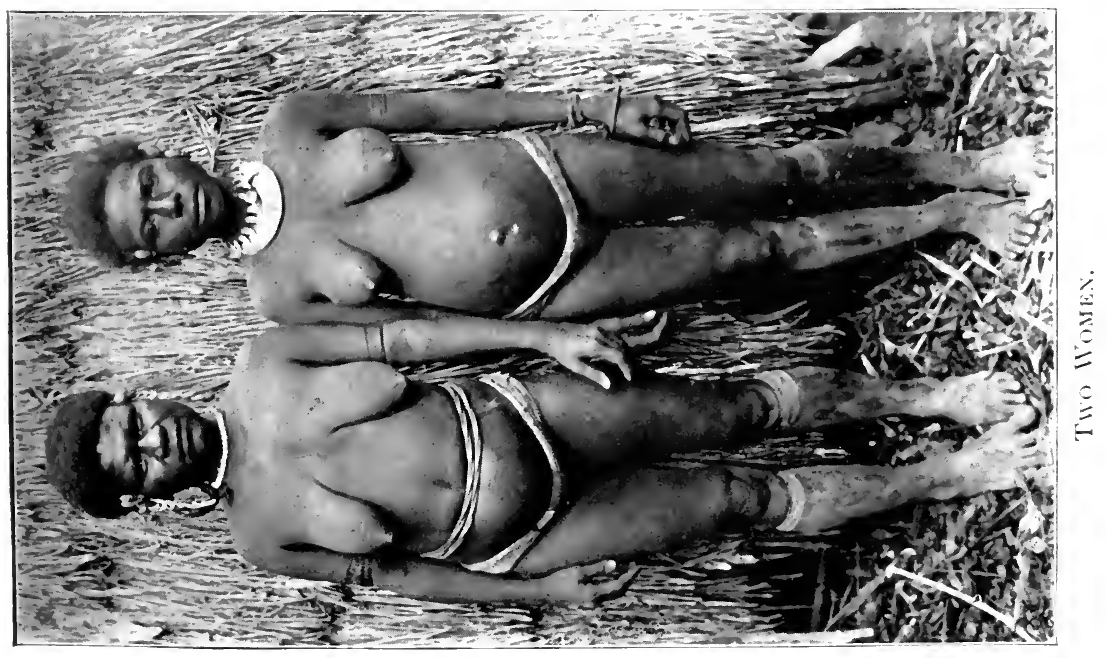



hurl stones upon an enemy climbing up the slope. The stockade is made of timber, is about 15 to 25 feet high, and is generally constructed in three or more parallel rows or lines, each of the lines having openings, but the openings never being opposite to one another. These protections have now, however, been largely, though not entirely, discontinued. ${ }^{1}$ It is, or was, also the practice, when expecting an attack, to put into the ground in the approaches to the village calthrop-like arrow-headed objects, with their points projecting upwards.

The average size of the villages is small compared with that of the large villages of Mekeo, some of them having only six or eight houses, though many villages have thirty houses, and some of them have fifty or sixty or more. The houses and emone are much smaller than those of Mekeo, and much ruder and simpler in construction and they have no carving or other decoration. There are no communal houses.

The houses are ranged in two parallel rows along the side of the ridge, with an open village space between them, the space being considerably longer than it is broad, and more or less irregular in shape. The houses are generally built with their door-openings facing inwards towards the village enclosure.

At one end of the village, and facing down the open space, is the chief's or sub-chief's emone. These are, like the Roro marea and the Mekeo ufu, used, not only in connection with ceremonies, but also as living houses

1 I do not suggest that these defences are peculiar to the Mafulu area. I believe they are used by other mountain natives of the Central District 
for men, especially unmarried men, and for the accommodation of visitors to the village. There are probably also in the village the emone of one or more of the notables before mentioned, of which one will be at the other end of the village and any others will be among the houses at the side of, and facing into, the village enclosure. There are not often more than three emone, true or otherwise, in one village.

You of course do not find the surrounding palm groves of Mekeo and the coast; nor do you generally see the waste space behind the houses, or the ring of garden plots outside the waste space, the position of the village on its ridge being usually hardly adapted to the latter. You may, however, often find garden plots very near to the village. Each family has its own house, and, except as regards the emone and their use, there are no separate houses for men or women, or for any class of them.

The Mafulu emone is an oblong building, erected on piles of very varying height, the interior floor being anything from 3 to I 5 feet above the ground. In size also it varies very much, but generally it is internally about $\mathrm{I} 2$ to $\mathrm{I} 5$ feet long from front to back, and about 8 to $\mathrm{I} 2$ feet in width. The roof, which is thatched with long, rather broad leaves, is constructed on the ridge and gable principle, with the gable ends facing the front and the back, and the roof sloping on both sides in convex curves from the ridge downwards. Remarkable and specially distinctive features of the building are the thatched roof appendages projecting from the tops of the two gable 
ends (front and back), the forms of which appendages are somewhat like a hood or the convex fan-shaped semicircular roof of an apse, and in construction are sometimes made as rounded overhanging continuations of the upper part of the roof, and sometimes as independent additions, not continuous with, and not forming parts of, the actual roof. In front of the building, but not at the back, is a platform at a level about a foot below that of the inner floor, extending the whole length of the front of the building, and projecting forwards to a distance of from 2 to 5 feet. The approach from the ground to this platform in the case of a high-built emone is a rudely constructed ladder, but when the building is only low and near the ground it is generally merely a rough sloping piece of tree trunk, or even only a stump. The two gable ends are enclosed with walls made of horizontal tree branches, two or three of which are, at both the front and rear ends of the building, discontinued for a short distance in the centre, so as to leave openings. These openings are, say, 2 feet or more above the level of the front outside platform, and I foot or more above that of the inside floor, and are usually very small; so that, in entering or leaving the building, you have to step up to, or even climb, and wriggle yourself through the opening, and then step down on the other side. Inside the building you find the centre of the floor space occupied by a longitudinal fireplace, about 2 feet broad, extending from front to back of the building; and the floors on each side of this fireplace slope upwards somewhat from the visible level of the fire- 
place towards the sides of the building. The fireplace part of the interior is, in fact, dropped to a level below that of the adjoining floors, so as to form a long trough, which is filled up with soil upon which the fire can burn; and it is the visible top level of this soil covering which is practically flush with the inside

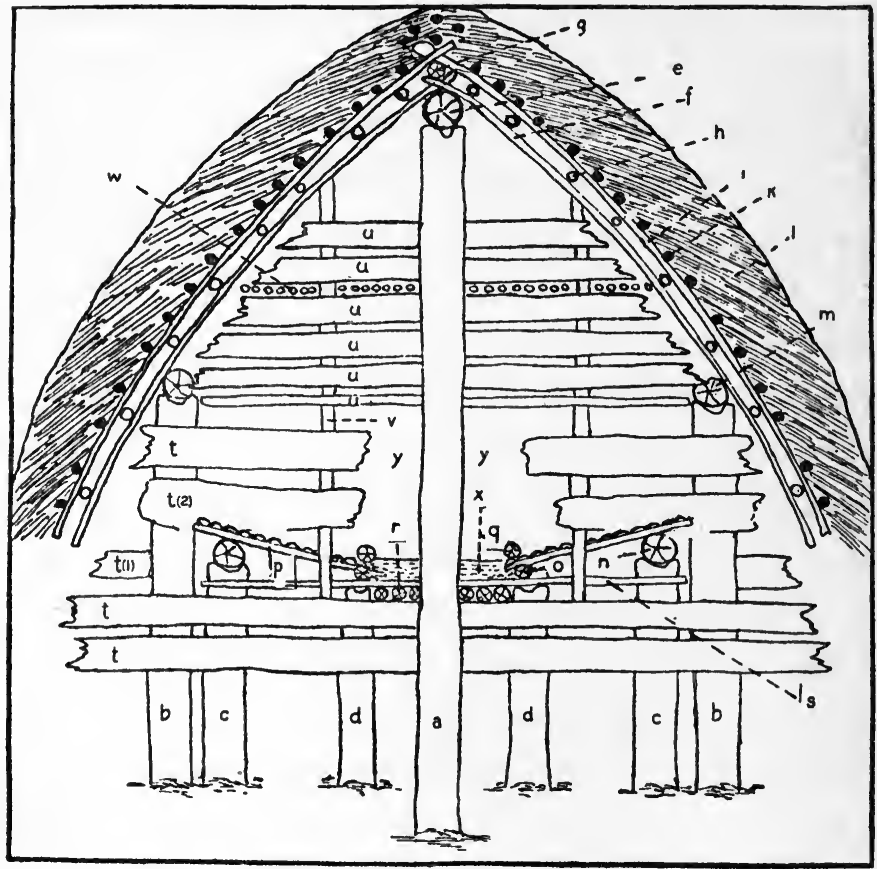

Fig. 4.-Diagram of Front of Emone (Front Hood of Roof AND Front Platform and Portions of Front Timbers omitted, so as TO SHOW INTERIOR).

lower level of the adjacent upward-sloping floors. Some distance below the roof there is usually an open ceiling of reeds, used for the purpose of storing and drying fruits and other things, and especially, as will be seen hereafter, for drying fruit required in the preparation for the big feast. 


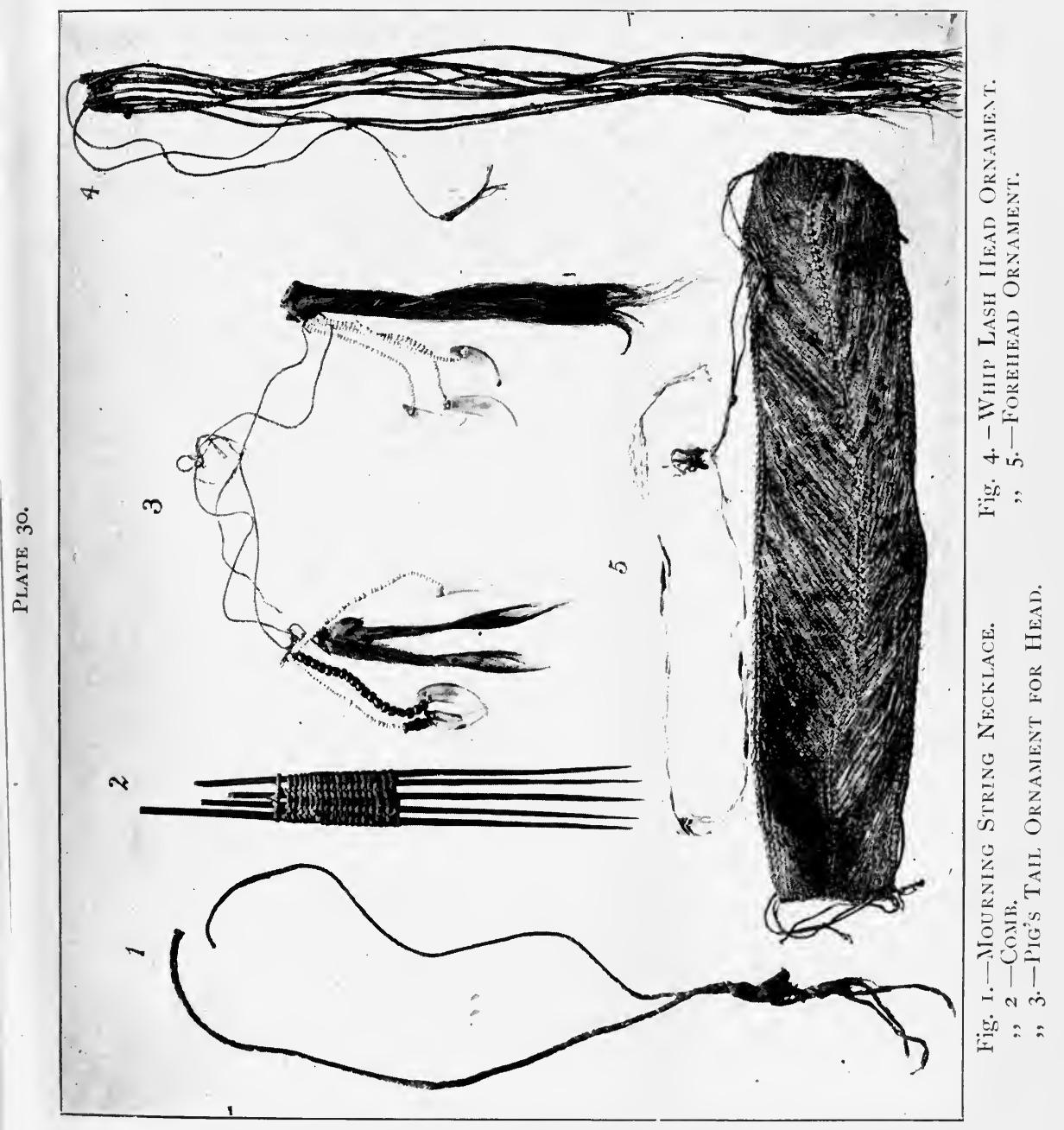



Fig. 4 is a diagram of the front of an emone, disclosing the internal plan of the floor and fireplace, for which purpose the front hood of the roof and the front platform are omitted from the plan, and of the horizontal front timbers the third up from the bottom is shown at the ends only, the middle part being omitted, and small portions of the timbers immediately above them are omitted. The words in parentheses appearing in the explanatory notes to the figure are the Mafulu names for the various parts of the building.

\section{Explanatory Notes to Fig. 4.}

(a) Main posts, one at the front of the building, one in the middle, and one at the back (apopo).

(b) Posts supporting roof, a line of them running along each side (tedele).

(c) Posts supporting outer edge of flooring, a line of them on each side (emuje or aje).

(d) Post supporting inner edge of flooring and hearth, a line of them on each side ( $f \circ j^{\prime} u l^{\prime}$ emuje).

(e) Lower ridge pole (tanguve).

(f) Main downward-sloping roof work, strongly made, going all the way back, only four or five of them on each side (loko-loko).

(g) Upper ridge pole (tope).

(h) Main horizontal roof work, resting on $f$ (gegebe).

(i) Upper downward-sloping roof work, not so thick as $f$, resting on $h$, going all the way back at intervals of about I foot (engala).

(k) Upper horizontal roof work, not so thick as $h$. resting on $i$ (gegebe) 
(८) Thatch made of leaves (asase).

Note.-The roof (excluding the hood) projects forward and overhangs a little beyond the post $a$, so as to overhang the greater part, but not the whole, of the platform; the hood (not shown in this figure) is really intended to shelter the flatform.

(m) Pole supporting roof (karia).

(n) Pole supporting outer edge of floor (karia).

(o) Pole supporting inner edge of floor and enclosing hearth (jakusube).

(p) Floor, composed of transverse woodwork (koimame) with thin light longitudinal lath work on top of it (ondovo).

(q) Pole above inner edge of floor and edging hearth, not so thick as $o$ (bubuje).

(r) Floor of fireplace, upon which soil is put ( foj' ul maovo).

(s) Pieces of wood supported by $c$ and $d$, going right across building and over floor of fireplace, but under its earth, all the way back (kooije).

$(t)$ Wall timbers below top of door-opening, at front and back (kautape).

Note. - $t$ ( I) goes right across under door-opening, but the middle portion of it is omitted from the diagram, and the lower edges of timbers $t$ (2) are partly broken off, so as to show floor and fireplace.

(u) Wall timbers above top of door-opening (dibindi).

Note. $-t$ and $u$ together-the whole wall-are called bou. 
(v) Uprights bracing together $t$ and $u$ (Mafulu name unknown).

(w) Ceiling made with reeds and used for storing and drying fruit, etc. It may occupy the whole length of the building and the whole width of it, or part only of either or both of these (avale).

$(x)$ Space filled up with soil and used as hearth $(f o j e)$.

(y) Door-opening, one at back also (akomimbe).

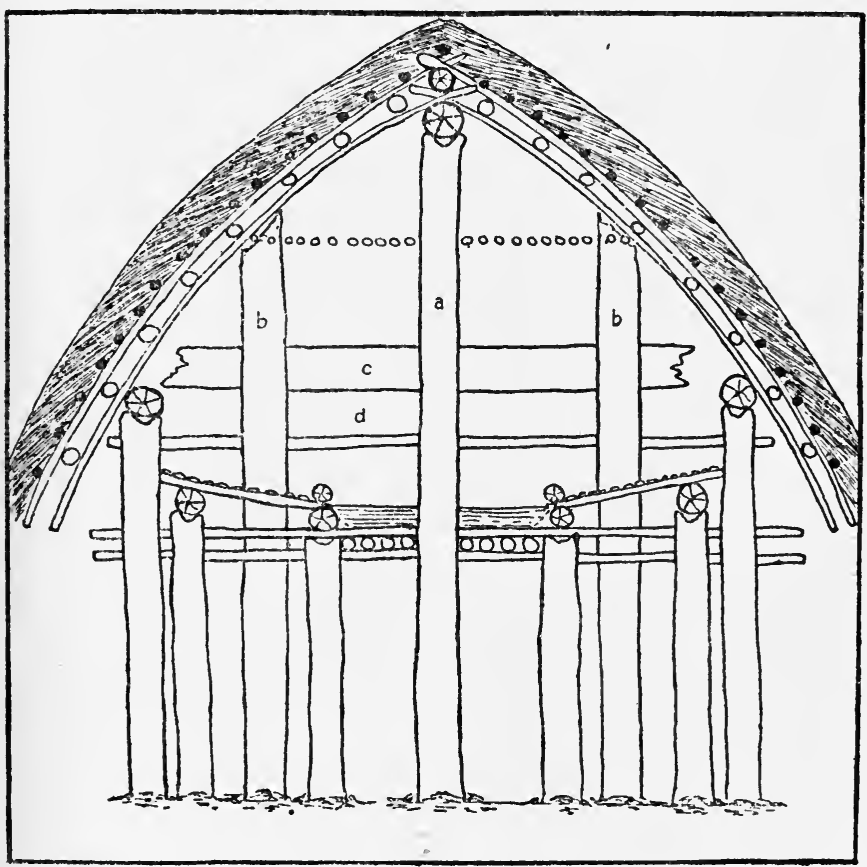

Fig. 5.-Diagram of Transverse Section across Centre of Emone.

Fig. 5 is a diagram of a transverse section across the centre of an emone, showing the internal construction. The explanatory note only deals with portions not explained in those to Fig. 4. 
CHAP.

\section{Explanatory Note to Fig. 5.}

Post $a$ is the main central support of the building corresponding with post $a$ in Fig. 4. Posts $b b$ are central side supports to the roof. Poles $c$ and $d$ are attached to posts $a b b$, and help to strengthen the fabric. These poles are also used for hanging up sleeping hammocks, the other extremities of which are hung to the loko-loko of the roof (Fig. 4, f). The name for post $a$ is $d u d u$, but this word is often used to express the whole structure $a b b c d$.

I have endeavoured in the diagrammatic sketchFig. 6-to illustrate the apse-like projection of the roof of an emone and the platform arrangements. I have in this sketch denuded the apse roof of its thatch, showing it in skeleton only; and I have shaded all timber work behind the platform, in order more clearly to define the latter.

\section{Explanatory Notes to Fig. 6.}

(a) Front end of thatch (asase) of main roof.

$(b c d)$ Front apse-shaped roof (siafele), the thatch having been removed to show its internal construction.

$(b c, b e, b d)$ Downward-sloping roof work (engala).

$(f f, c d)$ Horizontal roof work (gegebe), carried round in curves.

Note.-Sometimes the apse-shaped roof is constructed as a continuation of the main roof of the building, in which case the gegebe of the former are a continuation of those of the latter. Sometimes the apse roof is a separate appendage, not connected with 


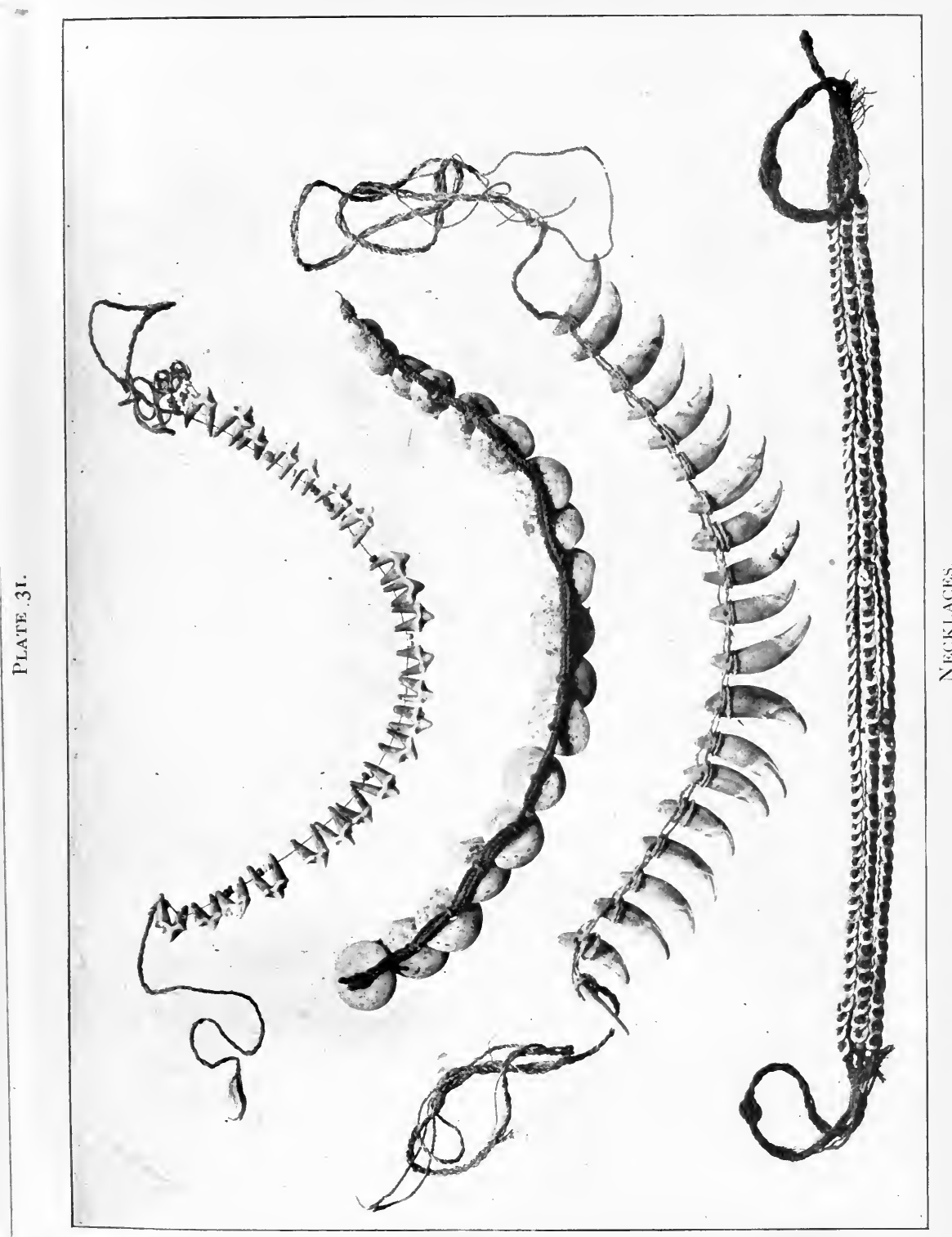



the main roof, and in that case the gegebe of the former are separate from those of the latter, and are fixed at their extremities to the loko-loko of the main roof.

$(g)$ Posts supporting the platform (purum'ul' emuge).

(h) Horizontal platform supports resting at one end

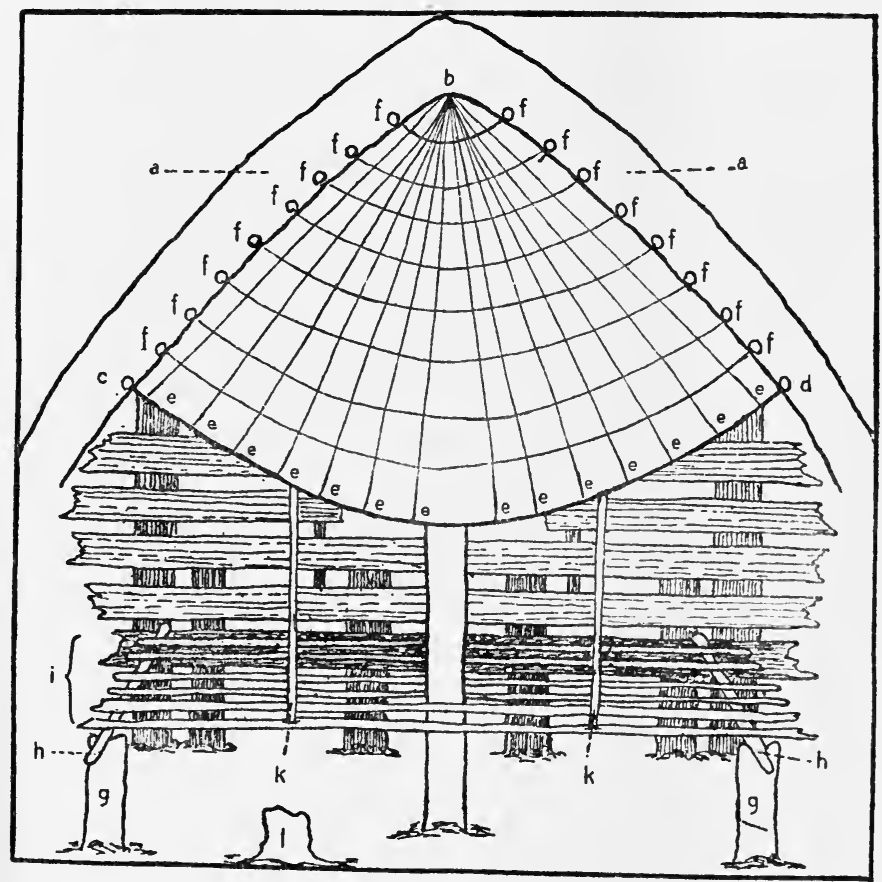

Fig. 6.-Diagrammatic Sketch of Apse-like Projection of Roof of Emone and Platform Arrangements

on $g$ and at the other end fixed to either the tedele or the emuje.

(2) Platform (purume).

Note.-It will be seen that the front apopo passes through the platform. 
(k) Additional supports to the apse roof, which are sometimes added, but are not usual. Their lower ends rest on the platform and they are connected with the apse roof at its outer edge (Mafulu name unknown).

(l) A stump by which to get on to the platform. This is often a rough sloping piece of tree-trunk; where the platform of the emone is high it is a rudely constructed ladder (gigide).

Note.-The entire façade of the front gable end is called konimbe (which means door) or purume (which means platform). That of the back gable end is called apei.

Note.-The height of the door-opening above the outside platform is shown in this figure.

The houses are in construction very similar to the emone, and in fact the above description of the latter may be taken as a description of a house, subject to the following modifications: (i.) The house is never raised high, its floor always being within a foot or two of the ground. (ii.) It is smaller than the emone, its average internal dimensions being about 8 to I 2 feet long, and 8 to ro feet wide. (iii.) The roof generally slopes down on both sides to the level of the ground (concealing the side structure of the house) or nearly so. (iv.) The projecting hood of the roof is only added at the front of the building, and not at the rear; and it is usually separate from, and not continuous with, the real roof. ${ }^{1}$ (v.) The platform is

1 Though this curious-shaped hood in front of a house is apparently a speciality of the mountains, so far as British New Guinea is concerned, I do not suggest that it does not exist elsewhere. In fact, some of the 
generally small and narrow, and often only extends for half the length of the front of the house, and, being always within a foot or two of the ground, it does not possess or require a ladder or tree-trunk approach; it is also narrower. Frequently there is no platform at all. (vi.) There is no entrance opening at the back of the house. (vii.) The front entrance opening is smaller and narrower and more difficult of entry. When the family are absent, they generally put sticks across this opening to bar entry, whereas the entrance opening of the emone is always open. (viii.) The centre house support very often consists of one post only, instead of a combination. (ix.) There is often on one side of the entrance opening a small space of the inside of the house fenced off for occupation by the pigs, and there is a little aperture by which they can get into this space from outside. (x.) The avale ceiling is usually absent; and, even if there be one, it will only extend under a small portion of the roof. ${ }^{1}$

native houses which I have seen in the Rubiana Lagoon district of the Solomon Islands had a somewhat similar projection, though in them the front wall of the house, with its little door-opening, was carried round below the outer edge of the hood, which thus formed part of the roof of the interior, instead of being merely a shelter over the outside platform, as is the case in Mafulu.

1 Dr. Haddon refers (Geographical Journal, Vol. XVI., p. 422) to conical ground houses with elliptical and circular bases found in villages on the top of steep hills behind the Mekeo district and on the southern spur of Mt. Davidson, and says that in some places, as on the Aduala affluent of the Angabunga (i.e., St. Joseph's) river, the houses are oblong, having a short ridge pole. I think that the elliptical houses to which he refers have probably been Kuni houses, to which his description could well be applied, and that the oblong houses have been Mafulu. The villages with very narrow streets, and the houses of which are, he says, built partly on the crest and partly on the slope, are also in this respect typically Kuni. 
The following are explanations of my plates of villages and their buildings.

\begin{tabular}{|c|c|}
\hline Plate. & Explanation. \\
\hline 55 & $\begin{array}{l}\text { Village of Seluku (community of Sivu), with chief's emone at the } \\
\text { end facing up the enclosure. }\end{array}$ \\
\hline 56 & $\begin{array}{l}\text { Village of Amalala (community of Sivu), with chief's emone at } \\
\text { the end of the enclosure. }\end{array}$ \\
\hline 57 & $\begin{array}{l}\text { The same village of Amalala (photographed in the other direc- } \\
\text { tion), with secondary emone at the end of the enclosure. }\end{array}$ \\
\hline $5^{8}$ & $\begin{array}{l}\text { Village of Malala (community of Sivu), with secondary emone at } \\
\text { the end of the enclosure. }\end{array}$ \\
\hline 59 & $\begin{array}{l}\text { Village of Uvande (community of Alo), with chief's emone at } \\
\text { the end of the enclosure. }\end{array}$ \\
\hline 60 & $\begin{array}{l}\text { Village of Biave (community of Mambu), with chief's emone at } \\
\text { the end of the enclosure. }\end{array}$ \\
\hline 61 & The chief's emone in village of Amalala. \\
\hline 62 & $\begin{array}{l}\text { The chief's emone in the village of Malala, at the other end of } \\
\text { the enclosure. }\end{array}$ \\
\hline $\begin{array}{l}63 \\
64\end{array}$ & $\begin{array}{l}\text { A house in the same village. } \\
\text { A house in village of Levo (community of Mambu). }\end{array}$ \\
\hline 04 & A house in village of Levo (community of Mambu). \\
\hline
\end{tabular}

\section{Communications.}

The native paths of the Mafulu people, or at all events those passing through forests, are, like those of most other mountain natives, usually difficult for white men to traverse. The forest tracks in particular are often quite unrecognisable as such to an inexperienced white man, and are generally very narrow and beset with a tangle of stems and hanging roots and creepers of the trees and bush undergrowth, which catch the unwary traveller across the legs or body or hands or face at every turn, and are often so concealed by the grass and vegetation that, unless he be very careful, he is apt to be constantly tripped up by them; and moreover these entanglements are often armed with thorns or prickles, or have 


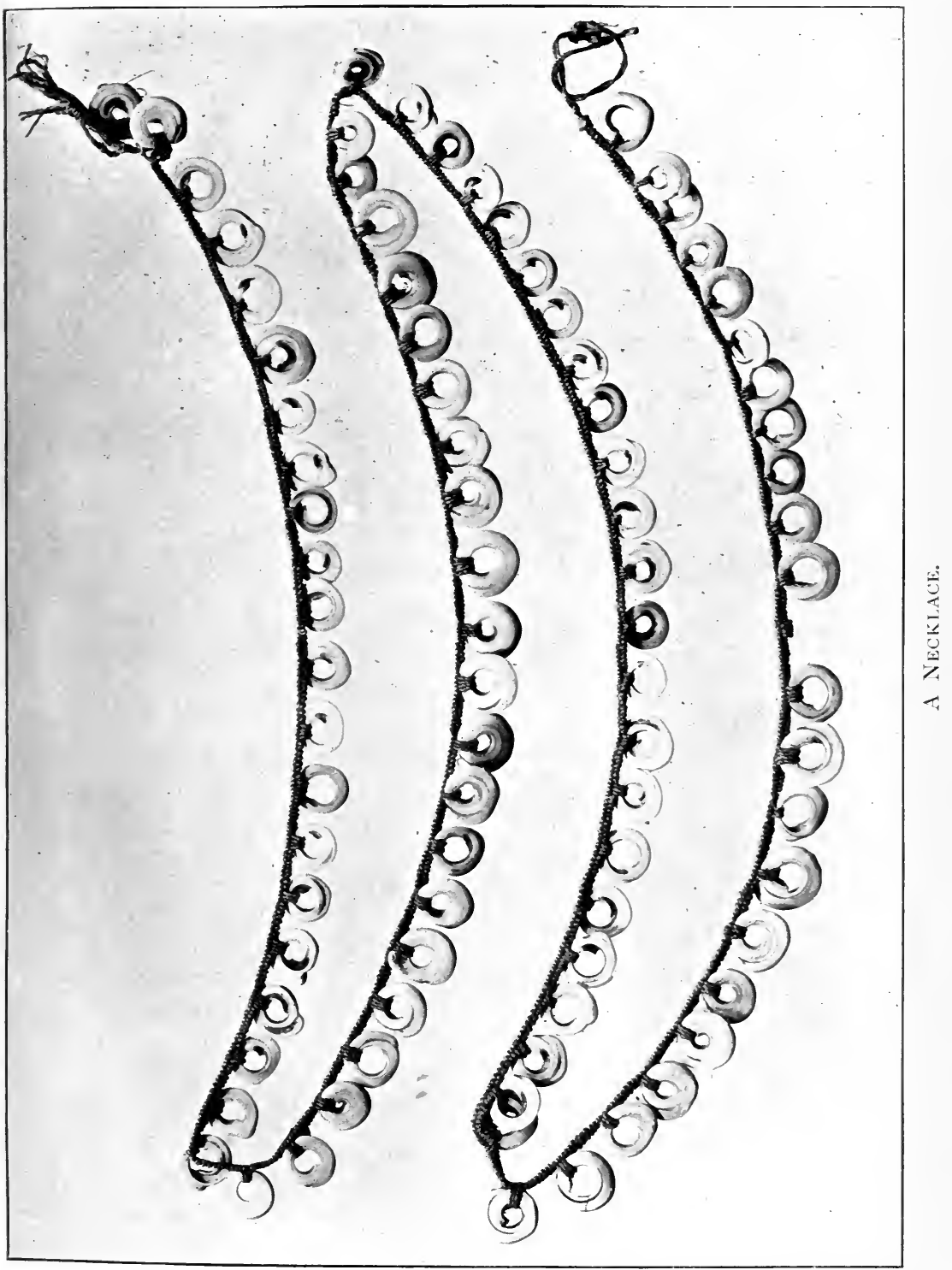



serrated edges, a sweep of which may tear the traveller's clothes, or lacerate his hands or face. Then there are at every turn and corner rough trunks of fallen trees, visible or concealed, often more or less rotten and treacherous, to be got over; and such things are frequently the only means of crossing ditches and ravines of black rotting vegetable mud. Moreover the paths are often very steep ; and, indeed, it is this fact, and the presence of rough stones and roots, which renders the very prominent outward turn of the people's big toes, with their prehensile power, such useful physical attributes.

Their bridges may be divided into four types, namely : (I) A single tree thrown across the stream, having either been blown down, and so fallen across it accidentally, or been purposely placed across it by the natives. (2) Two or more such trunks placed in parallel lines across the stream, and covered with a rough platform of transverse pieces of wood. (3) The suspension bridge. I regret that I am unable to give a detailed description of Mafulu suspension bridges, but I think I am correct in saying that they are very similar to those of the Kuni people, one of whose bridges is described in the Annual Report for June, I909, as being I 50 feet long and 20 feet above water at the lowest part, and as being made of lawyer vine (I do not know whether this would be right for Mafulu), with flooring of pieces of stick supported on strips of bark, and as presenting a crazy appearance, which made the Governor's carriers afraid of crossing it, though it was in fact perfectly safe, and had very little 
movement, even in the middle. I also give in Plate 65 a photograph taken by myself ${ }^{1}$ of a bridge over the St. Joseph river, close to the Kuni village of Ido-ido, which, though a Kuni bridge, may, I think, be taken as fairly illustrative of a Mafulu bridge over a wide river. $^{2}$ Plate 66 is a photograph, taken in Mafulu, of another form of suspension bridge used by them, and adapted to narrower rivers, the river in this case being the Aduala. (4) The bamboo bridge. This is a highly arched bridge of bamboo stems. The people take two long stems, and splice them together at their narrow ends, the total length of the spliced pair being considerably greater than the width of the river to be bridged. They then place the spliced pair of bamboos across the river, with one end against a strong backing and support on one side of the river and the other end at the other side, where it will extend for some little distance beyond the river bank. This further end is then forcibly bent backward to the bank by a number of men working together, and is there fixed and backed. The bamboo stems then form a high arch over the river. They then fix another pair of stems in the same way, close to and parallel with the first one; and the double arch so formed is connected all the way across with short pieces of wood, tied firmly to the stems, so as to strengthen the bridge and form a footway, by which it can be crossed. They then generally add a hand rail on one side.

1 This photograph had to be taken from an awkward position above, from which I had to point the camera downwards to the bridge.

2 See also description of suspension bridge over Vanapa river in lower hill districts given in Annual Report for June, 1889, p. 38. 
One can hardly leave the question of physical communications without also referring to the marvellous system of verbal communication which exists amongst the Mafulu and Kuni and other mountain people. Messages are shouted across the valleys from village to village in a way which to the unaccustomed traveller is amazing. It never seemed to me that any attempt was made specially to articulate the words and syllables of the message, or to repeat them slowly, so as to make them more readily heard at a distance off, though the last syllable of each sentence is always prolonged into a continuous sort of wail. This system of wireless telegraphy has, however, been before described by other writers, so I need say no more about it. 


\section{CHAPTER VII}

GOVERNMENT, PROPERTY, AND INHERITANCE

\section{Government and Justice.}

There is, as might be expected, no organised. system of government among the Mafulu, nor is there any official administration of justice.

As regards government, the chiefs in informal consultation with the sub-chiefs and prominent personages deal with important questions affecting the community or clan or village as a whole, such as the holding of big feasts and important ceremonies, the migrations or splitting-up or amalgamation of villages, and warlike operations; but events of this character are not frequent. And as to justice, neither the chiefs nor any other persons have any official duties of settling personal disputes or trying or punishing wrongdoers. The active functions of the chiefs, in fact, appear to be largely ceremonial.

Concerning the question of justice, it would seem, indeed, that a judicial system is hardly requisite. Personal disputes between members of a village or clan, or even of a community, on such possible subjects as inheritance, boundary, ownership of 


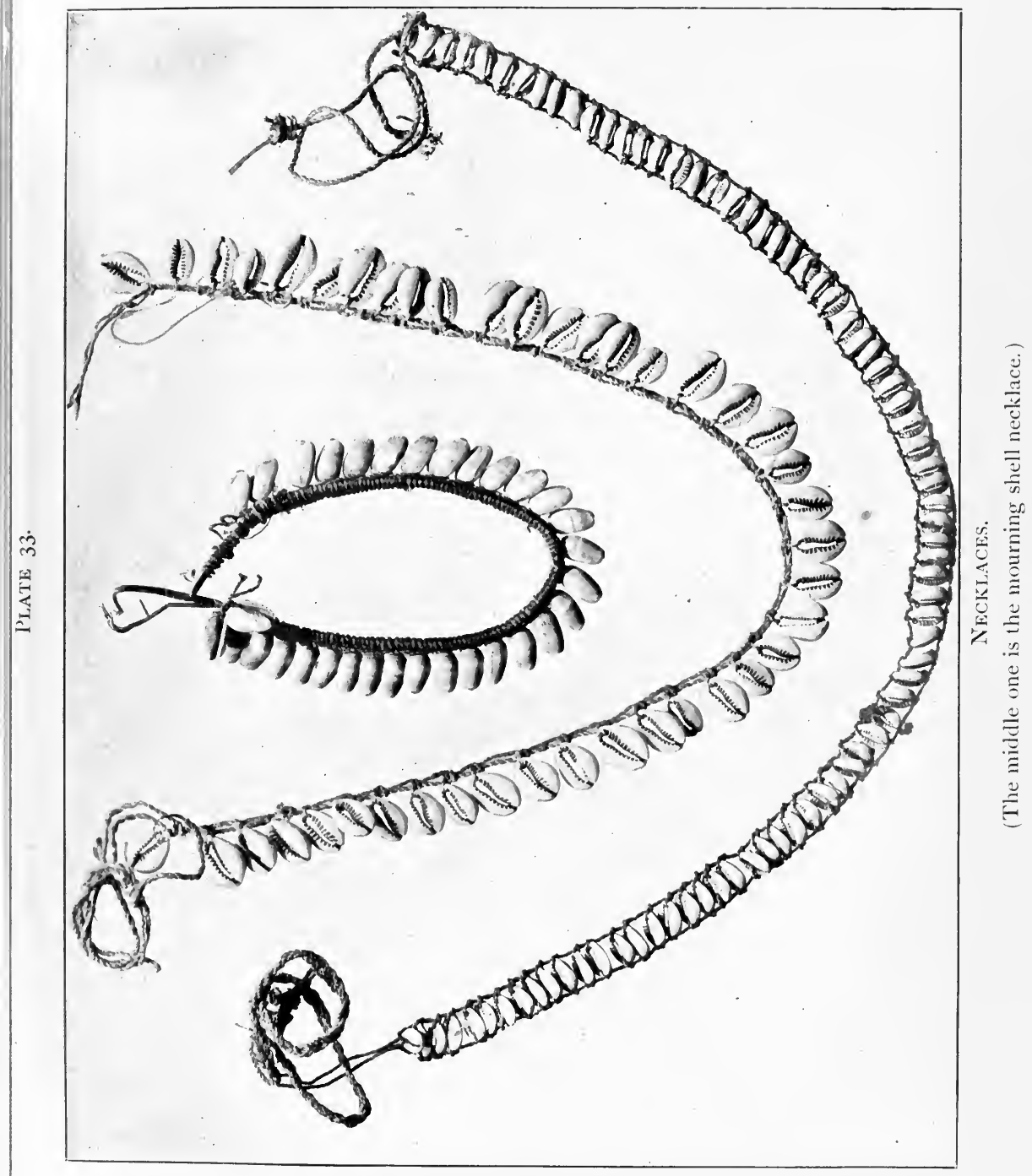



property, trespass and the like, and wrongful acts within the village or the community, are exceedingly rare, except as regards adultery and wounding and killing cases arising from acts of adultery, which are more common.

There are certain things which from immemorial custom are regarded as being wrong, and appropriate punishments for which are generally recognised, especially stealing, wounding, killing and adultery; but the punishment for these is administered by the injured parties and their friends, favoured and supported by public opinion, and often, where the offender belongs to another clan, actively helped by the whole clan of the injured parties.

The penalty for stealing is the return or replacement of the article stolen; but stealing within the community, and perhaps even more so within the clan or village, is regarded as such a disgraceful offence, more so, I believe, than either killing or adultery, that its mere discovery involves a distressing punishment to the offender. As regards wounding and killing, the recognised rule is blood for blood, and a life for a life. The recognised code for adultery will be stated in the chapter on matrimonial matters.

Any retribution for a serious offence committed by someone outside the clan of the person injured is often directed, not only against the offender himself, but against his whole clan.

There is a method of discovering the whereabouts of a stolen article, and the identity of the thief, through the medium of a man who is believed to have special 
powers of ascertaining them. This man takes one of the large broad single-shell arm ornaments, which he places on its edge on the ground, and one of the pigbone implements already described, which he places standing on its point upon the convex surface of the shell. To make the implement stand in this way he puts on the point, and makes to adhere to the shell a small piece of wild bees' wax, this being done, I was told, surreptitiously, though I cannot say to what extent the people are deceived by the dodge, or are aware of it. The implement stands on the shell for a few seconds, after which it falls down. Previously to doing this he has told his client of certain possible directions in which the implement may fall, and intimated that, whichever that may be, it will be the direction in which the lost article must be sought. He has also given certain alternative names of possible culprits, one of such names being associated with each of the alternative directions of falling. The fall of the implement thus indicates the quarter in which the lost article may be found and the name of the thief. Father Clauser saw this performance enacted in connection with a pig which had been stolen from a chief; the falling bone successfully pointed to the direction in which the pig was afterwards found, and there was no doubt that the alleged thief was in fact the true culprit. Presumably the operator makes private enquiries before trying his experiment, and knows how to control the fall of the implement. 


\section{Property and Inheritance.}

The property of a Mafulu native may be classified as being ( $\mathrm{I}$ ) his movable belongings, such as clothing, ornaments, implements and pigs; (2) his house in the village ; (3) his bush land; (4) his gardens.

The movable belongings are, of course, his own absolute property.

The viliage house is also his own; but this does not include the site of that house, which continues to be the property of the village. Every grown-up male inhabitant of the village has the right to build for himself one house in that village; he is not entitled to have more than one there, but he may have a house in each of two or more villages, and a chief or very important man is allowed two or three houses in the same village. On a house being pulled down and not rebuilt, or being abandoned and left to decay, the site reverts to the village, and another person may build a house upon it. ${ }^{1}$ Houses are never sold, but the ordinary life of a house is only a few years.

The man's bush land is his own property, and his ownership includes all trees and growth which may be upon it, and which no other man may cut down, but it does not include game, this being the common property of the community; and any member of the community is entitled to pass over the land, hunt on it, and fish in streams passing through it, as

1 Compare the Koita system under which the owner of the house owns the site of it also, and the latter passes on his death to his heirs (Seligmann's Melanesians of British New Guinea, p. 89.) 
he pleases. The whole of the bush land of the community belongs in separate portions to different owners, one man sometimes owning two or more of such portions; and it is most remarkable that, though there are apparently no artificial boundary marks between the various portions, these boundaries are, somehow or other, known and respected, and disputes with reference to them are practically unknown. How the original allocations and allotments of land have been made does not appear to be known to the people themselves.

The man's garden plot or plots are also his own, having been cleared by him or some predecessor of his out of his or that predecessor's own bush land; and he may build in his gardens as many houses as he pleases. His ownership of his garden plot is more exclusive than is that of his bush land, as other people are not entitled to pass over it. But on the other hand, if he abandons the garden, and nature again overruns it with growth-a process which takes place with great rapidity-it ceases to be his garden, and reverts to, and becomes absorbed in, the portion of the bush out of which it had been cleared; and if, as it may be, he is not the sole owner of that portion of bush, he loses his exclusive right to the land, which as a garden had been his own sole property.

No man can sell or exchange either his bush land or his garden plots, and changes in their ownership therefore only arise through death and inheritance. This statement, however, is, I think, subject to the qualification that an owner of bush-land will some- 


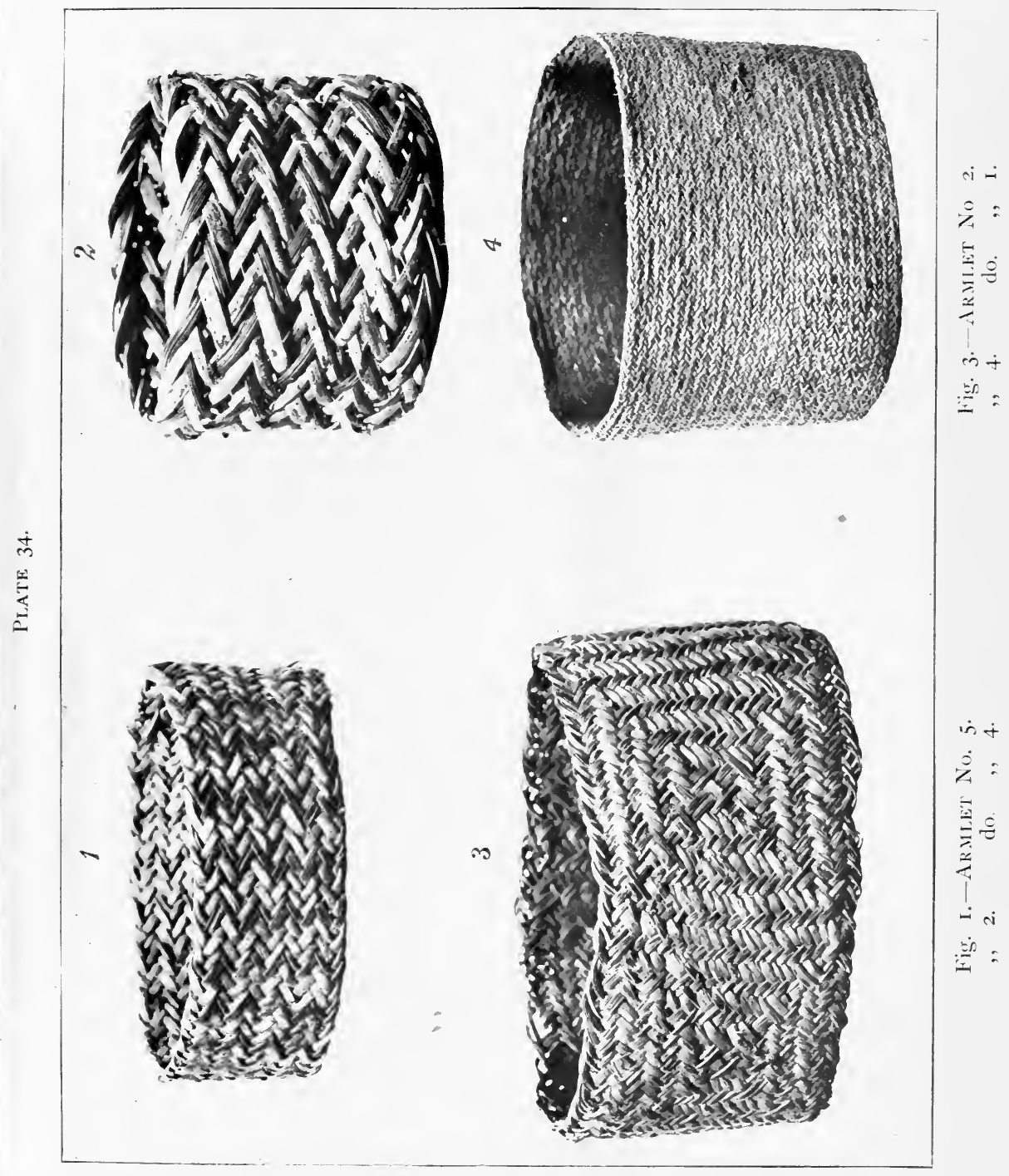



times allow his son or other male descendant to clear and make for himself a garden in it; but I am not sure as to the point.

On a man's death his widow, if any, does not inherit any portion of his property, either movable or immovable, but three things are allowed to her. She is generally allowed one pig, which will be required by her at a later date for the ceremony of the removal of her mourning; and she shares with her husband's children, or, if there be none, she has the sole right to, the then current season's crops and fruit resulting from the planting effected by her late husband and herself, though this is a right which, after her return home to her own people, she would not continue to exercise ; and she is allowed to continue to occupy her husband's house, but this latter privilege terminates at the mourning removal ceremony, when the house will be pulled down, and its site will revert to the village, and she will probably return to her own people in her own village, if she has not done so previously.

Subject to these three allowances, I may dismiss the widow entirely in dealing with the law of inheritance. I may also dismiss the man's female children by saying that, if there be male children, the females do not share at all in the inheritance, and even if there be no male children the female children will only perhaps be allowed, apparently rather as a matter of grace than of right, to share in his movable effects; and that, subject to this, everything goes to the man's male relatives. I may also eliminate the man's pigs, as 
apparently any pigs he has, other than that retained for his widow, are killed at his funeral.

On the death of an owner everything he possesses goes, except as above mentioned, to his sons. They divide the movable things between them, but the bush and garden land pass to them jointly, and there is no process by which either of these can be divided and portioned among them. The male children of a deceased son, and the male children of any deceased male child of that deceased son (and so on for subsequent generations), inherit between them in lieu of that son. There does not appear, however, to be any idea in the Mafulu mind of each son of the deceased owner being entitled to a specific equal fractional share, or of the descendants of a deceased son of that owner being between them only entitled to one share, per stirpes. They apparently do not get beyond the general idea that these people, whoever they may be and to whatever generations they may belong, become the owners of the property.

They take possession of and cultivate the existing gardens as joint property. Any one of them will be allowed to clear some of their portion of bush, and fence it, and plant it as a garden, and it will then become the sole property of that one man, and if he dies it will pass as his own property to his own heirs ; though, as before stated, if he abandons it, and lets it be swallowed up by the bush, it will cease to be his own garden, and will again be included in the family's joint portion of bush land, and on his death his heirs will only come into the joint bush ownership. 
VII GOVERNMENT, PROPERTY, INHERITANCE I2I

In this way the ownership of a garden must often be in several persons, with no well-defined rights inter se, and the general ownership of bush land which has never been cleared, or which, having been cleared, has been abandoned and reverted, must often be in a very large number of persons without defined rights. In fact, so far as bush land is concerned, one only has to remember that on the death of an owner it passes into joint ownership of children-that on the deaths of these children fresh groups of persons come into the joint ownership-that this may go on indefinitely, generation after generation-that bush, having once got into the ownership of many people, is hardly likely to again fall by descents into a single ownership - that indeed the tendency must be for the number of owners of any one portion of bush steadily to increase-and finally that there is no way by which the extensively divided ownership can be terminated by either partition or alienation-and one then realises the extraordinary complications of family ownership of bush land which must commonly exist.

As regards both movable effects and gardens and bush land there must be endless occasions for dispute. How are the movable things to be divided among the inheritors, and, in particular, who is to take perhaps one valuable article, which may be worth all the rest put together? How are questions of doubtful claims to heirship to bush and garden land to be determined? How is the joint ownership of the gardens to be dealt with, and how is the work there to be apportioned, and the products of the gardens 
divided? How are the mutual rights of the bush land to be regulated, and especially what is to happen if each of two or more joint owners desires to clear and allocate to himself as a garden, a specially eligible piece of bush? Such situations in England would bristle with lawsuits, and I tried to find out how these questions were actually dealt with by the Mafulu; but there is no judicial system there, and the only answer I could get was that in these matters, as in the case of inter-community bush boundaries and personal bush boundaries, disputes were practically unknown; though it was pointed out to me, as regards bush land, that the amount of it belonging to any one family was usually so large that crowding out could hardly arise.

If a man dies without male descendants in the male line, then, subject perhaps to some sort of claim of his daughters, if any, to share in his movable effects, his property goes to his nearest male relative or relatives in the male line. This would primarily be his father, if living, but the father could hardly be the inheritor of anything but movable things and perhaps garden land, as the deceased could not be the owner of bush land during the lifetime of his father. Subject as regards movable things and perhaps gardens to this right of the father, the persons to inherit everything would be deceased's brothers and the male descendants in the male line of any such brothers who had died; or in default of these it would be the father's (not the mother's) brothers and their male descendants in the male line, and so on for more distant male relatives, every descent being traced 


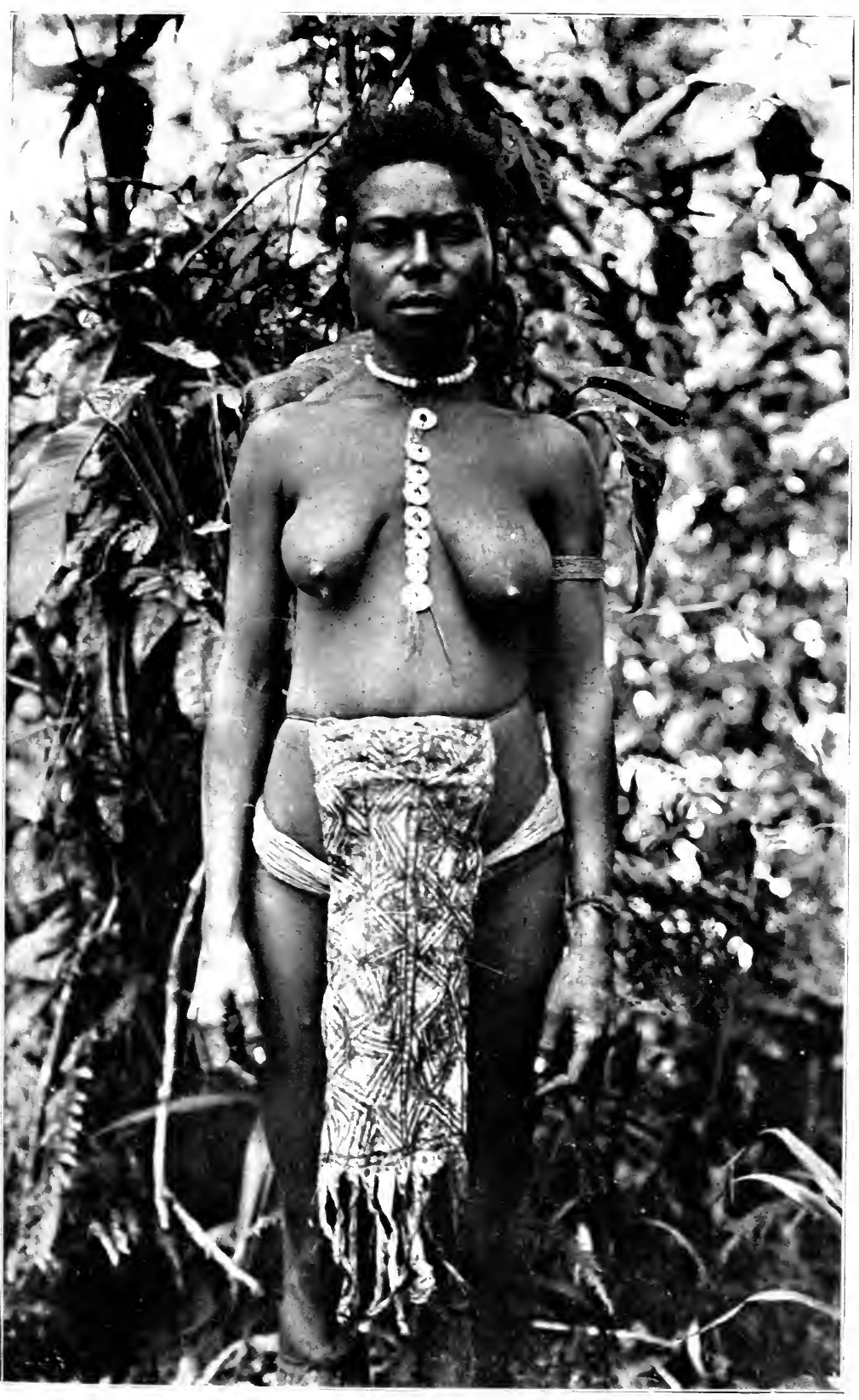

WOMAN WEARING DANCING APRON. 

strictly in the male line only, on a principle similar to that above explained.

Male infants, by which term I mean young children, there being of course no infancy in the defined sense in which the term is used in English law, like adults, may become possessed of property by inheritance as regards bush and garden land, and by inheritance or otherwise as regards movable property, but they would hardly be likely to be the owners of houses; and the descent from these infants is the same as that in the case of adults.

No woman can possess any property, other than movable property, and even this is at best confined to the clothes and ornaments which she wears. On the death of a married woman all her effects go to her husband, or, if he be dead, they go to her children or descendants, male and female, equally. If she has no children or descendants, they go to her husband's father, or, failing him, to such other person or persons as would have been entitled to inherit if her effects had been those of her husband. Her own blood relations do not come in, as she had been bought and paid for by her husband. If the deceased woman were a spinster, then her effects would pass to her father, or, failing him, to her brothers, or, failing them, to her nearest male relatives on her father's side.

The guardianship of and responsibility for infant children whose father dies falls primarily upon the children's mother, and she, if and when she returned to her own people, would probably take the children away with her, though her sons, who shared in the inheri- 
tance from their father, would usually come back again to their own village when they became grown up, and might do so even when comparatively young. If there is no mother of the children, the guardianship and responsibility is taken up by one or more of the relatives of either the deceased father or deceased mother of the children, and it might be that some children would be taken over by some of such relatives, and some by others. There appears, however, to be no regular rule as to all this, the question being largely one of convenience.

Adopted children have in all matters of inheritance the same rights as actual children.

From the above particulars it will be seen that there is no system of descent in the female line or of mother-right among the Mafulu, and I could not find any trace of such a thing having ever existed with them. As to this I would draw attention to the facts that the mother's relatives do not come in specially, as they do among the Roro and Mekeo people, in connection with the perineal band ceremony; that a boy owes no service to his maternal uncle, as is the case among the Koita; that there is no equivalent of the Koita Heni ceremony; that in no case can a woman be a chief, or chieftainship descend by the female line; that children belong to the clan of their father, and not to that of their mother; and that no duty or responsibility for orphan children devolves specially upon their mother's relations. 


\section{CHAPTER VIII}

\section{THE BIG FEAST}

THIS is the greatest and most important social function of a Mafulu community of villages. I was unable to get any information as to its real intent and origin, but a clue to this may, I think, be found in the formal cutting down of the grave platform of a chief, the dipping of chiefs' bones in the blood of the slain pigs, and the touching of other chiefs' bones with the bones so dipped, which constitute such important features of the function, and which perhaps point to an idea of in some way finally propitiating or driving away or "laying" the ghosts of the chiefs whose bones are the subject of the ceremony.

The feast, though only to be solemnised in one village, is organised and given by the whole community of villages. There is no (now) known matter or event with reference to which it is held. It is decided upon and arranged and prepared for long beforehand, say a year or two, and feasts will only be held in one village at intervals of perhaps fifteen or twenty years. The decision to hold a feast is arrived at by the chiefs of the clans of the community which proposes to give it. The village at which the feast is to be held will not necessarily be the largest one of the community, or one in which is a then existing 
chief's emone. The guests to be invited to it will be the people of some other (only one other) community, and at the outset it will be ascertained more or less informally whether or not they will be willing to accept the invitation.

When the feast has been resolved upon, the preparations for it begin immediately, that is a year or two before the date on which it is to be held. Large quantities will be required of yam, taro and sugar-cane, and of a special form of banana (not ripening on the trees, and requiring to be cooked); also of the large fruit of the ine, a giant species of Pandanus (see Plate 80-the figure seated on the ground near to the base of the tree gives an idea of the size of the latter and of the fruit head which is hanging from it), which is cultivated in the bush, and the fruit heads of which are oval or nearly round, and have a transverse diameter of about i 8 inches; and of another fruit, called by the natives malage, which grows wild, chiefly by streams, and is also cultivated, and the fruit of which was descibed to me as being rather like an apple, almost round, green in colour, and 4 or 5 inches in diameter. ${ }^{1}$ And above all things will be wanted an enormous number of village pigs (not wild pigs); and sweet potatoes must be plentiful for the feeding of these pigs. And finally they will need plenty of native tobacco for their guests. In view of these requirements it is obvious that a year or two is by no means an excessive period for the preparations for the feast.

1 See note 1 on p. 128. 

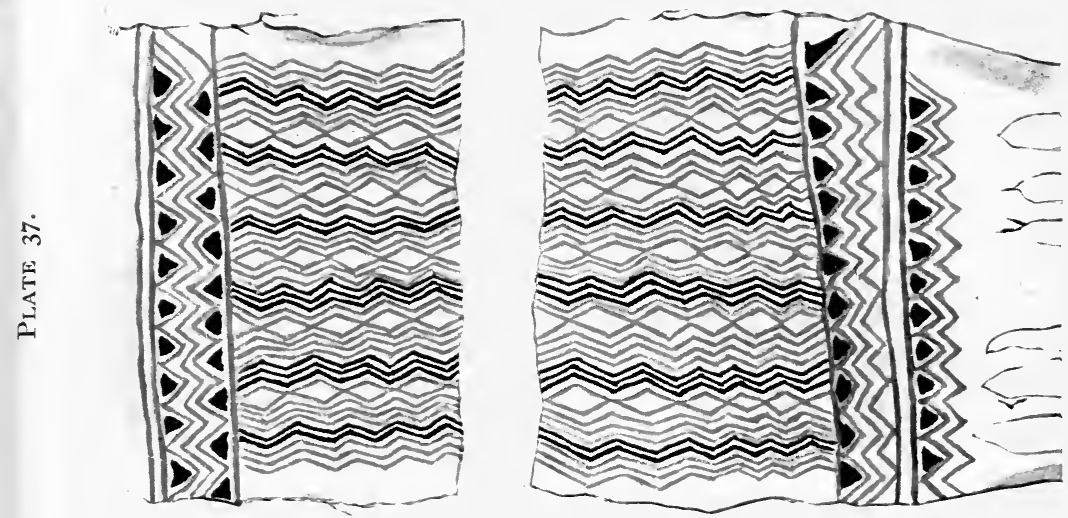

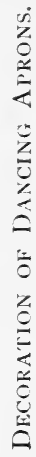

ن

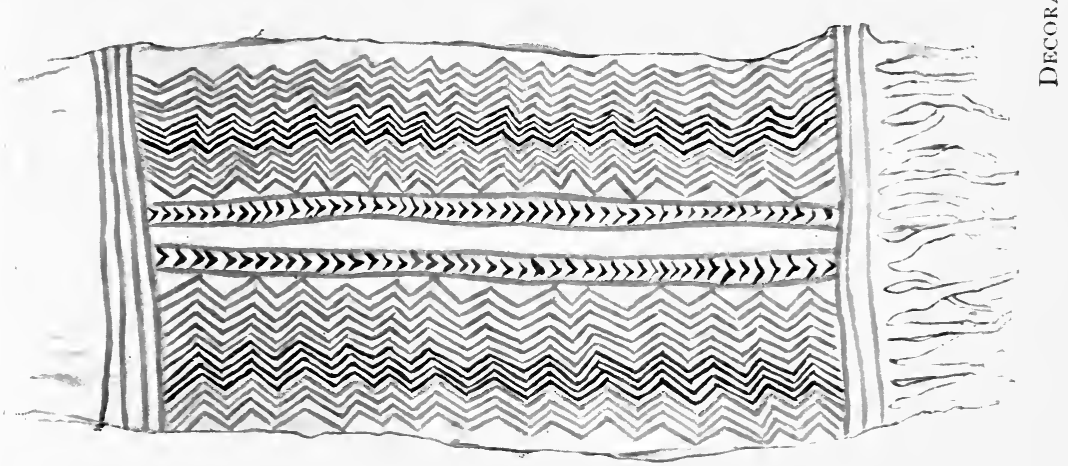



The existing yam and taro gardens, intended for community consumption alone, will be quite insufficient for the purpose, and fresh bush land is at once cleared, and new gardens are made and planted, the products of these new gardens being allocated specially for the feast, and not used for any other purpose. There is also an extensive planting of sugar-cane, probably in old potato gardens. For bananas there will probably be no great need of preparation, as they are grown plentifully, and there is no specific appropriation of these; but the sufficiency of the supply of the tobacco for the visitors, and of the sweet potatoes for the pigs, has to be seen to, also that of the ine Pandanus trees, the fruit of which has often to be procured from elsewhere, and of the malage trees. And finally the village pigs must be bred and fattened, for which latter purpose it is a common practice to send young pigs to people in other communities ; and these people will be invited to the big feast, and will have pig given to them, though not members of the invited community; but never in any case will any of them have a part of a pig which he himself has fattened. The cultivated vegetable foods and the pigs are not provided on a communistic basis, but are supplied by the individual members of the community, each household of which is expected to do its duty in this respect ; and no person who or whose family has not provided at least one pig (some of them provide more than one) will be allowed to take part in the preliminary feast and subsequent dancing, to be mentioned below.

The bringing in and storing of the ine and malage 
fruits commence at an early stage. The ine fruits are collected when quite ripe; they split the large fruit heads up into two or more parts, put these into baskets roughly made of cane (at least half a fruit head in each basket), and place these baskets in the avale or ceiling of the emone, where the fruits get dried and smoked by the heat and smoke of the fire constantly burning beneath. If, as is sometimes the case, the emone has no avale, one is constructed specially for the purpose. The fruits are left there until required; in fact, if taken away from the smoke, they would go bad. Sometimes, instead of putting portions of the fruit heads into baskets, they take out from them the almond-shaped seeds, which are the portions to be eaten, string these together, each seed being tied round and not pierced, and hang them to the roof of the emone above the avale. The fruits of the malage are gathered and put into holes or side streams by a river, and there left for from seven to ten months, until the pulp, which is very poisonous, is all rotted away, a terrible smell being emitted during the process; they then take the pips or seeds, the insides of which, after the surrounding shells have been cracked, are the edible parts, and place these in baskets made out of the almost amplexicaul bases of the leaves of a species of palm tree, and so store them also on the avale of the emone. ${ }^{1}$

1 Father Egedi describes in Anthropos a Kuni method of preparing a fruit similar to the one described here, and which also gives rise to terrible smells. The tree is referred to by him as being a bread-fruit; and Dr. Stapf thinks that the malage may possibly be one of the Artocarpus genus, of which some have smooth or almost smooth fruit, and some 
Large preparations of a structural and repairing - nature are also required in the village where the feast is to be held. The emone, the true chief's emone, of the village is repaired or pulled down and entirely rebuilt; or, if that village does not possess such an emone, one is erected in it. In point of fact the usual practice is, I was informed, to build a new emone, the occasion of an intended feast being the usually recognised time for the doing of this. ${ }^{1}$ The houses of the village are put into repair. The people of the other villages of the same community build houses for themselves in the feast village, so that on the occasion of the feast all the members of the community (the hosts) will be living in that village. View platforms, from which the dancing can be watched, are built by all the people of the community. These are built between the houses where possible, or at all events so as to obstruct the view from the houses as little as possible. They are built on upright poles, and are generally between 2 and 20 feet high, each platform having a roof, which will probably be somewhat similar to the roofs of the houses. Sometimes there are two platforms under one roof, but this is not usual. Sometimes the platforms, instead of being on

are said to have poisonous sap, and the seeds of many or which are eaten, or of some closely allied type.

1 The information obtained by me at Mafulu did not go beyond the actual facts as stated by me. I cannot, however, help suspecting that there is, or has been, a close connection between the building of an emone and the holding of a big feast, and that the latter may be compared with the tabu ceremonial of the Koita described by Dr. Seligmann (Melancsians of British New Guinea, pp. I4I and 145 et seq.). Indeed there are some elements of similarity between the two feasts. 
posts, are in trees, being, however, roofed like the others. Two or more houses may join in making one platform for themselves and their friends. All the above works are put in hand at an early stage.

The following are done later, perhaps not till after the sending out of the formal invitation (see below), but they may conveniently be dealt with here. The people erect near to, but outside, the village in which the feast is to be held one or more sheds for the accommodation of the guests, the number of sheds depending upon the requirements of the case. These are merely gable and ridge-shaped roofs, which descend on each side down to the ground, or very close to it, being supported by posts, and there being no flooring. They are called olor' eme, which means dancers' houses. Posts about 20 or 25 feet high and I 2 inches or nearly so in diameter are erected in various places in the village enclosure, and each of these posts is surrounded with three, four, or five upright bamboo stems, which are bound to the post so as together to make a composite post of which the big one is the strong supporting centre. The leaf branches of these bamboos, starting out from the nodes of the stems, are cut off 3 or 4 inches from their bases, thus leaving small pegs or hooks to which vegetables, etc., can be afterwards hung; and in the case of each post one only of its surrounding bamboos has the top branches and leaves left on. Each household is responsible for the erection of one post. I may here say in advance that upon these post clusters will be hung successively, yams and taro in the upper 

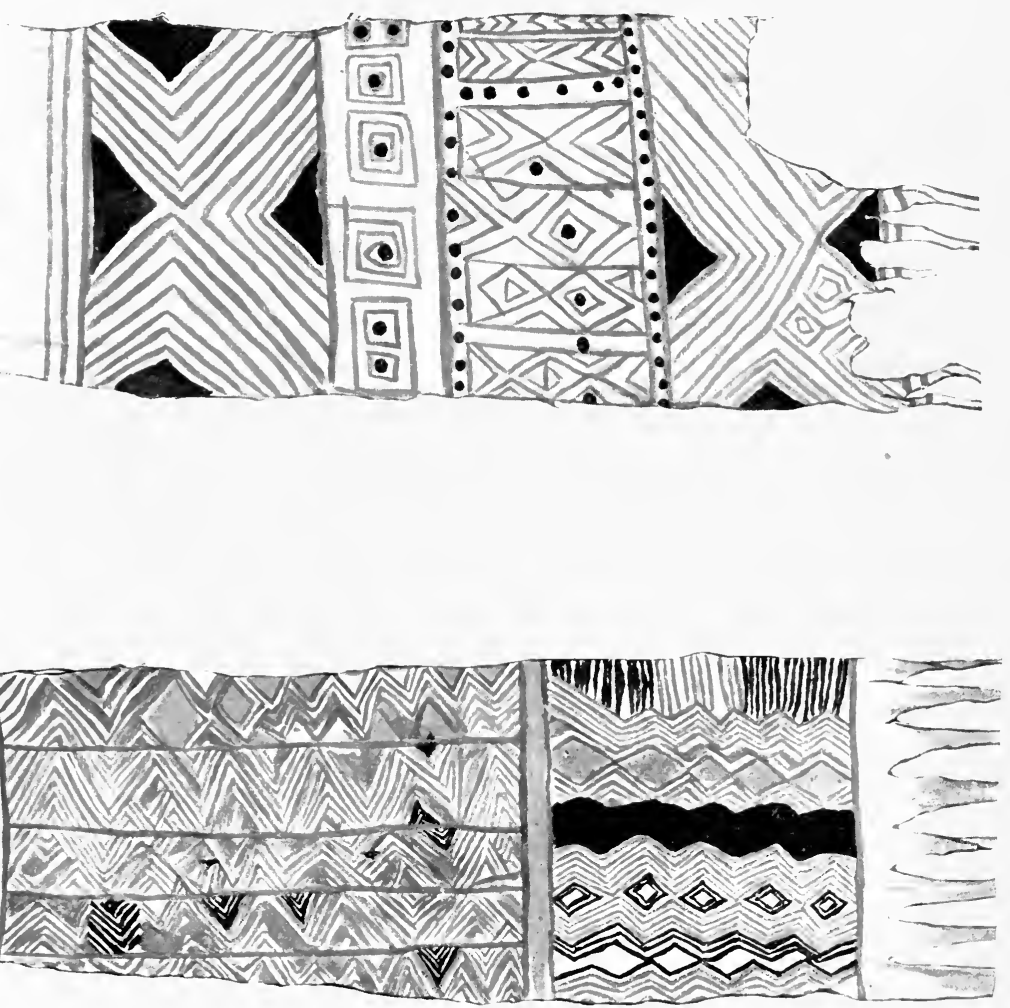

parts, human skulls and bones lower down, and croton leaves by way of decoration at the bottom. The sugar-cane and banana and ine and malage are dealt with in another way. There is a further erection of thin poles, which will be mentioned in its proper place.

About six months before the anticipated date of the big feast there is a preliminary festivity, which is regarded as a sort of intimation that the long-intended feast is shortly to take place. To this festivity people of villages of any neighbouring communities, say within an hour or two's walk, are invited. There is no dancing, but there is a distribution among the guests of a portion of each of the vegetables and fruits which will be consumed at the feast, and a village pig is killed and cut up, and its parts are also distributed among the guests, who then return home.

After this preliminary festivity dancing begins in the village in which the feast is to be held and in the other villages of the same community, and this dancing goes on, subject to weather, every day until the evening prior to the day upon which the feast takes place. The men dance in the villages, beginning at about sundown, and going on through the evening, and perhaps throughout the night. Only men who or whose families have provicied at least one pig for the feast are allowed to join in the dancing. Bachelors join in the dancing, subject to the above condition. The women dance outside their villages, and, as regards them, there is no pig qualification.

About a month before the date on which the feast is 
proposed to be held, a formal invitation is sent out to the community which is to be invited to it, and who, as above stated, have already been approached informally in the matter. For this purpose a number, perhaps ten, twenty, or thirty, of the men of the community giving the feast start off, taking with them several bunches of croton leaves-one bunch for each village of the invited community. These men, if the invited community be some distance off, only carry the croton leaves as far as some neighbouring community, probably about one day's journey off, where they stay the night, and then return. During their progress, and particularly as they arrive at their destination, they are all singing. Then the men of this neighbouring community carry the croton leaves a stage further; and so on till they reach their ultimate destination. This may involve two or three sets of messengers, but occasionally one or two of the original messengers may go the whole way. These croton leaves are delivered to the chiefs of the several clans of the invited community, and they are tied to the front central posts of the village emone, the true emone of the chief's village, and, as regards other villages, the emone of the sub-chiefs. ${ }^{1}$

The exact date of the feast depends upon the guests, who may come in a month after receiving the croton leaves, or may be later; and the community giving the feast do not know on what date their guests will arrive

1 Compare the Roro custom for the messengers carrying an invitation to important feasts to take with them bunches of areca nut, which are hung in the marea of the local groups of the invited itsubu (Seligmann's Melanesians of British New Guinea, p. 218). 
until news comes that they are actually on their way, though in the meantime messengers will be passing backwards and forwards and native wireless telegraphy (shouting from ridge to ridge) will be employed.

As soon as the formal invitation has been sent the people of the community giving the feast begin to bring in the yams from the gardens, which they do day by day, singing as they do so; and these yams are stored away in the houses as they are brought in. When the yams have all been collected, they are brought out and spread in one, two, or three long lines along the centre of the village open space. The owner of each post knows which are his own yams, and they will go to his post. When the yams are laid out on the ground, the chiefs inspect them, and select the best ones, which are to be given to the chiefs of the community invited to the dance. To these selected yams they tie croton leaves as distinguishing marks. Then each man stands by his own yams, and has a boy standing by his own post; each man picks up his best yams, and whilst holding these they all (only the men with the yams) begin to sing. The moment the song is over, each man rushes with his selected best yam to his post, and hands the yam to the boy, who climbs up the post, and hangs up the yam. After this they hang the rest of the yams, each man running with them to the post, and giving them to the boy, who climbs up and hangs the yam whilst the man runs back for another, the performance being all in apparent disorder and there being no singing. Some of the best-shaped 
yams are hung to little cross-sticks about 3 or 4 feet long, which the boys then and there attach to those bamboo stenıs which have their top branches and leaves left upon them, the sticks being attached just below these branches. These selected yams will include those with the croton leaves, which are intended for chiefs. Of the rest the better yams are hung up higher on the posts, and the poorer ones lower down. The lowest of them will probably be 5 or 6 feet from the ground.

After hanging the yams, the next step is to erect in the ground all round the village enclosure and in front of the houses a number of tall young slender straightstemmed tree poles, with the top branches and leaves only left upon them. These poles are connected with one another by long stems, fixed horizontally to them at a height of 7 or 8 feet from the ground, the stems thus forming a sort of long line or girdle encircling the village enclosure.

The men then go to their gardens and bring in the sugar-canes, singing as they do so, and these they hang to the horizontal stems, but without ceremony. The sugar-canes are all in thick bundles, perhaps 12 or 18 inches thick, and these bundles are hung horizontally end to end immediately under the line of stems, so as also to make a continuous encircling line.

Next they bring in the bananas, again singing, and these they hang up on the tall, slender tree poles, and on the platforms of the houses, and under the view platforms, but without ceremony. 

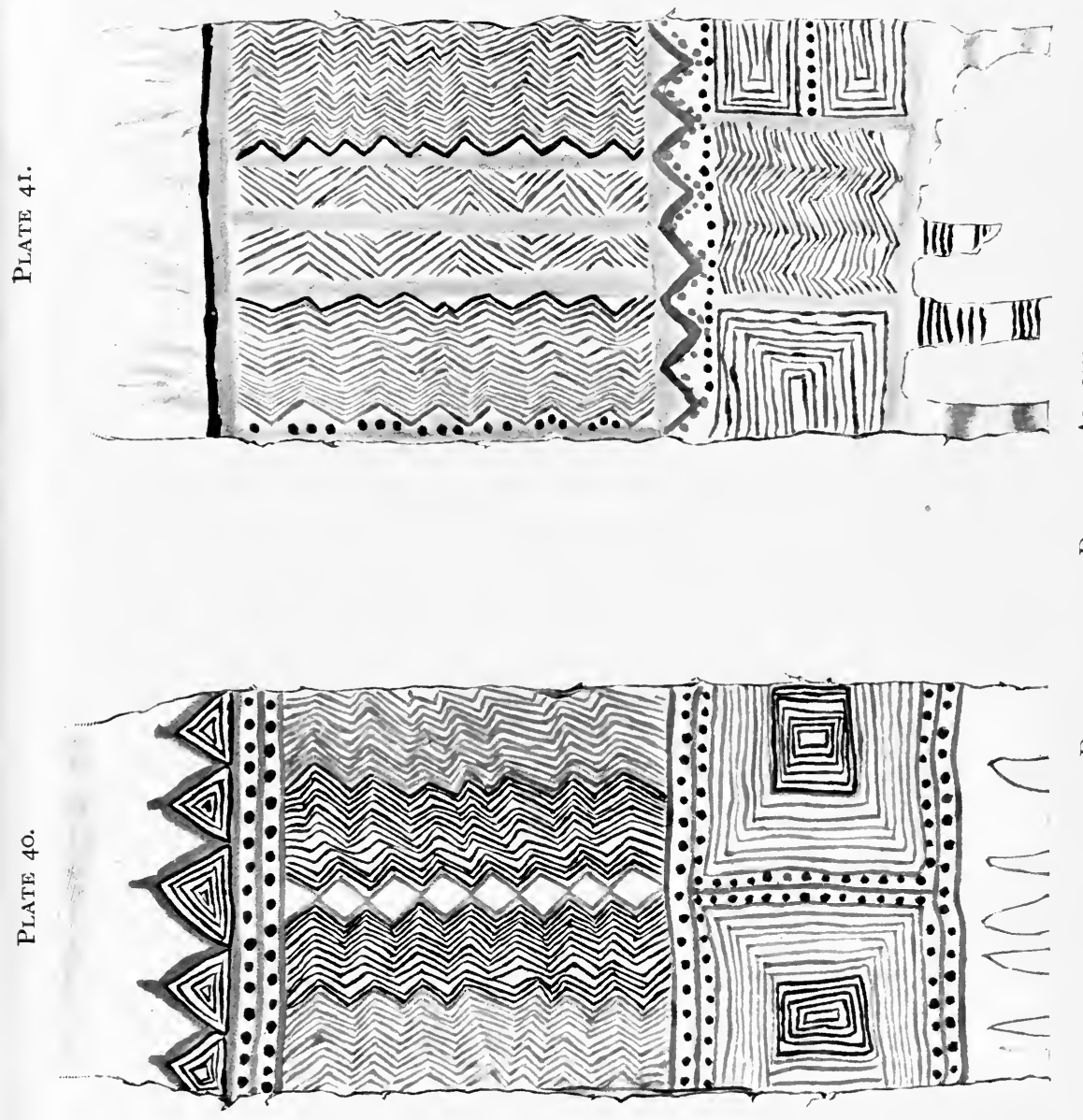

Lastly, again singing, they bring in the taro, and hang these up, mixed with the yams (not below them) on the posts, again without ceremony. The hanging up of the taro is left to the last, and, in fact, is not done till it is known that the guests are on their way, as the taro would be spoilt by bad weather.

In hanging the yam and the taro the people all work simultaneously - that is, they are all hanging yams at the same time and all hanging taro at the same time. But as regards the sugar cane and banana each man works in his own time without waiting for, or being waited for by, the others. Women may help the men in all these things, except the ceremonious hanging up of the yams.

They do not, however, hang all the yam, sugar-cane, banana and taro, some of each being kept back in the houses for a purpose which will appear hereafter.

The ine and malage fruits are not hung up at all, but are kept in the avale of the village emone until the day of the actual feast, when the various vegetables and fruits are, as will be seen, put in heaps for distribution among the guests.

They then further decorate the posts with human skulls and bones, which are hung round in circles below the yams and taro, but not reaching to the ground. These are the skulls and bones of chiefs and members of their families and sub-chiefs and important personages only of the community, and the bones used are only the larger bones of the arms and legs; skulls will, so far as possible, be used for the purpose in preference to the other bones. These skulls and bones are taken 
from wherever they may then happen to be; some of them will be in burial boxes on trees, ${ }^{1}$ some may be in graves underground, and some may be hung up in the village emone; though it may here be mentioned that those underground and in the emone are not, as I shall show later, in their original places of sepulture.

Finally croton leaves, tied in sheaves, are arranged round the posts below the skulls and bones, so as to decorate the posts down to the ground.

One other specially important matter must here be mentioned. There will probably be in or by the edge of the village enclosure a high box-shaped wooden burial platform, ${ }^{2}$ supported on poles, and containing the skull and all the bones of a chief, these platforms and a special sort of tree being, as will be explained later on, the only places where they and their families and important personages are originally buried. If so, the people add to the bones on this platform such of the other skulls and special arm and leg bones, collected as above mentioned, as are not required for decorating the posts. If, as is most improbable, there is no such burial platform, then they erect one, and upon it place all the available skulls and special bones not required for the posts.

These various preparations bring us to the evening before the day of the feast, upon which evening the women, married and unmarried, of the community, whose families have supplied pigs for the feast, dance

1 See note on p. 256 as to the use by me of the terms "grave," "bury" and "burial."

2 Ibid. 
together in full dancing decorations in the village enclosure, beginning at about sundown, and, if weather permits, dancing all through the night. There is no ceremony connected with this dancing.

The next day is the feast day. The guests are in the special guest houses outside the village, where they are dressing for the dance. They have probably arrived the day before, in which case they may have come into the village to watch the women dancing in the evening; but they are not regarded as having formally arrived. These guests include married and unmarried men, women and children, nobody of the invited community being left behind, except old men and women who cannot walk. The women have brought with them their carrying bags, in which they carry all their men's and their own goods (e.g., knives, feathers, ornaments, etc.), including not only the things used for the ceremony, but all their other portable property, which they do not wish to expose to risk of theft by leaving at home.

They have also brought special ornamental bags to be used in the dance as mentioned below.

The people of the village in the meantime erect one, two, or three (generally three) trees in a group in the very centre of the village enclosure.

And now come the successive ceremonies of the feast, in which both married and unmarried men and women take part; in describing these ceremonies I will call the people of the community giving the feast the "hosts," and the visitors attending it the "guests."

First : All or nearly all the men hosts go in a body 
out of the village to the guests' houses, singing as they go. They are all fully ornamented for a feast, but do not wear their special dancing ornaments, and they do not carry their spears, or as a rule any other weapons. Each chief's ornaments include a bunch of black cassowary feathers tied round his head behind, and falling down over his shoulders, this being his distinctive ornament; but otherwise his ornaments do not differ from those of the rest, except probably as regards quantity and quality. The object of this visit is to ascertain if the guests are ready, and if they are not ready the men hosts wait until they are so. Then the men hosts return to the village, singing as before, and all the guests, men and women, follow them; but they do not sing, and they do not enter the village. The men hosts, on returning, retire to their houses and the view platforms, where also are the women hosts, thus leaving the village enclosure empty.

Second: All the women guests, except two, then enter the village. They are fully ornamented for the feast, but do not wear their special dancing ornaments. They all have large carrying bags on their backs, not the common ones of everyday use, but the ornamental ones; and in these they carry and show off all their own and their husbands' riches. other than what they respectively are actually wearing. They enter at one end of the village enclosure (I will hereafter call this the "entrance end") by the side of the end emone of the village (this may be the chief's true emone or it may be the secondary emone), 


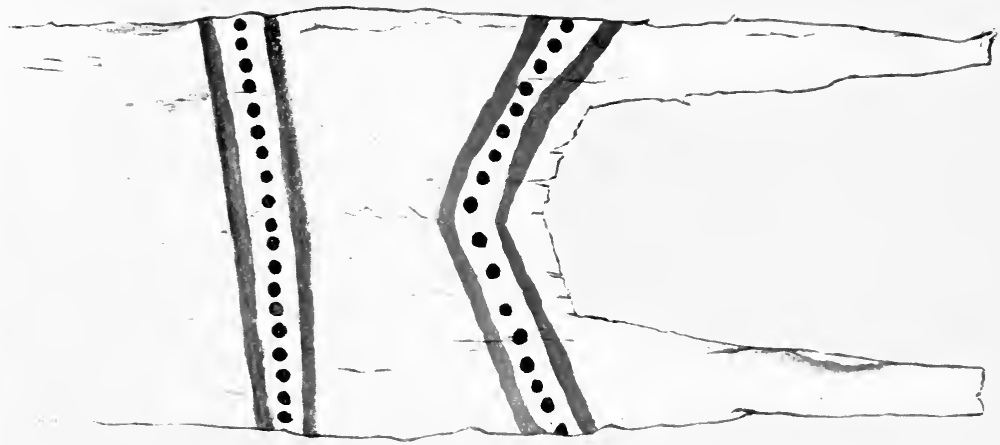

ㄴ.

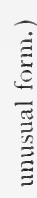

- $\bar{\pi}$

55

2.1

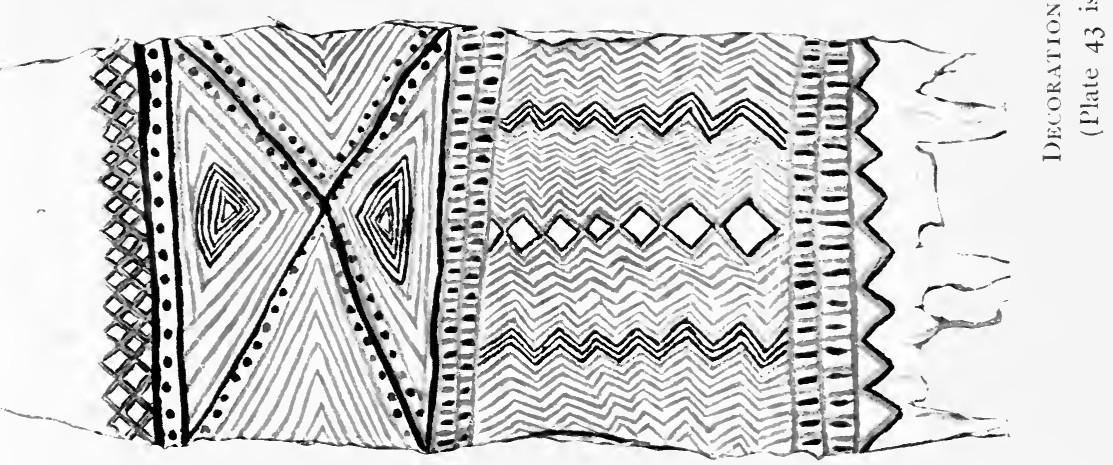



and walk in single file along one side of the village enclosure, and half of them walk round the other end (which I will call the "far end") in front of the emone there (which also will be either the true one or the other one), and back again along the other side, until there are two rows of them, vis-à-vis at opposite sides of the enclosure, none of them remaining at the far end in front of the emone there. If they are very numerous, there may be lines on both sides of the enclosure, stretching from end to end; whereas if they are few only, they would be in facing lines at the far end only of the enclosure. This is all done silently.

Third : All the women hosts, fully ornamented for a feast, but without special dancing ornaments, then enter the enclosure at the entrance end, and congregate at the far end of it, in front of the far emone, and between the two facing lines of women guests, and facing towards the centre of the enclosure. The group of them stretches as far forward towards the centre of the enclosure as their number allows ; but it will never extend beyond the special trees, which have been last erected in the centre. This also is done in silence.

Fourth: The two women guests excluded from the general entry now come in. They are presumably the wives of chiefs. They are also decorated for the feast, but without full dancing ornaments. Each of them, however, holds in her mouth something intended to give her a terrible appearance, probably two pairs of pigs' tusks, one pair curling, crescent-like, upwards, 
and the other pair similarly curling downwards, or a piece of cloth; but this is only carried by her for this particular scene of the performance, and not afterwards. Each of them also carries two spears, one in each hand. These two women rush into the village enclosure, one entering at each side of the emone at the entrance end. They run along the two sides of the enclosure, one at each side, in front of the lines of women guests already there (between them and the central group of host women), brandishing their spears as they do so, but in silence. When they reach the far end of the enclosure they meet each other in front of the emone there; and then, if that happens to be the true (chief's) emone, they brandish their spears in a hostile manner at the building, the spears sometimes even striking it, though they do not leave the women's hands, and there is probably a little pause or halt in their running for the purpose of this attack. They then pass each other, and return as they had come, still brandishing their spears, but each on the opposite side, until they are both at the entrance end of the enclosure. If the emone at this end is the true emone, then the attack is made upon it, instead of upon the other one. They then generally again pass each other, and go round the enclosure a second time, and again attack the emone exactly as before. During the first part of this performance the host women congregated in the far end of the enclosure are all dancing a sort of non-progressive goose step, there being, however, no singing. But, when the two guest women on the return journey 
of their second circuit reach the front row of the - host women, the latter advance in a body silently dancing (but not travelling so fast as the two guest women) down the enclosure, and so following the two

Far end.

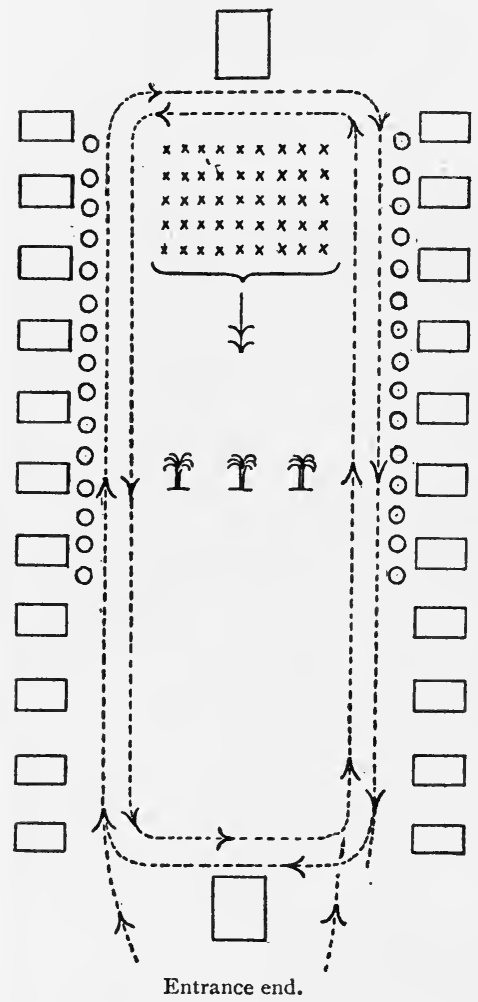

NOTES TO FIG. 7 .

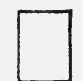

$=$ Two end emone of village.

$\square=$ Houses of village.

0 = Guest women (general body) in two facing lines.

$X=$ Host women in a group, all facing down the enclosure.

旅 = Three special trees (to be

1 afterwards knocked down).

$\ldots \rightarrow \ldots=$ Courses followed by the two special guest women in stage $4 \cdot$

$\longrightarrow$ = Course followed by host women in second part of stage 4 .

N.B.-The decorated posts are scattered about the village enclosure.

Fig. 7.-Diagram Illustrating

Positions of PEOPle DURING

Performance at Big Feast.

guest women, until they are all congregated at the entrance end of the enclosure. The positions of the dramatis personce up to and including the stage of proceedings lastly described will be better understood by reference to Fig. 7 and its accompanying notes. At 
the end of this stage the lines of guest women are still as shown; but the two special guest women and all the host women are at the entrance end of the enclosure.

Fifth : Such of the guest men as are not going to join in the real ultimate dance (see heading 9) enter the village at the entrance end, they also being fully ornamented, but not wearing their special dancing ornaments. They carry their spears, and perhaps in their other hands their clubs or adzes. Any chiefs who may be among them wear their black cassowary feather ornaments, like those of the host chiefs. They all advance along the enclosure, jumping and dancing and brandishing their spears, but not singing; and in front of them go all the host women, dancing as before, also in silence. This double body of people, host women in front, and guest men behind. advance en masse along the village enclosure. When, in doing this, the guest men reach the three last-erected special trees in the middle of the enclosure, they attack the trees with their spears, never letting the spears leave their hands, and with kicks, and thus try to knock the trees down. If they succeed in doing so, then this part of the performance is at an end, and these guest men disperse and spread about at both sides and ends of the village; but the host and guest women return from wherever they are to the entrance end. If the guest men's first attack on the trees is not successful, they pass them, and continue their advance, as before, to the far end of the enclosure and return back again in the other direction, the host women still dancing in front of them; and on this return journey 


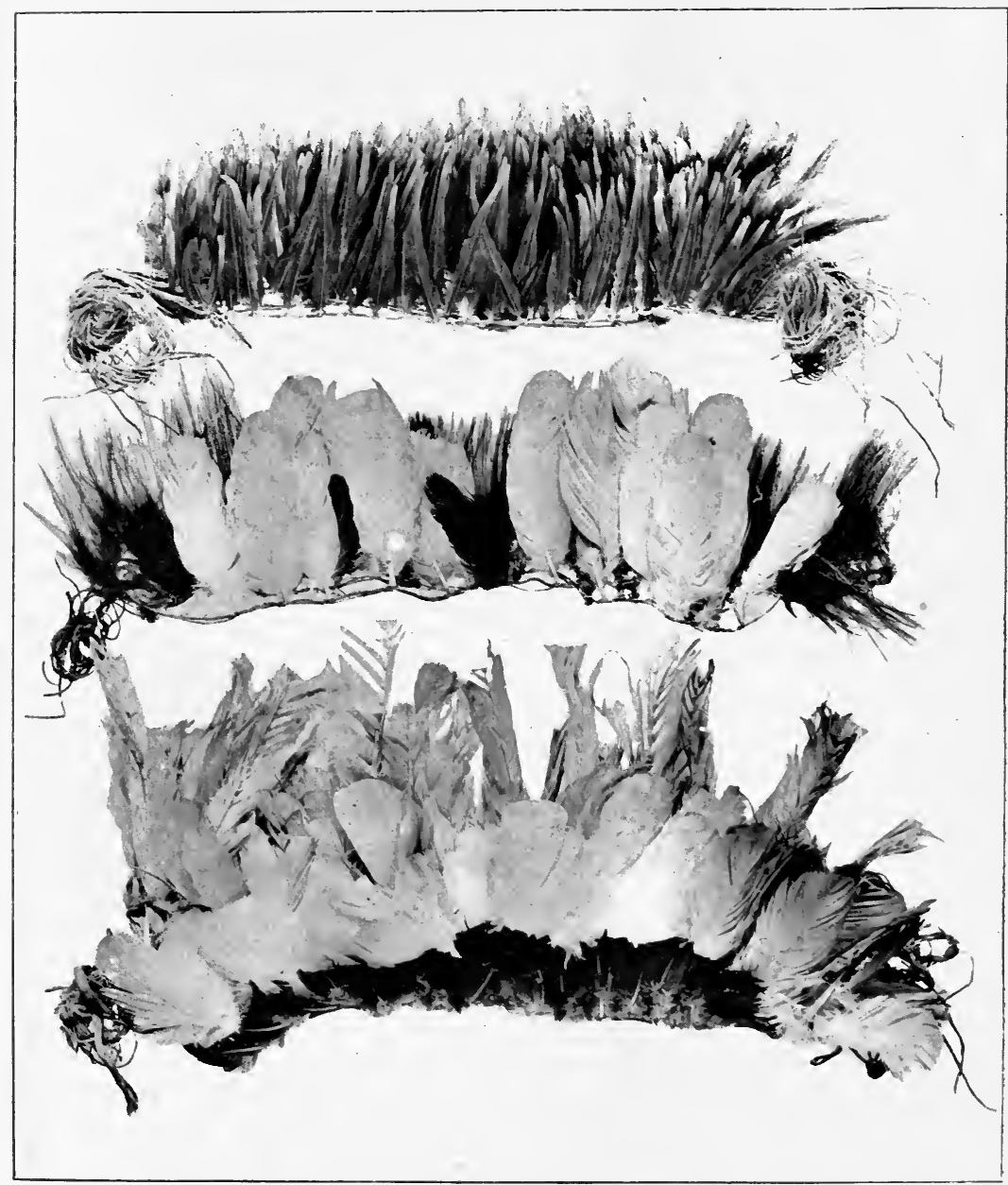

Head Feather OrNaments. 

they repeat their attack on the trees. If again un-successful, they go on to their starting point, and go a second time through the same performance as before, going up the enclosure, and, if necessary, down again ; and, if still unsuccessful, they will probably try a third time, the host women always dancing in front of them as before. The whole of this is one continuous movement, going on till the trees are down. If after the third double attempt the guest men have still been unsuccessful, they relinquish their efforts; and in that case the pig-killer of the hosts' village (as to whom see below) steps forward, and cuts down the trees with his adze. When the trees are down, the performance is at an end, the guest men retire, and the host and guest women return to the entrance end, as above stated.

Sixth: Such of the chiefs of the guests as do not intend to join in the real ultimate dance (heading 9) then step forward into the enclosure at the entrance end. Their number may be two or three or more. They wear their full dancing ornaments, including their black cassowary feather ornaments and the enormous feather erections on their heads, which for chiefs are even larger and heavier than for other people. They carry their drums, but not spears or clubs or adzes. The two special guest women who have already been mentioned and two other guest women, all with their full dancing ornaments, also come forward. A line is formed with the chiefs in the middle and the four women at the two ends. In front of this line are all the host women, still decorated as before, but without special dancing ornaments. Then the whole group, 
host women in front and the guest chiefs and their four attendant guest women in a line behind, dance forward along the enclosure. In doing, this, they face the direction in which they are progressing, and their progress is slow. This is done to the accompaniment of the beating by the dancing chiefs of their drums, but there is no singing. When the dancing party reach the far end of the enclosure, they go back again in the same way; and so on again until the chiefs (with the great weights they are carrying) are tired; then they stop. But the men hosts thereupon politely press them to go on again, giving them in fact a sort of complimentary encore, and this they will probably do. After about half-an-hour from the commencement of the dancing they finally stop. Then the chief of the clan in one of whose villages the dance is held comes forward and removes the heavy head-pieces from the dancing chiefs.

Seventh: An important ceremony now occurs. The chief of the clan cuts away the supports of the burial platform already mentioned, whereupon the platform falls to the ground, and the skulls and bones upon it roll on the ground. These are picked up, and the skulls and big arm and leg bones are put on one side. There is no singing or ceremony in connection with this. The platform is not rebuilt; and what is afterwards done with the skulls and bones will be seen hereafter.

Eighth: There is now a distribution among the chiefs and more important male guests of the yam, taro, sugar-cane and bananas, which at the time of the 
hanging up on the village posts were kept back and "put into the houses, and of tobacco. The chief of the clan, with help from others, makes a number of heaps of these things in the centre of the village enclosure, the number of heaps corresponding to the number of recipients. Then, standing successively before each of these heaps, he calls out in turn the names of the men who are to receive them, chiefs being given the first priority, and specially important people the next. Each man comes forward, usually bringing with him his wife or some other woman with a bag, picks up his heap, and takes it away. And so with all of them in turn, till all is finished. On each heap there is usually, but not always, a portion of a village pig, which has that morning been killed under the burial platform, before it was cut down. The guests, men and women, then return to the guest houses, where the women cook the food which has been given, and it is eaten by the men and themselves.

Ninth: The real dance now takes place, beginning perhaps at 9 or 10 in the evening, and lasting the whole night, and perhaps till ro o'clock the following morning. The dancing is done by some only of the guest men, and none of their women, and none of the hosts, either men or women, join in it. The dancers are all arrayed in full dancing ornaments, including their heavy head feather erections, and chiefs also wear their cassowary feathers ; and they all carry" their drums and spears, and sometimes clubs or adzes. After the dance has begun, the chief of the clan in whose village the dance occurs distributes, 
with assistance, among the more important of these dancers, especially chiefs, the skulls and bones which had been put on one side after the cutting down of the burial platform, and probably some or all of the skulls and bones which had been hung upon the big posts; and the dancers receiving these skulls and bones wear them as additional decoration upon their arms throughout the dance. Guest chiefs dance with the others, but owing to the heavy weight of the head ornaments they have to carry, they will be tired sooner than the others. The dancing party enter the village at the entrance end, walking backwards. Directly after they have entered the village they, still having their backs to it, begin to beat their drums, after doing which for a short time they turn round, and the dancing begins. The dancers beat their drums whilst dancing, but neither they nor the other people sing during the actual dancing. There are, however, intervals in the dancing (not the mere rest intervals, such as they have in Mekeo, and which they also have in Mafulu, but intervals which are themselves an actual part of the dance), and during these intervals the drums are not being beaten, and the dancers and the other people, hosts, guests, men and women, all sing. I shall have something more to say about dancing generally later on. At a subsequent stage the skulls and bones with which the dancers have been decorated, including those which had fallen from the burial platform, are all again hung up among the other skulls and bones on the big posts.

Tenth: This is the stage at which occur various 
Plate 45.

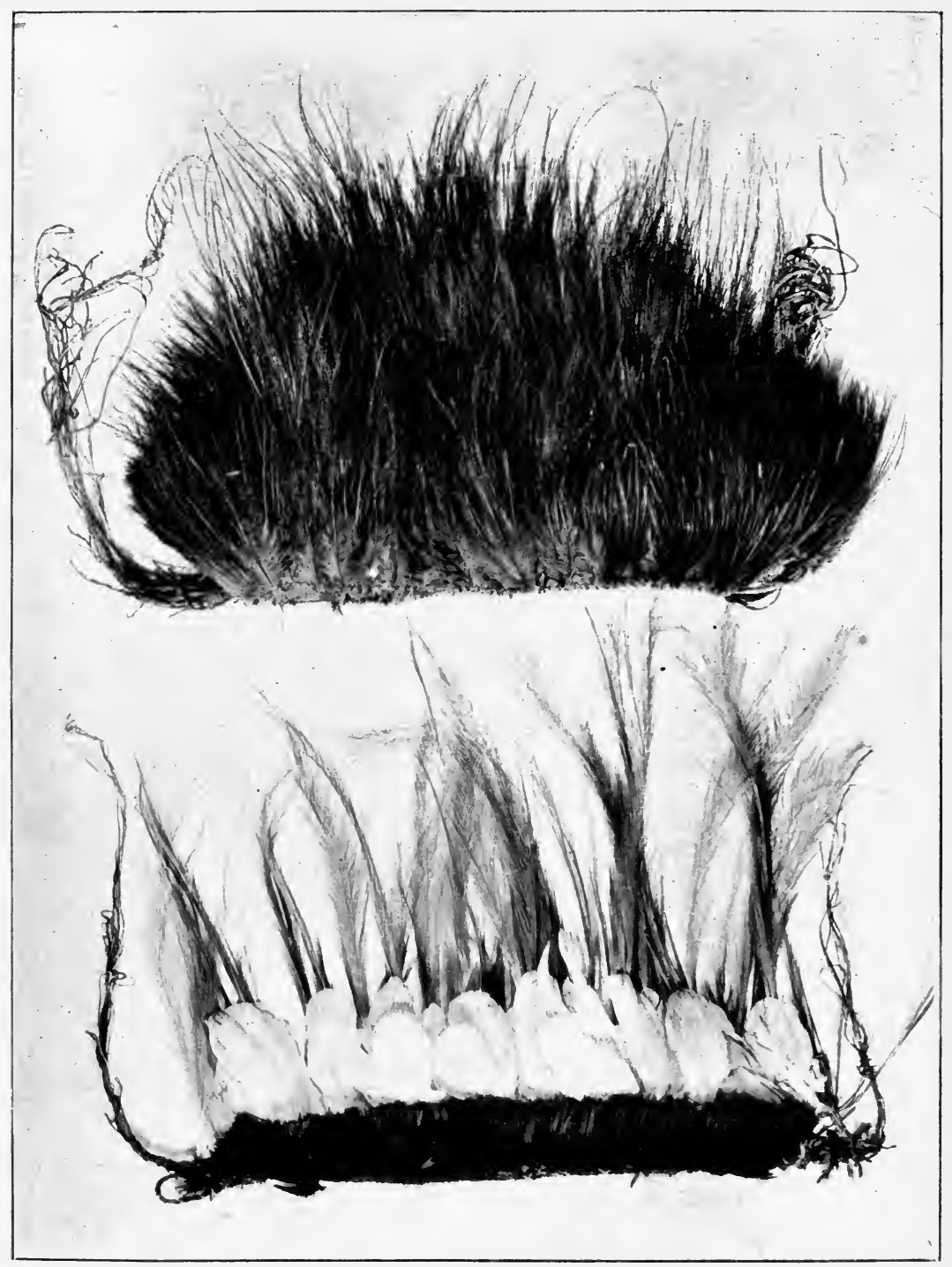

Heal Feather Ornaments. 

other ceremonies, which, though themselves quite distinct from that of the big feast, and performed, often several of them together, when there is no big feast, are also, some or all of them, generally or always introduced into it, as being a convenient occasion for them. The ceremonies in question are those connected with the assumption of the perineal band, admission to the emone and the giving of the right to carry a drum and dance, that of nose-piercing, and that on the devolution of chieftainship. The nosepiercing ceremony has already been described. The others will be dealt with later.

Eleventh: Next comes the general distribution among the guests of the vegetables and fruits, including all those which have been hung up and displayed, as above described, and the ine fruit, prepared in two ways, and malage fruit. Every male guest who has joined in the real dance is, speaking generally, entitled to have a share; though sometimes, where there are two or three members of one family, shares may be given to one or two of them only, instead of to each. The chiefs of the community giving the feast work together in carrying out the distribution. The various things are collected into a number of heaps about the village, the number of heaps corresponding to the number of portions to be distributed; and each heap contains something of everything. Excluded from these heaps, however, are the ine seeds which have been put on strings and preserved separately, as before explained. For these are erected stakes about ro feet high, round which the strings of seeds 
are twined. The number of these stakes is less than the number of heaps, because they are only planted near to the heaps which contain none of the ine fruit prepared the other way, so that each dancing guest gets some of this fruit, done in either one way or the other. Then the chiefs of the hosts' community stand round one of the heaps and shout wildly, calling upon the recipient. This may be done by name, or it may in the case of a chief be done by the name of a spot, say a mound or hollow, adjoining the village from which he comes. Here, again, priority is given first to chiefs, and next to important personages. The man so called upon comes running forward with his wife or another woman, picks up his vegetables and fruit, and runs back again with them. Then the chiefs go on to another heap, and again afterwards to the others, one by one, going through the same process in each case, until everything has been distributed. Some of the women then go back to their own villages, carrying with them a portion of the food which has been given to their husbands, but leaving the rest with the latter. Sometimes some of the guest men go home also. But anyone who is proposing to return to the village of the feast must leave some of his food, or bring food on his return, as no more will be given to him.

Twelfth: The next stage is the collection of the village pigs. This may take some time, as many of them are running about in the bush, and have to be caught; and some of them have been agisted out as above mentioned, and have to be fetched. This may involve a delay of a week or ten days, during which 
most or all of the guests remain, sleeping in their guest houses at night, and perhaps roaming about among other villages in the neighbourhood by day. During this interval there is neither singing nor dancing.

Thirteenth: The village pigs are all brought in alive, and placed under the houses of the village, each pig having its legs tied up and being tied to the house. When all is ready, the chief of the clan announces that the killing of the pigs will take place on the following morning.

Fourteenth: The next morning all the people, both hosts and guests, are in the village to watch the pigkilling; and people from other communities, who are not guests, and will not receive any pig, come too. The pigs are brought out one by one, and killed by hitting them on the head with clubs or adzes or anything else. This is not a chief's duty. There is a man who is the recognised pig-killer, and who, as already stated, will probably be a man of some position, though not either a chief or a sub-chief. Where there are many pigs, as at the big feast, there will be a number of other men helping him. Each pig is killed on the site of the burial platform which has been cut down. As the pigs are killed, their bodies are carried away and placed on the ground in a row, commencing at the end of the village enclosure, and forming a central line along it ; and it is usual also to place upon the row of dead pigs a continuous line of long thin poles, laid end to end, which are afterwards kept tied to the emone as a record of the total length of the line of pigs, and thus 
of the number of pigs killed. The number of pigs killed is generally very large in proportion to the size of the community giving the feast, much more so than is the case in the villages of Mekeo and the coast. It may be anything from fifty to over one hundred; in fact at a recent feast given by a community of seven villages, having between them about a hundred houses, they killed I 35 pigs. Some chiefs of the hosts' community then take some of the bones (not skulls) from the big posts, and dip them into the mouths of the pigs, from which the blood is flowing. They have been seen to dip one bone into several pigs. There does not appear to be any method of selection of the bones to be dipped. They then touch with the bones which have been so dipped the skulls and all the other bones on the posts, which include the skulls and other special bones of all the chiefs and members of their families and other prominent people buried in and by the villages of the community since the last previous big feast was held there. After this all the bones are again hung up on the posts. I may say here in advance that, when the feast is over, all the bones are removed from the posts ; and, the ceremony as regards those bones having been performed, they will never again be the subject of ceremonial observance. They, or some of them, may be hung up in the emone, but if so it is known that they are not to be used again for ceremonial purposes; or they may be put in a box in a tree, or hung up on a tree, not necessarily of the special species used for burying; or they may be simply flung away anywhere in the bush. Whilst the 
Plate 46.

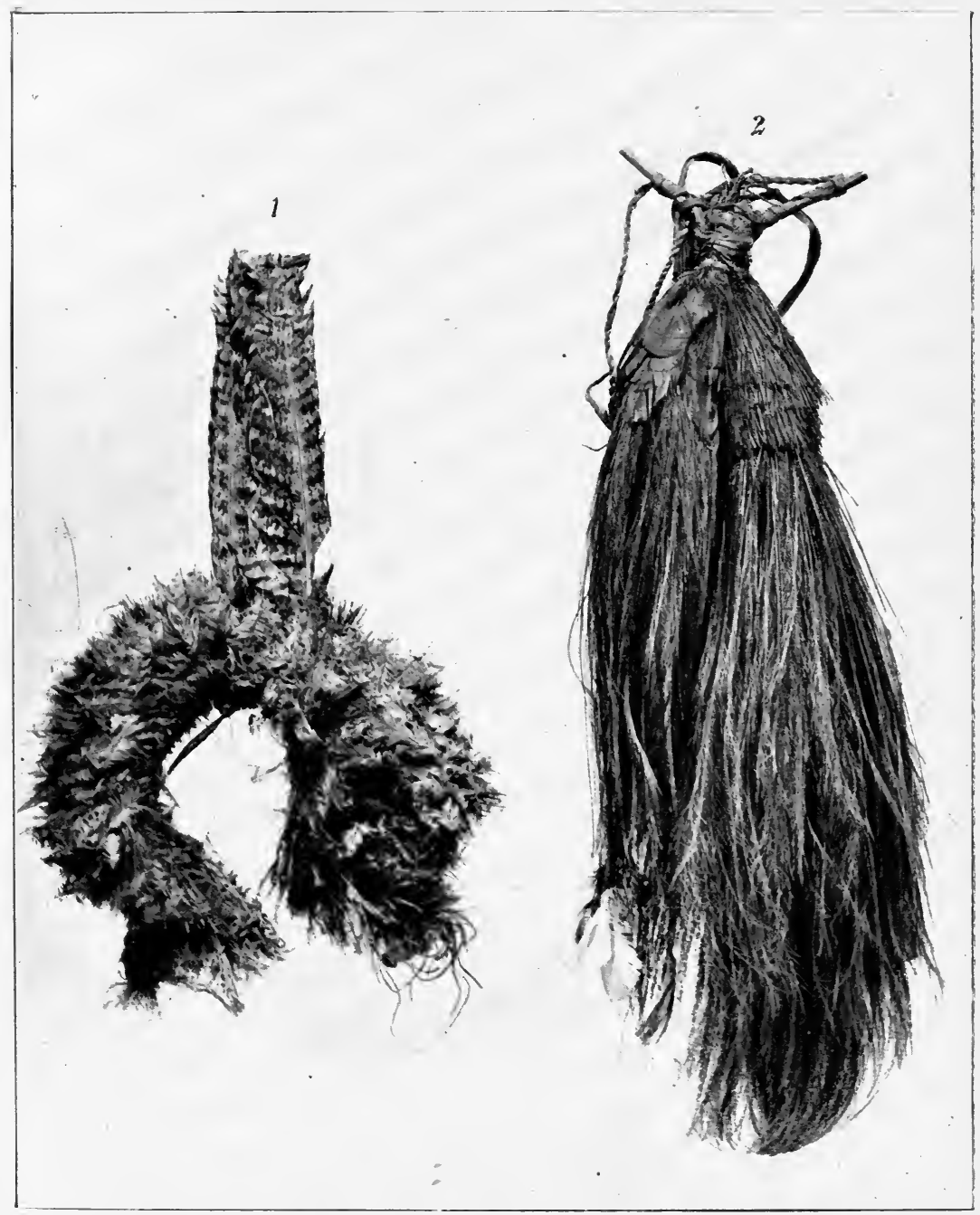

Fig. I.-Head Feather Ormanent.

, 2.-BACK ,, , 

bodies of the slain pigs lie in a line, and before the cutting up, it is the duty of each man who has had a pig fed up for him to pay the man who has done so, the payment probably being a string of dogs' teeth, or head feather ornaments, Next, the hosts set to work to cut up the pigs. This is not done by a chief or special person, nor is there any ceremony connected with it. Each pig is cut into seven parts, namely, (I) the head, $(2-5)$ the four legs, (6) the bowels and internal parts, and (7) the back and sides. I was told that each part of each pig is destined for a certain person, as arranged beforehand. It follows that, if there are, say, Ioo pigs, there are 700 predestined pieces, which are known and remembered, though there are no means of recording them. It is difficult to believe the truth of this, but I was assured that it was correct. The pieces of each pig are placed on banana leaves, by the side of the spot where the body had lain, and all the pieces are distributed among the male guests. Everybody who has given a pig knows the length of each part of it, though he could not express it in numerals. Each male guest has a piece given to him, which, if the feast be a return feast, will correspond in some way, which I could not understand, with what he had himself provided at the previous feast. But dancers receive larger and better portions than do mere singers. People who have fed up pigs for members of the hosts' community also receive portions. In the distribution of pig each man is called in turn as before, and in the same order of priority, and runs up and gets his piece of pig, and 
runs back with it; but in this case he is not accompanied by a woman.

Fifteenth: The feast is now over, and all the guests return to their homes, taking away with them everything that has been given to them.

Sixteenth: The village has, however, to undergo a process which I may perhaps call purification. As soon as possible after the guests have gone, the men of the community go off into the bush and capture wild pigs, for which purpose they may have to hunt for three or four days, or even for a week or more. They must have at least one pig, and they generally have two or more, even up to six. When caught, the pigs are brought alive into the village, and are killed upon the site of the cut-down burial platform, this being done by the pig-killer. The pigs are then cut up and eaten by the members of the villages of the community, those of the village itself eating their portions there, and those of the other villages taking their portions away and eating them in their own villages. Except as regards the killing of the pigs on the site of the grave, the whole performance appears to be quite informal. After the eating of the pigs, perhaps on the same day, or if, as is probable, the feast lasts until late in the evening, then on the next day, the women of the village clear away the filthy mess of blood and garbage by which the village enclosure is filled, and sweep the enclosure from end to end with branches of trees. Then the bulk of the villagers leave the village and go off into the gardens and the bush for a period of about six months. The feast has 
denuded the village of food, including even sweet potatoes, to which they have had no time to attend during the period before the feast, and which have been used up in the feeding of the village pigs required for it. New gardens are needed, and therefore new bush has to be cut down, and the land must be cleared and planted with various things, and especially with sweet potato. For this purpose it is requisite or usual for them to build temporary houses on the scene of their labours, in which the people live. The old people, however, remain in the village, as do also some of the younger ones, who have to tend the gardens close to it. At the end of the period they all return, and village life goes on as usual. What the idea in the native mind may be concerning what I have called the purification of the village is a matter upon which I was unable to find any clue, beyond what may be suspected from the actual facts of the proceeding ; but I think it probably has a superstitious origin. Although in theory all the village pigs have been killed and given to the guests at the big feast, there are always some left wandering in the bush, which have not been caught. These pigs are, however, never used in the purification ceremony, in which they always kill wild pigs only. It has been suggested to me that a reason for this may be that, if they killed village pigs, they would thereby advertise the fact that they had not killed and distributed all their village pigs at the big feast; but this hardly seems to be a satisfactory explanation. It clearly falls to the ground as regards present intent if, as I was 
told, there always is an unkilled residue of village pigs after a big feast. The practice of killing wild pigs only would seem to associate itself with the fact that pigs killed at this ceremony are eaten in the village itself, for there seems to be no doubt that among the Mafulu people village pigs are never eaten in their own village on ceremonial occasions; and indeed it seems doubtful whether they are ever eaten there at all.

In fact, it appears to be a general custom in connection with all ceremonial feasts to which outside guests are invited, to kill village pigs only at the feast, and for these to be given to the guests to be eaten by them in their own villages, and afterwards to have a second feast, to which outside guests are not invited, and at which wild pigs are killed, and eaten by the. villagers themselves within the village.

The pig-killing is generally, and perhaps always, done in the morning.

It is thought by the Mafulu Fathers of the Mission as regards the subsequent partial desertion of the village that, although it is only partial, and although there is a practical reason for it, it is based upon superstition, and is regarded by the people as being a formal leaving of the village, pending its complete purification.

Plates 67 to 70 are reproductions of four photographs which Father Clauser was good enough to give me, the two former ones having been taken at the big feast held in the village of Amalala in the year 1909 and the two latter prior to and at a big feast held in the village of Seluku. 


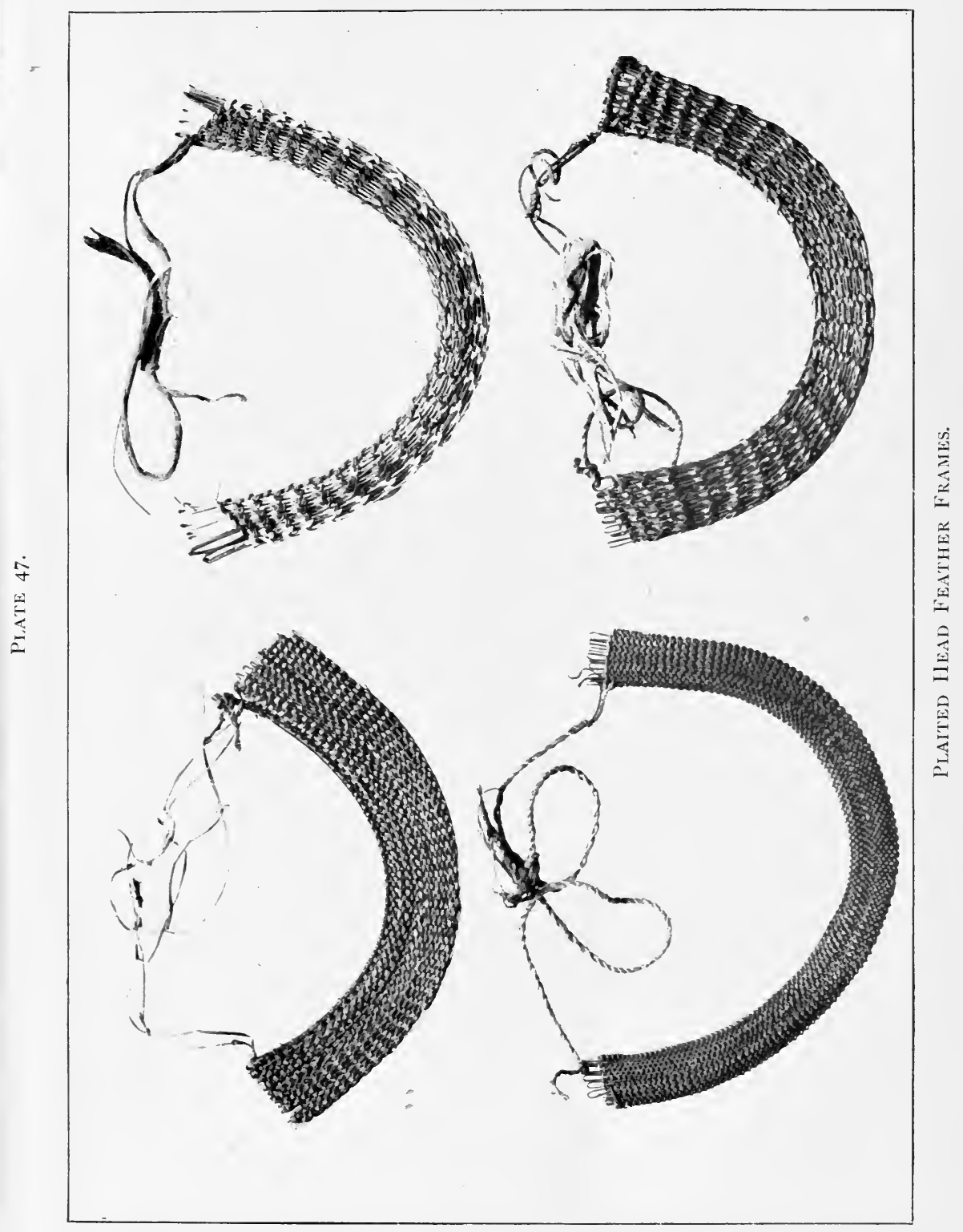



I have thought it better to avoid the insertion of - frequent, and perhaps somewhat confusing, references to these plates in the body of my notes upon the feast, and to take the plates separately, drawing attention to what appear to be points of interest in them.

Plate 67 represents the scene at Amalala immediately prior to or during the general distribution of vegetables and fruits (ante heading I I). A comparison of this scene with the village in its normal condition, as shown in Plates 56 and 57 , gives some idea of the very extensive and elaborate preparations which are made for the feast. On the right hand side are seen some view platforms, and beyond them on the same side is a normal house. Here and there are the big posts surrounded with bamboo stems (notice these posts denuded of their bamboo appendages still remaining in the village enclosure as shown in Plates 56 and 57). Some of the vegetables are seen still hanging upon these post clusters, and near the base of two of them are seen the sheaves of croton leaves. There are apparently no skulls and bones upon the posts seen in the plate, but possibly the re-hanging of these had not been attended to when the photo was taken, or perhaps they had been suspended to other posts not shown in the photograph. Upon the ground are the heaps of vegetables, and close to some of these are the stakes round which are twined strings of seeds of the ine Pandanus.

Plate 68 is a photograph taken after the subsequent pig-killing, and shows the pigs' bodies lying in a row along the centre of the village enclosure, with the 
measuring line of poles placed above them. It will be noticed that the elaborate view platforms have been cleared away, but that the bamboo stems have not yet been removed from their central posts.

Plate 69 represents a scene at Seluku prior to a big feast then about to be held. The view platforms have not yet been erected. But the post clusters have been erected, and the yams and croton leaves have been hung upon them. In the centre of the village enclosure is the chief's grave platform, which will be cut down during the festivities in the way above described.

The bones of the chief are in the box-like receptacle at the top of the structure, and the receptacle rather further down (underneath the other one) contains the bones of a chief's child.

Plate 70 shows five men at the Seluku feast with full dancing ornaments, including the great feather head ornaments. One of them has donned a piece of European calico, and the one to the extreme right appears to have done the same. These would doubtless be regarded as highly decorative additions. A few long thin dancing ribbons can be seen hanging from their belts. The elaborate carved (turtle?) shell ornament hanging over the breast of the man to the left is certainly not of Mafulu make, and has probably come from the coast. I never saw anything like it when I was at Mafulu. The two boys in front are holding the ornament of elaborately prepared strings of feathers hung upon a stick, and worn by dancers on their backs, and into which the best feathers are generally put. 


\section{CHAPTER IX}

SOME OTHER CEREMONIES AND FEASTS

Ceremony on Birth.

THERE is no ceremony on the birth of a child, except in the case of the first-born of a chief. On this occasion the women of a neighbouring community are invited. They come in their full dancing ornaments, and armed in both hands with spears and either clubs or adzes. They rush into the village, first to the chief's house and then to his emone; and at each of these they make a warlike demonstration, actually hurling their spears at the buildings with such force that the spears sometimes go through the thatch of the roof. Then follows a distribution of vegetables among the visitors, after which one, two, or three village pigs are killed under a chief's burial platform or on the site of a past one, cut up in the ordinary way; as at the big feast, given to the visitors and taken away by them, and the ceremony is over. There is no singing. ${ }^{1}$

1 It is the custom among the Kuni people when any woman (not merely the wife of a chief) has her first baby for the women of her own village, and probably of some neighbouring villages also, to assemble in the village and to attack her house and the village club-house with darts, 


\section{Ceremony on Assumption of Perineal Band.}

This ceremony is performed for both boys and girls, and usually for several at one time.

The children are heavily adorned with ornaments, consisting, as a rule, chiefly of dogs' teeth, which are hung round their necks, or over their foreheads; and they usually have belts of dogs' teeth round their waists. Any persons may decorate the children.

Prior to the ceremony a number of box-like receptacles are erected in the village by the children's relatives, there being one receptacle for each child for whom the ceremony is to be performed. These receptacles are made with upright corner poles 8 or io feet high, boxed in with cross-pieces of wood up to a height of 5 or 6 feet. In these receptacles are put yams and taro, upon their upright poles are hung bananas and upon their cross-pieces of wood are hung lengths of sugar-cane; all this being done by the families of the children.

Guests are invited from some other community or

which the women throw with their hands at the roofs. At Ido-ido I saw that the roofs of the club-house and of some of the ordinary houses had a number of these darts sticking into them. The darts were made out of twigs of trees, and were about five or six feet long; and each of them had a bunch of grass tied in a whorl at or near its head, and some of them had a similar bunch similarly tied at or near its middle. See also Dr. Seligmann's reference (Melanesians of British New Guinea, p. 298) to the Roro custom for warriors, when returning from a successful campaign, to throw their spears at the roof and sides of the marea. In Mekeo there is no corresponding ceremony on the birth of a first child; but men, women and children of the village collect by the house and sing all through the night ; and in the morning the woman's husband will kill a pig or dog for them, which they cook and eat without ceremony. 


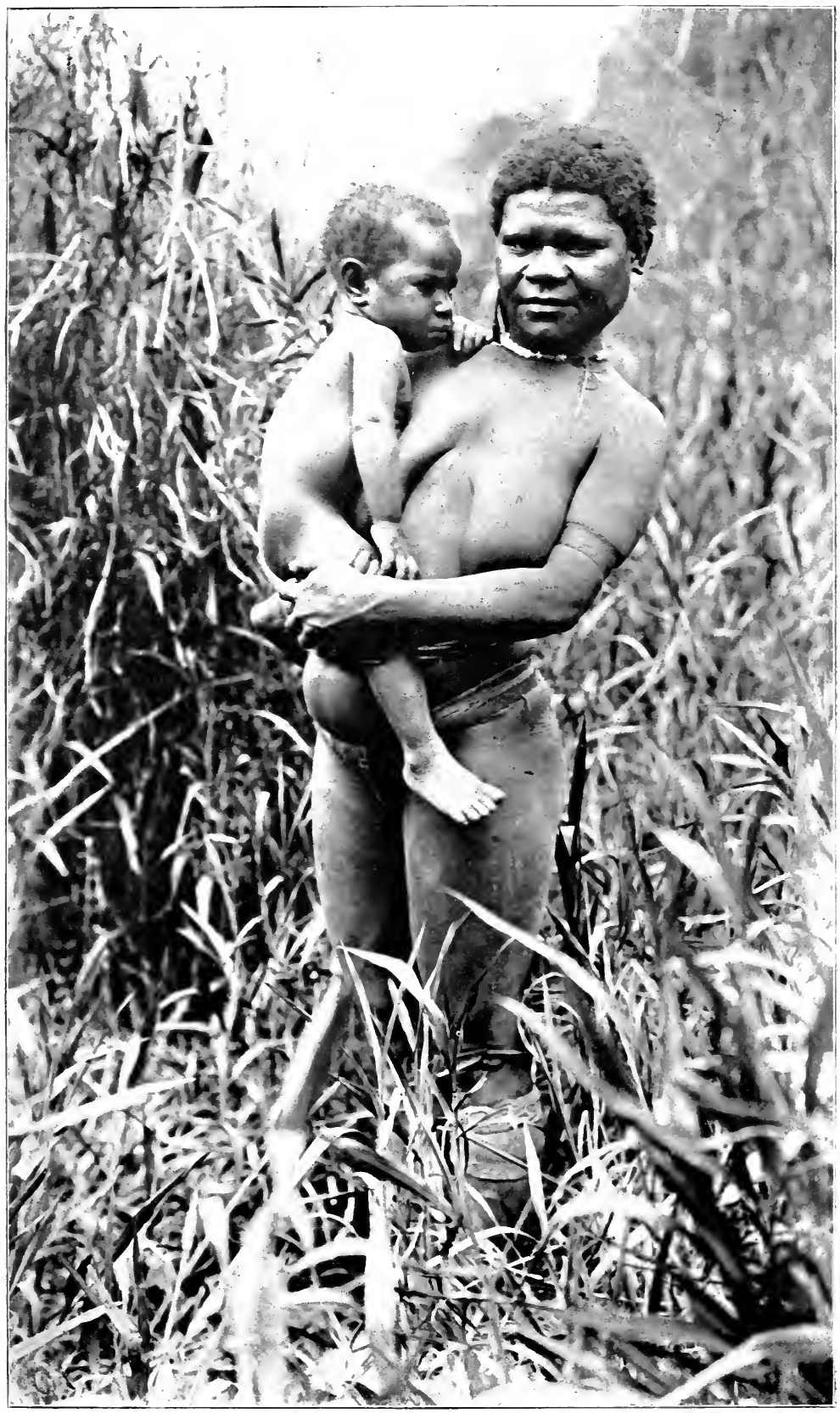

MOTHER AND BABY. 

communities. There is a dance, in which only people from outside communities take part. A village pig must be provided by the family of each child. Each of these pigs is killed by the pig-killer under a chief's platform grave, or, if no such platform then exists, upon the site of one, and is cut up. Before the cutting-up, however, the child in each case stands upon the body of the pig, and whilst he so stands he is dressed with a feather ornament put over his head, but which, instead of being tied up in the usual way at the back of the head, is left with the ends hanging down over his shoulders. The putting on of this ornament is not a chief's duty, but is done for each child by a certain person who has bought the pig from that child's family.

Plate 7 I shows a little girl upon whom the perineal band ceremony has just been performed. She has a string of dogs' teeth over her forehead, and a belt of dogs' teeth round her waist, an enormous crescent-shell ornament, some long pigtails, and on her head is the feather ornament, which hangs down at the sides over her shoulders. Plate 72 is a scene taken at the feast held in connection with the performance of the ceremony upon her and some other children.

I could not find out who the person who buys the pig and performs the ceremony would ordinarily be, nor what motive he has for buying and paying for a pig which is about to be killed and cut up and distributed amongst other people; and I am convinced that there must be something further behind the matter, which I have been unable to ascertain. I may say 
that, knowing that among the Roro and Mekeo people a brother or other male relative of the child's mother takes a prominent part in the perineal band ceremony, being the recipient of the dog or pig which is killed, and the person who puts the band upon the boy, I specially enquired as to any similar relationship on the part of the person who buys the pig and performs the ceremony among the Mafulu; but I could find no trace of anything of the sort. ${ }^{1} \quad$ Nor, as already stated, could I find any system of service being rendered by a boy to his maternal uncle, such as exists among the Koita, ${ }^{2}$ nor anything in the nature of the Koita Heni ceremony, described by Dr. Seligmann. ${ }^{3}$

It will be seen that this purchasing of the pig by a person who takes a prominent part in the ceremony affecting an individual appears in other ceremonies of that nature among the Mafulu.

Following this performance there is a general distribution among the people, including both visitors and members of the village, of the various vegetables and fruits, and among the visitors only of the portions of village pig. The vegetables are eaten then and there, but the visitors take away the pig for eating in their own villages. The actual putting on by the child

${ }_{1}$ Dr. Seligmann refers to this custom among the Roro people (Melanesians of British Nerw Guinea, p. 256), and there is no doubt that it exists among the Mekeo people also. Father Desnoes, of the Sacred Heart Mission, told me that in Mekeo, though the pig used to be given when the boy adopted his perineal band at the age of four, five, six, or seven, it is now generally given earlier. The pig is there regarded as the price paid for the child, and is called the child's engifunga.

${ }^{2}$ Seligmann's Melanesians of British New Guinea, p. 67.

3 Ibid., p. 71. 
of his perineal band is done afterwards without further ceremony.

The same ceremony is observed in the case of the son or daughter of a chief, except that in this case the child is more fully decorated, the family give two or more pigs, there are more visitors, and the whole ceremony is on a larger scale; also that, after the performance of standing on the dead pig and receiving the feather ornament, the child is placed standing on a platform, which may be only 5 or 6 feet high, but may be as much as I 5 feet, though no further ceremony appears to be performed whilst it is on that platform. If children of ordinary people undergo the ceremony at the same time as a chief's child, they apparently stand on the platform also.

When the ceremony is performed at a big feast, it is substantially the same as that above described, subject to certain variations, which almost naturally arise from the change of conditions. There is no special dancing, as distinguished from the dancing programme of the big feast. The vegetable food provided will be included in the general stock, so that the people of the village will not share in it; and the ceremony of standing on the pig is postponed till a later day, and on that day, the child, having worn his special ornaments, other than the feather ornament, at the big feast, will not again wear them when he stands on the pig, though his feather ornament is put upon him on that later day.

It may be mentioned that this perineal band ceremony and all the other ceremonies relating personally to both 
children and adults, if not performed at a big feast, may be performed together, the people concerned in each ceremony being taken more or less in batches; and indeed this generally is so. But in that case each class of ceremony would be performed separately. One person may have more than one ceremony performed for him on the same occasion, but if so a separate pig must be provided in respect of each of these ceremonies, and there must be a separate receptacle and a separate supply of food in respect of each of them, though it does not follow that the total amount of food to be provided, other than pig, is proportionately increased.

At a subsequent date there will be a purification ceremony, at which a wild pig or pigs will be killed. and eaten by the villagers; though, if the perineal band ceremony has taken place during a big feast, the purification ceremony in connection with the latter will be the only one to take place.

There is no system of seclusion of either boys or girls on attaining puberty, or in connection with initiation, or on attaining a marriageable age. Nor is there any initiation ceremony, or wearing of ceremonial masks, or use of bull-roarers. The custom by which chiefs' children, when assuming the perineal band, are made to stand on a platform reminds one, however, of the Hood Peninsular custom for girls to stand on a dubu platform for the initiation ceremony, as referred to by Dr. Seligmann. ${ }^{1}$

1 Melanesians of British New Guinea, p. 2 I. 


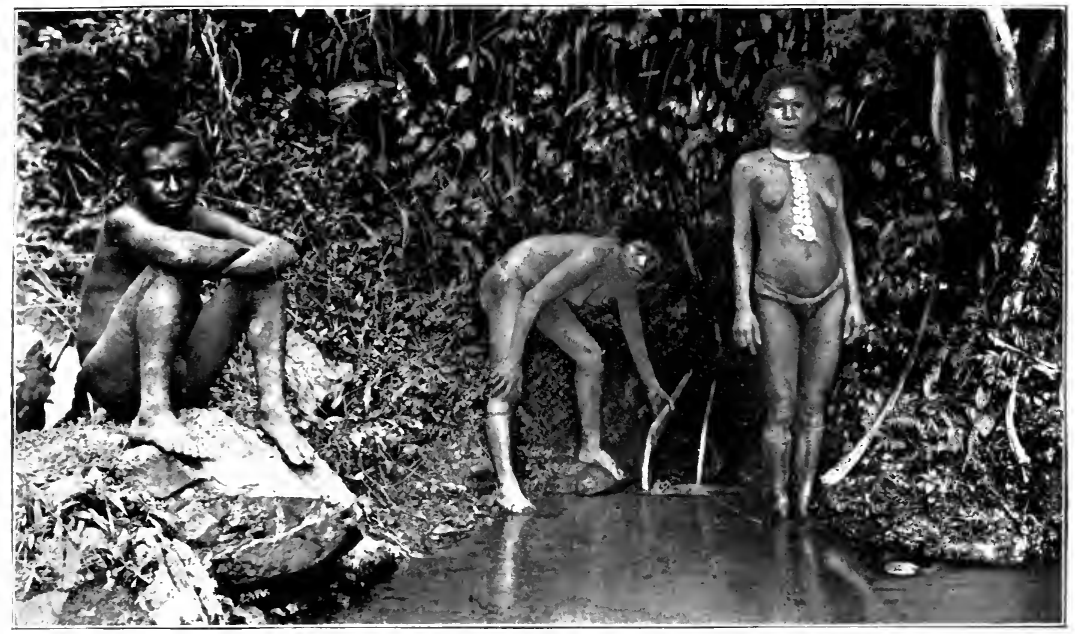

AT THE SPRING.

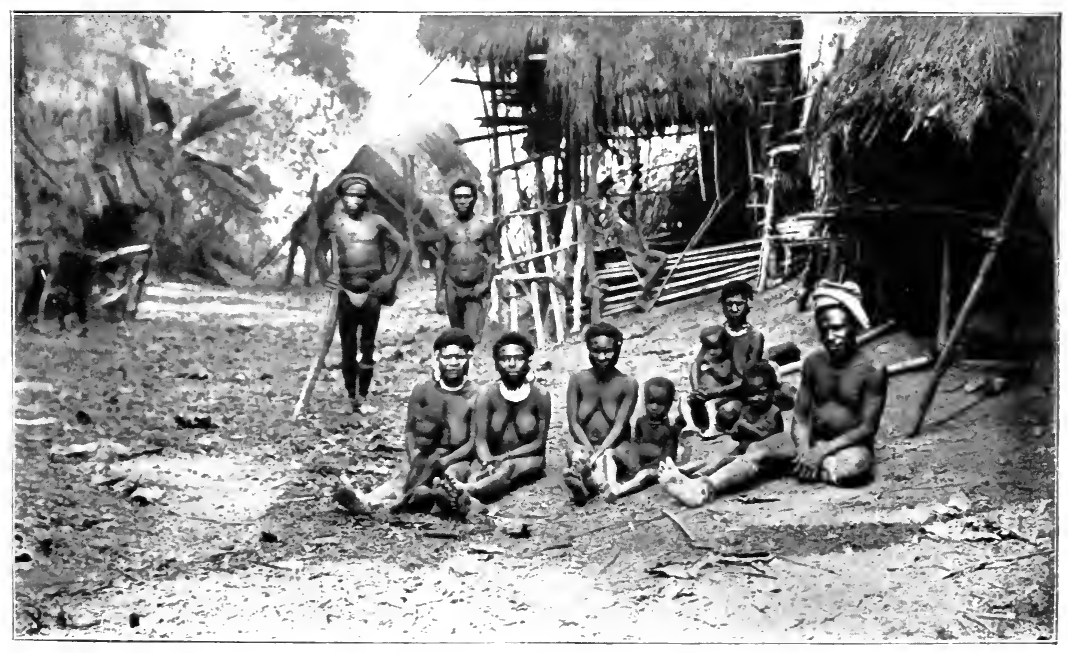

A Social Gathering. 



\section{Ceremony on Admission to Emone.}

Both boys and girls must undergo a ceremony before being allowed to enter the emone. It generally takes place when they are two, three, or four years old. The preliminary decoration of the child is similar to that adopted for the perineal band ceremony, except that, if the child has lost either of its parents, this decoration is omitted. The erection of receptacles and provision of food and pigs, and the invitation of guests and dancing, and the killing of the pigs are the same as in the case of the other ceremony; also each child has to stand on the pig which his people provide for him.

There is, however, no putting on of a feather ornament, but instead of it the following performance takes place :-Each child has been carried by its mother or father or other relative, but is taken from that person by the man who has bought the pig. This man places the child on the dead pig; then he immediately picks the child up again, and runs with it to one of the emone, upon the platform of which two rows of men are sitting, and hands it to the man at the end of one of the rows. The child is then rapidly passed from hand to hand along that row, and then along the other row, after which it is returned to its carrier, who runs with it to the other emone, on which also two rows of men are sitting, and where a similar performance takes place. During all this performance there is much shouting and calling out to the child-carrier to hurry. Finally, when the child is 
again handed back to this man, he returns it to its parents, and the ceremony is finished.

The ceremony in the case of a chief's child seems to be the same as that for other children, the platform business of the perineal band ceremony being apparently omitted in this case.

If the ceremony is performed at a big feast, the variations are substantially similar to those of the perineal band ceremony ; and in particular the placing of the child on the pig, and the running with it to the emone, are postponed to a later date.

The observations as to the subsequent purification in connection with the perineal band ceremony apply to this ceremony also.

It will be noticed that girls are included in this admission to the emone. When a girl has undergone the admission ceremony she has free entry into the emone-except that she must not sleep there-until she formally receives her perineal band, upon which her permission to enter the emone ceases.

\section{Ceremony Conferring Right to use Drum and Dance.}

This ceremony also applies to both boys and girls; but I omitted to ascertain the age at which it usually occurs. It is similar to the perineal band ceremony, except that the child is dressed in dance ornaments (though not the fullest formal dance ornaments), until we reach the stage of standing on the pig, and putting on of the feather ornament, which is 
omitted; and, instead of it, the person who has bought the pig places the child upon it, and then for a short time beats a drum, after which he gives the drum to the child, who also beats it, and then returns it to him.

I cannot say whether in this case there is any variation of the ceremony as regards a chief's child; but I do not think there is.

Here again I believe that, when the ceremony takes place at a big feast, the variations are similar to those above described, and in particular the standing on the pig and drum-beating are postponed.

The observations as to the subsequent purification in connection with the perineal band ceremony apply to this one also.

\section{Ceremony on Devolution of Chieftainship}

When chieftainship devolves on the death of a chief to his successor, there is no ceremony connected with the devolution. ${ }^{1}$

When a chief resigns in his lifetime, however, there is a ceremony. There does not appear to be a special dance and feast connected with this, it being always tacked on to some other ceremony or group of ceremonies. This particular ceremony does not, in fact, begin until after the pig-killing. The retiring chief will have provided one or more pigs for the purpose of his ceremony, and these will have been killed with the others. He addresses the people and

1 In Mekeo such a devolution of chieftainship is the occasion for a very large feast. 
tells them that he is giving up his office and transferring it to his successor; but in doing so he says nothing about that successor's title to succeed, that being always known and recognised. $\mathrm{He}$ then sits on his pig, and hands to his successor a bamboo knife, such as is used for the cutting up of pigs. The successor, having received the knife, takes the place of the retiring chief on the pig, and tells the people that he accepts the office of chief; after which he goes round to all the pigs which are there in connection with all the various ceremonies to be gone through, one after another, and in each case makes with the knife just given to him a small slit at the end of the mouth of each pig. ${ }^{1}$ This act is regarded as a performance by the new chief of a chief's office; and, as under present customs the killing of the pig is commonly done by the pig-killer, and the cutting of it up is done by anybody, one is tempted to wonder whether the ceremony points to some chief's duty of the past, which has ceased to exist, or to some unknown origin of the status of the pig-killer.

Ceremony on Building of a New Emone.

The usual occasion for the building of a new emone is an impending big feast, the then existing emone in the village being out of repair, or there being then no

1 This ceremony is different from the Mekeo ceremony on the elevation by a chief of his successor to a joint chieftainship, of which some particulars were given to me by Father Egedi; but there is an element of similarity to a Mekeo custom for the new chief, after the pigs have been killed and partly cut up by someone else, to cut the backs of the pigs in slices. 
Plate ji.

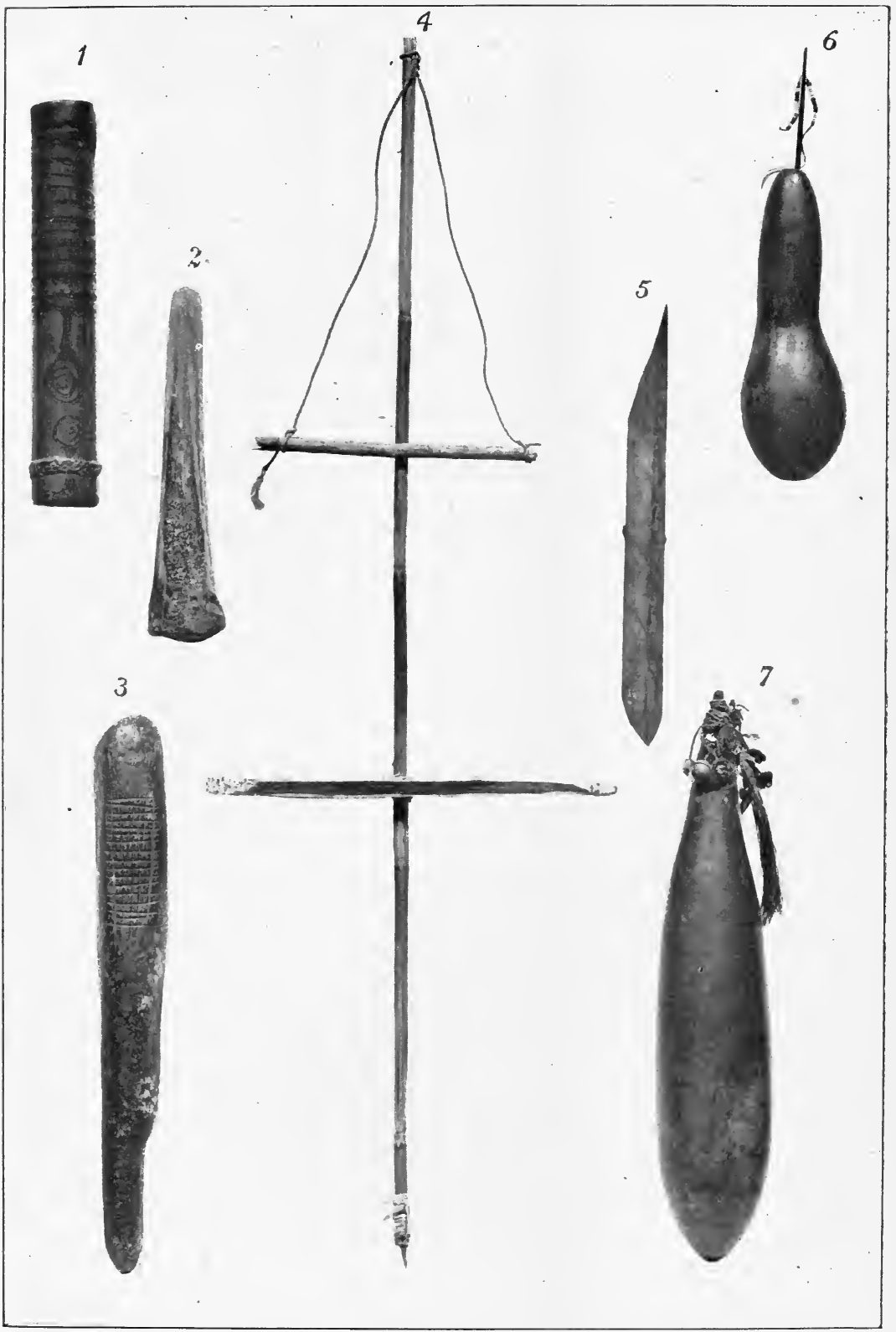

Fig. I.-Small Sioking Pipe (an unusual form).

,, 2.-Pig-bone Scraping Implement.

, 3.-Stone Bark Cloth Beater.
Fig. 4.-Drilling Implenent.

,, 5.-BAMBoo KNife.

,, 6 and 7.-Lime Gourds

(used for betel chewing). 

true emone in the village. But emone are built at other times also.

The actual building of the emone is carried out by the whole clan without ceremony; but when it is finished they erect tall slender straight-stemmed tree poles, passing through the roof of the emone, and to these they tie bunches of croton leaves. When the emone is being built in anticipation of a big feast, these poles are like, and in fact are part of the series of, the poles erected for the purpose of the feast, as above described. Croton leaves are also attached to poles after the repairing of a then existing emone.

In the case of a new emone, after its completion they light a fire in it, and in that fire cook a wild pig ; vegetable food is provided, and the clan, including members of the village and of other villages, have a little clan feast of the vegetables, followed by a cutting up and distribution of the pig. But there is no dancing. 


\title{
CHAPTER $\mathrm{X}$
}

\author{
MATRIMONIAL AND SEXUAL
}

A воу is regarded as having reached a marriageable age at about 16,17 , or 18 , and the age for a girl is a few years younger. They do not as a rule marry before they have received their perineal bands; but there does not appear to be any definite custom against their doing so; nor are there any acts which must be performed to qualify for marriage, nor any indications by dress or ornament or otherwise that a boy or girl has attained a marriageable age.

Marriages are usually contracted with women of another community, though sometimes the wife will belong to a village of another clan in the same community. Very rarely only is she of another village of the same clan, and still more rarely is she of the same village, clan exogamy being the rule, and marriages within the clan, and still more within the village, being regarded as irregular and undesirable, and people who have contracted them being considered as having done wrong.

There does not appear to be any system of special matrimonial relationship between any communities; and the mode described below, by which a youth will 
by lighting a fire decide in which direction he must travel to seek a wife, would be hardly consistent with any such system.

They have their prohibitive rules of consanguinity; but these are based merely upon the number of generations between either party and the common ancestor. The number of degrees within which prohibition applies in this way is two, thus taking it to the grandparent; and the result is that no man or woman may properly marry any descendant of his or her paternal or maternal grandfather or grandmother, however distant the actual relationship of the persons concerned may be. ${ }^{1}$ Marriages within the prohibited degree do in fact occur ; but they are discountenanced, and are rare.

Polygyny is usual, and is largely practised. A man will often have two or three, or sometimes even four, wives; and a chief or rich man may have as many as six. In the case of an ordinary person the wives all live with their husband in the same house; but a chief or rich person may have two or more houses. A man who is already married, and then marries again, goes through a formality, if it may be so called, similar to that of a first marriage. Opposition from the first wife sometimes occurs, but this is unusual.

I According to Ir. Seligmann, among the Koita the forbidden degrees of relationship extend to third cousins (Melanesians of British New Guinea, p. 82); whereas it will be seen that among the Mafulu it only extends, as between people of the same generation, to first cousins. But a Mafulu native who was grandson of the common ancestor would be prohibited from marrying his first cousin once removed (great-granddaughter of that ancestor) or his first cousin twice removed (great-greatgranddaughter of that ancestor). 
Infant betrothals are common; but they are quite informal, and not the subject of any ceremony. The parents in such cases, whether of the same or different communities, are usually intimate friends, and are thus led to offer their children to each other for intermarriage. There is a known case of a girl of 16 or 17 years of age, who was what I can only call betrothed to the unborn son of a chief. A curious element in this case was that at the date, prior to the birth of the proposed husband, of what I call the betrothal, the price for the girl was actually paid-a thing which is never done till the marriage - and that, as I was most solemnly assured, the living girl and the unborn boy were in fact regarded, not merely as betrothed, but as actually married, and that, when the boy died, which he did in infancy, long before marital relationship between them was possible, the girl was regarded as being a widow. I could not ascertain what happened as regards the price which had been paid for the girl. A couple betrothed in childhood are not subject to any restrictions as to meeting and mutual companionship, nor is there any mutual avoidance, nor any increased probability, based on their betrothal, of immorality between them; though in the more usual case of betrothal between children of different communities they in ordinary course are not likely to be constantly seeing each other.

A young man will speak of his sweetheart, present or prospective, as his ojande, which means his "flower"; and this is so even if he does not yet know her; and, when asked where he is going, he 


$$
\text { ral }
$$



will reply that he is going to seek an ojande. If he is not already betrothed, and is matrimonially inclined, he has various expedients for accomplishing his desires. A boy who wants to marry, and does not know where to seek a wife, will sometimes light a fire in the bush, or better still in an open space (not in the village), when the air is still, and wait until a slight breeze blows the flame or smoke a little in some one direction; and he will then select a community or village which lies in that direction as the spot in which to seek a wife.

A boy will often carry in a small bag (this does not refer to the special small charm bag already described) some pieces of wood and stone, and will rub a piece of tobacco between two of these, and send this tobacco to the girl of his choice through a female relative of hers or some other friend; and he believes that in some mysterious way this will draw her heart towards him, and make her accept him. The pieces of wood and stone need not be of any particular kind; but he will have carried them for a considerable time, until they have, as he thinks, acquired the specific odour of his body; and it is then that they have obtained their special power. It is impossible to induce a boy to part with a piece of wood or stone which has been so seasoned by time, and would take long to replace. Sometimes a boy will acquire these things by purchase from a magic man, who professes to be able to impart to them a more effective power. 
A proposal of marriage is usually made by the boy through some female relative of the girl, or other suitable person, and not directly by him to the girl herself.

Another custom may be mentioned here, though it only relates to a man who is already married, but wants another wife or wives. In clearing the bush for yam gardens it is usual, as regards the smaller trees, to cut away the side branches only, leaving the main trunks for posts up which the yams will climb; but the man in question will in the case of one (only one) of these smaller trees leave uncut one, two, or three of the upper branches, the number so left being the number of the wives he desires; and everyone understands its meaning.

As regards the relationship of unmarried boys and girls generally, they are allowed to associate together, without any special precautions to prevent misconduct, and a good deal of general immorality exists.

The marriage ceremony, following a parental betrothal, or with parental acquiescence, is a very informal matter, and in fact both the bargaining for the wife and the ceremony of the marriage are in striking contrast to the elaborate system of bargaining and mock raiding by the girl's family, and the wedding ceremonies, which are adopted in Mekeo. A day is fixed for the marriage, and on that day the boy goes to the house of the girl's parents, after which he and she and her parents go to the house of the boy's parents, and the girl is paid for then and there. After this the young people immediately live together 
as a married couple in the house of either his or her parents, until he has been able to build a house for himself. Neither are there any special ceremonies in connection with the fixing of the price. This is generally very small. Dogs' teeth, pearl shell, necklaces, adzes, etc., are the usual things in which it is paid; but there is always a pig, which has been killed under, or on the site of, the grave platform above referred to. The price, in fact, depends upon the position and wealth of the girl's parents, except that there is always only one pig. The price is paid to the father of the girl, or, if dead, to her eldest brother or other nearest male paternal relative.

A runaway marriage is still simpler. The boy has proposed to the girl through her friend, and she has consented; and they simply run off into the bush together, and remain in the bush, or the gardens, or a distant village, until the boy's friends have succeeded in propitiating the girl's father, and the price has been paid; and then the couple return to the village.

After marriage, the husband and wife are not as a rule faithful to each other, the marriage tie being only slight. Adultery on the part of the wife, but not of the husband, is regarded as a serious offence, if discovered. The injured husband will beat the guilty wife, and is entitled to kill the man with whom she has misconducted herself, and will usually do so; though nowadays he often dares not do so in districts where he fears Government punishment. Sometimes he will be content if the adulterer pays him a big 
price, say a pig; and this compensation is now commonly accepted in districts where the husband dares not kill. In either case, the husband generally keeps the wife.

Formal divorce or separation does not exist. A husband who wants to get rid of his wife will make her life so miserable that she runs away from him. But more usually the separation originates with the wife, who, not liking or being tired of her husband, or being in love elsewhere, will run away and elope altogether with another man. In such a case, the husband may retaliate on that other man in the way already mentioned; but that is rather the method adopted in cases of incidental adultery, and as a rule, when the wife actually elopes, she and her paramour go off to some other community, and the husband submits to the loss. He will, however, claim from the wife's people the price which he paid for her on his marriage. This is sometimes paid, but not always; and, as the wife almost always belongs to another clan, and generally to another community, the refusal to pay this claim is one of the frequent causes of fighting, the members of the husband's clan, and often the whole community, joining him in a punitive expedition.

When a man dies, or at all events after the removal by the widow of her mourning, she goes back to her own people, generally taking with her any of their young children who are then living in the house. There is no devolution of the wife to the husband's brother, or anything of that nature. Nor, in case of 


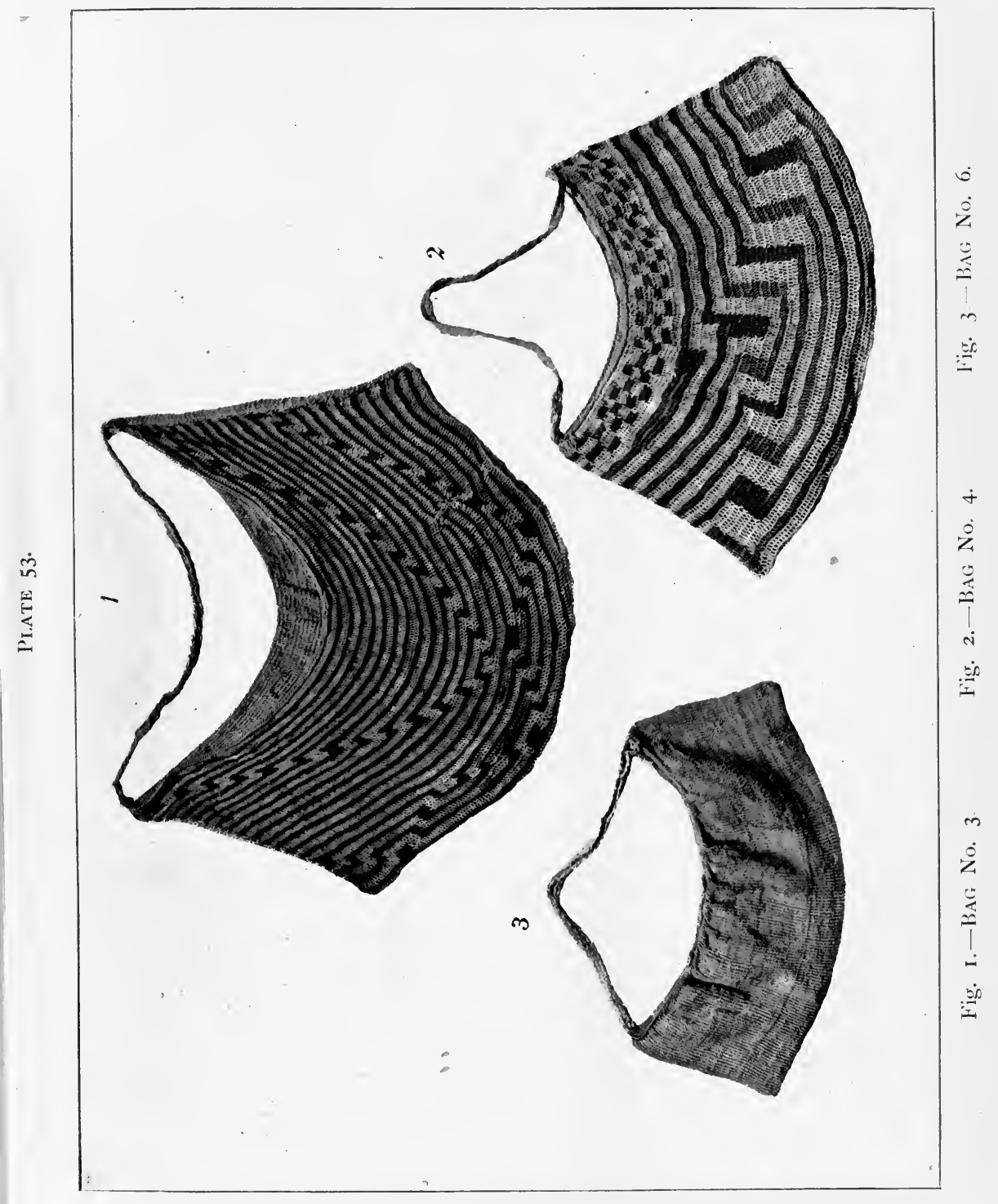



the death of the wife, does the husband marry her sister.

Speaking of the people generally, it may certainly be said that sexual morality among men, women, boys and girls is very low ; and there is no punishment for immorality, except as above stated. 


\section{CHAPTER XI}

KILLING, CANNIBALISM, AND WARFARE

\section{KiLLING.}

INDIVIDUAL killing in personal quarrel, as distinguished from slaying in warfare, is exceedingly rare, except in cases of revenge upon adulterers. In these cases, however, it is regarded as the appropriate punishment; and even the family of the adulterer would hardly retaliate, if satisfied as to his guilt. There is no system of head-hunting, or of killing victims in connection with any ceremonies, or of burying alive, ${ }^{1}$ or of killing old and sick people, though the ceremonial blow on the head of a reputed dying man must sometimes be premature.

Abortion and infanticide, however, are exceedingly common, the more usual practice being that of procuring abortion. Although sexual immorality so largely exists, and young unmarried women and girls are known to indulge in it so freely, and it is not seriously reprobated, it is regarded as a disgrace for one to give birth to a child; and if she gets into trouble she will procure abortion or kill the child. The same thing is also common among married 
women, on the ground that they do not wish to have more children. There is another cause for this among married women, which is peculiar. A woman must not give birth to a child until she has given a pig to a village feast; and if she does so it will be a matter of reproach to her. If, therefore, she finds herself about to have a child, and there is no festal opportunity for her to give a pig, or if, though there be a feast, she cannot afford to give a pig, she will probably procure abortion or kill the child when born. I was told by Father Chabot, the Father Superior of the Mission, that among the neighbouring Kuni people a woman would kill her child for extraordinary reasons; and he furnished an example of this in a woman who killed her child so that she might use her milk for suckling a young pig, which was regarded as being more important. Whether such a thing would occur in Mafulu appears to be doubtful ; but it is quite possible, more especially as the Mafulu women do, in fact, suckle pigs.

Abortion is induced by taking the heavy stone mallet used for bark cloth beating, and striking the woman on the front of the body over the womb. It is also assisted by the wearing of the tight cane belt already mentioned. I could not hear of any system of using drugs or herbs to procure abortion; but herbs are used to produce general sterility, which they are believed to be effective in doing.

Married women also often kill their children as the result of a sort of superstitious ceremony. The child being born, the mother, in accordance 
with the custom of the country, goes down to the river, and throws the placenta into it. She then, however, often takes a little water from the river, and gives it to the babe. If the latter seems by the movements of its lips and tongue to accept and take the water into its mouth, it is a sign that it is to live, and it is allowed to do so. If not, it is a sign that it is to die, and she throws it into the river. This custom, which is quite common, has presumably had a superstitious origin, and it seems to be practised with superstitious intent now. There appears, however, to be no doubt that it is also followed for the purpose of keeping or killing the child, according to the wish of the mother. There is further, confirming the last statement, a well-known practice, when the mother goes down to the river with her baby, for some other woman, who is childless and desires a child, to accompany the mother, and take from her and adopt the baby; and as to this, there is no doubt that, before doing so, the woman ascertains from the mother whether or not she intends to keep her child, and only goes with her to the river if she does not intend to keep it. This is done quite openly, with the full knowledge of the second woman's husband and friends; and everyone knows that the child is not really hers, and how she acquired it. ${ }^{1}$

1 Half-a-dozen years ago, before open systematic killing and cannibalism were checked, it was a Kuni custom, when a woman died in her confinement, to bury the living baby with the dead mother. I have not heard of this custom in Mafulu, and do not know whether or not it exists, or has existed, there; but as regards matters of this sort the Mafulu and the Kuni are very similar. My statement that there is no burying alive must be taken subject to the possibility of this custom. 


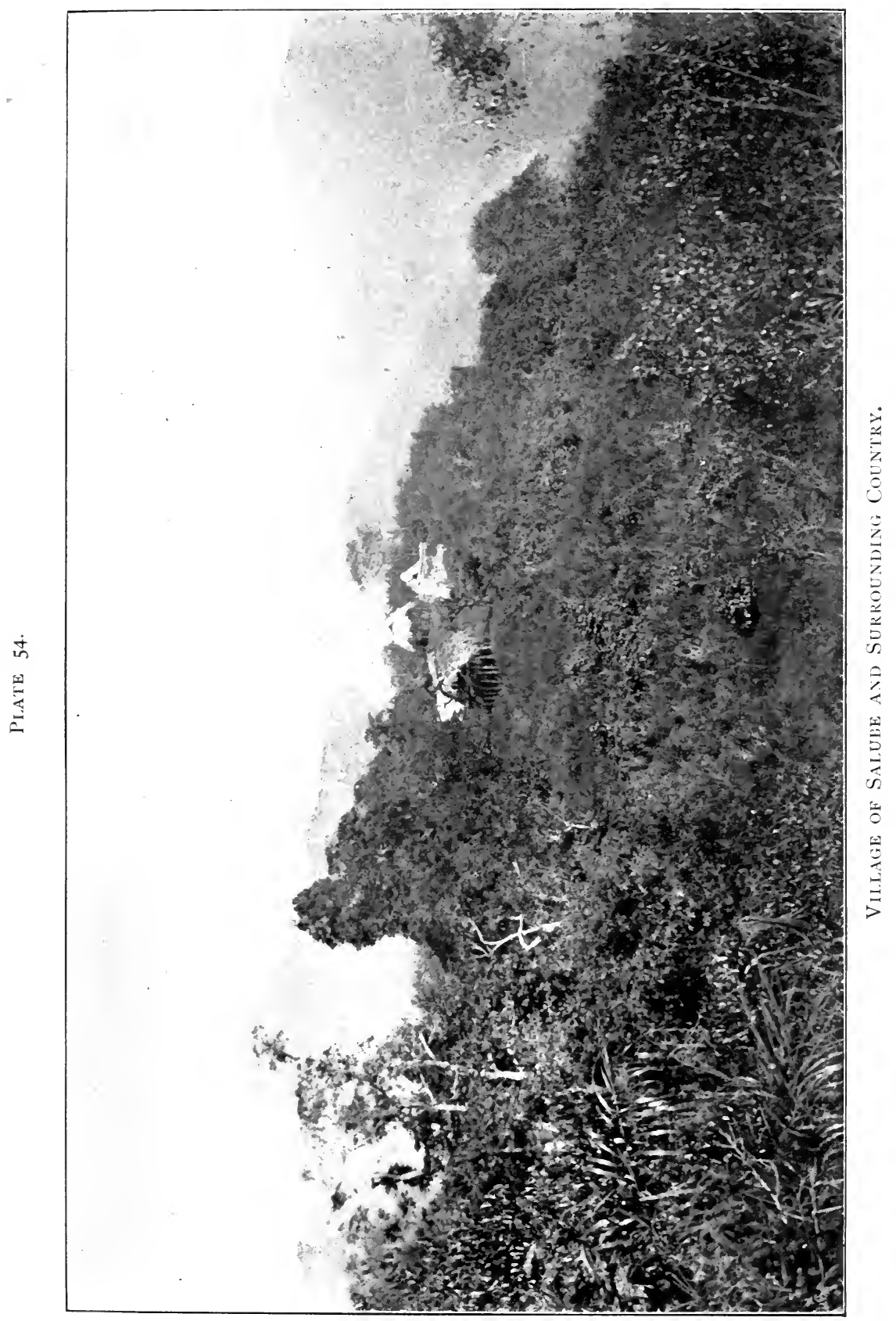





\section{Cannibalism.}

There is no doubt that the Mafulu people have always been cannibals, and are so still, subject now to the fear in which they hold the controlling authority of the white man, and which impels such of them as are in close touch with the latter to indulge in their practice only in secrecy. Their cannibalism has been, and is, however, of a restricted character. They do not kill for the purpose of eating; and they only eat bodies of people who have been intentionally killed, not the bodies of those who have been killed by accident, or died a natural death. Also the victim eaten is always a member of another community. The killing which is followed by eating is always a hostile killing in fight; but this fight may be either a personal and individual one, or it may be a community battle. The idea of eating the body appears to be a continued act of hostility, rather than one of gastronomic enjoyment; and I could learn nothing of any belief as to acquiring the valour and power of the deceased by eating him. I was informed that the man who has killed the victim will never himself share in the eating of him, this being the case both as regards people killed in private personal fighting and those killed in war. ${ }^{1}$ I tried to find out if there were any ceremonies connected with the eating of human flesh; but could learn nothing upon the subject, the natives being naturally not readily communicative with white men on the matter.

1 This custom is found elsewhere. 


\section{WARFARE.}

Warfare generally occurs between one community or section of a community (probably a clan) and another community or section of one; it very rarely occurs within a community. Sometimes two communities join together in opposition to a third one; but alliances of this sort are usually only of a temporary character. War among these people is now, of course, forbidden by the British authorities, and indulgence in it is a serious punishable offence; but it cannot be said to be abolished.

The usual ground for an attack is either that some member of the attacked community or section of a community has by personal violence or by spiritsupported sorcery killed a member of the attacking community or section, or it is of the matrimonial character above explained. The underlying idea of the war is a life for a life; and in the matrimonial matter one life is the sum of vengeance required. Hence the primary object of an attack has usually been accomplished when the attacking party has killed one of their opponents. If there are two or more persons whose deaths have to be avenged, a corresponding number of lives is required in the battle. Then the attacking party may suffer loss during the fight, in which case this has to be added to the account; and loss by the attacked is introduced into the other side of it to their credit. The number killed in a battle is not, however, often great.

When the required vengeance has been accom- 
plished, the attacking party usually cease fighting and return home, if the enemy allow them to do so. They may retire before their vengeance has been accomplished; but in that case they are probably doing so as a defeated party, with the intention of renewing the attack on a subsequent occasion. If the attacking party cease fighting and try to return, the enemy may continue their counter attack, especially if they have themselves suffered loss in the fighting; but I was told that the enemy would not as a rule follow the attacking party far into the bush. It may be that what is regarded by the attackers as a correct balance of lives struck, on which they may retire, is not so regarded by the enemy, in which case the latter may try to prolong the fight; and, if the attackers get away, there will probably be a retaliatory expedition, in which the position of attackers and attacked is reversed. The primary idea of a life for a life is, however, generally understood and acknowledged; and if the enemy recognise the truth of the alleged reason for the attack, and have not lost more life than was required to balance the account, they usually rest satisfied with the result.

No ceremony or taboo appears to be adopted in anticipation of proposed hostilities for the purpose of securing success; but individual fighters often wear charms, upon whose efficacy they rely. Nor do there appear to be any omens in connection with them other than certain general ones to be referred to hereafter. The preparations for a fight and its conduct can hardly be regarded as subjects of much 
organisation, as the chiefs are not war chiefs, and there are no recognised permanent leaders or commanders of the forces, and no recognised war councils or systematic organisation, either of the fighting party or of the conduct of the fight. All adult males of the community engaged are expected to take part, and the leadership will generally fall upon someone who at the moment is regarded as a strong and wise fighter.

The men start off on their expedition as an armed, but unorganised, body, their arms being spears, bows and arrows, ${ }^{1}$ clubs, adzes and shields, and none of their weapons being poisoned. During their progress to the enemy's community they are generally singing, and their song relates to the grievance the avenging of which is the object of the expedition. The warriors do not, I was told, as a rule carry a full supply of provisions, as they rely largely upon what they can find in the bush, and what they hope to raid from their enemy's plantations. On reaching the scene of battle they adopt methods of spying and scouting and sentry duty, though only on simple and unscientific lines. They have apparently no generally recognised systems of signs of truce or truce envoys or hostages. There are certain recognised cries, which respectively signify the killing of a man and the taking of a prisoner, by which, when such an event occurs, the fighters on both sides are aware of it. An enemy wounded on the battlefield

1 From Dr. Haddon's distribution chart in Vol. XVI. of The Geographical Journal, it will be seen that the Mafulu district is just about at the junction between his spear area and his bow and arrow area. 


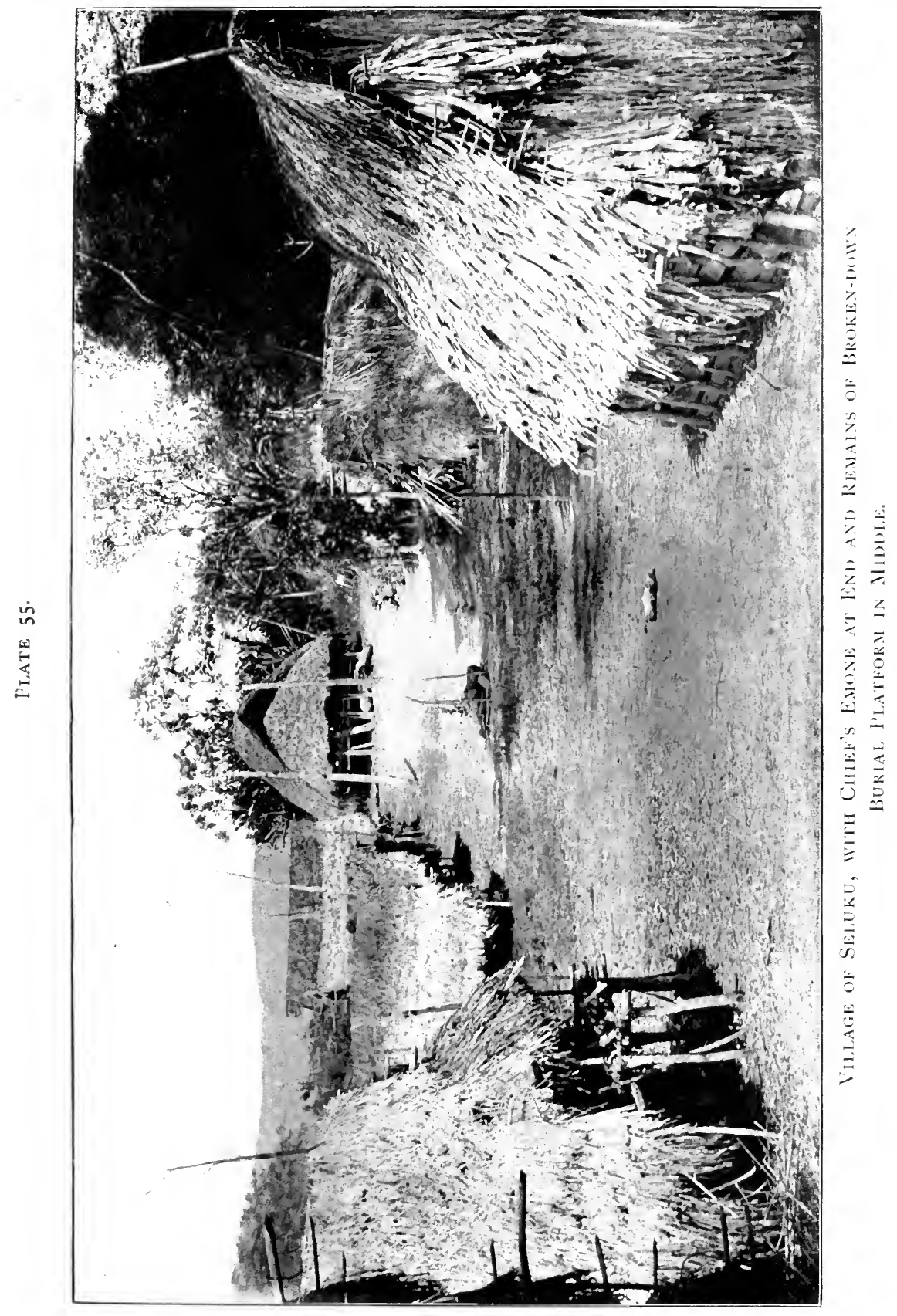



may be killed at once or may be taken prisoner. All prisoners, wounded or otherwise, are taken home by the party that secures them, and are then killed, apparently without any prior torture, and generally eaten. A prisoner thus carried off would be regarded as a man killed, which in fact he shortly will be. The women of a community follow their fighting men in the expedition, their duty being to encourage the fighters on the way out, and during the fight, by their singing; but they remain in the rear during the battle, and do not actually fight. These women, of course, also run the risk of being killed or wounded or taken prisoners.

Fighting between two communities may go on intermittently for years. Then perhaps the communities may get mutually weary of it, and decide to make peace. This act is ratified by an exchange between the two communities of ceremonial visits, with feasts and pig-killing, but no dancing, the pigs and vegetables and fruit distributed by the hosts among the visitors on the return visit being exactly similar in character and quantity to what the latter have given the former on the prior visit.

The Mafulu war spears are made out of a very hard-wooded palm tree and another hard red-wooded tree, the name of which I do not know. They are round in section, tapering at both ends, and are generally from io to I 2 feet long, and about threequarters of an inch in diameter at the widest part. There are three forms of point. The first (Plate 73, Fig. I) is simply a tapering off in round section. 'The second 
(Plate 73, Fig. 2) is made square in section for a distance of 2 to $2 \frac{1}{2}$ feet from the tip. The third (Plate 73, Fig. 3) is in section a triangle, of which two sides are equal and the other side is a little larger, this triangular form being carried for a foot or less from the tip, and the larger surface being barbed bilaterally. This last-mentioned form is also generally decorated with a little tuft of bright-coloured feathers, just above the point where the barbing begins.

The bows (Plate 74, Fig. I) are made of split bamboo, the convex side of the bow being the inner section of the split bamboo. These bows are quite short, generally about 4 feet long when straightened out, and have triangular-shaped knobs at the ends for holding the bowstrings. The bowstrings are made of what appears to be strong split canes (not sugarcanes). The arrows (Plate 73, Fig. 4) are from 6 to 8 feet long, which is extraordinary in comparison with the length of the bows, and are made in two parts, the shaft being made of a strong reed, and the point, which is inserted into the reed shaft and is generally a foot or more long, being single and round-sectioned, and made of the same materials as are used for spears. There are no feathers or equivalents of feathers, and the shaft end of the arrow is cut square and not notched.

The clubs (Plate 75, Figs. I and 2) are stoneheaded, the heads being of the pineapple and disc types; but these heads are the same as those used on the plains and coast, whose people, in fact, get them 
from the mountains, and as these are so well-known, it is not necessary for me to describe them.

The adzes (Plate 75, Fig. 4) are of the usual type, the stone blade being lashed directly on to the handle. There are two common forms. In one, which is also used for ordinary adze work, the haft is cut from a natural branch, with the angle of the head part set obliquely. In the other, which is also used for cutting timber, the haft is cut from a branch with the angle of the head part set at right angles, or nearly so. I do not know to what extent this second form is common in New Guinea. It is not found in Mekeo.

The shields (Plate 74, Figs. 2 and 3) are thick, heavy, cumbrous weapons, made out of the wood used for making wooden dishes. The outer surfaces are convex, and the inner ones concave, the natural convexity of the circular trunk of the trec from which they are made being retained. These shields are $4 \frac{1}{2}$ to 5 feet long, and usually about I 5 or 16 inches wide in the broadest central part, getting somewhat narrower towards the two ends, where they are rounded off. Each shield has two strong cane handles in the centre of its internal concave side, each of which handles is fixed by means of two pairs of holes bored through the shield, and of thongs which are passed through these holes and attached to the ends of the handles. The shields are carried by passing the left arm through the upper handle downwards, the left hand holding the lower handle. 


\section{CHAPTER XII \\ HUNTING, FISHING AND AGRICULTURE}

\section{Hunting.}

THIs is engaged in more or less all the year round, especially as regards wild pigs when wanted for village killing. The animals chiefly hunted are pigs, kangaroos, wallabies, the "Macgregor bear," snakes, cassowaries and other birds.

The hunting weapons and contrivances used are spears, bows and arrows, nets and traps; but adzes and clubs are used in connection with net hunting. The spears are those used for war. The bows and arrows employed for hunting animals and cassowaries are also the same as those used for war; but these are not much used. For bird-shooting (excluding cassowary-shooting) they generally use arrows (Plate 73, Fig. 5) the points of which are made of four rather fine pieces of bamboo cane, closely bound together at the place of insertion into the reed shaft, and also bound together further down,

1 I have never seen the animal called the "Macgregor bear," and I do not know what it is. The Fathers assured me it was a bear; but in view of the great unlikelihood of this, I consulted the authorities at the Natural History Museum, and they think it is probably one of the marsupials. It is named after Sir William Macgregor. It is found in the mountains, where the forest is very thick. 


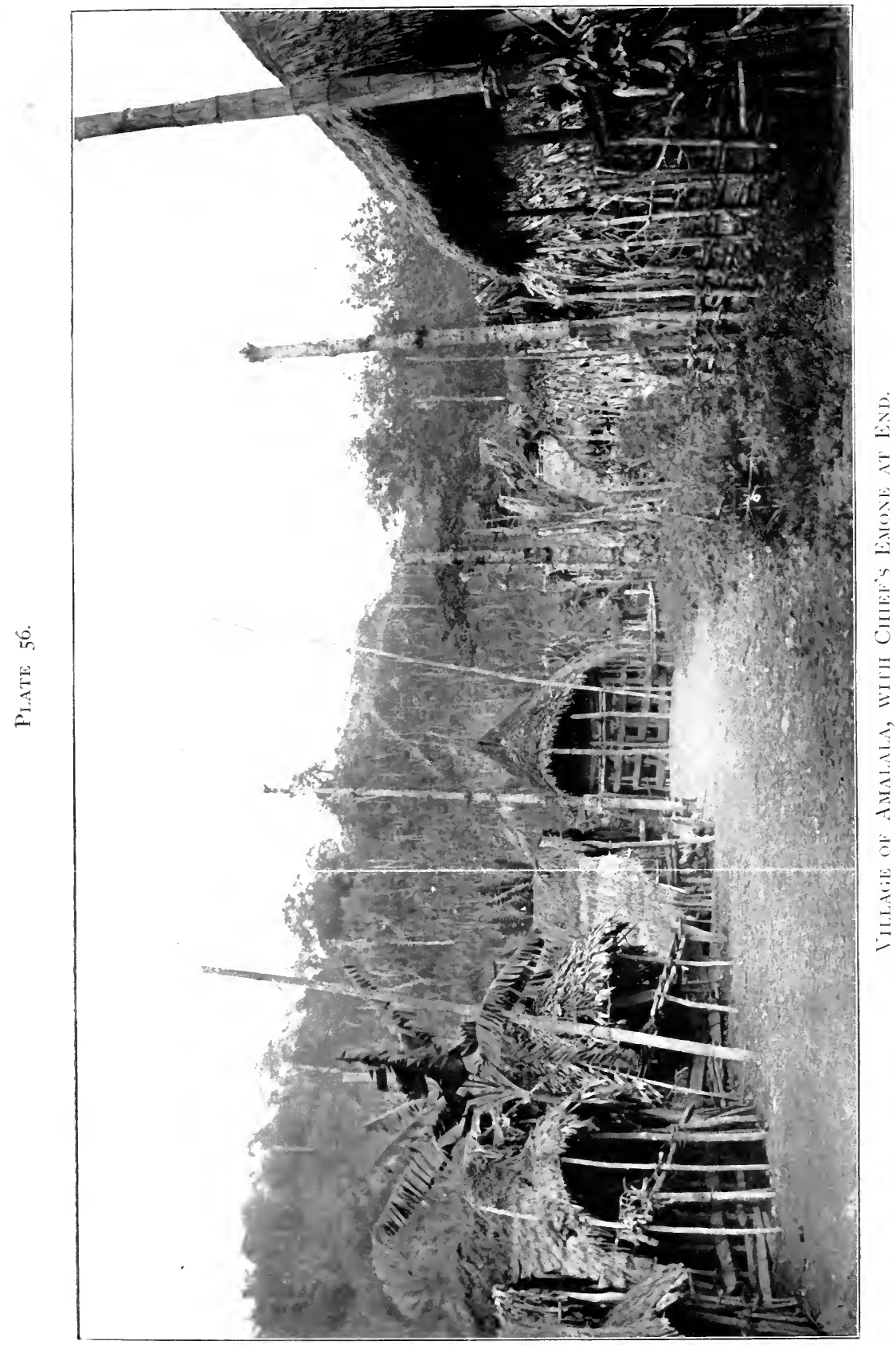



but with a piece of stick or some other material inserted between them inside this second binding, so as to keep them a little apart and make them spread outwards, thus producing a four-pronged point. The arrows vary in length from 5 to 6 or 7 feet, and their points vary from 4 to 10 inches. The adzes and clubs are the same as those used for war.

The people generally hunt in large parties for pigs (hunted with either spears or nets), kangaroos and wallabies (hunted with nets only), and Macgregor bears, cassowaries, and big snakes (hunted with spears only). The hunters may be members of a single village or of a whole community. They generally return home on the same day, except when hunting the Macgregor bear, which is only found on the tops of high mountains, and so requires a longer expedition. They usually take out with them large numbers of young boys, who are not armed, and do not take part in the actual killing, but who, when the party reaches the hunting ground, spread out in the bush, and so find the animals. While doing this the boys bark like dogs. Sometimes dogs are taken instead, but this is unusual, as they have not many dogs.

A preliminary ceremony is performed by a person whose special duty it is, and who, I think, is usually the pig-killer. He takes a particular kind of fragrant grass, makes an incantation over it, rubs it on the noses of the dogs (if there are any), ${ }^{1}$ and then ties it in several

${ }^{1}$ Compare the Motumotu (Toaripi) practice of rubbing the dogs' mouths with a special plant, referred to by Chalmers (Pioneering in Neze Guinea, p. 305). 
portions to the meshes of the net to be used. If there are dogs, but no net, then, after rubbing the dogs' noses, he throws the grass away. If there is a net, but no dogs, then, after making the incantation, he ties the grass on to the net as above mentioned. This appears to be the only ceremony in connection with hunting; and there is no food or other taboo associated with it, but some of the charms worn are intended to give success in hunting.

In spear hunting, when children and not dogs are employed, the children shout as soon as the animal has been found, and then retreat; and, when the animal has been found by either children or dogs, the hunting men attack it with their spears, if possible surrounding it.

In net hunting, which of course can only be adopted in fairly open spaces, the hunters place their net by means of pole supports in the form of a crescent, perhaps as much as 50 or 60 yards long, this length, however, requiring several nets put end to end together, and 2 or 3 feet high. The net is generally put across the base of a narrow ravine, or across a narrow ridge, these being the routes along which the animals usually travel. The children or dogs search for the animal, as in spear hunting; and when it is found, most of the hunters place themselves in a crescentshaped formation behind the animal, so that it is between them and the net, and then gradually close in upon it, and so drive it into the net. Behind the net are other hunters, more or less hidden, who kill the animal with club or adze when it is caught in the 
net. They sometimes use spears in the event of an animal jumping over the net, and so trying to escape; though in net hunting the spears are more especially carried for purposes of self-defence in case of an attack by the animal.

There is always an enormous amount of shouting all through the hunt. When the animal has been caught, they generally kill it then and there, except as regards pigs required alive for village ceremony, and which are disabled, but not killed. The huntings, except when pigs are specially required, are usually general; and when any sort of animal has been killed the hunters are content. They surround the beast, and make three loud shouting screams, by which the people of the village or community know, not only that an animal has been killed, but also what the animal is. It is then brought home, and eaten by the whole village, if the hunt be a village hunt, or by the community, if it be a community hunt.

Individual hunting, in which I include hunts by parties of two or three, is also common. Solitary hunters are generally only searching for birds (not cassowaries); but parties of two or three will go after larger game, such as pigs, cassowaries, etc. Such parties hunt the larger game with spears, clubs and adzes, and shoot the birds, other than cassowaries, with bows and arrows. They kill their victims as they can, and bring them home; and they, and probably some of their friends, eat them.

Trap hunting is much engaged in by single indi- 
viduals. A common form of trap used for pigs is a round hole about 6 feet deep and 2 feet in diameter, which is dug in the ground anywhere in the usual tracks of the pigs, and is covered over with rotten wood, upon which grass is spread; and into this hole the pig falls and cannot get out. The maker of the hole does not necessarily stay by it, but will visit it from time to time in the hope of having caught a pig. Small tree-climbing animals are often caught by a plan based upon the inclination of an animal, seeing a continuous line, to go along it. A little pathway. of sticks is laid along the ground, commencing near a suitable tree, and carried up to the base of that tree, and then taken up the trunk, and along a branch, on which it terminates, the parts upon the tree being bound to it with cane. At the branch termination of this path is either a noose trap, made out of a piece of native string tied at one end to the branch, and having at the other end a running noose in which the animal is caught, or a very primitive baitless framework trap, so made that the animal, having once got into it, cannot get out again. Or instead of a trap, the man will erect a small rough platform upon the same tree, upon which platform he waits, perhaps all night, until the animal comes, and then shoots it with his bow and arrow. Another form of trap for small animals is a sort of alley along the ground, fenced in on each side by a palisading of sticks, and having at its end a heavy overhanging piece of wood, supported by an easily moved piece of stick, which the animal, after passing along the alley, disturbs, so bringing 


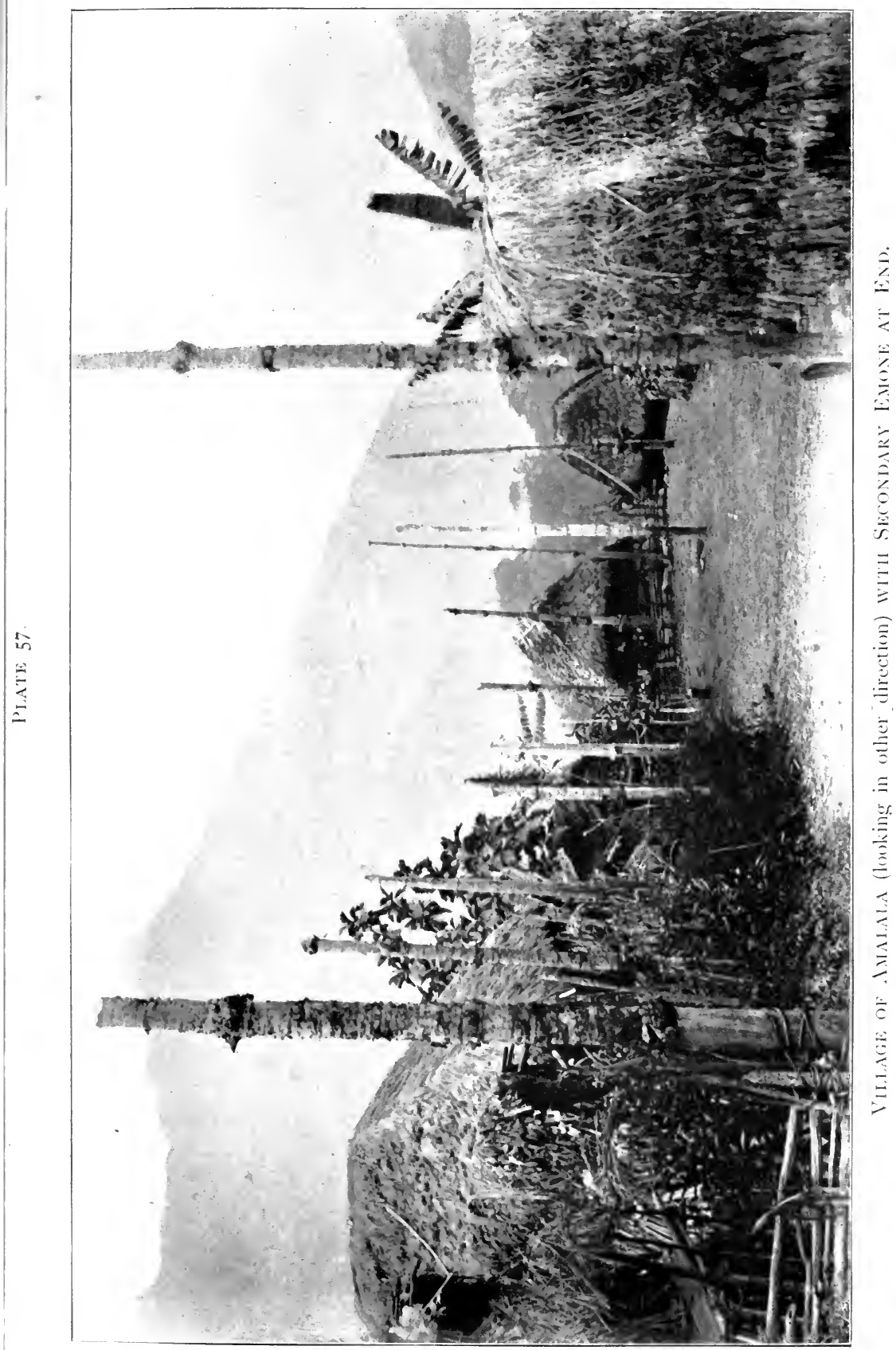



down the piece of wood on to the top of it ; this trap also has no bait. Large snakes are caught in nooses attached to the ground or hanging from trees.

Birds of all kinds, except cassowaries, are killed with bows and arrows. There is also a method of killing certain kinds of birds of paradise which dance on branches of trees, and certain other kinds and bower birds, which dance on the ground, ${ }^{1}$ by means of nooses as above described, these being tied to the branch of the tree, or, in the case of ground nooses, tied to a stick or something in the ground. The natives know the spots where the birds are dancing, and place the noose traps there. Another method of killing birds is adopted on narrow forest-covered ridges of the mountains. An open space or passage about 2 or 3 yards wide is cut in the bush, across the ridge; and across this passage are suspended three parallel nets, the inner or central one being of a close and impassable mesh, and the two outer ones having a mesh so far open that a bird striking against it can get through. These nets are made of very fine material, and so are not easily seen, especially as they are more or less in shade from the trees on each side of the passage. A bird flying from the valley on either side towards the ridge is attracted by this open passage, and flies into and along it ; it strikes against one of the more open outer nets, and gets through it, but is confused and bewildered, and so is easily

1 The birds of paradise which dance in trees include, I was told, what the Fathers called the "Red," the "Blue," the "Black," the "Superb" and the "Six-feathered." Those which dance on the ground include the "Magnificent." 
stopped by the central close-meshed net, where it is shot with bow and arrow.

\section{Fishing.}

Fishing is carried on by the Mafulu people by means of weirs placed across streams, the weirs having open sluices with intercepting nets, and smaller nets being used to catch such fish as escape the big ones. They do not fish with spears, hooks, or bows and arrows, or with fishing lines, as is done in Mekeo; and even their weir and net systems are different from the Mekeo ones. Fishing with them is more or less communistic, as it is generally engaged in by parties of ten or twenty men (women do not fish), and sometimes nearly all the men of a village, or even of a community, join in a fishing expedition; and everyone in the village or community shares more or less in the spoil. The fishing season is towards the end of the dry season, say in October or November, when work in the gardens is over, and the rivers are low. I cannot give the names of the fishes caught, but was told that the chief ones are large full-bodied carp-like fish and eels.

The large weir nets are simply ordinary frameless nets about 3 to 5 yards long, and I yard wide, with a fairly small mesh. The smaller ones are hand nets, made in two forms. One of these is made of ordinary fine netting, and is bag-shaped, being strung on a round looped end of cane, of which the other end is the handle, the net being about the size of a good- 
sized butterfly net. The other form is also framed on a looped cane; but the loop in this case is larger and more oval in shape, and the netting is made of the web of a large spider. To make it they take the already looped cane to where there are a number of such webs, and twist the looped end round and round among the webs, until there is stretched across the loop a double or treble or quadruple layer of web, which, though flat when made, is elastic, and when used becomes under pressure more or less bagshaped.

The fishers first make a weir of upright sticks placed close together among the stones in the river bed, the weir stretching across the greater part of, or sometimes only half-way across, the river. The side of the river left open and undammed is filled up with stones to such a height that the water flowing over it is shallow, and the fish do not escape across it. In the middle of the weir they leave an open space or sluice, behind which they fasten the big net. ${ }^{1} \quad$ Plate 76 shows a weir on the Aduala river, a portion of the open sluice being seen on the left. After forming the weir, but before fixing the net, the fishers all join in a sort of prayer or invocation to the river. For example, on the Aduala river they will say, "Aduala, give us plenty of fish, that we may eat well." This is the only ceremony in connection with the fishing, and there is no food or other taboo associated with it ; but here again charms are often relied upon. The big net

1 In Mekeo the weir is made with wicker-work, at the openings in which basket fish-traps are placed. 
catches most of the fish which are carried down by the rush of water through the opening in the weir; but a group of fishermen stand round it with their hand nets, with which they catch any fish that leap out of the big net, and would otherwise escape, the ordinary hand nets being usually used for larger fish, and the cobweb ones for the smaller fish. They often have two or three of these weirs in the same stream, at some little distance from each other.

A fishing party will often stay and live for some days at the place where they are fishing, and eat the fish each day as they catch it; so that what they bring home for the village or community may only be the result of the last day's sport. But the women will sometimes come to the fishers, bring them food, and take some fish back to the village or community. Each community has waters which it regards as being its own; but disputes as to this apparently do not arise.

A solitary individual sometimes goes off to catch fish with one of the hand nets above described or with his hands, and eats or keeps what he catches; but this is unusual.

\section{Agriculture.}

Agriculture is never communistic, being entirely an individual or family matter, men and households and families having their own gardens and plantations. The trees and plants chiefly cultivated are those already mentioned as being used for food. 


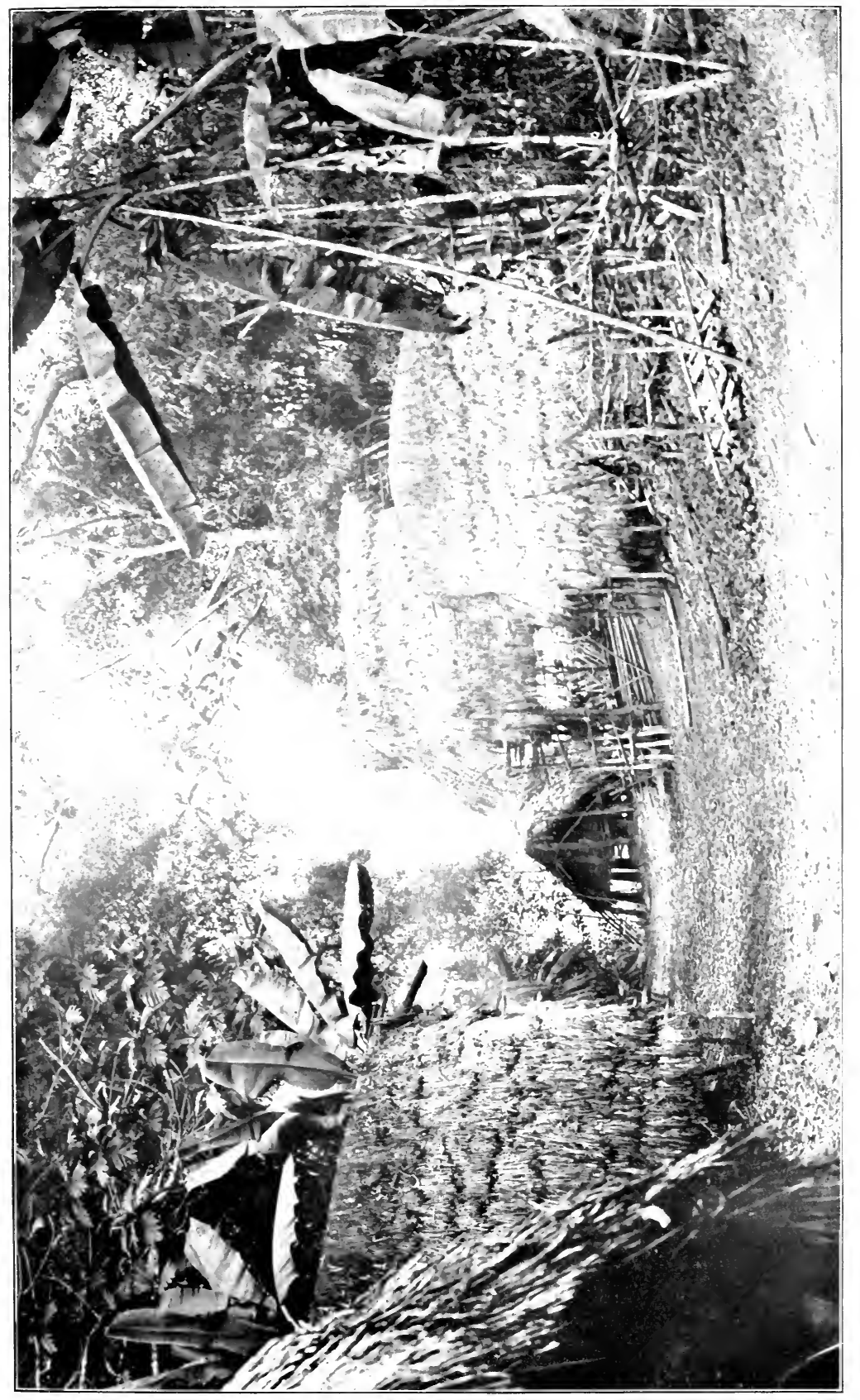



The clearing of the ground is done by men, and is begun about the end of June. The trees and their branches are used for fencing, the fencing beingalso done by men. The clearing away of the undergrowth is done by women, who pile it in small heaps, which are spread over the cleared space, being so close together that they almost touch one another. When these have got quite dry, which may be in a few days, or not for some time, they burn them, and the ashes add fertility to the soil. There is no general digging up of the ground, as distinguished from the digging of holes for individual plants. The clearing of the trees is done with stone adzes, or in difficult cases by fire; but some of the people now have European axes, of which some have been acquired from white men, and some from plain and coast natives. In clearing for planting yam and plants of the yam type they leave the upright stems of some of the trees and shrubby undergrowth for the yams, etc., to trail over. Cultivation of some of the more usual plants is done as follows.

Sweet potatoes and vegetables of similar type are planted by the women in August and September. They make little holes in the ground about 2 feet apart, and in them plant the potatoes, the roots used being the young sarmentose runners, which they cut off from the parent plants, the latter being merely cut down to the ground, and the old tubers being left in it. These runners are left to grow, and in about three or four months the young potatoes are ready for eating, and afterwards there will be a continuous supply from the runners. The digging up of the day- 
to-day supply of potatoes is done by the women, the work in this, and in all other digging, being done with small pointed sticks, roughly made and not preserved; though now they sometimes have European knives, these knives and axes being the two European implements which they use in agriculture, if they possess them.

Yams and similar vegetables are planted by men in August and September, near to the young tree stems up which they are to trail, and at distances apart of 2 or 3 yards. In this case, however, there are two plantings. In the first instance the yam tubers are planted in pretty deep holes, the tubers being long. The yams then grow, and twine over the tree stems, and spread. After about ten months the men dig up the tubers, which in the meantime have grown larger, and cut away from them all the trailing green growth, and then hang the tubers up in the houses and emone, to let the new growing points sprout. Then in about another two months the men replant the smaller tubers, while the larger ones are retained for food.

There are two curious Mafulu practices in connection with yam-planting. First, before planting each tuber they wrap round it an ornamental leaf, such as a croton, which they call the "sweetheart of the yam." Against this leaf they press a piece of limestone. They then plant the tuber with its sweetheart leaf around it and the piece of limestone pressing against its side, and fill in the soil; but as they do the latter they withdraw the piece of limestone, which they use successively for other yams, and, indeed, keep in their houses for use 
year by year. In the villages near the Mafulu Mission Station the limestone used is generally a piece of stalactite, which they get from the limestone caves in the mountains. The belief is that by planting in this way the yams will grow stronger and better. Secondly, there is a little small-leafed plant of a spreading nature, only a few inches high, which grows wild in the mountains, but which is also cultivated, and a patch of which they always plant in a yam plantation. This plant they also call the "sweetheart of the yam "; and they believe that its presence is beneficial to the plantation.

Yams are ready for supplying food eight or ten months after planting. They are not, like the potatoes, dug up from day to day, as they can be stored. The usual period of digging and storing is about June or July, and this digging is done by both men and women, the former dealing with the larger yams, which are difficult to get up, and the latter with the smaller ones.

The yam is apparently regarded by the Mafulu people as a vegetable possessing an importance which one is tempted to think may have a more or less superstitious origin-witness the facts that only men may plant it and that it is the only vegetable in the planting of which superstitious methods are employed, and the special methods and ceremonies adopted in the hanging of the yams at the big feast. But I fancy this idea as to the yam is not confined to the Mafulu; and indeed Chalmers tells us of a Motu superstition which attributes to it a human origin ${ }^{1}$; and a perusal

1 Pioneering in New Guinea, pp. 3 and 4. 
of the chapter on sacrifices in Dr. Codrington's book, The Melanesians, leaves the impression on one's mind that among these people the yam is the one vegetable which is specially used for sacrificial purposes.

Taro and similar vegetables are planted by women in August and September among the yams, at distances of 2 or 3 feet apart. For this purpose they take the young secondary growths which crop up round the main central plants during the year. ${ }^{1}$ They are ready for eating in, say, May or June of the following year. They are dug up by women from day to day as wanted, as they, like the sweet potato, cannot be kept, as the yams are, after being taken up. There is, however, a method when the taro is ripe and needs digging up, but is not then required for eating, of making a large hole in the ground, filling it with grass, digging up the taro, putting it on the grass in the hole, covering and surrounding it with more grass, and then filling up with soil, and so preserving the taro for future use by a sort of ensilage system. I was told that this was not done on the plains.

Bananas are planted by men, this being done every year, and off and on all through the year, generally in old potato gardens. In this case they take the young offshoots, which break out near the

1 Dr. Stapf tells me that taro is usually propagated by means of tubers or division of crowns, that is that either the whole tuber is planted or it is cut up, as potatoes are done, into pieces, each of which has an eye, and each of which is planted. It would appear that the Mafulu method, as explained to me, amounts to much the same thing, the only difference being that instead of planting a crown, or a piece with an eye from which a fresh shoot will proceed, they let that shoot first grow into a young plant and then transplant the latter. 


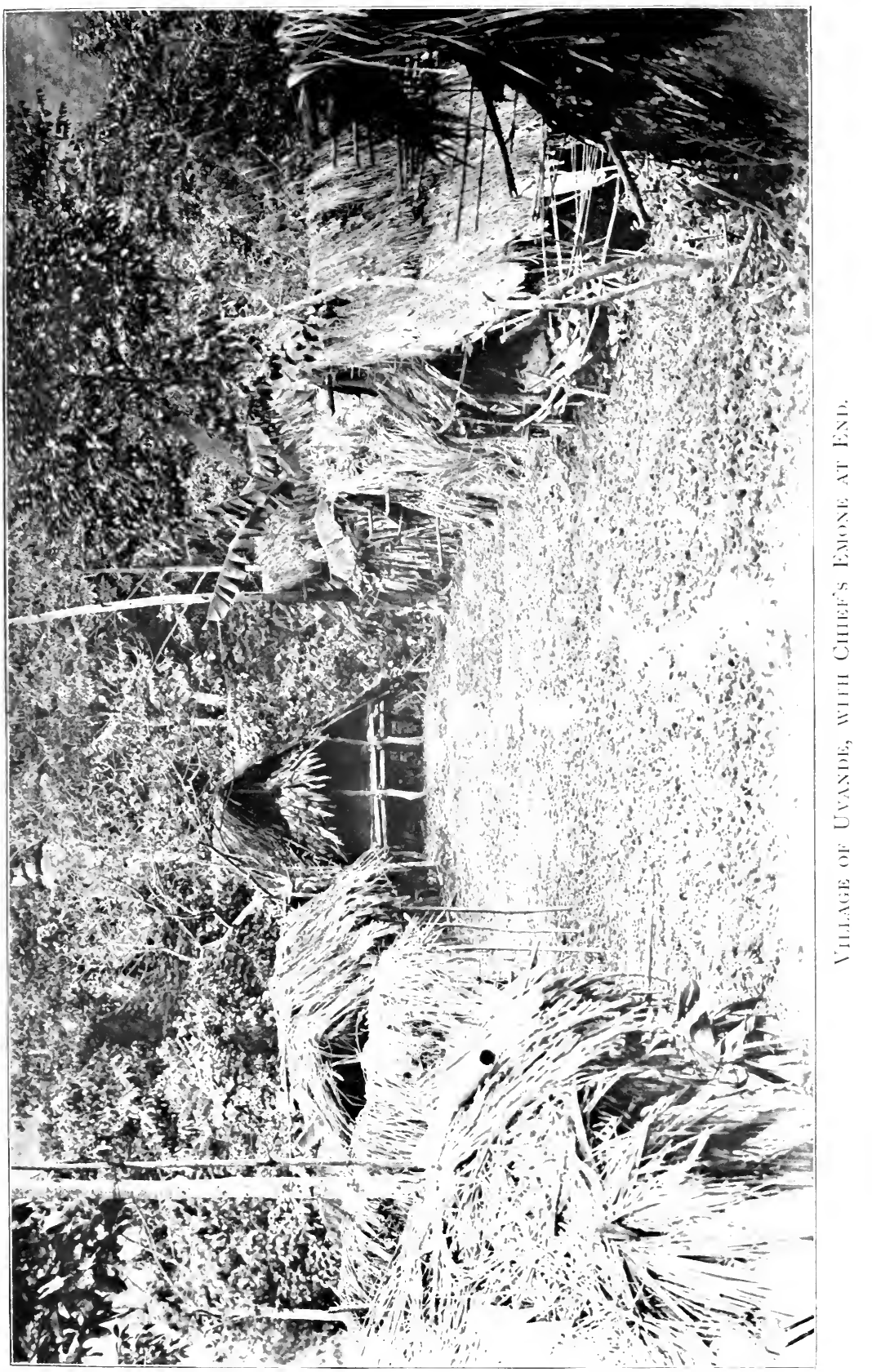



bases of the stems. The closeness of planting varies - considerably. The fruit is gathered all through the year by men. A banana will generally begin to bear fruit about twelve months after planting, though some sorts of banana take as long as two years.

Sugar-cane is planted by men off and on during the whole year, generally in old potato gardens, the growing points at the tops of the canes being put into the ground at distances of 5 or 6 feet apart. Each plant produces a number of canes, and these begin to be edible after six or eight months. They are then cut for eating by both men and women.

As regards both banana and sugar-cane, the people, after planting them in the potato gardens, allow the potatoes to still go on growing and spreading; but these potatoes are merely used for the pigs, the people only eating those grown in their open patches.

Beans of a big coarse-growing sort, with large pods from 8 to 18 inches long, are planted by women about September by the garden fences of the potato and yam gardens, and allowed to creep up these fences. They furnish edible fruit in about three or four months from the time of planting, and are then gathered by the women. Only the inside seeds are eaten (not the pod); and even these are so hard that twenty-four hours' boiling does not soften themindeed, they are usually roasted.

Pandanus trees are grown in the bush and not in the gardens. The ine, which is a large form (Plate 80 ), is always grown at a height of not less than 5,000 feet; but there is a smaller one which is grown 
by a river or stream. The malage is always grown in the valleys near brooks and rivers.

As regards the gardens generally, they may be roughly divided into sweet potato gardens and yam gardens. In the former are also grown bananas, sugar-cane, beans, pumpkin, cucumber and maize; and in the latter taro and beans, and the reed plant with the asparagus flavour to which I have already referred. The general tending of the bananas and sugar-canes, and to a certain extent the yams, is done by men ; but in other respects the garden produce is looked after by women, who also attend to the weeding and keeping of the gardens clean, the men looking after the fences.

Having planted a certain crop in a garden, they let it go on until it is exhausted, the period for this being different for different crops ; but afterwards they never again plant the same crop in the same garden. When a crop is exhausted, they may possibly use the same garden for some other purpose; but as a rule they do not do so, except as regards the use of old potato gardens for banana and sugar-cane. When fresh gardens are wanted, fresh portions of bush are cleared; and the old deserted gardens are quickly re-covered by nature with fresh bush, the growth of vegetation being very rapid. Most of the gardens are bush gardens, and, though these may sometimes be close to the village, you do not find a regular system of gardens within the village clearing, as you do in the Mekeo district, the situations of the villages being indeed hardly adapted for this. 


\section{CHAPTER XIII}

BARK CLOTH MAKING, NETTING AND ART.

Bark Cloth Making and Netting.

I PUT the two processes of bark cloth making and netting together, as being the only forms in which material is made in pieces of substantial size.

Bark cloth is used for making perineal bands, men's caps, illness-recovery capes, bark cloth head strings, mourning strings and dancing aprons and ribbons. Netting is used for fishing and hunting nets, sleeping hammocks, the various forms of carrying bags and the mourning vests worn by the widows of chiefs.

\section{Bark Cloth Making.}

Bark cloth is made by both men and women out of the bark of three different kinds of tree; but I do not know what these are. They strip the bark from the tree, and from the bark they strip off the outer layer, leaving the inner fibrous layer, which is about $1 / 8$ th of an inch in thickness. They have no method of fastening two pieces of bark or cloth together, so every garment has to be a single piece, and the size of the piece to be made depends upon the purpose for 
which it is wanted. The cloth is made in the usual way by soaking the prepared bark in water for about twenty-four hours, and then hammering it with a heavy mallet upon the rounded surface of a cut-down tree trunk (Plate 79).

The mallet used (Plate 5I, Fig. 3), however, differs from the wooden mallet of Mekeo and the coast. It is a heavy black roller-shaped piece of stone, tapering a little at one or both ends, and being broader at the beating end than at the holding end. It varies in length from 10 to 18 inches, and has a maximum width of about 2 or $2 \frac{1}{2}$ inches. The beating surface is not flattened, as is the case with the Mekeo beaters, but it is rather deeply scored with a series of longitudinal and transverse lines, crossing each other at right angles, or nearly so. This scoring generally covers a surface space of about 3 inches by 1 or 2 inches, and is done with pointed pieces of similar stone, or with the tusks of wild pigs.

As the hammering proceeds the bark becomes thinner and larger in surface, and when this process is finished, the cloth is hung up to dry.

The colouring of the cloth, if and when this is added, is done by men only, and, like body-staining, is nearly always in either red, yellow, or black. The red stain is obtained from the two sorts of earth used for red face and body-staining, being, as in the other case, mixed with water or animal fat, so as to produce a paste. Another source of red stain used for cloth is the fruit of a wild tree growing in the bush, which fruit they chew and spit out. I do not know what the 


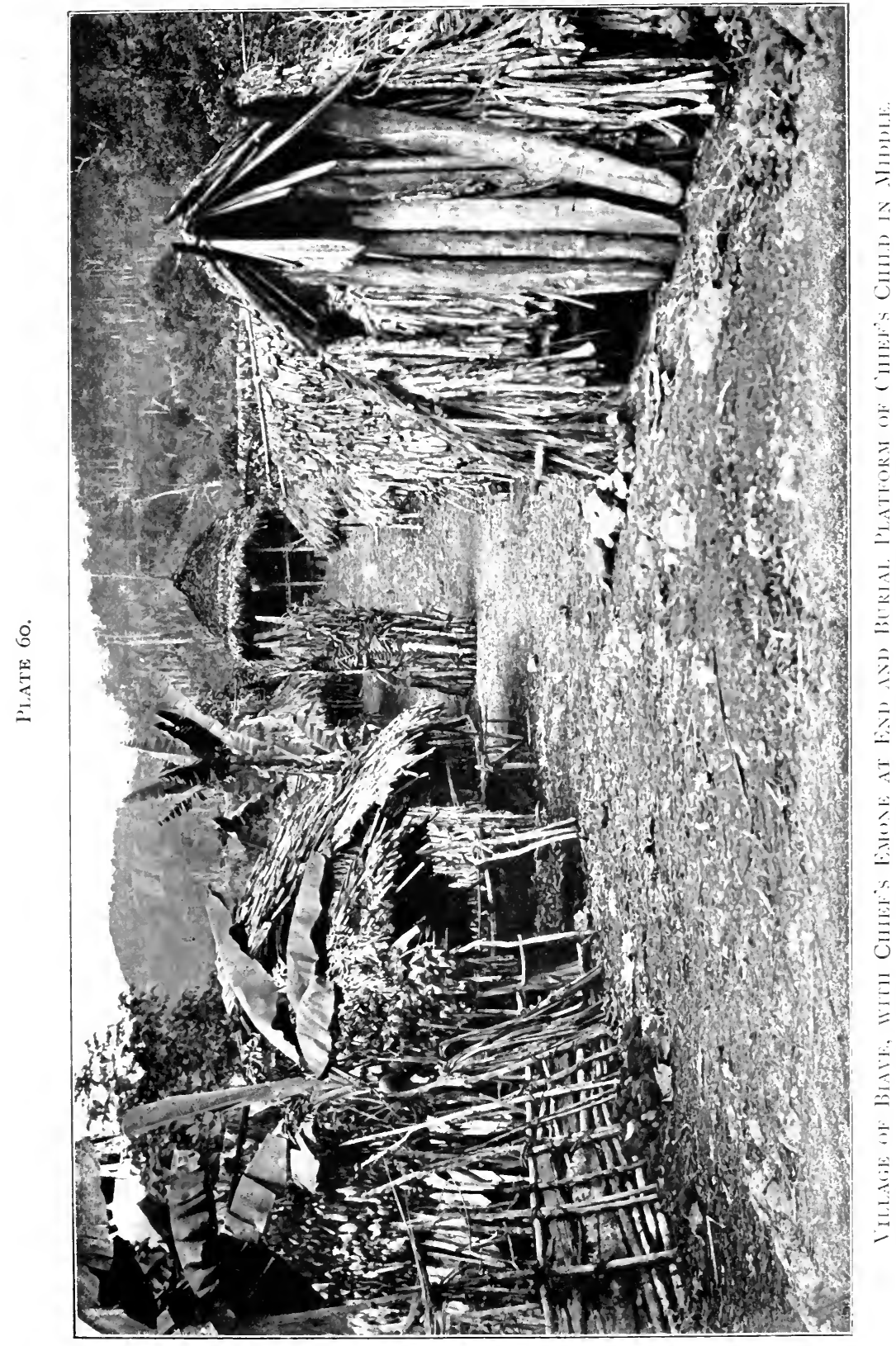



tree is, but I do not think it is the Pandanus, whose fruit is, I believe, used for body-staining. The yellow stain is obtained from the root of a plant which I understand to be rather like a ginger. They dry the root in the sun, and afterwards crush it and soak it in water, and the water so coloured becomes the pigment to be used. The black stain is obtained in the same way as that used for face-staining. These dyes are put on to the cloth with the fingers, which the men dip into the dye, or with feathers. In making a design they do not copy from a pattern placed before them, nor do they first trace the design on the cloth.

\section{Netting.}

In dealing with netting, I should begin with the making of the string; but, as I think the method adopted is not confined to the mountains, it is perhaps sufficient to refer to my previous description of threadmaking in connection with the manufacture of legbands; though in most netting the strings are necessarily very much thicker and stronger than are the threads used for leg-bands, and they are threestranded.

Hunting and fishing nets are made by men in a simple open form of netting, worked on the common principle of the reef knot, and having diamond-shaped holes, with a knot at each corner of each hole. I shall refer to this form of netting as "ordinary network." The nets are made of thick, strong material, except as regards the hand fishing nets, which are 
made of the fine material used for making leg-bands. These nets are never coloured.

Hammocks are made by men. They are sometimes done entirely with ordinary network, and are then, I think, similar to Mekeo-made hammocks; but often only two or three lines of netting are done in this way, the rest of the net being made in a closer and finer pattern of interlacing knotless network, which is never adopted on the coast and Mekeo plains (all nets of this description found there having come down from the mountains) and which I will call "Mafulu network." I I have watched the making of one of these nets, and will endeavour to describe the process. The ultimate result of the Mafulu network part of this is shown in Plate $8 \mathrm{I}$.

The maker first formed a base line of three strands of native string stretched out horizontally. This

a

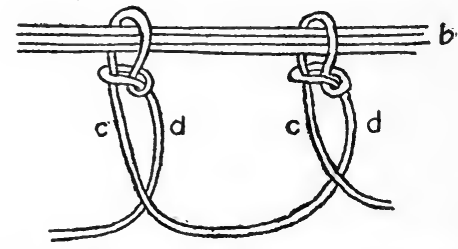

Fig. 8.-Mafulu Net Making (IST LiNe OF NeTWORK). base line is marked $a b$ in Fig. 8. He then wound a long length of netting string round a rough piece of stick to be used as a sort of netting shuttle. He next worked the netting string on to the base line by a series of loops or slip-knots as shown in Fig. 8, strand $c$ of each loop bending upwards and becoming

1 I have examined at the British Museum some net work of the dwarf people of the interior of Dutch New Guinea, brought home by the recent expedition organised by the British Ornithologists' Union, and found it to be similar in stitch to the Mafulu network. 
strand $d$ of the next loop to the right, and the series of loops extending for the whole length of the base line, and thus constituting the first loop line of the net. The hitches of the loops, which appear loose and open in the figure for the purpose of showing their construction, were really drawn tight on the base line. On to these loops he then worked one line of ordinary network, as shown in Fig. 9, the strings $a b c d$ in this figure being the loops above mentioned, and the knots of this also being, of course, drawn tight, and not made loose and open, as shown in the figure. The base of this line again formed a series

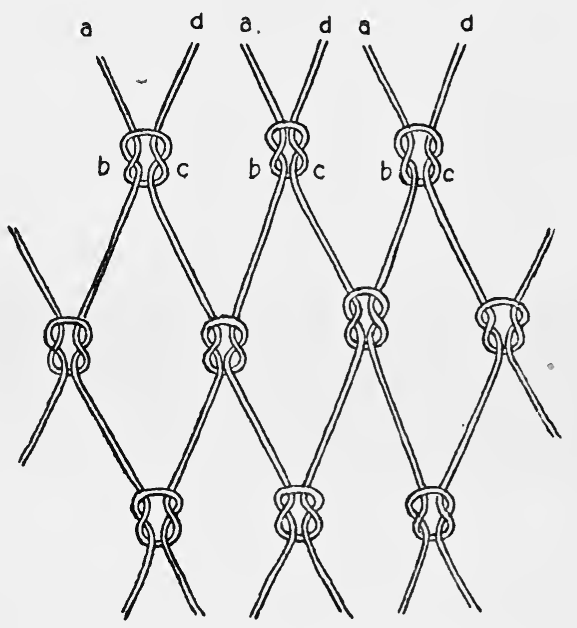
of loops. He only Fig. 9.-Mafulu Net Making (2ND, 3RD, made one of these lines of mesh for my instruction; but it is usual in the making of hammocks to have two or three of them, as appears in the figure. The next stage commenced the Mafulu network. The form of this is shown in Fig. IO; and here again the actual network was more closely drawn than is shown in the illustration, though it was not drawn tight, as in the case of the ordinary network. The first line of Mafulu network was worked on to the loops above 
it, so as to form a continuous line, in which many loops of Mafulu work were attached to each loop of the line of ordinary work above, the former being considerably smaller than the latter. The rest of the network is similarly made in the Mafulu method, each loop of each line being connected with a loop of the line above, until the worker almost reaches the other end of the hammock, which latter is finished off with ordinary network and a final base line, so as to correspond with the commencing end. Often there are only four or five loops of Mafulu

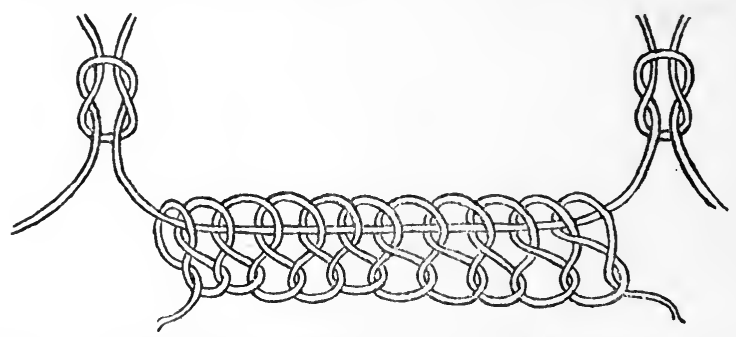

Fig. 10.-Mafulu Net Making (5Th Line of Network, to Which Rest of Net is Similar in Stitch)

network attached to each loop of ordinary network above them; and I have seen hammocks in which the mesh of the ordinary network part is much smaller, so that each loop of the bottom line of this mesh has attached to it only one loop of the top line of Mafulu mesh; and this last variation is common as regards carrying bags.

The hammocks are never coloured; but they are sometimes decorated with a few Pandanus or malage seeds hung from their borders.

The different forms of carrying bags have already 


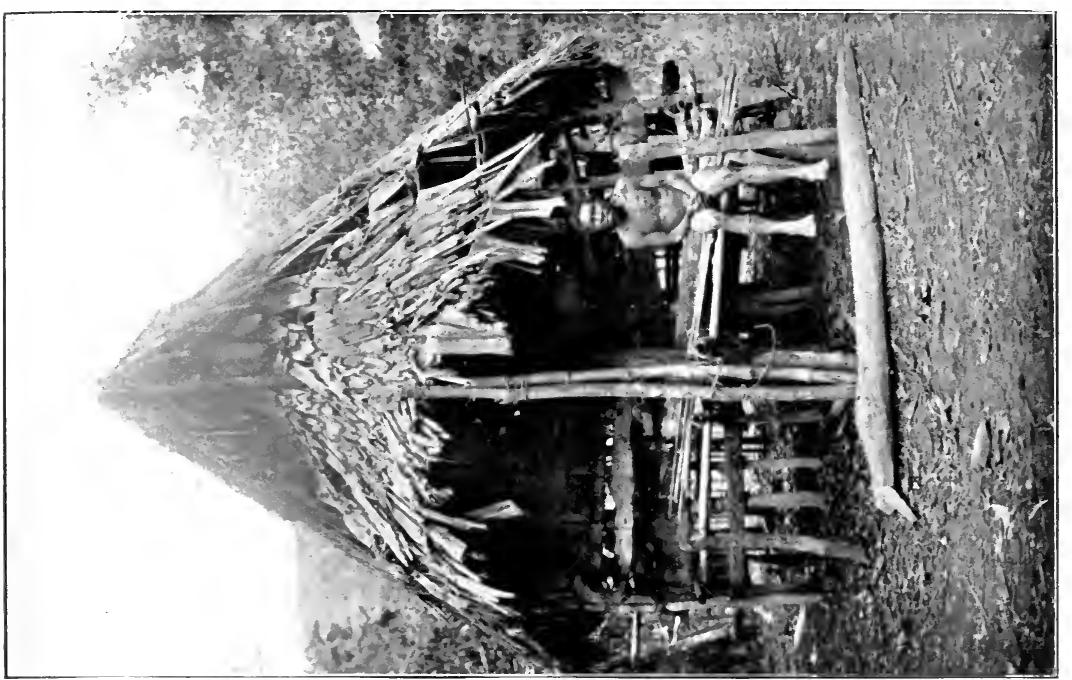

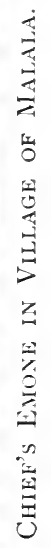

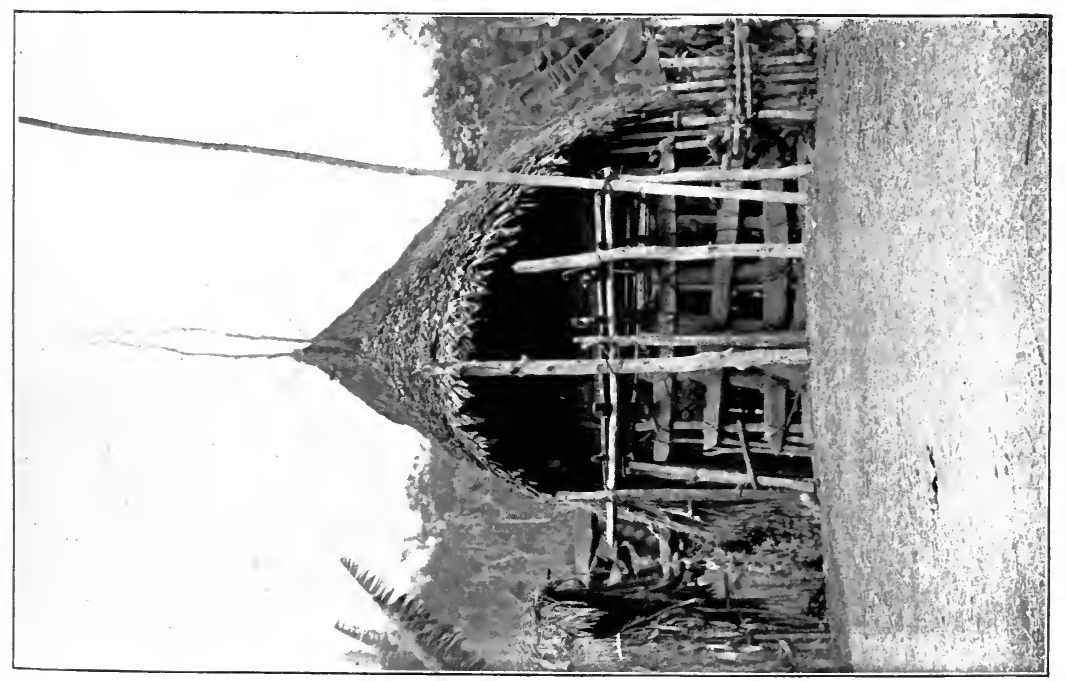

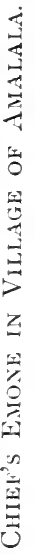



been referred to. I will now deal with their manufacture and colouring. They are made exclusively by women; and the fibres used in their manufacture are not the same as those employed for making nets and hammocks. I will deal separately with the five forms already described by me.

Nos. I and 2 are made of either ordinary or Mafulu network, and are never coloured. When these, or any other bags, are made of Mafulu network, their elasticity is very great. No. 3 is always made of Mafulu network, and coloured. No. 4 is made of Mafulu network, and is sometimes coloured, and sometimes not. No. 5 is made of Mafulu network, and is sometimes coloured. The string used in making this bag is different from that used for the others, and is obtained from the bark of a small shrub.

The question of manufacture introduces another form of bag (Plate 53, Fig 3), which I may call No. 6. It is used by men for the purposes of No. 4, and No 5 is also sometimes made in the same way. The method of manufacture of No. 6 is, I was told, an uncommon one; and, though I was able to procure one of these bags, I had not an opportunity of observing the process by which it was made. The appearance of the bag, however, suggests a process not unlike that of knitting. Its outer surface displays a series of thick, strong tricord-plaited, vertical ridges, all close together, and looking very like the outside ridges of a knitted woollen stocking; but on the inner surface these ridges are not to be seen, and the general appearance of this inside is one of horizontal lines. 
The material of this bag is much closer, thicker and heavier than is that of any of the others.

The colouring of Nos. 3,4 and 5 is not put into the netting after its manufacture, as is done with bark cloth. The string itself is dyed beforehand, and the lines of colour are worked into the bag in the process of netting. The colouring is confined to the front of the bag only, being the part which is visible when the bag is worn hanging over the back or shoulder. Speaking generally, the colouring is black; but there is often a little red introduced along with the black. The pattern is in the general form of parallel horizontal lines or stripes, which, however, are in places made to recess or turn downwards or upwards at right angles, and subsequently turn upwards or downwards again, and then continue horizontally as before, thus giving variety to the mere design of straight horizontal lines ; and these rectangular breaks are often introduced at more or less symmetrical intervals. There are other details in these patterns, which can be observed in the plate. I have one of these bags the lines in which are blue, red and yellow; but I think this colouring is not usual. The pigments are obtained from the sources described above with reference to bark cloth.

The colouring of my specimen of No. 6 bag is also worked into the bag in the process of knitting, or whatever that process should be called. But this colouring merely consists of four faint horizontal lines of pale reddish-brown; and I was told that these bags are generally uncoloured, or only slightly coloured in thin lines. 
XIII BARK CLOTH MAKING, NETTING, ART 209

The mourning vests worn by chiefs' widows are, I - believe, made of Mafulu network; but unfortunately I did not see one of these, and so cannot describe them.

\section{Art, Design, etc.}

Art and design among the Mafulu people are only of a simple and primitive type. There is no carving or other decoration on their houses, or even on their emone, nor is there any on their stone or wooden implements. Art and design, other than the arrangement of feather ornaments, is, in fact, apparently confined to the very simple designs scratched upon some of their broad abdominal belts, smoking pipes and lime gourds and perhaps occasionally on one or two other things, and to the plaited designs displayed in the manufacture of other abdominal belts and of arm and leg ornaments and plaited forehead ornaments and feather frames, and to the very simple linear patterns in which some of their network is made, and the ground-staining and pattern-colouring of their perineal bands, dancing aprons and ribbons. As regards the latter, the designs are of a very simple nature, never apparently representing anything either realistically or conventionally, and being confined to geometric designs of straight lines and bands, rectangular and zig-zag patterns with coloured triangles within the zig-zag patterns, and spots. The patterns of the perineal bands and dancing ribbons are very simple indeed; but those of the dancing aprons are more elaborate, covering a considerable surface of 
cloth, and often displaying a fair variety of design on the same apron.

The Mafulu have no visible method of recording events or numbers, or sending messages, either by marks or notches on sticks, or tying of knots in string, or any other method, and they are quite unable to grasp the meaning of a map.

The limited nature of the ideas of artistic design possessed by the Mafulu people is, I think, a matter for surprise. They are believed to have Papuan or Papuo-Melanesian blood in their veins. But, even if they also have another distinct and more primitive ancestry of their own, not associated with the PapuoMelanesian types, or even with the pure Papuan types, found on the coast and in the plains, one would imagine that contact with these types would have caused the Mafulu people to learn something of the more advanced art which these other peoples display and that we should not have to record a sudden drop from artistic designs embodying curves and natural imitative art to a system confined to straight lines, zig-zags, and spots. This contact with the coast and plain people, or at all events with the latter, has certainly existed for some time back; for, though the mutual fear and antagonism between coast and mountain natives, which is usually found among savage peoples, has doubtless existed in this case, and is even now not altogether eradicated, ${ }^{1}$ direct or indirect trading

1 The I9Io comet was regarded by some of the Mekeo people with terror, because they thought it presaged a descent of the mountain natives upon themselves. 

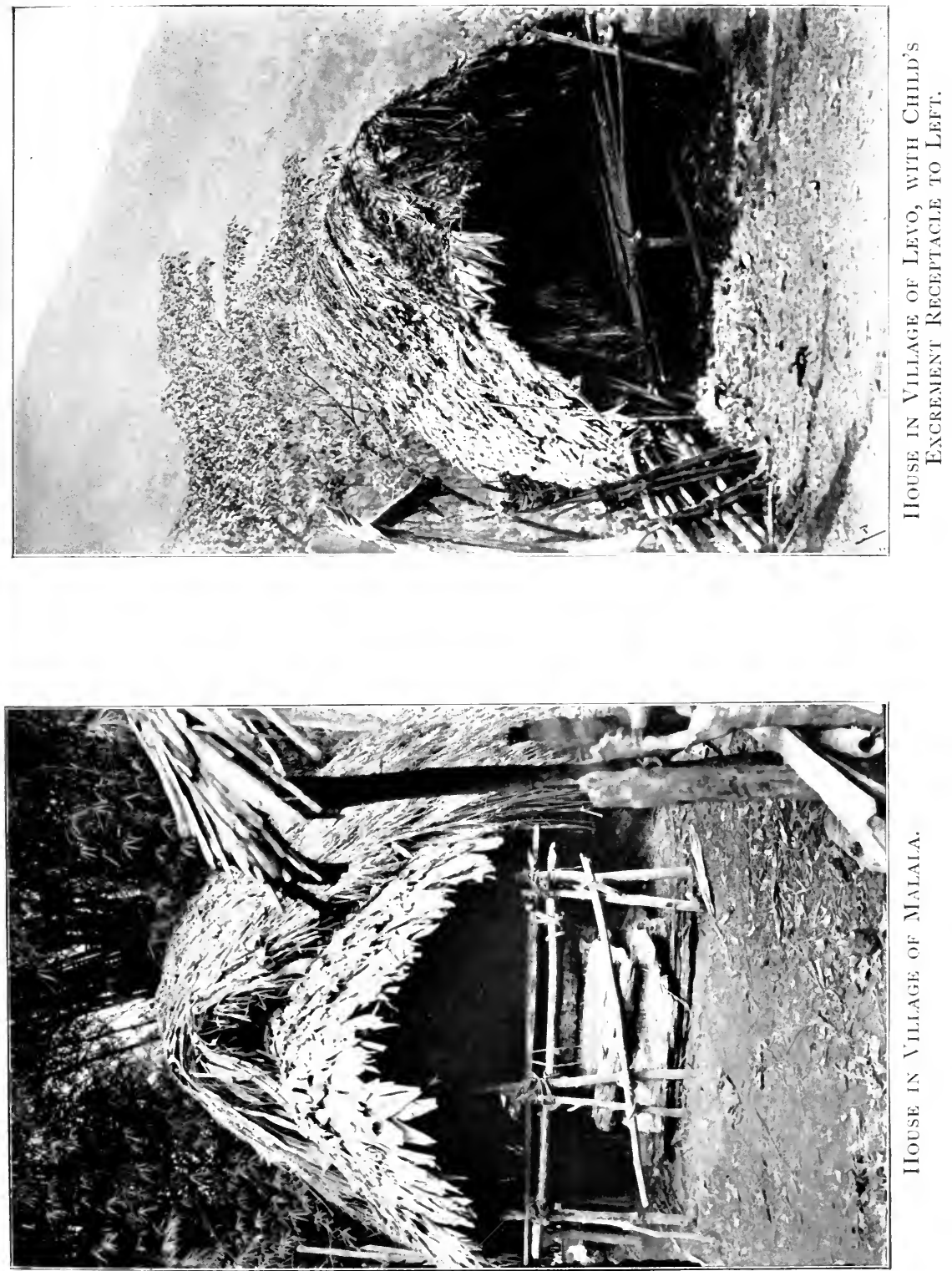

relationship, including in particular the interchange of the stone implements and feathers of the mountains for the shell decorations of the coast, is not a mere recent development of the last few years only. It seems to me that the existence of this decorative hiatus points to a rather small inherent sense of design in the Mafulu mind. It may be, however, that the absence of imitative art, to which I have already referred in connection with totemism and clan badges, is partly due to the absence of totemism and of the imitative stimulus, which, as Dr. Haddon has more than once pointed out, ${ }^{1}$ arises from it.

1 See Evolution in Art (1895), p. 264; and Geographical Journal, Vol. 16, p. 433. 


\section{CHAPTER XIV}

MUSIC AND SINGING, DANCING AND TOYS AND GAMES

\section{Music and Singing.}

ThE Mafulu people are naturally musical and have good musical ears-much more so than is the case in Mekeo and on the coast, thus conforming to what I believe to be a general rule that music is usually more indigenous in hill country than it is in the plains. Their instruments are the drum, the jew's-harp and a small flute; but the flute is not a true Mafulu instrument, and has probably been acquired from Mekeo.

The drum (Plate 75, Fig. 3) is like the Mekeo drum, but smaller, and its open end is cut in deep indentations. The wooden body of the drum is made from various trees. A pine tree is the favourite one; but others are used, including a tree the native name of which is arive, which word is also the native word for a drum. The membrane is made of the skin of a reptile, probably the "iguana." The maker of a drum must climb up the tree from the wood of which he is about to make it, and there, until the drum is finished, he must remain sitting among the 
branches, or, if these are inconvenient for the purpose, he may erect a scaffold around the trunk of the tree, with a platform on the top of it, and work upon that. Whilst working, he must always keep the upper or tympanic end of his drum facing the wind, the idea of this being that the wind gets into the drum, and makes it musical. His food is brought to him, whilst in his tree, by some woman, probably his mother if he is a bachelor, or his wife if he is married, and he lets down a string by which he hauls it up ; but he is under no special restriction as to the food he may eat. There is no superstition, such as is found among the Roro and Mekeo people, compelling him, in the event of his seeing a woman during the making of the drum, to throw it away and begin a new one.

The jew's-harp (Plate 20, Fig. 2), though seen in Mekeo, is, I was told, as regards its manufacture, an instrument of the mountains. It is made out of bamboo or palm, or some other tree having a hollow or soft interior, from which is cut a piece about 8 or Io inches long. A portion of this piece is cut away longitudinally, leaving for the making of the instrument only two-thirds or half, or even one-third, of the convex outside stem circumference on one side and the flat surface of the cut-away part on the other, and the latter is then hollowed out, leaving, however, a solid head an inch or two long at one end. The hollow piece thus produced is cut into three longitudinal sections or strips, of which the two outside ones are longer than the central one. The two outside strips are left at their full width from the head downwards to a 
distance of 2 or 3 inches from the other end, from which point they are cut away, very much as one would cut away the divided nib of a quill pen, so that the actual tips of these two strips are quite slender, being no broader than their thickness. These two ends are tied together with fine vegetable fibre. The centre strip, which is generally narrower than the other two at its commencement by the head, is further reduced in width by a more immediate and gradual process of paring down, and so becomes a very slender vibrating tongue or reed, the tip of which goes almost up to, but does not quite reach, the point at which the tips of the two outer strips are bound together. A hole is bored through the solid head; and through this hole is passed a thick string of native make from 5 to 10 or 12 inches long, secured at one end by a knot on the flat side of the head, to keep the string from slipping out, and having at the other end a large, rough, ornamental tassel. The tassel is generally in part composed of the untwisted fibres of the string itself; but to these is added something else, such as a bunch of feathers, or two smaller bunches of feathers ; and among these may be seen such miscellaneous articles as a fragment of dried-up fruit, or a part of the backbone of a fish. For playing the instrument, they place its tail end, with the hollow side inwards, to the mouth, holding the extreme tip of that end in the fingers of the left hand, and keep the tongue of the instrument in a constant state of vibration, by smart, rapid, jerky pullings of the tasselled string.

The flute is merely a small simple instrument made 


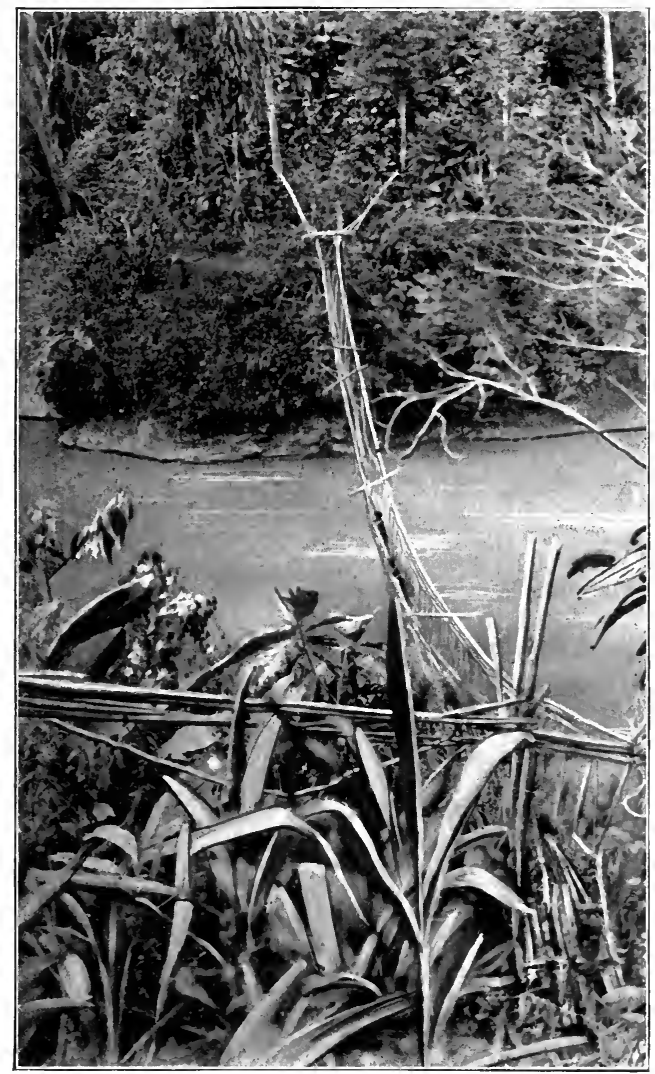

Suspension Bridge oter St. Joseph River (form used for broad rivers).

Plate 66.

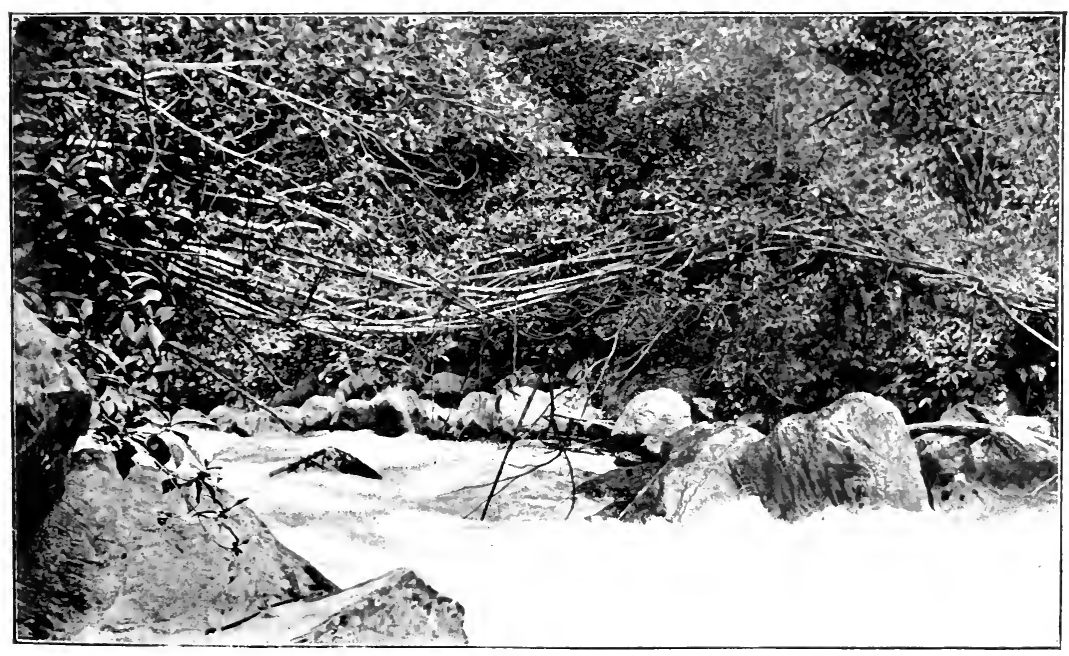

Bridge over Aduala kiver (form used for narrow rivers). 

out of a small bamboo stem, with one or two holes bored in it.

All these instruments are played by both men and women ; but the jew's-harp and flute are regarded only as toys.

I believe the Mafulu people occasionally sing at dances to the beating of the drums; but this is quite unusual; and they never sing to the music of the jew's-harp or flute. Both men and women sing, generally several or many together, not so often alone Their songs are all very simple, and are chiefly sung in unison or octaves. I was told that they sometimes accomplish simple harmonies, the notes of which may simultaneously rise or fall either with the same or different intervals, or may rise and fall in contrary motion; or the harmony may be produced by one man or part of the group sustaining a note, whilst another changes it; and I myself heard an example of the latter of these, and also heard singing in which, while a group of men were singing the same simple air, some of them were occasionally singing one part of it, whilst the others seemed to be singing another part, thus producing a very simple catch or canon. I am not, however, quite certain as to this. Their songs are both cheerful and plaintive; but the latter predominate, and are mainly in the minor key. The subjects of their songs are generally sentimental love, and include ditties by young men about their sweethearts; and I believe that some of their songs are indecent, though I am not sure of this. They 
also have warlike songs; and, when a special event occurs, songs are often composed with reference to it. For example, not long ago a chief was taken by the authorities to Port Moresby, and died there; and songs about this were sung all through his district. Anyone will compose a topical song; in fact, a man will begin singing one in the emone, making it up as he goes on, and the others will join. The men have a very pretty custom of singing together very softly when at the end of the day they have retired to their emone, and have lain down to sleep, the singing being very gentle, and producing what I can only describe as a sort of crooning sound, like a lullaby or cradle song. I once heard one of these songs sung by my carriers the last thing at night as they lay beneath the floor of the building in which I was sleeping; and the effect was absolutely charming.

As an example of Mafulu music I give the following, which, though not, I fear, quite accurate, is I think a substantially correct version of the music of a war song sung by the Mambule and Sivu communities in connection with joint hostilities by them against another community, and I have so far as possible added the song itself.
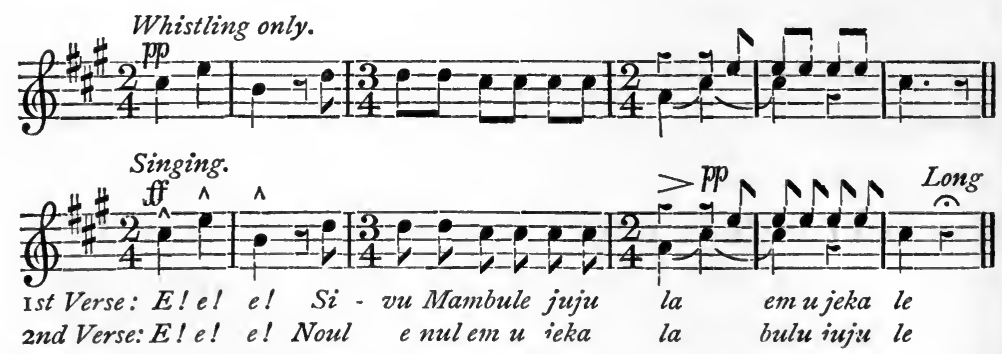
It will be observed that the first line is whistling only. I was informed that it is a common practice to whistle the air before singing the first verse; though I did not gather that it was always done. It will also be noticed that simple harmonies occur in the fourth and fifth bars. I cannot say whether the two parts in the music are sustained or taken up by the voices upon any defined scheme, and, if so, what that scheme is. Nor can I say whether the voices which take the lower notes in the music are silent after the word $l a$, or repeat that word in the sixth bar, with or without the upper voices, in order to bring the tune to a full close. I have only given two verses; and, as regards the song in question, I doubt if there were any more. Unfortunately I am unable to translate the words, and can only give the meanings of the following :-

$E ! e ! e !$ are merely meaningless exclamatory sounds, such as we have in civilised songs. Sivu is the name of a Fuyuge community close to the Mission Station, being, in fact, the one referred to by me in my chapter on communities. Mambule is the name of another of these communities, further away from the station, being, as stated in my introductory chapter, the name of the community from which the name Mafulu arises. I cannot give verbal explanations of any of the other words; but I may say that a rough translation of the second verse is "My village, your village is alike (or equal.)" 


\section{DANCING.}

The Mafulu people, like other New Guinea natives, are fond of dancing, and indulge in it extensively, especially in connection with feasts and ceremonies.

Their dancing is of an exceedingly active and lively character. The movements of the feet are lively and jumping, often half a hop and half a run ; and, whilst dancing, their heads are actively moving backwards and forwards and to both sides. The general progressive movement of a dancing party is slow, but not a crawl; and the progress along the village enclosure is usually accomplished by a series of diagonal advances, by which they zig-zag backwards and forwards across the enclosure, and in this way gradually travel along it. Very often the dancers divide themselves into two parties, which in their zig-zag progress alternately approach and recede from each other. The dancers are always facing in the direction in which at that moment they are moving. Men and women never dance together, except at the big feast, where they do so in the way already described.

This method of dancing is in striking contrast to that of the Mekeo people, whose movements are generally very gentle and slow, those of the feet, which are accompanied by a corresponding genuflexion, downwards and outwards, being a slow slight step, usually barely more than a shuffle, the feet being hardly lifted off the ground, and those of the head being confined to a slow and sedate backwards and forwards nodding. Also the progress of a party of 


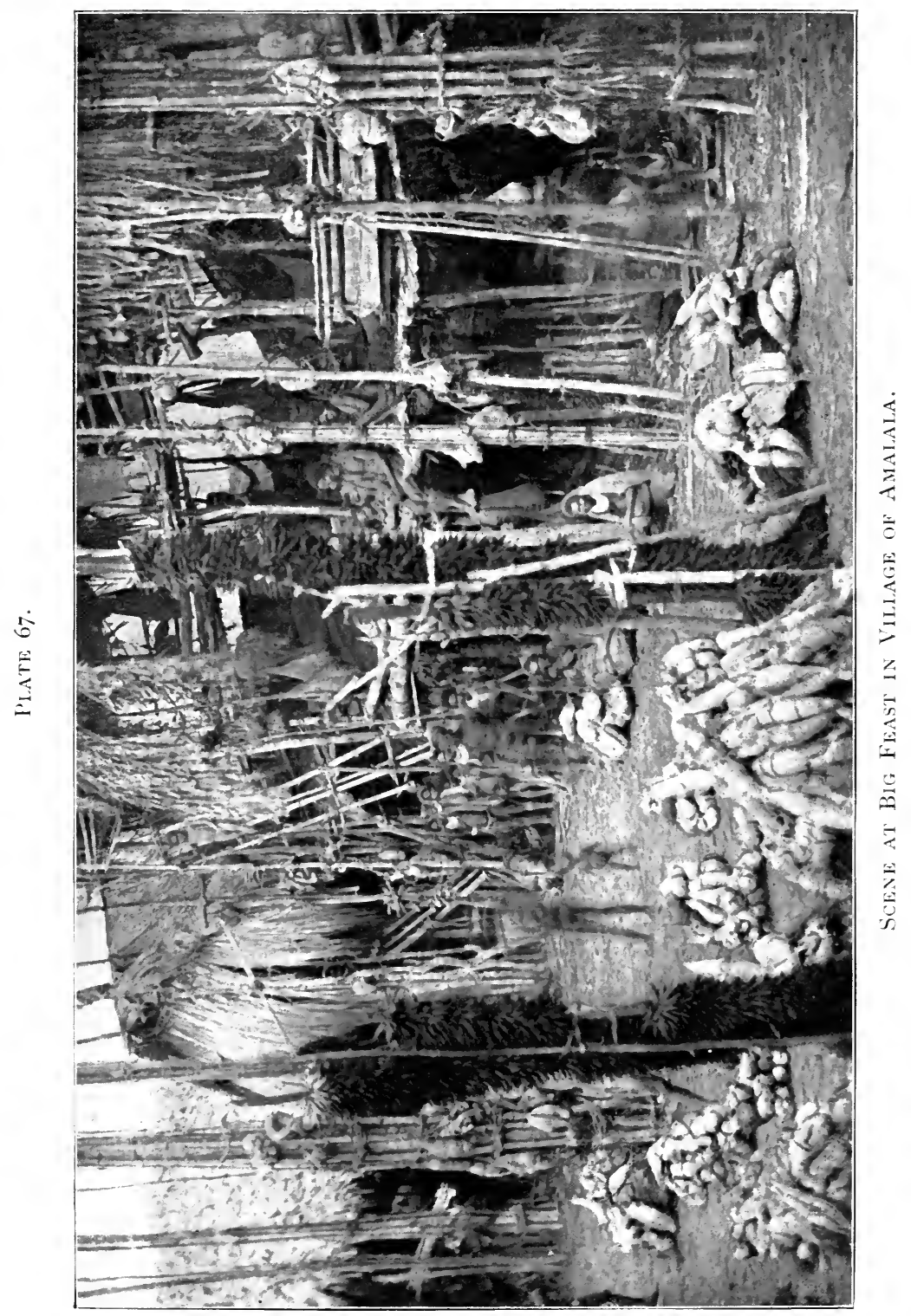



Mekeo dancers is generally very slow, - a crawl,-so much so as often to be barely perceptible, perhaps two or three inches being accomplished at each step, and the line of progress of a dancing party is usually a straight line down the village enclosure; and more commonly, though not always, the position of each dancer is sideways to the then actual direction of progression. And in Mekeo women and men often dance together in one group.

Another difference between Mafulu and Mekeo dancing is that among the Mafulu, though the drumbeating and dancing go on simultaneously, the singing, in which all the dancers and non-dancers of both sexes join, does not usually take place during the actual dancing, but only during periodic pauses, in which the drum-beating and dancing cease; whereas in Mekeo the drum-beating, dancing and singing all go on continuously and simultaneously. As regards these Mafulu pauses in the dancing, I should explain that these are quite distinct from the resting pauses (in which there is neither drum-beating, dancing, nor singing) which are customary both among the Mafulu and the Mekeo people.

A further difference arises as regards the dancing decorations. Both Mafulu and Mekeo natives have elaborate high framework read feather decorations, which are worn by some, but not necessarily all, of the dancers; and they are much ornamented about their bodies. But the Mafulu people generally wear their finest and most beautiful feathers on their backs, whereas among the Mekeo natives the head orna- 
ment is the chief feature of the decoration; and in Mekeo any man who has not a framework head decoration generally has sticking in his hair a tall, upright feather, which sways slowly backwards and forwards in response to the slow nodding movements of his head.

The special dancing ornaments worn by the Mafulu are the aprons worn by women, the ribbons worn by men and women, the forehead ornaments worn by men, the long shell nose ornaments worn by both, and the huge head feather erections. But for dances the people generally wear all the decorative finery they possess or are able to borrow; and they usually with special care paint their faces in various colours, and their bodies red.

The comparison above given between the dancing of the Mafulu people and that of the people of Mekeo brings me to a suggestion, made to me by Father Clauser, that the Mafulu mode of dancing had its origin in an imitation of that of the red bird of paradise, and the Mekeo mode in an imitation of that of the goura pigeon. In support of this suggestion he gave me the following information concerning the dancing of these birds, which may be compared with the description given above of the dancing of the Mafulu and Mekeo natives respectively :-

The movements of the red birds of paradise, when dancing, are remarkably lively, the birds hopping and jumping about the tree branches and from branch to branch, and bobbing their heads backwards and forwards and from side to side, almost as though they had gone mad. The progression along the branches is 
xiv MUSIC AND SINGING, DANCING, ETC. 221

fairly rapid ; but there is not apparently any continuous

- line of progression in any given direction, and the birds seem to have a curious way of approaching and receding from each other as they do so. The birds always face in the direction in which they are at the time moving, and do not dance sideways. Moreover, the dance is an alternation of wild dancing and intermittent pauses; and during the dancing both the males and females are silent, but during the pauses they are uttering their songs or cries.

The dancing movements of the goura pigeons are a gentle slow shuffle, and are accompanied by a slow bowing or nodding of the head. The progressive movement is exceedingly slow, and is always a continuous one in the same direction, and it is usually a sideways movement. The dancing and accompanying cooing of the pigeons go on continuously and simultaneously, and the rhythm of the latter is curiously like the more usual rhythm of the Mekeo drums.

I have unfortunately never had opportunities of observing the dancing of either of these birds, and so cannot personally vouch for the correctness of the above descriptions of them. But Father Clauser has often watched them, and he is undoubtedly a careful observer, upon whose testimony we may rely; and I may add that my efforts since my return to England to obtain evidence, confirmatory or otherwise, of these descriptions have produced confirmation of some of the facts stated, and have not produced any contradictions.

Then again attention must be drawn to the fact 
that the magnificent feather decoration of the bird of paradise is mainly upon or springing from its back or body, whilst the goura pigeon's sole projecting decoration, and perhaps its chief beauty, is the crest upon its head, to which the Mekeo single upright head feather may be likened.

My efforts to obtain light from native sources upon this question of imitation in Mafulu were fruitless, as the natives questioned knew nothing of it ; and on my return from Mafulu to the coast I did not again pass through the Mekeo villages. But on reaching the coast I made further enquiries upon the subject from the Fathers there of the Mission, and obtained three interesting pieces of information. First, I was told that the Mekeo clan Inawae of the Mekeo village Oriropetana, whose clan badge is the goura pigeon, and who are not allowed to kill and eat it, and whose bird totem it appears to be, say that they are descended from the goura pigeon, and that an ancestor of theirs, though himself a man, had all the powers and faculties of movement of those birds, and that he used to dance with them, and so learnt the dance and taught it to his people. Unfortunately no enquiry had been made as to the question of any imitative character in their present dancing, and the information only emanated from a particular clan with a particular association with the bird. I therefore do not attach undue general importance to this case. ${ }^{1}$

1 I would point out, however, that the Inawae clan is part of, and is probably largely representative of, the original Inawae ngopu group of the great Biofa tribe of Mekeo, and that this Inawae group is rather widely 


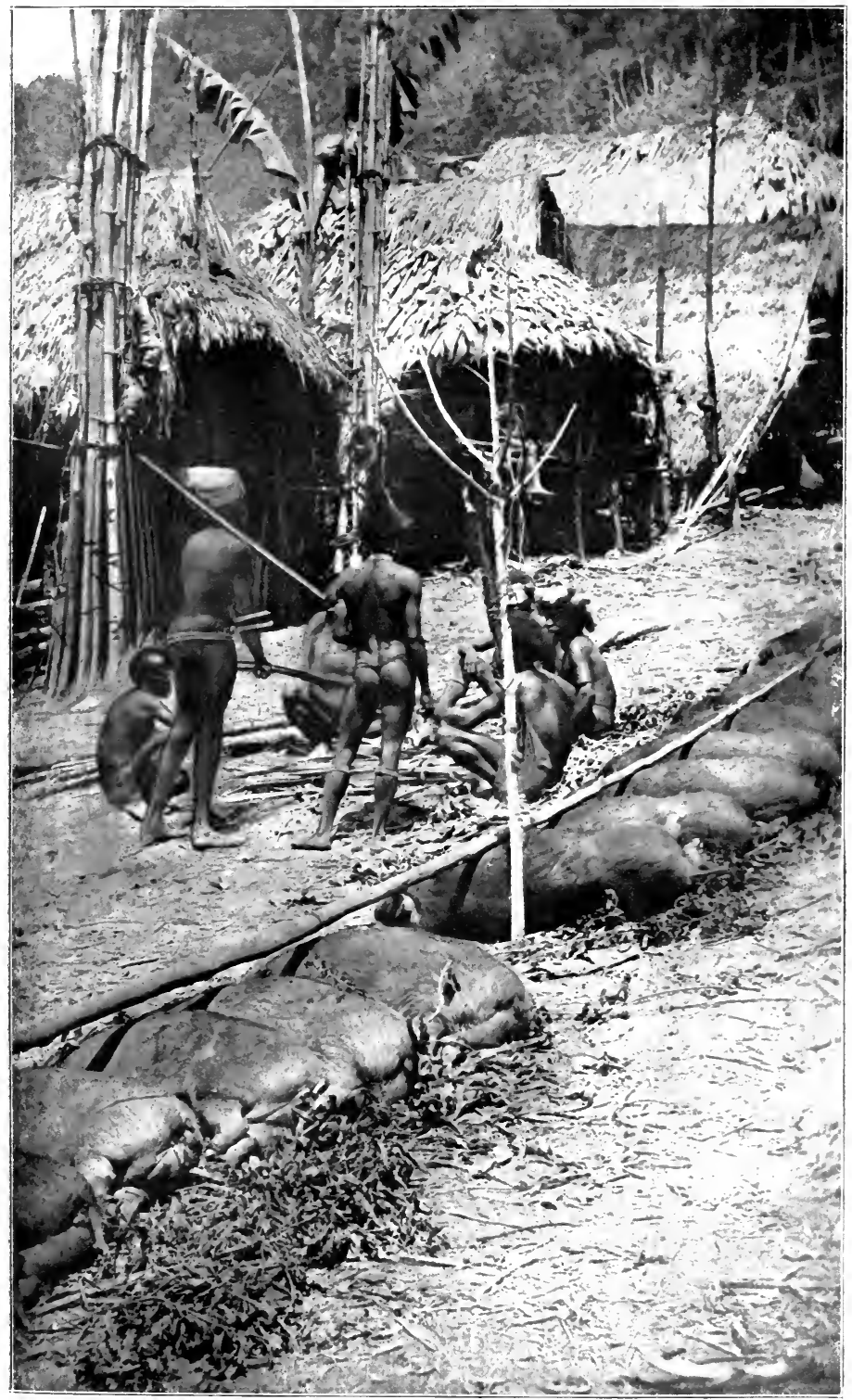

kow of Killed pigs at Big Feast at Viliage of Amalala. 

Secondly, I was told that the Pokau people, whose dance is practically the same as that of the Mekeo people, themselves say that their dancing is an imitation of that of the goura pigeon. This certainly tends to support Father Clauser's suggestion as regards Mekeo. Thirdly, some natives of Kuni, who are undoubtedly very similar and closely related to the Mafulu, and whose dancing is very similar to that of the latter, were questioned on the subject in my presence, and under my direction. The question put was, "When Kuni people are dancing, are they in their dance imitating anything, and if so what?" (no mention or suggestion being made of a bird or of anything else). The answer was that they were imitating the dance of the goloala, which I was told was not the red bird of paradise, but was another small species of that bird with a yellowish-white body, yellow head and yellowish-white wings. The leading question was then put to them, whether they were sure the bird was the yellow one described by them, and not the red one; which question was answered definitely in the affirmative. And subsequently, when, in order to test their definiteness and certainty in what they had told me, I showed them a few postcard pictures of birds of paradise, which included the red one and others, but not one such as is above described, and almost invited them to recognise one of these as being the bird they meant, they were firm in

scattered over Mekeo (see Seligmann's Melanesians of British New Guinea, p. 321 and pp. 369 to 372 ) ; so that the information obtained is probably not really of a merely local character. 
their insistence that the bird to which they referred was not shown in any of the pictures. This, I think, helps to support Father Clauser's suggestion as regards the Mafulu, subject of course to the question of the variety of bird of paradise which is imitated.

Dealing with this question of imitation as a whole, and taking into consideration the apparently marked similarities between the dancing of the two tribes of natives and the two genera of birds, and the further element, perhaps not so strong, as to the similarities in distribution upon the bodies of their decorations, and bearing in mind the evidence obtained from native sources, which, though obviously only fragmentary and insufficient in character, is so far as it goes distinctly confirmatory, I am impelled to suggest that Father Clauser's theory is not without foundation, and indeed amounts, subject to the question of the species of bird of paradise, to a very substantial possibility. And it is undoubtedly an interesting one. ${ }^{1}$

1 Sir W. Macgregor, in describing (Ann. Rep., June, 1890, p. 47) the movements and actions of the Kiwai (Fly river mouth) natives prior to a canoe attack by them upon him, says : "The canoes darted hither and thither, as if performing a circus dance or a Highland reel, and all these movements were accompanied by the chant of a paean that sounded as if composed to imitate the cooing-soft, plaintive, and melodious - of the pigeons of their native forests"; and he refers to the performance as a "canoe choral dance." It was, of course, not a dance in the sense in which I am dealing with the subject here; but the apparently imitative character of the singing is perhaps worth noticing in connection with this dancing question. See also the description (Country Life, March 4, I9I I) by Mr. Walter Goodfellow, the leader of the recent expedition into Dutch New Guinea, of the dancing and accompanying singing of the Mimika natives whom he met there, and his suggestion that the final calls of these songs were derived from that of the greater paradise bird. Mr. Goodfellow has since told me with reference to these Mimika songs that he was forcibly struck by the resemblance of the termination of most 


\section{Toys and Games.}

The Mafulu children have neither dolls nor other toys, and do not make cat's-cradles. The young boys amuse themselves with small bows and arrows and spears, which they make themselves. One common sport is for the boys, armed with their spears, to stand in a row and for another boy to roll in front of them a ball, made out of the root of a banana tree, with its many rootlets intertwined, and for the boys to try to hit it with their spears as it passes them. A similar game is played in Mekeo and on the coast; but there the ball is often made out of the outer fibre of a cocoanut. Small boys and girls amuse themselves with glissading down the steep grassy slopes. There is also a sort of fighting game for boys, in which young men sometimes join. A number of them divide themselves into two opposing groups, all armed with little darts, made of reeds on which a few leaves are left at the head ends; and these two groups mutually attack each other, advancing and retreating, according

of the songs to the common cry of the greater bird of paradise, and said : "They finished with the same abrupt note, repeated three times (like the birds)." Dr. Haddon has been good enough to lend me the manuscript of his notes on the dances performed in the islands of Torres Straits, which will probably have appeared in Vol. IV. of the Reports of the Cambridge Anthropological Expedition to Torres Straits before this book is publisbed. Here again I find interesting records of imitative dancing. One dance imitates the swimming movements of the large lizard (Varanus), another is an imitation of the movements of a crab, another imitates those of a pigeon, and another those of a pelican. At a dance which I witnessed in the Roro village of Seria a party from Delena danced the "Cassowary" dance; and Father Egedi says it is certainly so called because its movements are in some way an imitation of those of the cassowary. 
226 THE MAFULU MOUNTAIN PEOPLE ch. XIV to the fortunes of the fight. Boys, and men also, play at tug-of-war, using long canes for ropes; and boys and girls have swings, constructed either by looping two flexible rope-like tree stems together at the bottom, or with a single rope, with a loop at the bottom, in which to place their feet. But there are no racing or jumping or gymnastic games, and no group or singing children's games. 


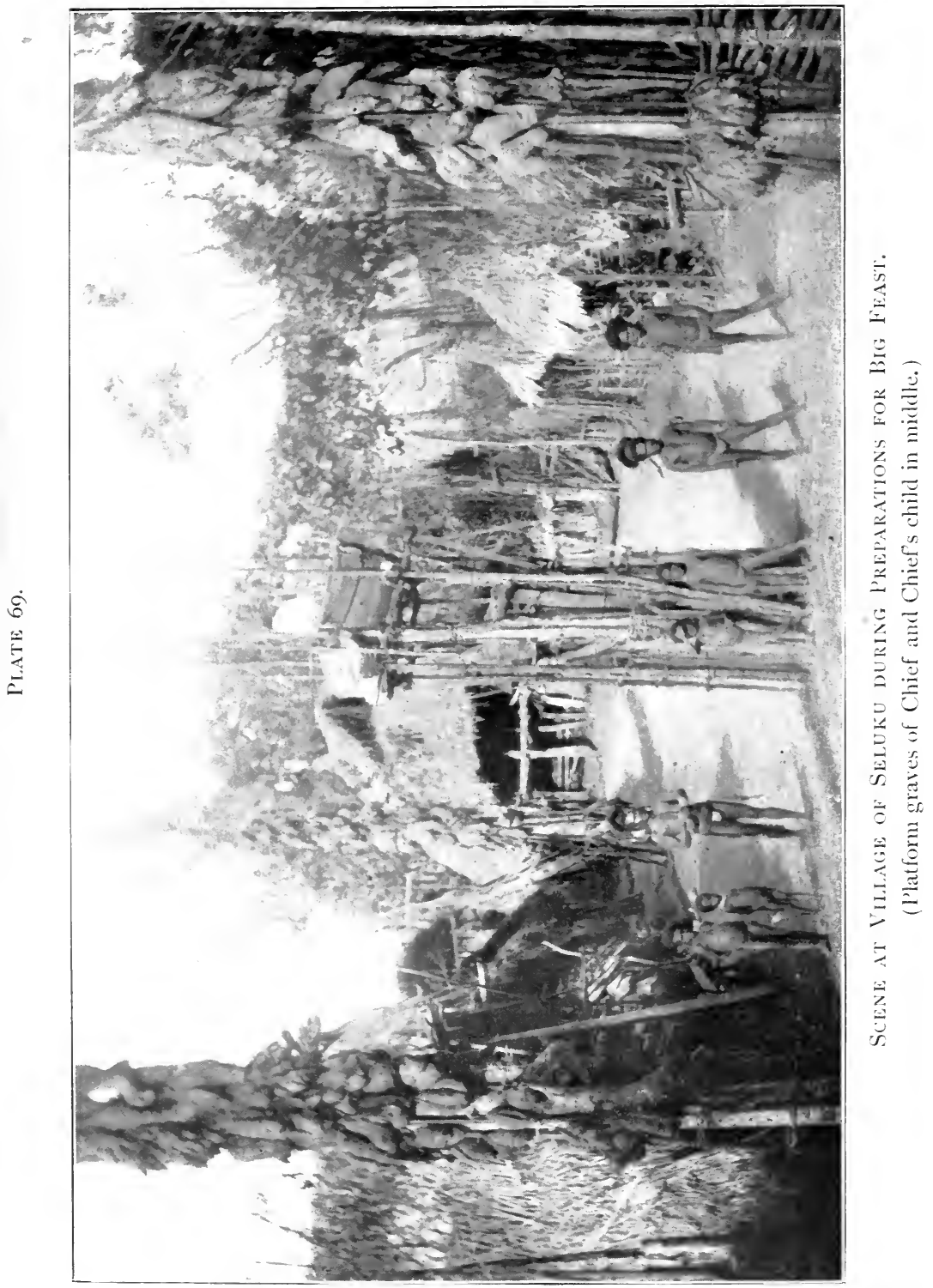





\title{
CHAPTER XV
}

\author{
COUNTING, CURRENCY AND TRADE
}

\section{Counting.}

Mafulu counting is accomplished by the use of two numerals (one and two) and of the word "another" and of their hands and feet ${ }^{1}$; and with these materials they have phraseology for counting up to twenty as follows :-

$$
\begin{aligned}
\mathrm{I} & =\text { Fida (one). } \\
2 & =\text { Gegedo (two). } \\
3 & =\text { Gegedo minda (two and another). } \\
4 & =\text { Gegedo ta gegedo (two and two). } \\
5 & =\text { Gegedo ta gegedo minda (two and two and } \\
& \text { another) [or Bodo fida (one hand) }] . \\
6 & =\text { Gegedo ta gegedo ta gegedo (two and two and } \\
& \text { two). }
\end{aligned}
$$

1 Compare the Western Papuan', who, according to Dr. Seligmann, also have only two numerals, but who are apparently not able to count to anything like the extent which can be done by the Mafulu (Melanesians of British New Guinea, p. 4). According to Mr. Monckton the Kambisi (Chirima valley) people only count on their fingers and up to ten, not on their toes and up to twenty (Annual Report, June, 1906, p. 89). Father Egedi told me that the Mekeo people only count on their fingers and up to ten. 
7 = Gegedo ta gegedo ta gegedo minda (two and two and two and another) [or Bodo fida ta gegedo (one hand and two) ].

$8=$ Gegedo ta gegedo ta gegedo ta gegedo (two and two and two and two) [or Bodo fida ta gegedo minda (one hand and two and another)].

$9=$ Gegedo ta gegedo ta gegedo ta gegedo minda (two and two and two and two and another) [or Bodo fida ta gegedo ta gegedo (one hand and two and two) ].

$\mathrm{IO}=$ Bodo gegedo (two hands).

I I = Bodo gegedov' u minda (two hands and another). [Note the " $\mathrm{v}$ " at the end of gegedo. The full word is really gegedove; but it is shortened to gegedo, unless the next word is a vowel. Also note the "u." There are two words for " and," namely ta and une. The "u" here is the une shortened, and put instead of $t a$ for euphony].

12 = Bodo gegedo ta gegedo (two hands and two).

$I_{3}=$ Bodo gegedo ta gegedo minda (two hands and two and another).

I 4 = Bodo gegedo ta gegedo ta gegedo (two hands and two and two).

I 5 = Bodo gegedo ta jovari fida (two hands and one foot).

16 = Bodo gegedo ta jovari fidan' u minda (two hands and one foot and another). [Note the " $\mathrm{n}$ " at the end of fida. The full word is really fidane, and the " $\mathrm{n}$ " is introduced here for euphony.] 
I 7 = Bodo gegedo ta jovari fida ta gegedo (two hands and one foot and two).

I 8 = Bodo gegedo ta jovari fida ta gegedo minda (two hands and one foot and two and another).

I9 = Bodo gegedo ta jovari fida ta gegedo ta gegedo (two hands and one foot and two and two). 20 = Bodo gegedo ta jovari gegedo (two hands and two feet).

As regards these numerals it will be seen that in some cases alternatives are given, whilst in other cases, where corresponding alternatives would appear to be equally applicable, they are not given ; the reason is that in these latter cases the alternatives do not in fact appear to be used.

There is no numerical phraseology to indicate any number above twenty ; and in the ordinary affairs of life, although numeration can be carried in this cumbrous way up to twenty, they rarely use the numerals beyond ten, and anything over that will be referred to as tale, tale, tale, tale (which may be translated " plenty, plenty, plenty, plenty").

Important counting, such as that of pigs at a feast, is accomplished by the actual use of the hands and feet. The fingers stretched open mean nothing; Closing down the thumb of the right hand indicates one; closing down also the first finger of that hand indicates two; and so on with the other fingers of the right hand, till you reach the closing down of the thumb and all the fingers of the right hand, which indicates five. Then, keeping all the right hand closed, they begin with the left hand also. Closing 
down only the thumb indicates six; and so on as before, until the thumbs and all the fingers of both hands are closed, which indicates ten. ${ }^{1}$

Then they go to the feet. They keep both hands closed and together, and with the right fist they point to the toes, beginning with the big toe of the right foot, and so along the other toes of that foot, and then go to the big toe of the left foot, and so along the other toes of that foot, thus reaching the enumerative total of twenty. They do not, when wishing to indicate a number, simply place their fingers and hands and feet simultaneously in the requisite position for doing so. They always go through the whole process of finger and toe counting from the beginning. For example, to indicate eight, they turn in the thumb and all the fingers of the right hand, and afterwards the thumb and two fingers of the left hand, separately, and one atter another, until the right position is reached; and similarly as regards numbers over ten, they solemnly turn down all the fingers one after another, and then point to the toes one after another; until they get to the right one for indicating the desired number. When the fingers and toes of the person counting are exhausted, he has recourse to those of another person, if he wishes to count further, although he has then passed the limit of numerical phraseology. For the purpose of counting big numbers they are always sitting, and as in counting they exhaust hands and

1 I believe that in Mekeo they begin with the left hand and with the small finger, thus reversing the Mafulu order of counting; but I am not quite certain as to this. 


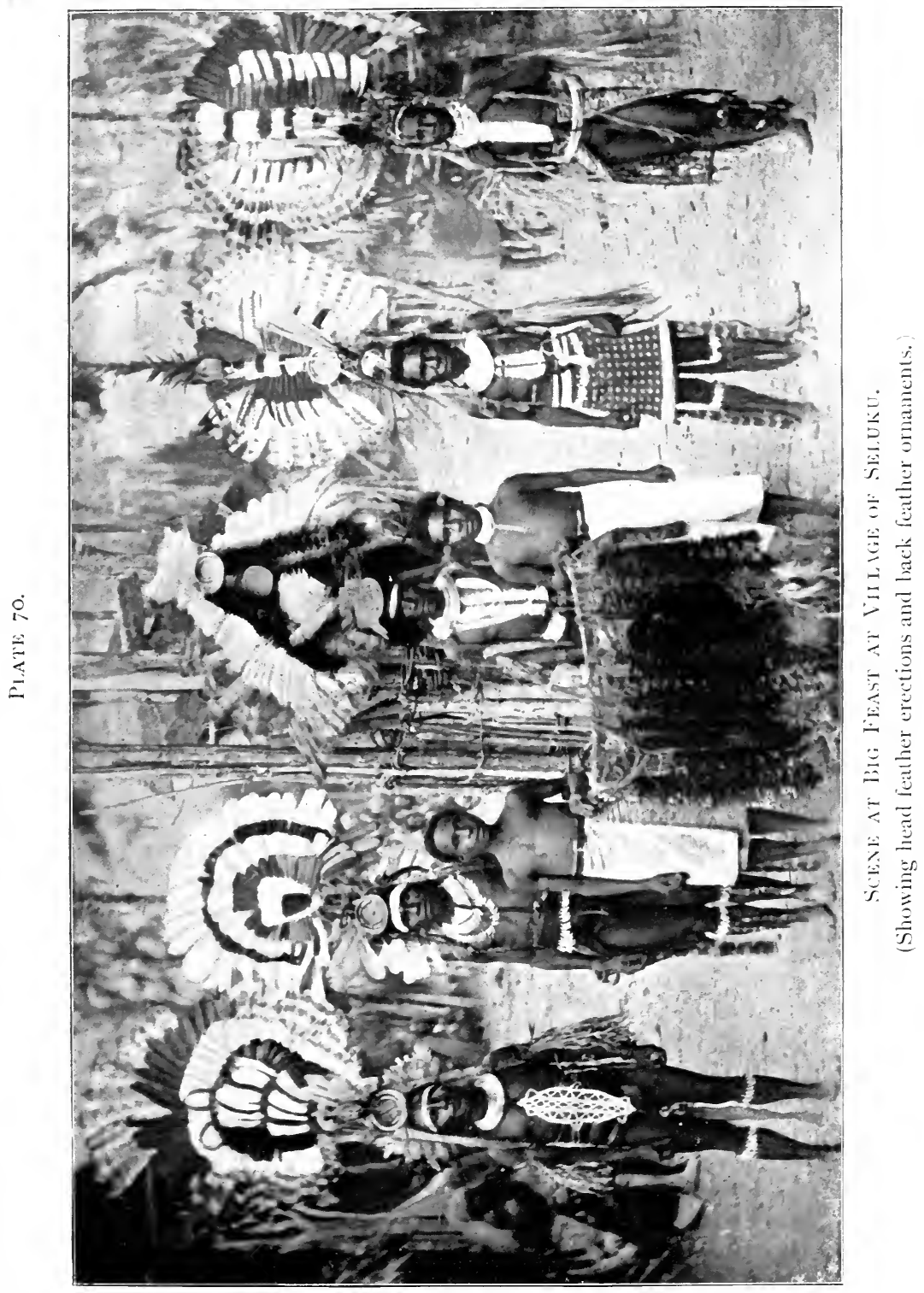



feet, the latter are put together, If, for example, they seach eighty, there are four men sitting, with all their hands and feet crowded together ; and if the number be eighty-three, there is also a fifth man with a thumb and two fingers of his right hand closed up. Sometimes a number above ten, but not over twenty, is indicated with the hands only by counting up to ten in the ordinary way, and then opening all the fingers and counting again, until they reach the requisite amount in excess of ten.

I do not think it can be said that these people have in their minds any real abstract idea of number, at all events beyond twenty. Each finger turned down and toe pointed to, in succession, seems to represent to their minds the article (e.g., a pig) which is counted, rather than a step in a process of mental addition. But this is a matter upon which I can only express myself in a very general way; and indeed the mental stage at which the mere physical idea of the objects counted has developed into the abstract idea of numbers would in any case be exceedingly difficult to ascertain, or even, perhaps, to define.

They never use pebbles or sticks or anything else of that kind, and have no method of recording numbers or anything else by notching sticks ; and they have no weights or measures.

\section{Currency and Trade.}

The Mafulu people have no currency in the true sense, every transaction being one of exchange; but nevertheless some specific articles, especially some of 
the dearer ones, can only be acquired by the offering of certain other specific articles, and certain things have definite recognised relative values for the purpose of exchange.

As examples of the former of these statements, I may say that a pig used to be always paid for in dogs' teeththough this practice is not now, I think, so strict-and that some of their finer head feather dancing ornaments and ornamental nose pieces can still only be paid for in dogs' teeth ; also that there is a special kind of feather ornament, composed of many small feathers fixed in a line on a string, which can only be obtained in exchange for a particular sort of shell necklace.

As examples of recognised relative values, I may state that the proper payment in dogs' teeth for a pig is a chain of dogs' teeth equal in length to the body of the pig, the latter being measured from the tip of its nose to the base of its tail ; and that the payment for the special feather ornament is its own length of the corresponding shell necklace.

Exchange and barter is generally only engaged in between members of different communities, and not between those of the same community. An apparent exception to this arises in the purchase of pigs at certain ceremonies above referred to ; but in this case it is really a matter of ceremony, and not one of ordinary barter. There are no regular markets, such as exist in some other parts of the country, the exchange of goods being effected by one or more individuals going with their articles of exchange to some other community, where they hope to get what 
they require. The nearest approach to a market - arises intermittently when there is to be a big feast. Then the communities giving, and invited to, the feast require a large supply of ornaments, especially for those who are going to dance, and probably do not possess a sufficient quantity. They therefore have to procure these ornaments elsewhere; and the natural place to go to is some other community, possibly a long way off, which has recentiy been in the same want of extensive ornaments for a feast, and has procured and used them, and now has them, so to speak, in stock, and will be glad to dispose of them again. Thus ornaments used for feasts are sold and resold and travel about the country very extensively. 


\section{CHAPTER XVI}

\section{LANGUAGE}

I HAVE been fortunate in having had some interesting and valuable linguistic material placed at my disposal for publication by Father Egedi and in having had further material added to it by Dr. Seligmann and Mr. Sidney H. Ray. I have thought it better to deal with it in five appendices, and I am greatly indebted to Mr. Ray for having undertaken the laborious task of their compilation. I give the following explanation concerning these appendices.

(I) Is a grammar of the Fuyuge language. The original manuscript is the work of Father Egedi, the materials from which it was prepared by him having been collected in the Mafulu villages. The appendix is Father Egedi's Grammar, translated and edited by Mr. Ray.

(2) Is a short note on the Afoa language prepared by Dr. W. M. Strong, when he was Government Agent in Mekeo, and handed by him to Dr. Seligmann for publication. To this note Mr. Ray has added a footnote.

(3) Is a note on the Kovio language prepared by Dr. Strong, and handed by him to Dr. Seligmann. 


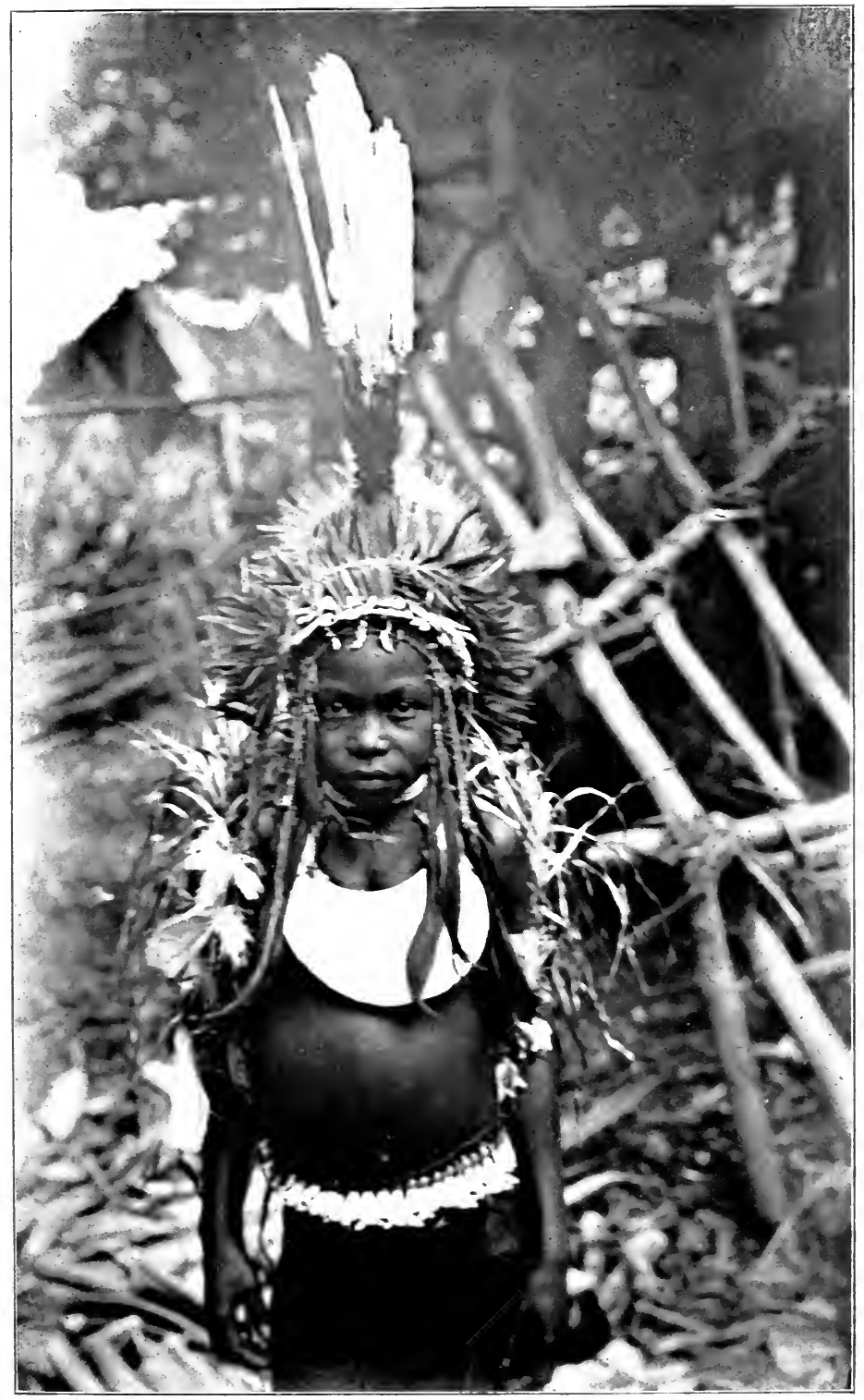

loung Girt, OrNanenter fok Perineal, Banil Ceremony. 

This note refers to the languages spoken in the neighbourhoods of Inavarene and the Inava valley and of the Upper Lakekamu river, all of which were found by Dr. Strong to be somewhat similar. The footnote is by Mr. Ray.

(4) Is a comparative vocabulary, prepared by $\mathrm{Mr}$. Ray, of the languages of some of the different Papuanspeaking people of the mountain districts of Central British New Guinea. The words in the "Mafulu" column are taken from a very lengthy MS. vocabulary compiled by Father Egedi in Mafulu. Those in the "Kambisa" column were all collected by the Rev. P. J. Money in the Kambisa villages of the Upper Chirima valley during Mr. Monckton's expedition, referred to in my introductory chapter. Most of these words are taken from the New Guinea Annual Report for 1905-6; but to them have been added other words, which had been collected by Mr. Money. The words in the "Korona" column are taken from an MS. vocabulary prepared by Dr. Strong at Korona, also mentioned in my introductory chapter, and handed by him to Dr. Seligmann. Those in the "Afoa" column are taken from an MS. vocabulary prepared by Dr. Strong in connection with his Afoa notes, to which are added in square brackets some other words taken from Father Egedi's vocabulary in Anthropos II., I 907, pp. IOI6-IO2I, this vocabulary being there called by him Tauata. The words in the "Kovio" column are taken from an MS. vocabulary prepared by Dr. Strong in connection with his Kovio notes, to which are added in square brackets some "Oru-Lopiku" words 
collected by Father Egedi, and published in Anthropos II., I907, pp. IOI6-IO2I. As regards this column I must explain that Dr. Strong's words were all collected within the districts to which his notes refer, but that Father Egedi's words, though in part collected there, were, I believe, in part collected further to the east.

(5) Is a series of notes by Mr. Ray upon the matter contained in the previous appendices.

I am perhaps open to criticism for introducing into a book of my own notes on the Mafulu people such extensive material written by others, and relating to other mountain districts as well as to that of the Mafulu; but my belief as to the probable similarity in many respects between the Papuanspeaking natives of these central mountain districts, and the obvious value and importance of the matter which has been so kindly placed at my disposal, justify me, I think, in introducing it; and indeed I should be doing but ill service to New Guinea ethnology if I did not take advantage of these opportunities which have been offered to me.

Though I am not qualified to discuss these materials from the grammatical and scientific linguistic point of view, there are a few matters to which I should like to draw attention, as affecting statements appearing in this book, and which were written by me before I received this linguistic material.

Regarding the question raised in my introductory chapter as to the extension of the Fuyuge linguistic area so far south as Korona, it will be noticed that a 
large number of the words in the Mafulu and Korona - columns are the same, or very similar. Dr. Strong, in some unpublished MS. notes in Dr. Seligmann's possession, to which I have had access, says as regards the Mafulu and Korona languages that "there is nothing to show that the two languages may not be for all practical purposes identical," and Mr. Ray in his concluding notes classes Mafulu and Korona together as dialects of Fuyuge. The village of Sikube, mentioned by Mr. Ray, is, I believe, on the Upper Vanapa river and north of Mt. Lilley, and so is well within the Fuyuge-speaking area as defined by the Fathers.

Concerning the Kambisa (Upper Chirima valley) column, the similarity of many of the words contained in it to those in either the Mafulu or the Korona column is obvious; and it is curious that some of these words appear to resemble the Korona words more than they do those of Mafulu. I also think I may say that the similarity between Kambisa words on the one hand, and those of either Mafulu or Korona on the other, is almost equal to the similarity between Mafulu and Korona; and Mr. Ray classes Kambisa along with Mafulu and Korona as dialects of Fuyuge. So the statement in the introductory chapter that the valley of the Upper Chirima river is included in the Fuyuge area has, I think, stood the test of some detailed linguistic comparison.

The note by Dr. Strong upon what he calls the Kovio language and his Kovio vocabulary both relate to a district which is within the Fathers' Oru-Lopiku 
linguistic area; and I venture to repeat the suggestion, made in my introductory chapter, that for the present should adopt the term Kovio for the two areas which the Fathers call Oru-Lopiku and Boboi, though eventually we may be able to distinguish between these two areas.

The Afoa or Tauata area is the Fathers' Ambo area. The Afoa column discloses a very few words which resemble the Fuyuge words; but it seems obvious that the Afoa language does not belong to the Fuyuge group, and this is the view taken of it by Mr. Ray.

There are two matters in Mr. Ray's classification in the fifth appendix which I wish to mention. It seems to have been already assumed that the Rev. James Chalmers' Kabana language could not have been collected on Mt. Victoria; and I would point out that this mountain is quite outside what now appears to be the Fuyuge area. As regards the Afoa language the references by Dr. Strong to Mt. Pizoko and Mt. Davidson bring me back to my observations upon the point in my introductory chapter. If the Fathers are right in putting Mt. Pizoko within the Fuyuge area, it is hardly correct to say (see introductory chapter) that the Afoa language is spoken in the villages on $\mathrm{Mt}$. Pizoko; but it might well be, as quoted by Mr. Ray, that a Fuyuge native in a Mt. Pizoko village spoke Afoa fluently, as this mountain is close to the Fathers' Fuyuge-Afoa boundary. Also Mt. Davidson is according to the Fathers in the Boboi area; but Dr. Strong seems to have regarded it as Ambo, and to have treated 


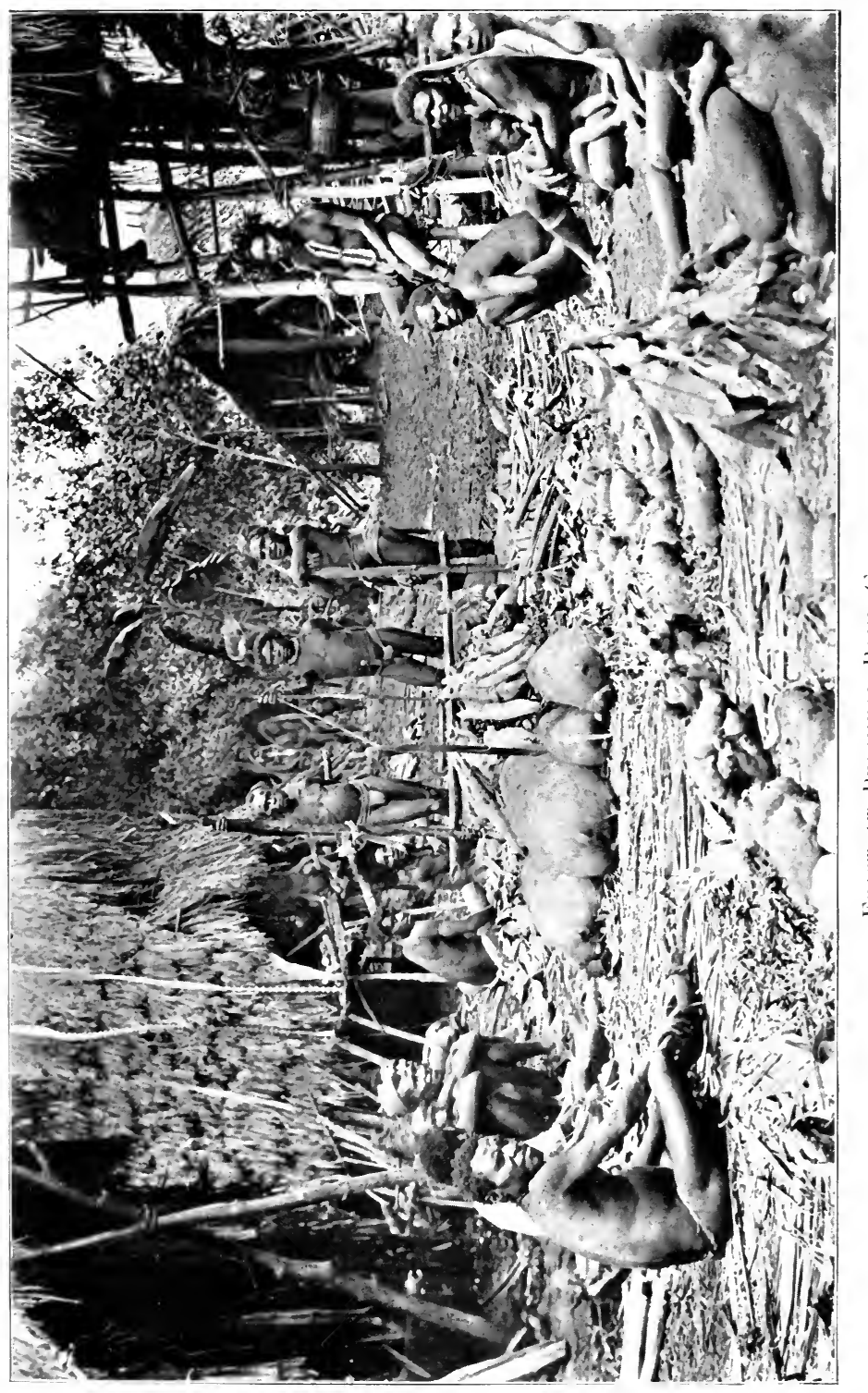



vocabulary matter collected from a native who came from a village "apparently on the slopes of" that mountain as having been taken from an Ambo native. In this case, however, there seems to be some doubt as to where this native did in fact come from; and the eastern slopes of Mt. Davidson are not far from the Fathers' Afoa boundary.

I think that these linguistic materials, taken as a whole, are, so far as they go, well in accord with the delimitation by the Fathers of the Fuyuge area, except as regards their view concerning Korona, as to which they did not profess actual knowledge, and merely expressed a doubt, and subject to the point that, for linguistic purposes at all events, the Fathers' use of the word "Mafulu" as representing the whole Fuyuge. area is perhaps not desirable, and would be better replaced by the term "Fuyuge," with subdivisions of "Mafulu," "Korona," and "Kambisa," as given by Mr. Ray ; though probably Sikube might be included in either Mafulu or Korona, as geographically it is evidently between these two. 


\section{CHAPTER XVII}

ILLNESS, DEATH, AND BURIAL

Ailments and Remedies.

ALL serious ailments occurring up to certain ages, and except in certain cases, are generally assumed to be the work of someone acting in connection with a spirit ; but, speaking generally, no efforts appear to be made by imprecation or other supernatural method to propitiate or contend against these spirits, except by the use of general charms against illness, and except, so far as the propitiation or driving out of the spirit is involved, by one or other of the specific remedies for specific ailments mentioned below. The natives have, however, for common diseases cures of which some are obviously purely fanciful and superstitious, but some are probably more or less practical.

The chief ailments are colds and complications arising from them, malaria, dysentery, stomach and bowel and similar complaints, toothache and wounds.

Dysentery has recognised and accredited curers, both men and women. The operator chews and crushes with his teeth the root of a vegetable (I do not know what it is) which they grow in their gardens, and then 
wraps it up into a small bundle in a bunch of grass, and gives it to the patient to suck. This remedy does not appear to be effective.

There are men who are specially skilled in dealing with stomach and bowel troubles. The operator takes in his hand a stone, and with the other hand he sprinkles that stone over with ashes. He then makes over it an incantation, in which, though his lips are seen to be moving, no sound comes out of them; after which he takes some of the ashes from the stone, which he still holds in his hand, and with these ashes he rubs the stomach of the patient, who, I was told, generally at once feels rather better, or says so.

There are also women who deal with cases believed to be caused by the presence in the stomach of a snake, which has to be got out. Here the operator takes a piece of bark cloth, with which she rubs the front of the patient's body, but without any incantation. Then, as she removes the cloth from the body, she makes a movement as though she were wrapping up in it something, presumably the escaped snake; and afterwards she carries the cloth away with her, and the cure is thus effected.

A man with toothache will say that " a spirit is eating my teeth." The people seem to have a knowledge of something inside the teeth, the nature of which I am not able to state definitely, but which apparently is, in fact, the nerve, and they recognise that it is in this something that the pain arises; but I could not ascertain the connection between this something and the spirit which is supposed to cause the 
trouble. If the aching tooth can be got at, they adopt a method the native explanation of which was translated to me as being a drawing or driving out of the mysterious something from the tooth. This is done in some way with an ordinary native comb, without extracting the tooth itself; but how it is done I could not ascertain. There is no incantation connected with the operation. Another cure is for the patient to chew the leaf of a certain tree (I do not know what tree), so that the sap of it gets into the hole in the tooth, and thereby, as they think, draws or drives out this nerve, or whatever the something may be. The Fathers of the Mission told me that both these two remedies do really appear to be effective.

Wounds are the speciality of many healers with special knowledge of the curative properties of various plants, and who gather the plant, make an incantation over it, boil it in water, and then with that water wash the wound. There are also men who operate surgically on wounds with knives made of stone or shell or bamboo.

Charms, probably of a poisonous nature, are used generally for the warding off of sickness, these being carried in the little charm bags.

A general and universal cure for all ailments is a piece of bark, tied with a piece of string to the neck or head, all neck ornaments having been first removed.

I regret that as regards all these matters I am only able to indicate shortly and generally the methods of cure, and can give no further explanation concerning them. 


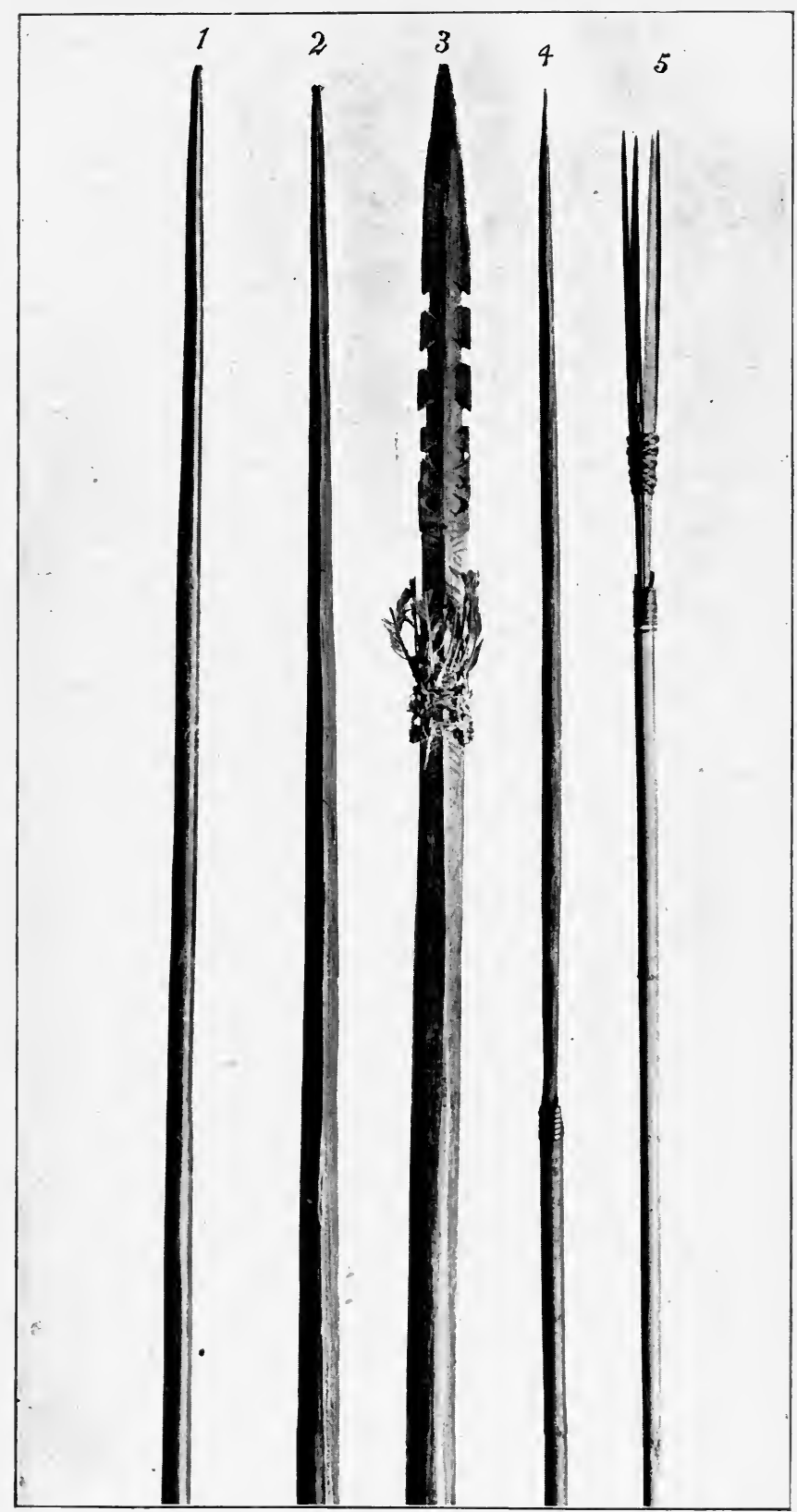

Fig. 1.-PolNT OF WAR SPEAR (round in section).

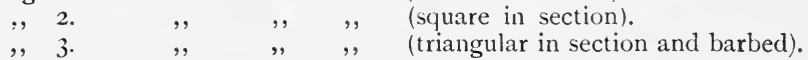

, 4. , "WAR ARROW.

, 5. , BIRD Shooting ARrow. 



\section{Death and Burial.}

\section{(Ordinary People.)}

When a man or woman is regarded as dying, he or she is at once attended by a woman whose permanent office it is to do this, and who has other women and girls with her to assist her, these others including, but not necessarily being confined to, the females of the dying man's own family and relatives. The house is full of women; but there is no man there. This special woman and the others attend the dying man, ${ }^{1}$ nursing him, washing him from time to time, and keeping the flies away from him; but they apparently do not attempt any measures for curing him, their offices only beginning when he is regarded as dying. In the meantime they all wail, and there are also a number of other women wailing outside the house.

The special woman watches the dying person; and when she thinks he is dead she gives him a heavy blow on the side of the head with her fist, and pronounces him dead. She apparently does not feel his heart, or do more than watch his face; and I should think it may often be that in point of fact he is not dead when the blow is given, and might perhaps have recovered.

Then the women inside the house say to one another that he is dead, and communicate the news to the people outside; whereupon the men in the village all commence shouting as loudly as they can.

1 Though here and afterwards I use the word "man," it must be understood that the notes apply to deaths of women also. 
The reason given for this shouting is that it frightens away the man's ghost; but if so it is apparently only a partial intimidation of the ghost, who, as will be seen hereafter, is subjected to further alarms at a later stage. The men communicate the news in the ordinary way adopted by these people of shouting it across the valleys ; and so it spreads to other villages, and even to other communities. The man being dead, the wailing of the women inside and outside the house is changed into a true funeral wailing song ; but this latter only continues for a few minutes. The special woman and some others, probably relatives only, remain in the house; but they do not touch the body at this stage. The other women, probably nonrelatives, go out. The relatives of the deceased, both men and women, immediately smear their bodies with mud, but no one else in the village does so.

This is the situation until the first party of women, generally accompanied by men, begin to come in from other villages of the same, and probably of one or more other, communities. These people have been laughing and playing and enjoying themselves on their way to the village, and do so freely until they get close to it. Then they commence wailing (not the funeral song) and shouting, calling the deceased by a relationship term, such as father, brother, etc., though they may never have heard of him before ; and, doing this, they enter the village, and go to the house. The incoming women, but not the men, all arrive smeared with mud. The women crowd into and about the house, still wailing as before, but not the funeral song. 
They all see the body; and each woman, after seeing it, comes out and sits on the platform of the house or on the ground outside. The party of outside village women then cease their first wailing, and commence the funeral song, in which they are joined by the female relatives of the deceased and other women of the village. But again this only lasts for a few minutes, the period being longer or shorter according to the importance of the person who has died.

Other similar parties, coming in from other villages, go through the same performance as they come into the village; and in each case, as the women of each fresh party come out of the house after seeing the corpse, there is a fresh outburst of the funeral song on the part of all the women present, but always only for a few minutes. This goes on till the last batch of visitors has arrived. The people of the village know when this last batch has come, because they have been told by cross-valley shouting which villages are sending parties. The total number of women in the village is then generally very large. After the last batch of visitors has arrived, and until the funeral ceremony, all the women again break out into the funeral song for a few minutes about once an hour in the daytime, but not so often at night.

The funeral takes place probably about twenty-four hours after death. The body is now wrapped up by the special woman attendant, helped by the female relatives of the deceased, in leaves, especially banana leaves, and bark of trees, and remains so wrapped up in the house. 
It is placed with the knees bent up to the chin, and the heels to the buttocks. In the meantime men of the village dig a grave 2 or 3 feet deep in the village open enclosure. When all is ready the funeral song begins again, the singers this time being the female relatives of the deceased and the women who have come from outside villages, but not the other women of the village of the deceased. Men of the village then carry the corpse, wrapped and doubled up, and place it, lying on its back, in the grave. There is no real procession from the house to the grave, though all the people assemble at the latter; but during the whole of the time, until the body is in the grave, the singing by the women of the funeral-song continues. As soon as the body is in the grave, all the men, both villagers and visitors, shout again as before, and for the same purpose. The grave is then filled up, the women in the meantime singing as before; and when this is done the funeral is over.

The relatives of the deceased now go into mourning. The widow or widower or other nearest relative wears the mourning string necklace already described. $\mathrm{He}$ or she, and also the other near relatives, smear their faces, and sometimes, but not always, their bodies, with black, to which, as regards the face, but not the body, is added oil or water. Some more distant relatives, instead of blackening themselves, wear the mourning shell necklace. And all this will continue, nominally without break, until the mourning is, formally removed, in the way to be explained hereafter. As a matter of fact, the insignia of mourning are not worn 
PLATE 74.

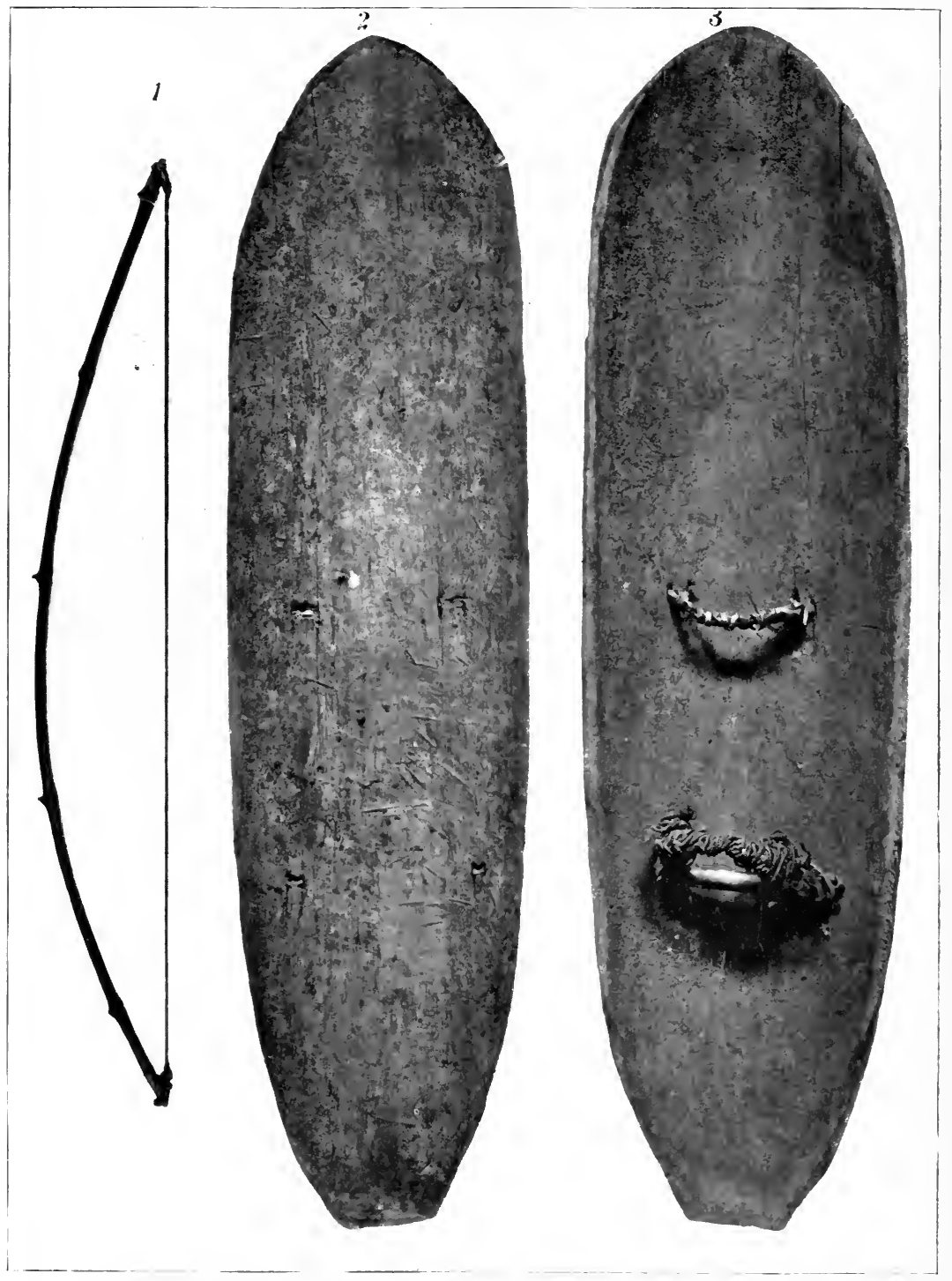

Fig. I. - Bow.

, 2.-Shield (outside).

, 3.- ,, (inside). 

without interruption, and the black smearing is by no means so retained; but on any special occasion the person would take care to appear in mourning. There is a custom under which the widow or widower or other nearest relative may, instead of wearing the mourning string necklace, abstain during the period of mourning from eating some particular food, of which deceased was most fond. ${ }^{1}$

In connection with mourning, I should also mention a curious custom, which I understand is common, though not universal, for a woman who has lost a child, and especially a first-born or very dear child, to amputate the top end of one of her fingers, up to the first joint, with an adze. Having done this once for one child, she will possibly do it again for another child; and a woman has been seen with three fingers mutilated in this way. ${ }^{2}$

The family of the deceased invite men and women from some other community, but only one community, to a funeral feast, which is held after an interval of two or three days from the day of the funeral. On

1 This food taboo is with the Mafulu only an optional alternative; but it may be compared with the corresponding food taboo placed upon all the relatives of the deceased by the Koita (see Seligmann's Melanesians of British New Guinea, p. 164).

2 I was told of this Mafulu practice as being adopted only on the death of the woman's child. But the custom is referred to by the Mekeo Government Agent (Mr. Giulianeti) in the Annual Report for June, I900, pp. 73 and 78 ; and, according to him, its adoption applies also to deaths of other relatives-husband, father, and mother being especially mentioned by him-and he suggests that there are rules as regards these amputations, and says he understood that a mother would cut off the first joint for her children, and the second for her husband, father, or mother. $\mathrm{He}$ also gives information as to the way in which the amputation is effected. 
the day appointed these guests arrive. They are all well ornamented, but, with one exception, they do not wear their dancing ornaments. One of them, however, usually a chief or the son of a chief of the community invited, comes in his full dancing ornaments. All the guest men bring with them their spears, and perhaps adzes or clubs.

When they arrive the following performances take place, the village enclosure being left by the villagers empty and open:-First two guest women enter the village enclosure at one end, and run in silence round it, brandishing spears in both hands, as at the big feast ; but they make no hostile demonstration. When these two women have reached their starting point, they again do the same thing, brandishing their spears as before, and all the guest men, except the specially dressed one, follow them by advancing with a dancing step along the enclosure, they also brandishing their spears, and also being silent. Thus the whole group goes to the other end of the village, passing the grave of the deceased as they do so; then they turn round, and come back again in the same way, but on their return they stop before they reach the grave.

Then the specially ornamented guest man enters alone, without his arms, but with his drum, which he beats. He dances up the village enclosure in a zigzag course, going from side to side of the enclosure, and always facing in the direction in which he is at the time moving; and during his advance he beats his drum, but otherwise he and all the other 
people are silent. When in this way he has reached the grave, the chief of the clan of the village where the funeral takes place, who does not wear any dancing ornaments, approaches him, and removes his heavy head ornament. This ends the first part of the ceremony ; and the villagers and guests then chat and conduct themselves in the ordinary way.

Plates 82 and $8_{3}$ illustrate scenes at a funeral feast in the village of Amalala. In the former plate the grave is very clear, and the remains of an older grave are visible behind the post a little to the left. At the upper end of the village enclosure are the visitors, who are about to dance along the enclosure past the grave, and then back again up to it. The figures in the emone behind are Amalala men, watching the performance. In the latter plate the visitor chief is seen dancing along the village enclosure towards the grave.

In the meantime the members of the family of the deceased bring in one or more village pigs and some vegetables. A number of sticks are laid upon the ground over the grave, the sticks crossing each other so as to form a rude ground platform (this is not done by any particular person), and these sticks are covered with banana leaves. ${ }^{1}$ The pigs are placed on this platform; and are then killed by the pig-killer and cut up, and the vegetables and pieces of pig are distributed by the chief of the clan, helped perhaps by the family of the deceased, among the male

1 The sticks are seen in the plates, having been placed on the grave before the photographs were taken. 
visitors. The one specially dressed visitor, being the only one who has really danced, gets much the largest share. For example, if there be two or more pigs, he will get an entire pig for himself. Then the ceremony is over, and the guests return home. The wood of the platform is not removed from the grave, but is left to rot there. The killing of the pigs at this ceremony is regarded as the act which will, they think, finally propitiate or drive away the ghost of the departed.

It will be noticed that, though representatives from several communities may be invited and come to the funeral, only one community is invited to the subsequent funeral feast, just as only one community is invited to the big feast, which latter we must, I think, associate with the general superstitious idea of laying the ghosts of past departed chiefs and notables. I cannot say what is the reason for the confinement of these invitations to one community only, but it must, I think, have had some definite origin ${ }^{1}$; and as to this I am struck by the similarity of the Massim idea, referred to by Dr. Seligmann, that an individual's death primarily concerns the dead man's hamlet and one other hamlet of his clan, with which certain death feasts are exchanged, other members of the clan being comparatively little affected. $^{2}$

As soon as possible after the funeral pig-killing, they catch some wild pig or pigs, and kill and eat them, and

1 I am not aware of any ground for believing that the community invited is one with which intermarriage is specially common. Indeed, as stated above, I do not think that there are special matrimonial relationships between communities.

${ }_{2}$ Melanesians of British New Guinea, p. I3. 
PIATE 75

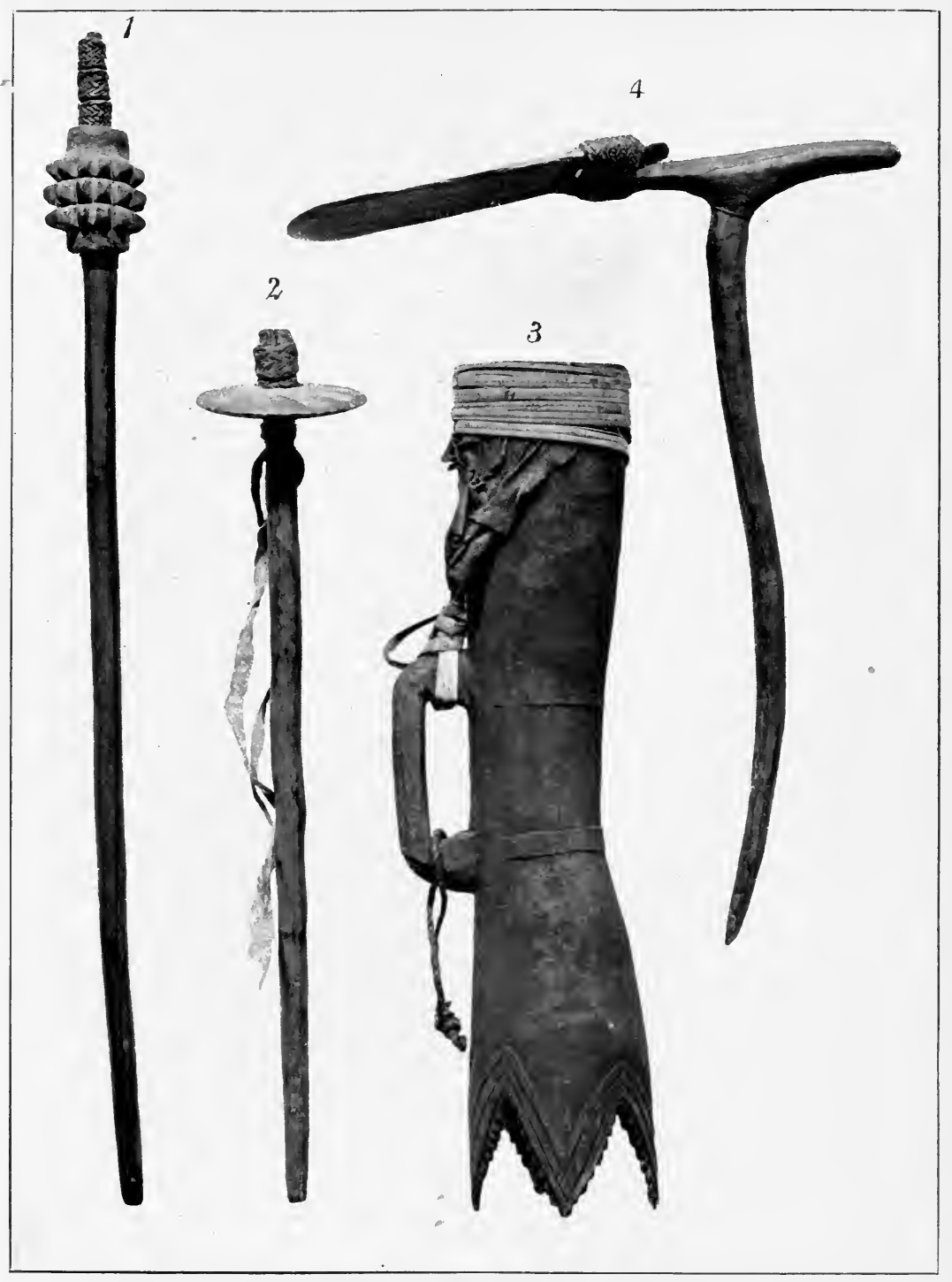

Fig. I. - Club (pineapple type of head).

,, 2.- ,, (disc ,, ., ).

, 3 -DRU.M.

, 4.-ADZE. 

sweep down the village by way of purification ceremony, very much as they do in the case of the big feast, except that it is on a very much smaller scale, and that the people do not afterwards leave the village.

The ceremony of removal of the mourning may take place after an interval of only a week or two, or of so much as six months, the date often depending upon the occurrence of some other ceremony, at which the removal of the mourning can be carried out without necessitating a ceremony for itself only. Visitors from some other community attend. The ceremony only applies to the nearest relative-the person who wears the string necklace; but, on his or her mourning being ceremoniously removed, the mourning of all others in respect of the same deceased ceases automatically. ${ }^{1}$ This nearest relative has to provide a village pig. There is a feast, and dancing and pig-killing and distribution of food and pig, in the usual way, and this may be in the village of the deceased or in some other village of the community. The pig-killing is done by the pig-killer under the platform of a chief's platform grave, or on the site of it. The pig, specially provided by the nearest relative, is bought and paid for by some person, as in the case of some of the ceremonies already described, and this person, after the killing of the pig, without special ceremony, cuts off the mourner's string necklace, dips it in the blood of the pig, and throws it away; then he takes

1 I was told that in the Mekeo mourning-removal ceremony each of the persons wearing the insignia of mourning has to go through the ceremony, which consists of the cutting of his necklace or something else with a shell. 
some coloured paint, usually red, and with it daubs two lines on each side of the face across the cheek of the mourner, who of course at this ceremony will still have his black paint. If the mourner has been refraining from food, instead of wearing the necklace, the ceremony is confined to the paint-daubing. Then the mourner pays this ceremonial pig-buyer for his services, probably in feathers or dog-teeth, and the mourning is at an end.

There will at a later date be a purification ceremony, at which wild pigs will be killed, such as has already been described. ${ }^{1}$

\section{Death and Burial.}

\section{(Chiefs.)}

A dying chief is attended by the special woman and others in the way above described, except that many women of the clan are there, and that this special attendance and its accompanying wailing begin earlier, perhaps two or three days earlier, than in the case of an ordinary person, and that all the women of the clan who are not in the house wail outside it.

In this case, however, there is a special ceremony for ascertaining whether or not the chief is in fact going to die-a ceremony which is usually performed at his own request. Some vegetable food, probably sweet potato, or perhaps sugar-cane or taro, is given him to eat; and this he will do although he may be

1 Compare Dr. Seligmann's references in Melanesians of British New Guinea to the mourning removal ceremonies of the Koita (p. 165), the Roro (p. 277), and the Mekeo (p. 359). 
very ill, and may not have been taking food, though of course, if he were insensible or unable to eat, this special ceremony could not be carried out. The inedible portions of this food, e.g., the peel of the potato or the hard fibres of the sugar-cane, are then handed to certain magical persons of the community, whose special duty it is to perform the ceremony about to be described, but as to whom I was unable to ascertain who and what they are, and whether they have any other special functions besides those of this ceremony. Some of these portions of food may even be sent to some similar magic person of high reputation in another community, in order that he also may perform the same ceremony. Each of these magic persons also has handed to him a portion of a perineal band belonging to, and recently worn by, the ailing chief.

Each of the magic men then wraps up the portion of food which has been given to him in the piece of band; and this he again wraps up in leaves, and continues doing so until the parcel has become a round ball 4 or 5 inches in diameter. The men then separate, and each of them goes off alone to a spot outside the village, where he collects some very dry firewood, and heaps it up against the trunk of a tree to a height of, say, 6 feet. He then engages in an incantation, after which he puts the ball inside the bottom of the wood pile, and lights the pile at the bottom. Then he lies down by this fire and closes his eyes. After an interval of perhaps two to five minutes he gets up, as though awakening from a bad dream, and hears 
the wailing in the adjoining village, and asks himself what all this wailing is about; and he then appears to remember for what purpose he is there, goes to the fire, and takes out the ball. If the fire has burnt or scorched the food wrapped up in the ball, it is an indication that the chief is to die. If not, it indicates that he will live. These magic men then return to the village, and report the result. If their report be that the chief is going to live, the people cease their wailing, but if it be that he is to die, the wailing continues.

Pausing here for a moment, I may admit that, though I have told the tale of this ceremony, with its private cogitations-real or pretended-of the magic men, as it was told to me, the tale is open to obvious questions. How can a magic man from a distant community hear the wailing? What would happen if the results of the ceremonies of the various magic men were to differ? What would be the situation if a chief whose death was indicated by the ceremony lived, or if one whose recovery was foretold became worse and died? All these points I tried to elucidate without success; but possibly the answer to the query as to divergence of results may be that the men take care that the results of their experiments shall not differ.

It is believed by the natives that, if a hostile community can secure some of the food remnants and band, and hand them to their own magic man, for him to go through the same ceremony, he may maliciously bring about an unfavourable result, and thus may cause 


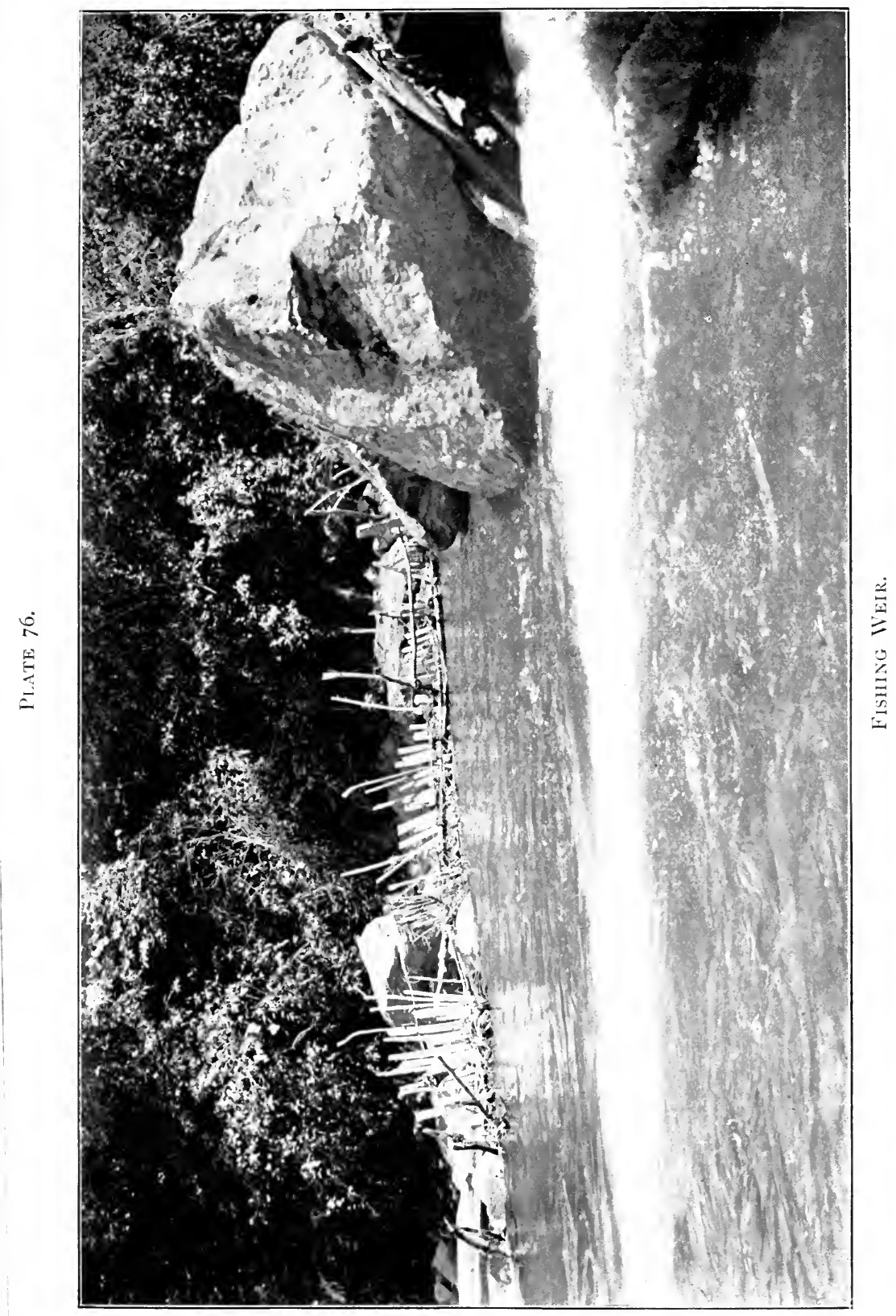



the death of the chief. If the belief that such a thing had happened arose, it would be a casus belli with that other community; and a case is known in which an inter-community fight did occur on this ground.

If the report be that the chief is to die, the special woman attendant will give him the blow on the head, as in the case of the ordinary villager. The shouting of the men outside when the chief's death is announced is much louder than in the case of a commoner; and as they shout they brandish their spears, and strike the roof of the chief's house with the spear points, and some of the men strike it with adzes and clubs. The spreading of the news to other communities is on a wider scale, and the number of people who respond to the news and come to the funeral is very great, and includes a larger number of chiefs and prominent men; there are more, and much larger, parties of them. The funeral song of the women, commenced on the announcement of death, lasts much longer - indeed for hours. In fact, as numerous large bodies of people keep coming in, and some of these coming from a distance may not arrive until just before the funeral, and as the funeral song has to be recommenced as each fresh party comes in, and lasts so much longer each time, it follows that this funeral song practically continues without ceasing from the moment when death is announced until the actual funeral. The immediate smearing by men and women of their bodies with mud is done by all the members of the entire community. When the guests reach the village, they are all, both 
men and women, smeared with mud, and they loudly call on the dead chief by his title amidi, or as babe (father). Also the various chiefs' wives among the guests remain in the house after seeing the body, instead of coming out with the other guest women.

The funeral does not take place till thirty-six or forty-eight hours after the death. The various chiefs' wives take part in the wrapping up of the body; and to the ordinary wrappings are added large pieces of bark cloth.

The grave ${ }^{1}$ is quite different from that of a commoner. There are two methods of sepulture adopted for chiefs, the grave being in both cases in or by the edge of the open village enclosure.

The first of these methods is a burial platform, a very rough erection of upright poles from 9 to 12 feet high, the number of which may be four, or less or more than that, at the top of which erection is a rude wooden box-shaped receptacle, about 2 or 3 feet square, and from 6 inches to a foot deep, and uncovered at the top, in which receptacle the corpse is placed. Sometimes the supporting structure, instead of being composed of a number of poles, is only a rough tree trunk, on which the lower ends of the branches are left to support the box.

1 I recognise that, though the terms "grave," "bury," and "burial" are correctly applied to the mode of interment underground of an ordinary person, the term "grave" is clearly an incorrect one for the overground platform box and tree box in one or other of which a chief s body is placed; and the use with reference to this mode of disposal of the dead of the terms "bury" and "burial" is, I think, at least unsuitable. But with this apology, and for lack of a short and convenient, but more accurate, substitute adapted to the three methods, I use these terms throughout with reference to all of them. 
The second method is tree burial. The tree in which this is done is a special form of fig tree called gabi, the burial box, similar to the one above described, being placed in its lowest fork, or, if that be already occupied, then in the next one, and so on. ${ }^{1} \quad A$ tree has been seen with six of these boxes in it, one above another. This tree is specially used for such burials. The natives will never cut it down. In selecting a village site they will often specially choose one where one of these trees is growing; and indeed the presence of such a tree in the bush raises a probability that there is, or has been, a native village there. ${ }^{2}$

1 This Mafulu practice of tree burial is referred to in the Annual Report for June, I900, p. 63.

2 Platform burial in one form or another is not peculiar to the Mafulu district. It is perhaps common among many of the mountain people. Sir William Macgregor found it in the mountains of the Vanapa watershed (Annual Report, 1897-8, pp. 22 and 23), and Dr. Seligmann regards it, I think, as a custom among the general class of what he calls "Kamaweka" (Melanesians of British New Guinea, p. 32). Mr. J. P. Thomson records its occurrence even in the lower waters of the Kemp Welch river (British New Guinea, p. 53, and see also his further references to the matter on pp. 59 and 67). In view of a suggestion which I make in my concluding chapter as to the possible origin of the Mafulu people, it is also interesting to note that platform or tree burial is, or used to be, adopted, for important people only, by the Semang of the Malay Peninsula and the Andamanese. As regards the Semang, though they now employ a simple form of interment, their more honourable practice was to expose the dead in trees (Skeat and Blagden, Pagan Races of the Malay Peninsula, Vol. II., p. 89); and, though the bodies of the Pangan (East Coast Semang) lay members were buried in the ground, those of their great magicians were deposited in trees (Ibid., Vol. II., p. 9I); and apparently this was the case among the Semang as regards the bodies of chiefs (Ibid., Vol. I., p. 587). And concerning the Andamanese it is recorded that the skeleton of a man who, for reasons given, was believed to have been a chief was found lying on a platform of sticks placed across forks of a tree about 12 feet from the ground, a mode which was compared with the method of underground burial which had previously been met with (Transactions of the Ethnological Society, New Series, Vol. V. 
If a burial platform afterwards falls down through decay, the people throw away all the bones, except the skull and the larger bones of the arms and legs; and these they deal with in one of three alternative ways. They either (I) dig a shallow grave in the ground under the fallen platform, and put the skull and special bones there, and then fill in the grave with soil, on this put a heap of stones, and on these put the wooden remains of the collapsed platform, planting round them tobacco or croton, or some other fine-leaved plant, or (2)they put the skull and special bones in a box on the gabi burying tree, or (3) they take them to the emone, and there hang them up till they are wanted for a big feast. In the same way, if a tree box falls, they retain only the skull and large arm and leg bones, and replace them in a new box in the same tree.

We have already seen a chief's burial platform in the two plates 69 and 70 relating to the big feast at Seluku, and the following plates are additional illustrations :Plate 84 is the grave of a chief's child in the village of Malala. The supports of the grave rise from the village enclosure fence behind, and are quite distinct from the underground commoner's grave, which is seen in front.

p. 42). Mr. Portman records (History of our Relations with the Andamanese, Vol. II., p. 547) similar tree burial of two chiefs and the wife of a chief, and refers to the practice of burying underground "or, what is more honourable," on a platform up in a tree (Ibid., Vol. I., p. 43). The practice is also mentioned by Mr. Man, who, after referring (The Andaman Islanders, p. 76) to underground interment and platform burial, of which "the latter is considered the more complimentary," states (pp. 76 and 77) that a small stage is constructed of sticks and boughs about 8 to 12 feet above the ground, generally (the italics are mine) between the forked branches of some large tree, and to it the body is lashed. 

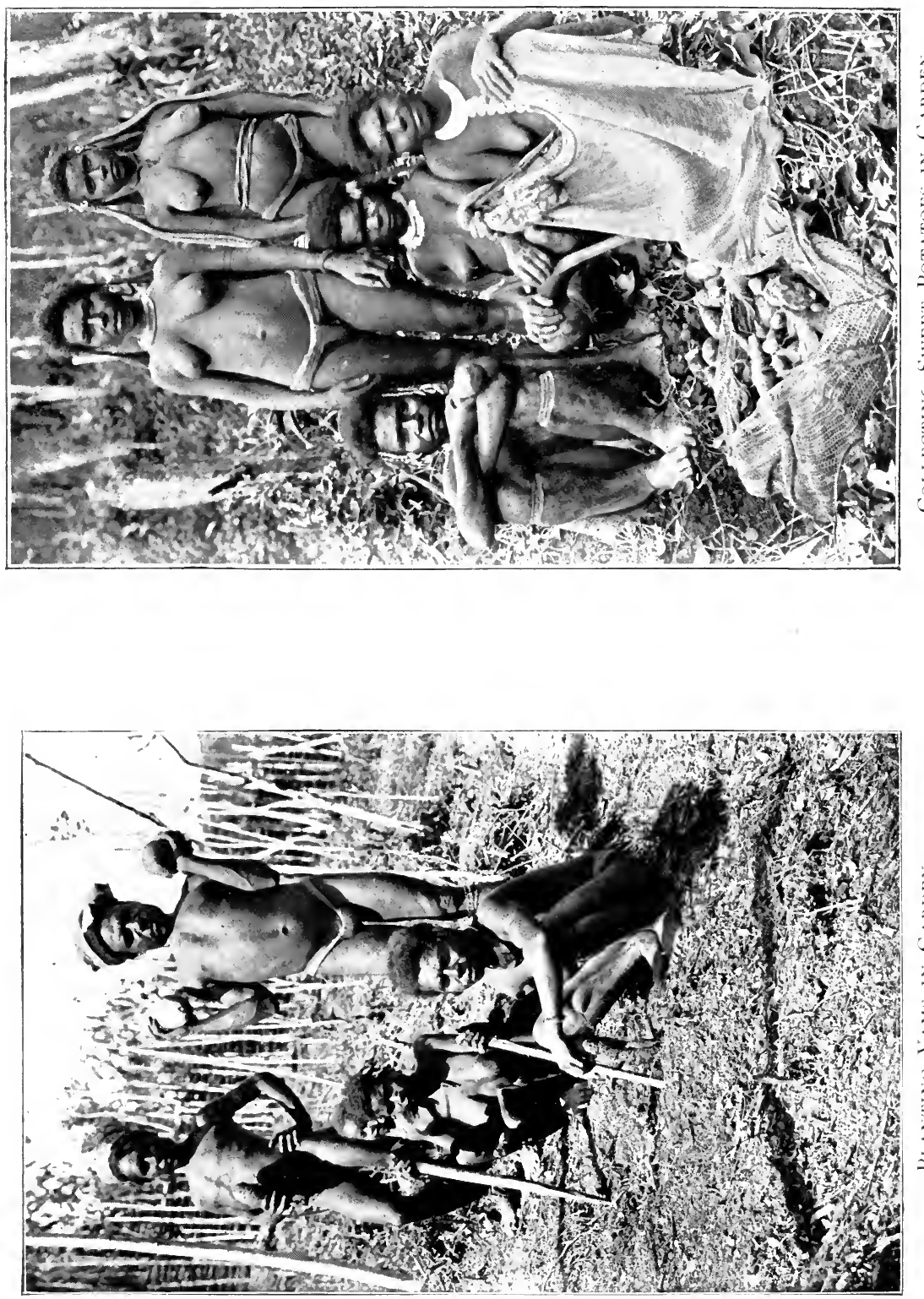

The positions of the two graves can be seen in the general view of the village (Plate $5^{8}$ ). Plate 85 is a group of graves of chiefs and chiefs' relatives in the village of Tullalave (community of Auga). Plate 86 shows the grave of a chief's child in the village of Faribe (community of Faribe). The form of this grave is quite different from those of the others, and is not, I think, so common, but a grave somewhat resembling it is seen in Plate 60.

Plate $8 y$ is a $g a b i$ fig tree, used for tree burial, near to the village of Seluku, and Plate 88 shows the remains of an old burial box in one of its forks. The bones are still in this box, and indeed one of them may be just discerned at the extreme left, close to the upright stem of the tree.

Plate 89 illustrates what I have said as to what is done when a burial platform falls down from decay. The skull and larger arm and leg bones of the body have been buried underground, and upon these have been heaped first stones and then the remains of the collapsed platform, and one little foliage plant and dried-up looking specimens of others can be seen around it. This picture was taken in the village of Seluku, and the actual position of the grave in the village enclosure is seen in Plate 55. Plate 90, of an emone in the village of Voitele (community of Sivu) illustrates the alternative plan of hanging the skull and bones up in the emone.

At the funeral all the women present, those of the village and of the whole community and the guests, join in singing the funeral song ; but here again there is 
no actual procession, and the carrying of the body is not necessarily entrusted to any particular person. When the grave, whether on a platform or on a tree, is reached, all the men present begin to shout loudly, and there is a terrible noise. They all have their spears, but there is no brandishing of them. Then some men (anyone may do this) climb up to the box, and others hand the wrapped body up to them, and they place it lying on its back in the box. This ends the actual burial ceremony.

The black mourning face, and sometimes bodystaining is then adopted by all the people of the community, and perhaps also by chiefs from other communities who have been friends of the dead chief. The special string necklace worn by the nearest relative and the other family emblems of mourning are the same as in the case of an ordinary person, except that the chief's widow will probably also wear the special mourning network vest already described, and that the mourning shell necklace, which in the case of an ordinary man is only worn by distant relatives, is worn by all the married men and women of the clan who have or can procure it.

The subsequent ceremony and feast are in this case held one or two days after the funeral, the acceleration in the case of a chief being necessary in consequence of the retention of the corpse above ground and the foul smell which immediately begins to emanate from it. This feast is on a very large scale, though here again only one community is invited. The guests enter the village just as they do in the case of the death of an 
ordinary person; but they are all specially well decorated, and the one guest who comes in full dancing ornaments will certainly be a chief, or at least a chief's son. The subsequent part of the ceremony, up to the removal of the head feather ornament from the dancer, is the same; but this removal is done by the nearest male relative of the deceased chief, who will probably be the person to whom the chieftainship has descended. Then follows the feast itself. The vegetables and village pigs for the feast are provided by the whole clan, and are in very large quantities. No platform of sticks is placed on the grave, the grave in this case not being underground; but the banana leaves are placed around (not under) the supports of the burial platform, or around the trunk of the burial tree. The pigs are killed upon these banana leaves by the pig-killer and his helpers, and the killed pigs are then placed in circles around the platform or tree, and are there cut up. The distribution of food and pig's flesh is made by the chief's nearest male relative, with assistance, here again the special dancer getting the largest share, and the ceremony is then over, and the guests return to their villages.

And now a true desertion of the village by its inhabitants takes place, as indeed is necessary, as the putrefying body is becoming so offensive; and it will be at least two or three weeks before the emission of the smells is over. The villagers all go off into the bush, with the exception of two unhappy men, more or less close relatives of the dead chief, who have to remain in 
the village. Whilst there alone they are well ornamented, though not in their full dancing decoration, but in particular, though not themselves chiefs, they wear on their heads the cassowary feathers which are the distinctive decoration of a chief, and they carry their spears. There they remain amidst the awful stench of the decomposing body and all the mess and smell of the pigs' blood and garbage about the village. It is a curious fact that, in speaking of these two men, the natives do not speak of them as watching over the body of the chief, but as watching over the blood of the killed pigs.

When the stench is over, the villagers in the bush are informed, and they then return to the village. Then follow the killing and eating of wild pigs and sweeping down of the village, as in the case of the death of an ordinary person, but again on a much larger scale.

It will be noticed that, though the desertion of the village after a big feast lasts for six months, that which follows a chief's funeral only lasts for a few weeks.

The removal of the mourning takes place after an interval which may be anything between one and six months. This is a special ceremony, and will not be postponed for the purpose of tacking it on to some other ceremony, as in the case of an ordinary person's mourning removal; but other ceremonies will often be tacked on to it. The guests invited are from only one other community. Here again the person actually dealt with is the chief mourner, and the removal of mourning from him or her terminates the mourning for 


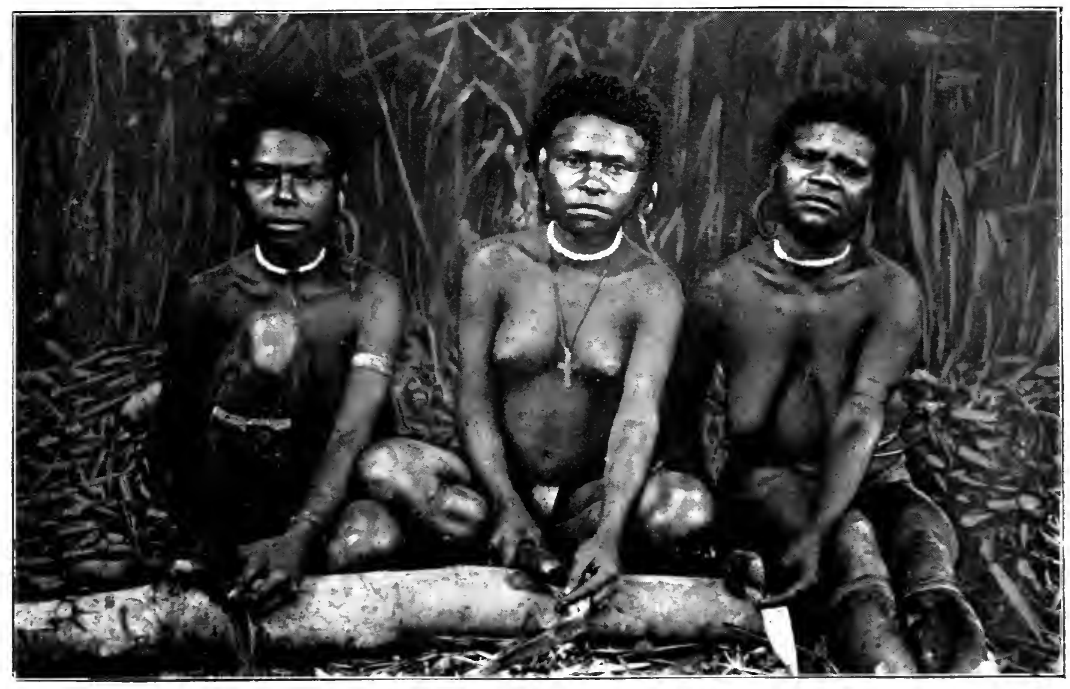

HAMMERING B.ARK CIOTH.

PI.ATE SO.

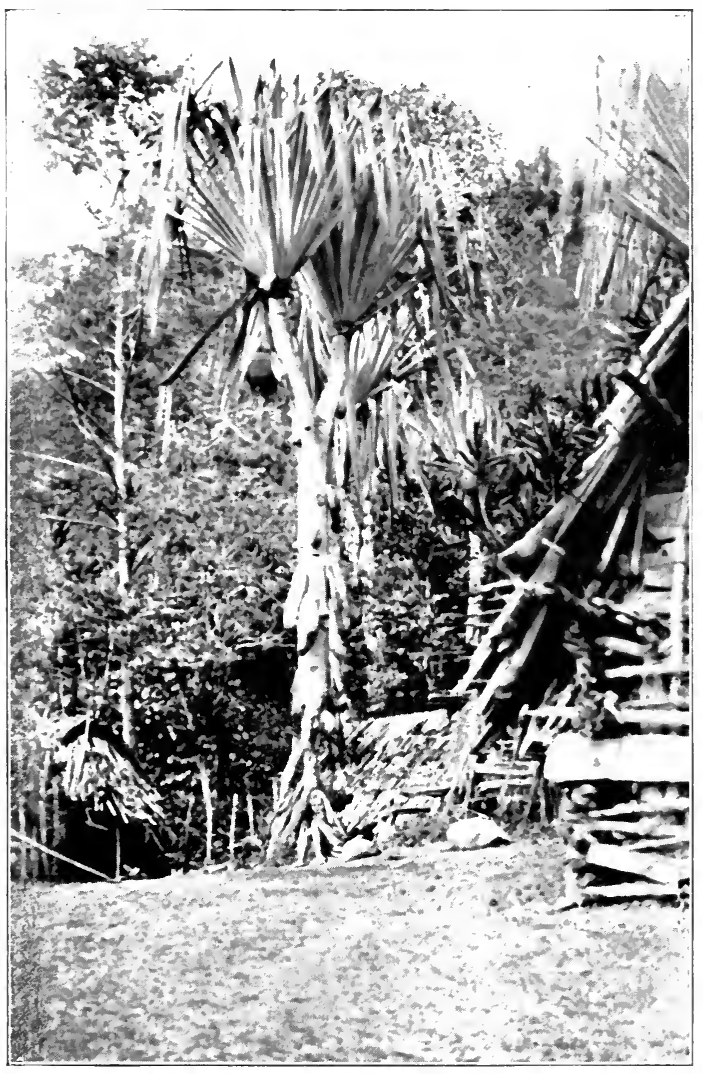

THE INE PANDANUS. 

everyone. The village pigs for this occasion are provided by the dead man's family, and not by the whole clan, as in the case of a chief's funeral feast. There will probably be two or three of such pigs provided; but, as the ceremony is also available for various other ceremonies, there may be a considerable number of pigs killed. The dancing and pig-killing and feast are the same as those of an ordinary mourningremoval ceremony, but on a larger scale. The pigkilling in this case is done round the platform or tree on which the chief is buried. The buyer of the pig, who cuts off the mourning necklace and daubs the face of the chief mourner, if not a chief, will at all events be a person of importance; but the ceremonies relating to all these matters are identical with those already described. There is also the subsequent purification ceremony, at which wild pigs are killed and eaten as before.

The graves of chiefs' wives and members of their families, and other persons of special importance, are platform or tree graves, like those of chiefs, and the funeral ceremonies on the deaths of these people are very similar to those of chiefs, though they are on a scale which is smaller, in proportion to the relative smallness of the importance of the person to be buried; and they are subject tc a few detailed differences, which the difference of the situation involves. The special magic ceremony for ascertaining if the patient is or is not going to die is not performed in the case of these people. 


\section{CHAPTER XVIII}

RELIGION AND SUPERSTITIOUS BELIEFS AND PRACTICES

\section{Religion and Superstitions.}

These are subjects which I should hardly have ventured to introduce into this book if I had had to rely exclusively upon enquiries made only during my stay among the Mafulu villages, without having the benefit of five years' observation by the Mafulu Fathers of the Mission. And, notwithstanding this additional facility, my notes on these questions will be found to involve puzzles and apparent inconsistencies; and there is no part of the book which should be read and accepted with greater reserve and doubt as to possible misunderstanding. Subject to this caution, I give the information as I have obtained it.

I heard nothing to justify the idea of the Mafulu people having any belief in a universal God or All Father; but there is a general belief among them in a mysterious individual named Tsidibe, who may be a man, or may be a spirit (they appear to be vague as to this), who has immense power, and who once passed through their country in a direction from east to west. Wherever you may be, if you speak of this 
personage, and ask to be told in which direction he travelled, they always point out one which is from east to west. They believe that it was Tsidibe who taught them all their customs, including dancing and manufacture, and that he ultimately reached and remained in the land of the white man, where he is now living; and that the superior knowledge of the white man in manufacture, and especially in the making of clothes, has been acquired from him. The idea of his ultimate association with the white man can hardly, however, be a very ancient tradition. One of the Fathers was seriously asked by a native whether he had ever seen Tsidibe. They seem to think that he is essentially a beneficent being. They regret his having left their country ; but they have no doubt as to this, and do not regard him as still continuing to exercise any influence over them and their affairs, have no ceremonies or observances with reference to him, and do not address to him any supplications. As traces of his passage through their country they will show you extraordinarily shaped rocks and stones, such as fragments which have fallen from above into the valley, and rocks and stones which have lodged in strange positions. But there are no ceremonies with reference to these and the natives have no fear of them, and indeed they will proudly point them out to you as evidences of this mysterious being having been in their country, and of his power. They would not hesitate to touch one of these stones, but they would never injure it. I learnt nothing about him which would justify me in suggesting that the Mafulu people 
deified him as an ancestor, or even regarded him as being one, though some of the matters attributed to him are perhaps not dissimilar from those often attributed to deified ancestors. ${ }^{1}$

They certainly have a lively belief in ghosts of people who have lived and died, and in spirits which have never occupied human form, all of whom (ghosts and spirits) are evil disposed, and in sorcery.

Every human being, male and female, has during life a mysterious ghostly self, in addition to his bodily visible and conscious self; and this ghostly self will on his death survive him as a ghost. There appears to be no idea of this ghostly self leaving the body in times of sleeping or dreaming; though, if a man dreams of someone who is dead, he thinks that he has been visited by that person's ghost.

At death the ghost leaves the body, and becomes, and remains, a malevolent being. There is no idea of re-incarnation, or of the ghost passing into any animal or plant, though, as will be seen hereafter, it sometimes apparently becomes a plant ; and there is no difference in their minds between the case of a person

1 I have been unable to find an account of any spiritual or partly spiritual being associated with the beliefs of Papuans or Melanesians who can be regarded as being similar to Tsidibe. Perhaps the nearest approach to him will be found in Qat of the Banks Islands, of whom much is told us by Dr. Codrington in The Melanesians, and who apparently is not regarded as having been of divine rank, but is rather a specially powerful, but perhaps semi-human, spiritual individual, who, though not having originally created mankind and the animal and vegetable world and the objects and forces of nature as a whole, has had, and it would seem still has, considerable creative and influencing powers over them all. But I could learn no detailed legends concerning Tsidibe; and the scanty information given to me concerning him differs from what we know of Qat. 


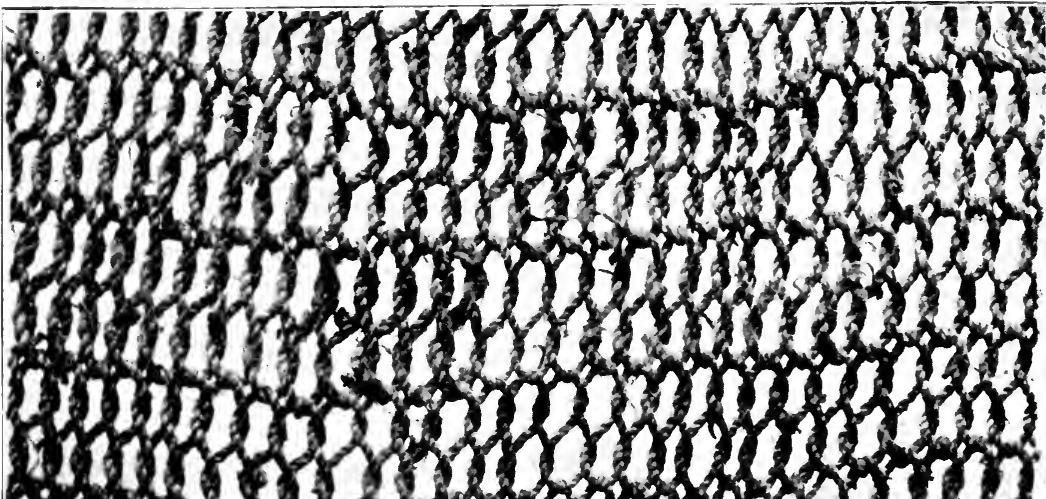
(1) 

who has died naturally and one who has been killed in battle or otherwise, or between persons who have or have not been eaten, or who have or have not been buried, though in case of burial there are the methods of getting rid of the ghost; and there is no superstitious avoidance of graves or fear of mentioning a deceased person by name, and no superstition as to the shadows of living persons passing over graves and sacred places. Except as above stated, I found no trace of any belief in a future state.

When on the death of a man or woman or child, the ghostly self leaves the body, or at all events when the funeral pig-killing has been performed, the ghost goes away to the tops of the mountains, where apparently it exists as a ghost for ever. The shouting immediately after the death, and afterwards at the funeral, are steps towards driving it there; and the pig-killing ceremony completes the process. On reaching the mountains the ghost becomes one of two things. The ghost of a young or grown-up person up to, say, forty or forty-five years of age becomes the shimmering light upon the ground and undergrowth, which occurs here and there where the dense forest of the mountains is penetrated by the sun's beams. It is apparently only the light which shimmers on the ground and undergrowth, and not that in the air. The ghost of an elderly person over forty or fortyfive years of age becomes a large sort of fungus, which is indigenous to the mountains, where alone it is found. Any native who on a hunting expedition or otherwise meets with a glade in which this shimmering 
light occurs will carefully pass round it, instead of going across it; and any native finding one of these fungi will neither eat nor touch, nor even tread upon it ; though indeed, as regards the eating, I understand that this particular fungus is one of the poisonous nonedible forms. A native who, after the recent death of another, is travelling in the mountains, and there finds a young fungus of this species only just starting into growth, will think that it is probably the ghost of the recently departed one.

As regards the use by me with reference to both sunbeams and fungi of the word "becomes," I recognise that it may justify much doubt and questioning. The idea of actually becoming the flickering light or the fungus, as distinguished from that of entering into or haunting it, is a difficult one to grasp, especially as regards the flickering light. I tried to get to the bottom of this question when I was at Mafulu; but the belief as to actual becoming was insisted upon, and I could get no further. I cannot doubt, however, that there is much room for further investigation on the point, which is of a character concerning which misapprehension may well arise, especially in dealing with such simple and primitive people as are the Mafulu natives.

The foods of these ghosts in both their forms are the ghostly elements of the usual native vegetable foods (sweet potato, yam, taro, banana, and in fact every vegetable food) and the ghostly elements of the excrement of the still living natives; and the ghosts come down from the mountains to the villages and 
gardens to procure these foods. Here again the difficulty as to meaning above referred to arises, as they can hardly imagine that the flickering lights cease to flicker in their mountain glades, or that the fungi cease to exist in their mountain habitats during these food-seeking incursions ; and yet, unless this be so, the superstitious difficulty is increased. A ghost is also sometimes for some reason or other dissatisfied with his mountain abode; and he will then return to the village (not apparently in the visible form of a flickering light or a fungus).

As the intentions of the ghost towards living humanity are always evil, his visits, whether for procuring food or in consequence of dissatisfaction with his habitat, are feared by the people; but I could not ascertain what was the nature of the injuries by the ghost to themselves of which they were afraid, nor could I hear of any actual instance of a disaster or misfortune which had been attributed to the machinations of such a ghost. When sleeping in their dark enclosed houses, however, the people fill up all openings by which the ghost might enter (this does not apply to the emone, the entrance openings of which are not closed at night; but perhaps the fact that a number of men are always sleeping together there gives them confidence); and when the Mission Station at Mafulu was started the natives were amazed at the missionaries daring to sleep alone in rooms with open doors and windows, through which the ghosts might enter.

Having by the shouting prior to and at the dead 
man's funeral wholly or partially driven his ghost to the mountains, and in some way, as it would seem, further placated or influenced the ghost by the subsequent pig-killing over or by his grave at the funeral feast, there is no method of which I could gain information by which the people can actually keep him there, or prevent his periodic returns to the village and gardens for food, or his return from a mountain home with which he is dissatisfied; and there are apparently no prayers, incantations or other ceremonies for the purpose of placating, or intimidating, or in any way influencing the ghost. This statement is subject, however, to the existence of the practice of pig-killing at the various other ceremonies before described (always apparently done under or by or on the site of a chief's grave), which is evidently superstitious in character, and must have reference to the ghosts of the departed chiefs and notables, being intended, or having originally been intended, to placate or influence them in some way or other; and especially it would seem that this must be so as regards the dipping of the mourner's string necklace in dead pigs' blood at the mourning-removal ceremony, and as regards the pig-killing at the big feast, at which the skulls and bones of all the then departed chiefs and notables are carefully collected, and made the objects of ceremonious dipping in blood, or touching with bones so dipped, and after which these skulls and bones may be thrown away, as not requiring further ceremony. And concerning all these ceremonies, if we bear in mind the special fear which many primitive people 


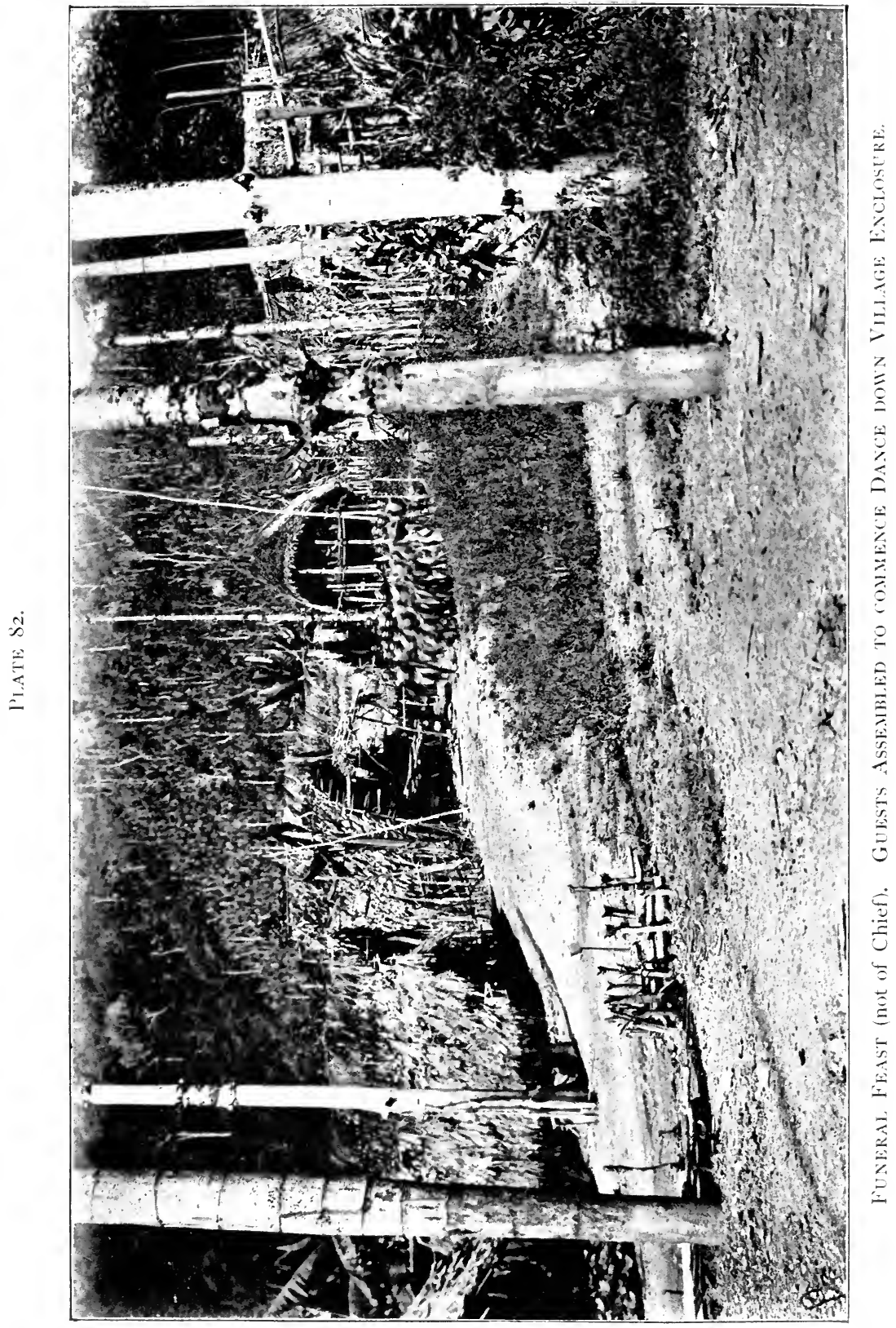



seem to have of the ghosts of their great men, as distinguished from those of the unimportant ones, it seems, I think, to be natural that the graves and the skulls and bones of the great ones should be those which are specially dealt with, and the dealing with which may possibly, so far as the big feasts are concerned, have been the original purpose for which the feasts were held.

The mental attitude and conduct of the people towards ghosts may have originated in some form of ancestor worship, but I found nothing now existing to indicate this; and in particular I could learn nothing of any recognition of, or ceremonial observances with reference to, the individual ghosts of known persons, as distinguished from the ghosts generally.

I could find no direct information as to any belief in ghosts of animals or plants; but the fact that the living edible plants have a ghostly self, upon which the human ghosts feed, seems to involve the idea during the life of those plants; and in that case one sees no reason why the ghost of the plant should not survive the plant itself, just as the ghost of the living person survives him at his death. Also the existence of a ghostly element in human excrement opens out a wide field of ghostly possibilities.

Spirits which have never been human beings are also malevolent; though when we come to the operations of magic men or sorcerers, and to incantations and the use of charms, the powers in connection with all of which appear to be ascribed to spirits, it will be 
noticed that these are by no means necessarily and invariably engaged or used for malevolent purposes.

I was not able to obtain any satisfactory information as to these spirits, or their supposed attributes, nor, except as regards illness and death, as to the nature of, and ground for, the fears which the natives feel concerning them ; indeed, this is a subject upon which most natives all over the world are inclined to be reticent, partly or largely from fear. Even as regards the sacred places which these spirits are supposed to haunt, though the natives are not unwilling to pass them, and will mention the fact that they are sacred, they are unwilling to talk about them. My notes as to spirits, other than those in connection with sorcery producing illness and death, must therefore be practically confined to the sacred places haunted by the spirits, and the demeanour and acts of the natives with reference to, and when they pass, these places.

Speaking generally, any place which has something specially peculiar or unusual in its appearance is likely to be regarded as the abode of a spirit. A waterfall, or a deep still pool in the course of a river (but not the river itself), or a deep narrow rocky river ravine, or a strangely shaped rock come under this category. There are also certain trees and creepers which are regarded as implying the presence of a spirit in their vicinity, although that vicinity has in itself nothing unusual. I can, however, only give a few illustrative examples of this general idea.

There are three special trees and two or three 
special creepers which imply the presence of a spirit. What the creepers are I could not ascertain; but the trees are a very large palm which grows on the mountains and not on the coast, a form of pine tree, ${ }^{1}$ and the gabi fig-tree, used for burial of chiefs. ${ }^{2}$ It does not necessarily follow that every specimen of any one of these trees and creepers is spirit-haunted; but some are known to be so, and all are apparently so much under suspicion that, though the natives will speak of them and will pass them, they are afraid to cut them down.

At the time when the path near the newly erected Mission Station at Mafulu was being opened some of these creepers had to be cleared away, and the Mission Fathers had the utmost difficulty with the natives, only two or three of whom could be persuaded to help in the work, whilst the others stood aloof and afraid. In the same way, when the Fathers wanted to cut down some of the special palms, only two natives were induced to help in this, and even they only did so on the condition that the Fathers themselves made the first strokes; and the Fathers were warned by the natives that evil would befall them. It was a curious coincidence that the Father who did this tree-cutting, being then and having been for a long time past

1 Dr. Stapf thinks it is probably a species of Podocarpus or Dacrydium.

2 Dr. Seligmann refers (Melanesians of British New Guinea, p. 185) to a specimen of Ficus rigo, in which a taboo, having the power of making Koita folk sick, is believed to be immanent. I do not know whether or not the gabi tree is Ficus rigo, but, if it be so, there is an interesting similarity in this respect between these people and the Mafulu. 
perfectly well in health, was that evening taken ill with a bad sore, which nearly necessitated his being carried down to the head Mission Station on the coast.

There is a very common ceremony performed when natives, in travelling through the country, pass a spirit-haunted spot. The leader of the party turns round, and in a low voice tells the others that they are approaching the spot, whereupon they all become silent, though up to that point they have been chattering. The leader then takes a wisp of grass and ties it in a knot, and all the others do the same. They then walk on in silence for a period, which may be anything from five to fifteen minutes, after which, as they pass the spot, the leader turns round and throws his bunch of grass on the ground, and the others do the same. In this way they avert the danger and afterwards chatter as before. ${ }^{1}$ Another somewhat similar ceremony commences, like the former one, with silence; but, instead of throwing grass down as they pass the haunted spot, the visible sign of which in this case is a hole in the ground, the leader stops and looks round at the others, and then presses the palm of his hand down into the interior of the hole, and the

1 A knotted wisp of grass is, I think, a common form of taboo sign in parts of New Guinea ; and Dr. Seligmann refers (Melanesians of British New Guinea, pp. 136 to 138 ) to its use by the Koita for the protection of cocoanuts and other trees and firewood, and as part of the protective sign for new gardens. The use of the wisp by the Mafulu people, as above described, is not a taboo used for the protection of an object from human interference, being intended to protect the travellers in some way from the spirit or spirits haunting the spot. But there is, I think, an underlying similarity of superstitious ideas involved by the two purposes for which the wisps are used. 


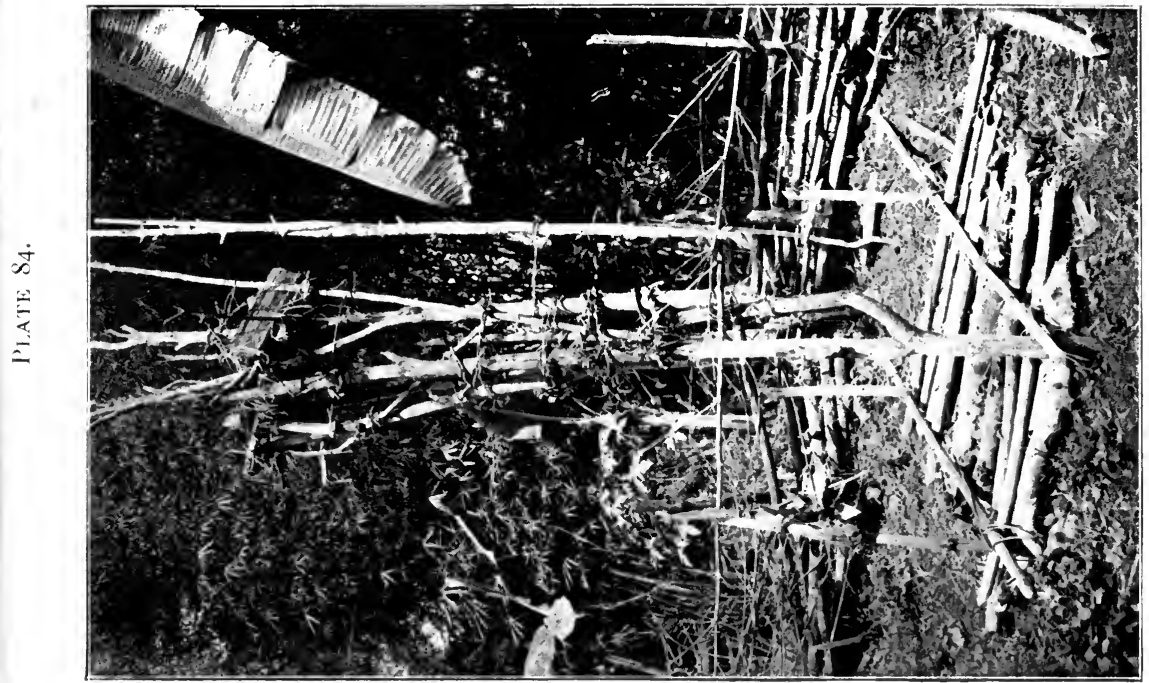

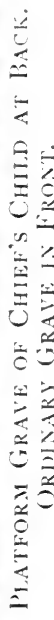

is

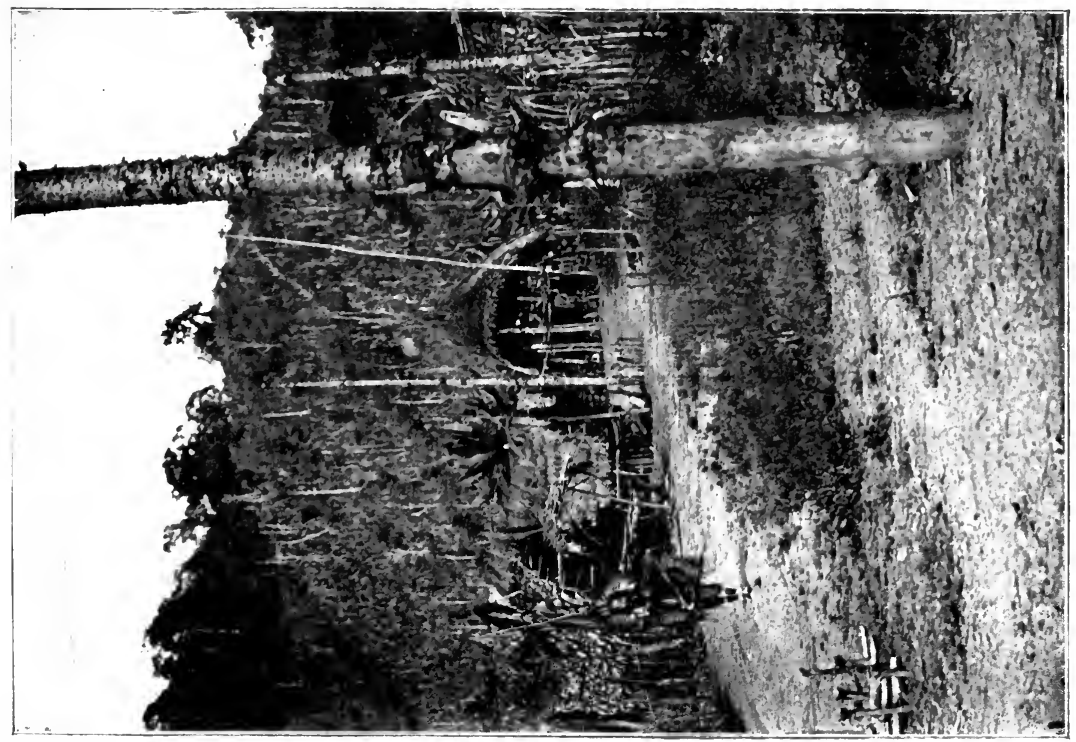

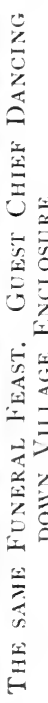



others do the same; and after this all is safe and well, as in the former case. In travelling through the country these holes with numerous impressions of hands in them are to be seen; and you may in one day's journey pass several of these signs of haunted places, of either or both sorts, within a comparatively short distance of one another. The hole in which the people put their hands may not have originally existed, and may have been produced by the oft-repeated pressure of hands on the ground as natives passed the haunted spot; but on this point I am unable to make any statement. Nor have I been able to ascertain what the difference, if any, is, or has been, between the places where they put grass and those in which they merely press the hands.

I found no evidence of any general idea of supernatural powers being possessed by natural inanimate objects, such as rivers or rocks ; but, as already stated, fishers are in the habit of addressing the stream in supplication for fish, and it is possible there are other examples of the same sort of thing, which I did not discover.

Magic or sorcery, and those who practise it, and incantations and charms, and those who supply charms, are naturally associated with either ghosts or spirits, or both. Among the Mafulu people they are, I was assured, associated solely with spirits, and not with ghosts; and, though I have no confirmatory evidence of the accuracy of this statement, I can only in these notes assume that it is correct. It may well be, however, that in the minds of the people themselves the 
distinction between the ghost of a person who has lived and died and the spirit which has never lived in visible human form is not really quite clearly defined; or that powers which are now regarded by them as spirits have had an origin, possibly long ago, in what were then believed to be ghosts. I shall revert to this point at a later stage.

SORCERY.

The Mafulu magic men or sorcerers are different from those of the Mekeo plains. There is not among the Mafulu, as there is in Mekeo, a large body of powerful professional sorcerers, who are a source of constant terror to the other people of their own villages, and are yet to a certain extent relied upon and desired by those people as a counterpoise to the powers of sorcerers of other villages; and a Mafulu native, unless prevented by a fear of outside hostility in no way connected with the supernatural, will travel alone outside his own community in a way in which fear of the sorcerers would make a Mekeo native unwilling to do so. The Mafulu sorcerers are a somewhat less powerful people; but they claim, and are supposed to have, certain powers of divination, or actual causation, or both, of certain things. So far as I could learn, the sorcerer's supernatural powers would never be exercised in a hostile way against anyone of his own village, or indeed of his own clan, or even, as a rule, of his own community. Apparently the sorcerer's victim is nearly always a member of some other community; and the sorcerers 
of a community do not appear to be in any way either feared or shunned by the members of that community. And, even as regards their acts of hostility against members of other communities, these do not seem to be performed to an extent in any way approaching what is found in Mekeo.

It seemed to me at first, as regards these sorcerers, that there was a confusion in the Mafulu mind between divination and causation. The question as to this arose specially in connection with the ceremony for ascertaining whether a chief was or was not going to die. The people of a clan and the ailing chief certainly assume that the sorcerers who perform the ceremony under instructions, whether they be of the same community or of some other community, will by their magical powers merely divine the death or recovery of the chief; and the idea does not enter their heads that these sorcerers may actually cause the death. And yet they will accuse a hostile sorcerer of causing the death by an exactly similar ceremony, and will go to war over the matter. Probably, however, it is rather a question of the sorcerer's assumed volition-that is, it is assumed that the friendly sorcerer does not want the chief to die, and the people rely upon him to confine himself to a divination ceremony, and not to engage in hostile sorcery; whereas a hostile sorcerer might do the latter. I may add that I was led to suspect that the burning test was regarded as being only a matter of divination, and that the causation, if it occurred, was effected by means, of the previous incantation. 
There are also, besides the sorcerers, a number of specialists, who can hardly perhaps be called true sorcerers, but who have certain specific powers, or are acquainted with certain specific forms of incantation, and whose services are from time to time sought by the people. It is impossible for me to point to any definite line of demarcation between the true sorcerers and these smaller people; and it cannot be doubted that the powers of the latter, like those of the former, are, or have been, based upon the supernatural, even though they themselves do not claim to be and are not regarded as being magic men in the highest sense. I think I may regard them as being more or less the Mafulu equivalents of the Roro individuals whom Dr. Seligmann calls "departmental experts." 1

Dealing first with the true sorcerers, they undoubtedly include among their number the men who perform the special ceremonial already described for ascertaining whether a sick chief is or is not destined to die. They also seem to include the makers or providers of the various charms, including those which are carried in the little charm bags and the love charms used by young men, as already mentioned. There are also two other matters which are regarded as coming within the province of the true sorcerers, of which one relates to rain and the other relates to illness and death. I will deal with them separately.

The rain sorcerer is apparently merely a diviner. Dr. Seligmann would perhaps include him among the departmental experts, but the Fathers of the Mission

1 Melanesians of British New Guinea, p. 281. 


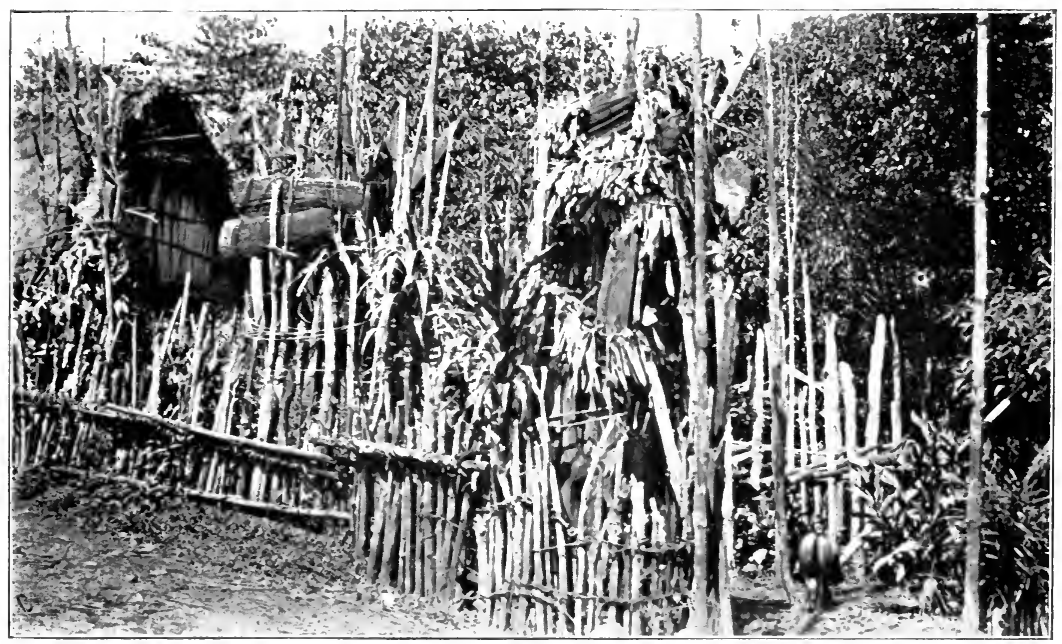

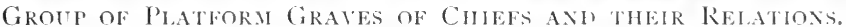

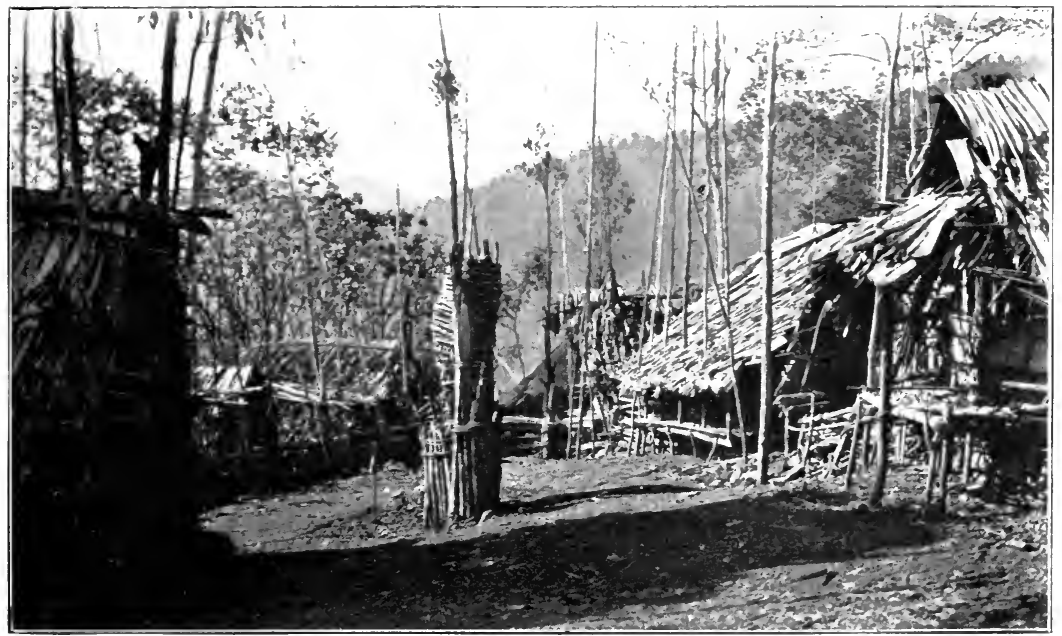

PlatFORM GRATE OF A CHIEF's CIHLD. 

regard him as being a true sorcerer. $\mathrm{He}$ is the man to whom the people go in anticipation of a proposed important event, such as a big feast, or perhaps a fighting or large hunting expedition, to ascertain and inform them whether the period in which it is proposed that the event shall occur will be fine or wet; but he does not profess to be able to do more than this, and they never expect him to prevent or bring about the rain, or in any way hold him responsible for the weather as it may in fact eventually occur.

The sorcery connected with illness and death is not so simple; and there is no doubt that it is not confined to powers of divination, but includes powers of actual causation. This department of sorcery obviously includes the ceremonial in connection with the supposed dying chief. But it is not confined to this ceremony, as it is generally believed by the Mafulu people that sickness, which does not necessarily end in death, and death itself, can be, and commonly is, brought about by the operation of sorcerers in one way or another through the medium of certain things. The only things of this nature concerning which I was able to obtain information are (I) the inedible part of some vegetable food which the victim has recently eaten (e.g., the outside part of a sweet potato or banana or the cane part of a sugar cane), and (2) the victim's discharged excrement or urine. I found no trace of any use for purposes of sorcery of the edible remnants of the victim's food, nor (except as regards a woman's placenta, to which I shall refer presently) of any part of his body, such as his hair or nails; and, in fact, the free way in 
which the natives throw away their hair when cut is inconsistent with any belief as to its possible use against them.

First, the inedible remnants of recently consumed vegetable food. The use of this as a medium for causing illness and death is apparently confined to the case of a victim who has passed the stage of very young childhood. Why this is so I could not learn; though in point of fact a mere infant would hardly be eating such things as a regular practice. A man or woman, however, never carelessly throws aside his own food remnants of this character; and his reason for this is fear of sorcery. He carefully keeps them under his control until he can take them to a river, into which he throws them, after which they are harmless as a medium against him. The fear concerning these remains is that a sorcerer will use them for a ceremony somewhat similar to that described in connection with the death of a chief, but in a hostile way. No such precautions are taken with reference to similar food eaten by very young children.

Secondly, the discharged excrement and urine. This, for some reason, only applies to the case of an infant or quite young child. Here again I could not learn the reason for the limitation; but it is confirmed by the fact that grown-up persons take no pains whatever to avoid the passing of these things into the possession of other people, whereas, as regards little children, the mothers or other persons having charge of them always take careful precautions. The mother picks up her little child's excrement, and wraps it in a leaf, 
and then either carefully hides it in a hole in the ground, or throws it into the river, or places it in a little raised-up nest-like receptacle, which is sometimes erected near the house for this purpose, and where also it is regarded as being safe. One of these receptacles, shaped like an inverted cone, is shown in Plate 9I, and a somewhat similar one is seen in Plate 64. As regards the urine, she pours upon it, as it lies on the ground or on the house floor or platform, a little clean water which she obtains from any handy source, or sometimes from a little store which, when away from other water supply, she often carries about with her for the purpose. I could get no information as to the way in which the sorcerer would use the excrement or urine as a medium for hostile purposes; though there is apparently no process similar to that of the fire used in connection with the inedible food remnants of the adult.

It will have been noticed that the mode of rendering the inedible food remnants of a grown-up person immune from sorcery, and one of the methods of making the infants' excrement immune, is that of throwing them into the river; and even as regards infants' urine, which apparently is not, and as a rule hardly could be, actually thrown into the river, the protection is obtained by pouring water upon it. I think that the belief among the islands of the Pacific in the power of water to protect against the machinations of spirits or ghosts is not confined to the Mafulu natives, or indeed to those of New Guinea. Dr. Codrington mentions its existence as regards human excrement in 
Melanesia. ${ }^{1}$ I would also refer to a custom of the Mafulu women after childbirth of throwing the placenta into the river, a practice which is similar to that of the Koita women, who drop the placenta into the sea. ${ }^{2}$ Probably these practices relating to placenta are also based upon some idea of protection from sorcerers and spirits, although I was informed that among the Mafulu there is no superstitious fear connected with the matter now. If the custom is in fact superstitious in origin, the list of media for the use of sorcery already given by me requires enlarging. ${ }^{3}$

Serious illness or death of either an adult or an infant, if not caused by visible accident, is by the Mafulu, as by other natives, generally attributed, subject to limitations, to the sorcerers. The belief of the Mafulu as to this arises if the victim, being an ordinary person, is comparatively young, or in the strength of life, say under forty or forty-five, or if the victim, being a chief or a member of a chief's family or a person of very high position, is even over that age, unless he is very old, and old age is recognised as the natural cause of his illness or death.

If the belief arises that the calamity, especially that of death, has been brought about by spiritualistic

1 The Melanesians, p. 203.

${ }^{2}$ Seligmann, Melanesians of British Nerw Guinea, p. 85.

3 I imagine a somewhat similar superstitious origin may be assumed as regards the idea of general purification (I of course do not refer to mere physical surface washing) by bathing; and Father Egedi says (Anthropos, Vol. V., p. 755) that the Kuni people, after a cannibal feast, had to confine themselves until the end of the moon which commenced before the feast to certain food, and that they then all bathed in running water and returned purified and free to eat any food. 

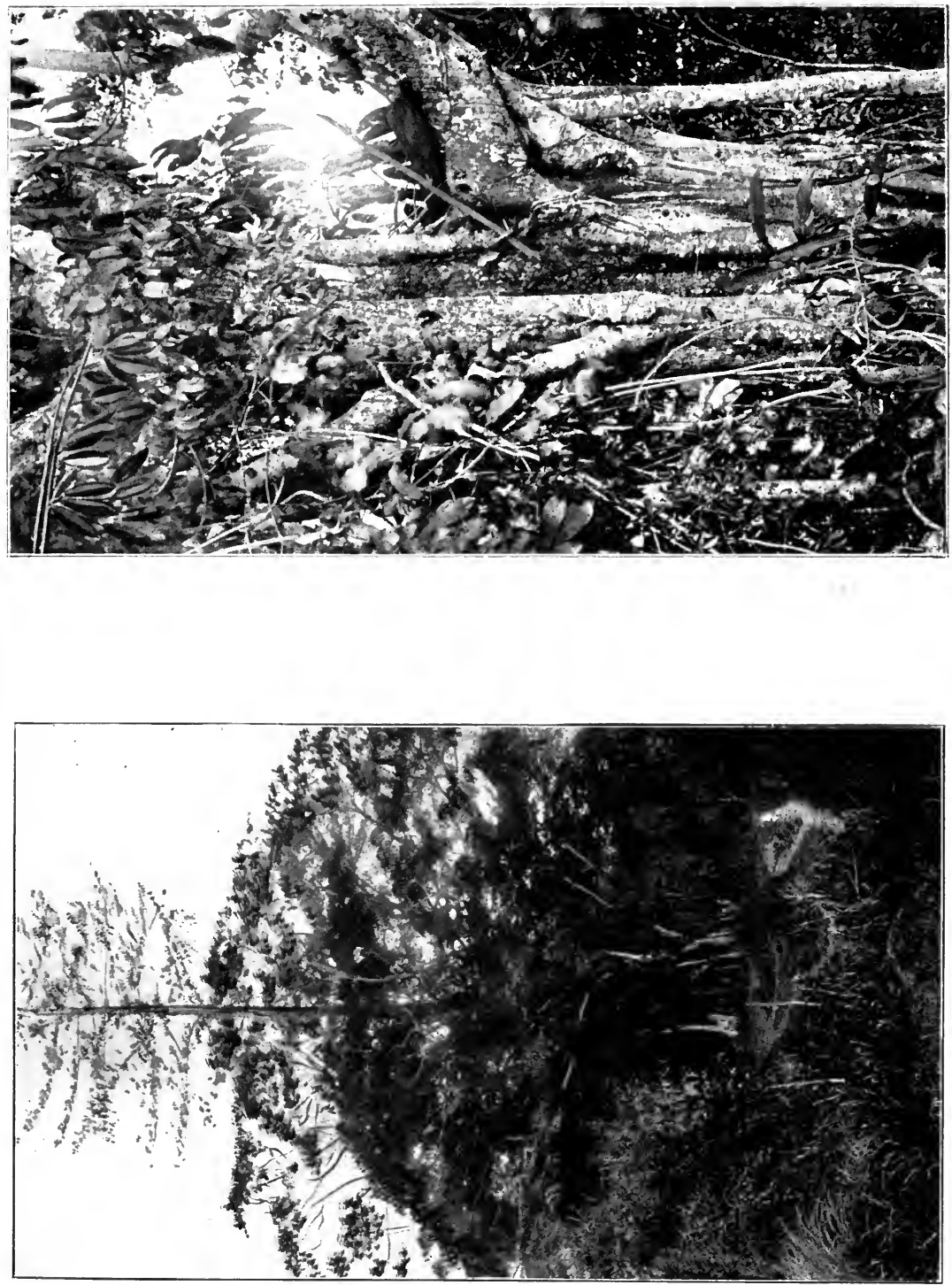

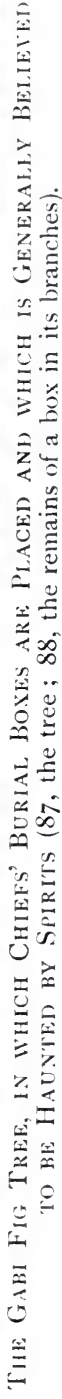



influence, the family will probably go to some person who is believed to be in touch with spirits and able to designate the culprit. I cannot say whether or not the person so employed is regarded as being a sorcerer in the full sense of the word, or as merely one of the inferior types of magic men above referred to. Probably he is only the latter, as I do not think there are any juvenile sorcerers among the Mafulu, and this particular person may be quite a young boy; indeed, there is in a village near to the Mafulu Mission Station a young boy who is supposed to have this power. As a matter of fact this boy is not quite right in his head; but this state of mind is not among the Mafulu in any way a necessary, or indeed a usual, qualification for a sorcerer or magic man of any sort. The person appealed to will perhaps tell them who has done the deed, or will make some oracular statement which will lead to his identification. The culprit identified by him will in any case be a member of another clan, and most probably of another community. When he has been discovered, there will probably be a fight, in which the members of the victim's clan, or even, especially if the victim be a chief or big person, the whole of his community, will join the injured relatives, this question of suspected causing of death being, like that of non-repayment of the price paid for a runaway wife, one of the frequent causes of intercommunity fighting.

Reverting here to the matter of ghosts and spirits, one cannot help noting a similarity between, on the one hand, the ghostly element of living food plants and 
the ghostly element of human excrement, which constitute the food of the ghosts, and, on the other hand, the physical inedible remnants of food recently eaten by an adult victim and the physical excrement and urine of an infant victim, which are the media used for hostile sorcery through the power of spirits; though, as regards the latter, I have no evidence of a belief that the spirits eat them. I tried to get further into this matter, but was unable to do so. Again one is struck by the fact that the special gabi tree, which is the tree used for the interment of chiefs and notables, is one of the trees whose presence is regarded as indicating a place inhabited by spirits. These elements of similarity tend, I think, to suggest the possibility of some confusion in the native mind as to the difference between ghosts and spirits, or of some originally ghostly origin in what are now regarded as spirits.

The class of magic men who are something less than sorcerers, and whose powers are perhaps confined to the knowledge of certain specific forms of incantation, would probably include the person who does the nose-boring, and perhaps the person who detects the causes of death above referred to. It would also, I think, include the men who ascertain the whereabouts of a stolen article and discover the thief, and who perform the ceremony in connection with hunting, and the persons who effect, or profess to effect, cures of a more or less superstitious nature, all of whom are probably not regarded as full sorcerers.

The professional pig-killer is not, as such, either a sorcerer or a magic man in the minor sense; and, if 
there has originally been anything of a superstitious or magic character associated with him or his functions, I was unable to find any trace of it, except perhaps as regards the ceremony and incantation in connection with hunting, which apparently is commonly performed by him.

\section{Charms.}

The Mafulu people believe in charms. I have already referred to those used by young men desirous of marrying. But there are many other more important charms for various purposes, such as averting illness and death, success in hunting and fishing, and perhaps preservation in time of war. These charms may be stones, small pieces of different sorts of bark, flowers, or various kinds of poisons, though the poisons appear to be only used for averting illness and death. They are all procured from sorcerers, who may be of the same or of some other village, or of another community, and there are sorcerers who have specialities in certain sorts of charms. These charms are often carried inside the small charm bags already mentioned.

\section{Omens.}

They believe in omens; but of these I was only able to hear of two examples-namely, flying foxes, ${ }^{1}$ and fireflies, the latter, though common in the plains,

1 Apparently flying foxes are good omens in Tubetube (Southern Massim). See Seligmann's Melanesians of British New Guinea, p. 653. 
being rare on the mountains, and both of these are bad omens. Any person or party starting off on a journey, or on a hunting or fishing expedition, and meeting either of these creatures would probably at once turn back; and I was told that even a full war party starting off on a punitive expedition would turn back, or at least halt for a time, if it met one or other of them. I cannot help thinking there must be some other omens, which I have failed to discover.

\section{General.}

Referring generally to supplications, incantations, and acts of propitiation, the only examples of them which I was able to discover were the above-mentioned supplication to the river prior to fishing, which is apparently spoken by the fishers themselves, and not merely by a sorcerer or magic man, and the incantations in connection with nose-piercing, with hunting, with a dying chief, with the stone operation for stomach complaints, and with the plant remedies for wounds, and the acts of propitiation, if such they are, in connection with ceremonious pig-killing, and especially with the ceremonies performed at a big feast and at or following a funeral ; and as regards the incantations I could learn nothing as to their nature, nor as to the specific spiritual powers for the influencing of which they are intended, nor the way in which those powers are moved by them.

In fact, concerning the whole question of ghosts, spirits, sorcery, charms, omens and superstitions, I 


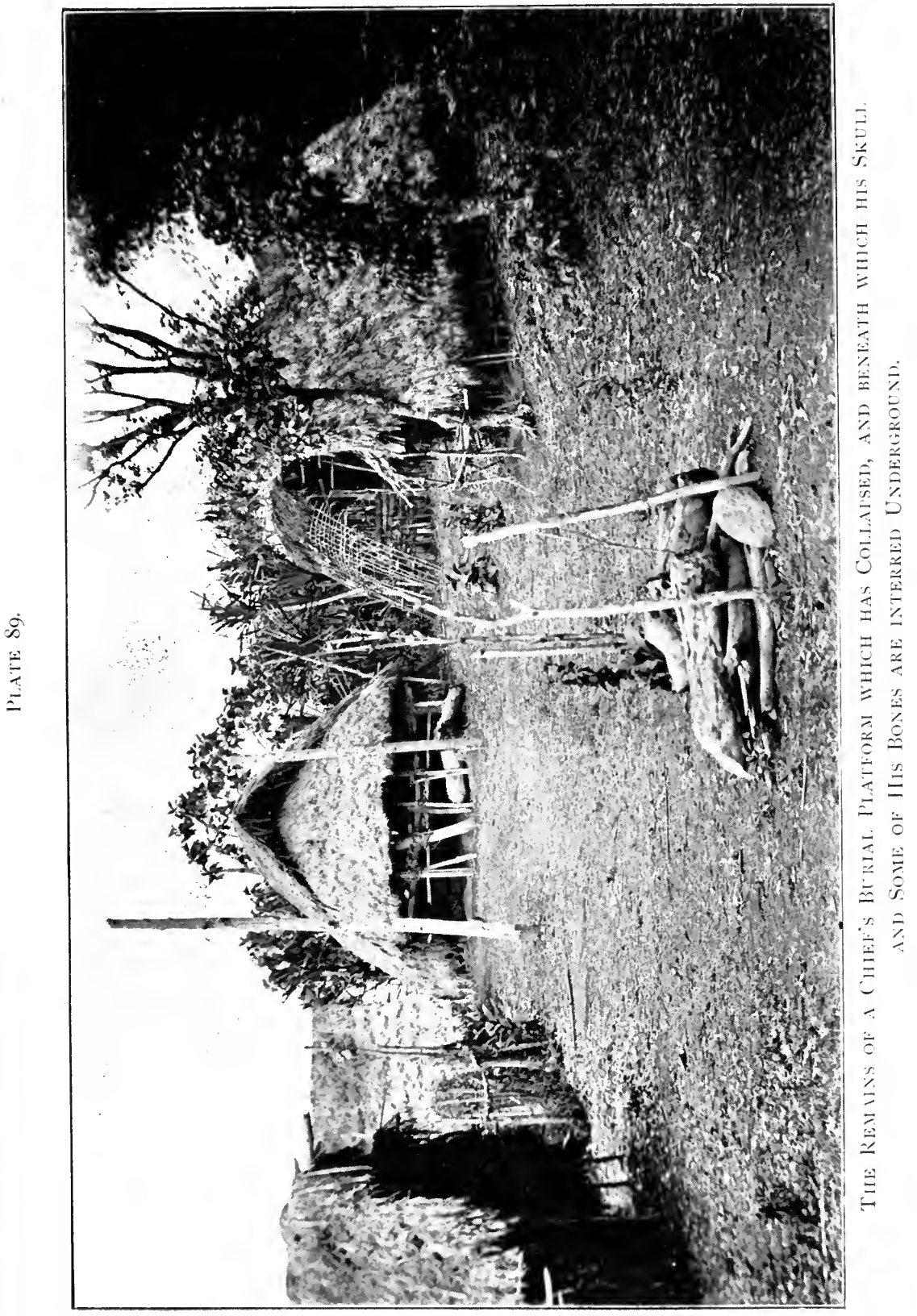



cannot imagine that I have accomplished more than the mere touching of the fringe of it; and I am sure that, when the Mafulu people have got rather more into touch with civilisation, and become more accessible and communicative about these things, there will be much more to be learnt. It may perhaps be that some of the apparently superstitious acts are, like many such acts performed in England, based upon beliefs which have long since been forgotten, and have themselves become mere formalities, to which the natives do not attach serious superstitious importance; though their fear of ghosts and spirits is undoubtedly a very real and general one.

There are no secret societies or mysteries, such as are met with in some of the Solomon Islands, and they have no superstition as to sneezing.

\section{TABOO.}

The subject of taboo may perhaps be referred to under the present heading, for, though there appear to be no totemic taboos, and though I have no material showing that the Mafulu taboos are based on superstitious ideas, it may, I imagine, be assumed that, while some of these taboos are possibly partly based on medical common sense, the element of superstition enters more or less into many of them. I have already referred to a few general restrictions connected with etiquette, and what I now propose to mention are food taboos.

Young men are not supposed to eat wild pig until 
they have married, but this is the only food restriction which is put upon them. ${ }^{1}$ A woman who is about to give birth to a child must eat no food whatever for a day or rather longer (never more than two days), before the child is born. I have already referred to the food taboo on persons undergoing the nose-piercing operation, and the optional food taboo to which the nearest relative of a deceased person may submit, in lieu of wearing the mourning string. There is also a general taboo against any food other than sweet potato and chewing of betel-nuts, with its condiments of lime and pepper, upon any male person who intends to take part, either as a dancer or singer, in any ceremonial dance. This latter term includes the dance at a big feast and the women's dance on the eve of it, but not the dancing during the six months' interval before it. It also includes the dance at any of the various minor ceremonies above described, and at a funeral ceremony. The period of restriction in the case of the big feast begins when the formal croton-leaf invitation has gone out to the guests, about a month before the date of the feast. In the case of a funeral it is necessarily only quite short, and in cases of other ceremonies it varies, being largely dependent on the length of period during which the approach of the ceremony is known. During the period of restriction the people avail themselves largely of the privilege of betel-chewing, and prior to a big feast their mouths get very red. In connection with personal ceremonies upon assumption of the

1 This is very different from the extensive food taboo restrictions which Father Egedi told me were placed upon the bachelors of Mekeo. 
perineal band, admission to the emone (excepting, as regards this, the case of a child of very tender years), qualifying for drumming and dancing, devolution of chieftainship and nose-piercing, the person concerned, male or female, is under the same food restriction for a day prior to that of the ceremony, and as regards nose-piercing this taboo is prior to the actual piercing, and is quite distinct from the subsequent taboo already referred to. There does not appear to be any taboo connected with fishing, hunting or war.

The observance of all these taboos is secured only by superstitious belief or public opinion, or both, there being no method of enforcing them by punishment or by any exercise of authority by the chiefs. 


\section{CHAPTER XIX}

NOTE ON THE KUNI PEOPLE

Father Egedi, who has studied the Kuni people, and has written a series of articles about them in numbers of Anthropos, told me that he regarded them as being a cross between the Papuan-speaking Mafulu and the Melanesian-speaking Papuo-Melanesians of Mekeo and the adjoining coast. Whether or not this is absolutely and strictly correct is a question upon which I will not venture to express an opinion.

In general physique and appearance the Kuni are distinctly and strongly of the type of the Mafulu, whilst their language is Melanesian; and, as regards other matters, they in some respects resemble and in other respects differ from the Mafulu.

As regards physique, Father Egedi distinguishes the Kuni from the natives of the adjoining coast by their slighter development, slender limbs iand darker colour of skin, in which respects they resemble the Mafulu; but he regards them as being lower-statured than the tribes of the interior, which term includes the Mafulu, ${ }^{1}$

1 Dr. Seligmann puts their average stature at $60 \frac{1}{2}$ in. (Lancet, Feb. I 7 th, I906, p. 427), which is less than the Mafulu average of $6 r^{\prime} I$ in. given by me above. 

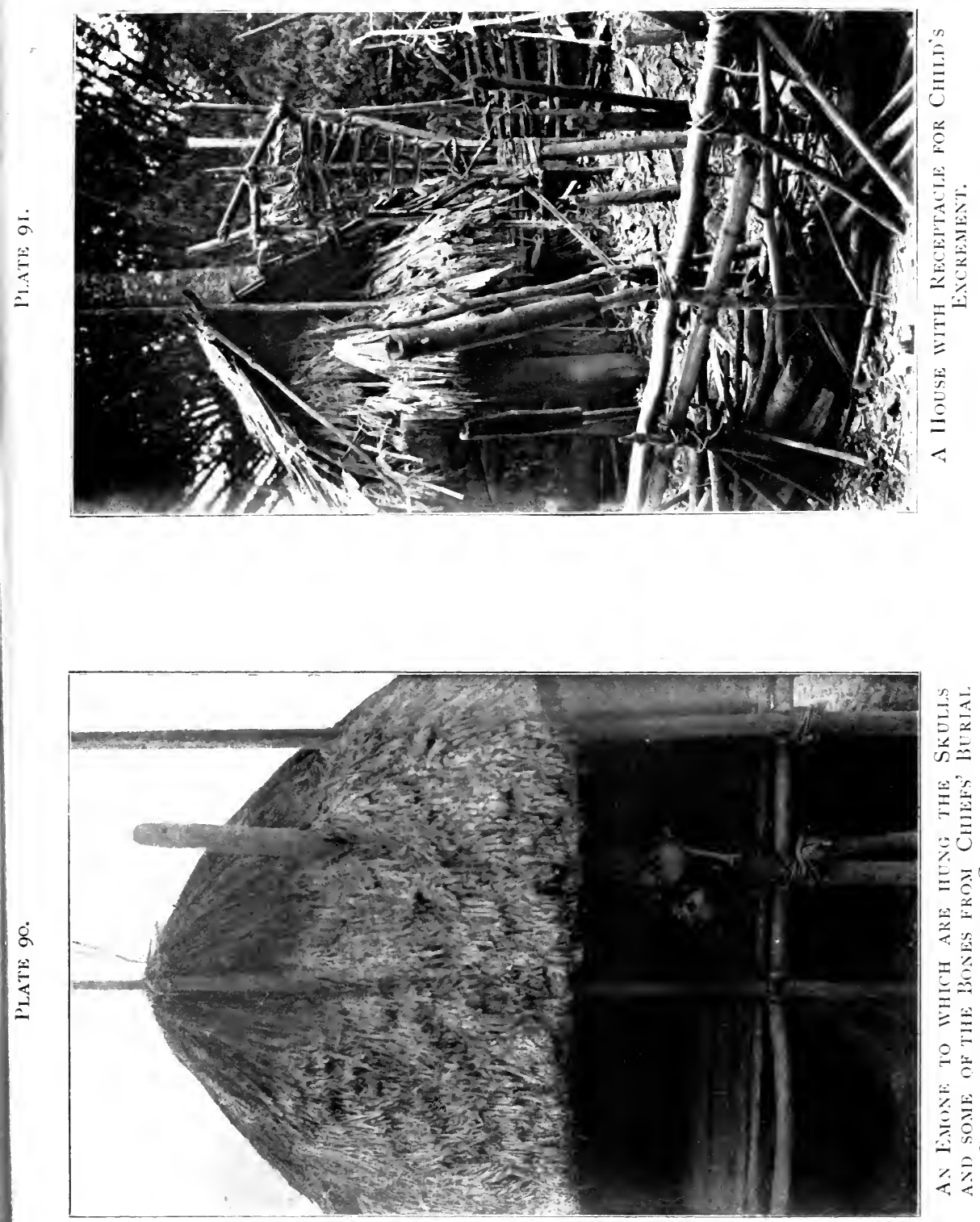

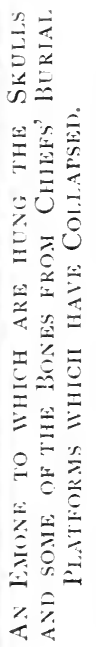



with greater regularity of features, and of lighter colour, all of which tallies, I think, with my own observation of them. But the fact that they are shorter in stature than the Mafulu, who are themselves shorter than the coast natives, is perhaps a matter for surprise, if they are a cross between the two. I have not measured any Kuni heads; but I should be disposed from general observation to say that they are very similar to those of the Mafulu, being predominantly mesaticephalic, with tendencies to brachycephalism. ${ }^{1}$

Many of the Lapeka people, who are Kuni, but are on the borders of the Upper Mekeo district, seemed to me to have distinctly flattish faces, with remarkably delicately cut features-some of the women in particular being exceedingly pretty in profile-and very bright sparkling eyes. Where these local characteristics came from I cannot say, as it could hardly be the result of an intermixture of Mekeo blood. ${ }^{2}$

The oblique eye, which is occasionally found on the coast, ${ }^{3}$ but which I never saw in Mafulu, is, according to Father Egedi, present, though only rare, among the Kuni. His large amount of opportunity for observation, and his known care and ability in this respect, compel me to assume his accuracy; but I can say that I saw a good many of these eyes among them, and indeed once, having about twenty of these Kuni

${ }^{1}$ Dr. Seligmann puts their average cephalic index calculated from fifteen measurements at 78 (Geographical Journal, Vol. XXVII., p. 234), which is below the Mafulu average cephalic index of 80 given by me above.

2 Father Egedi thinks that the Lapeka people have so:ne Pokau blood in them. Their language is a mixture of Kuni and Mekeo.

3 Seligmann's Melanesians of British New Guinea, p. I6. 
people squatting in front of me, I observed that about half of them had distinctly oblique eyes.

Father Egedi speaks of their hair as being "generally black, rarely bright, and more rarely chestnut"; and as to this, I would refer to the fact that the predominating colour of hair among the Mafulu is dark or darkish brown, so that in this respect the Kuni apparently tend more to the black-haired coast type of native than do the Mafulu.

Concerning matters other than physique and language, as I only passed through the Kuni district, and did not attempt serious ethnological investigation there, I can say but little beyond 'what I learn from Father Egedi's articles and a few other sources; and the material thus available only deals with a few questions.

It would appear from Father Egedi's observations that the relationship between villages arising from the splitting up into two or more of an original family village is not so permanent as I believe it to be among the Mafulu. Dr. Seligmann says ${ }^{1}$ that among the Kuni Father Egedi "could find no trace of intermarrying groups, or groups of clans claiming common descent," which statement applies to my investigations among the Mafulu. He further says ${ }^{2}$ that "The Dilava folk" (Dilava is a Kuni village) " marry into all the surrounding villages; and when a death occurs it is the head of the family of the deceased who says when mourning shall cease"-

1 Geographical Journal, Vol. XXVII., p. 235.

2 Ibid. 
statements of which the former, and I believe the latter, could hardly be correctly made concerning the Mafulu. He also refers ${ }^{1}$ to Kuni war chiefs, an office which does not exist among the Mafulu, and apparently understands that the office of these war chiefs is nonhereditary, a statement which could not be made of any Mafulu chief; and he refers ${ }^{2}$ to a funeral ceremony which is quite unknown in Mafulu. But his statement ${ }^{3}$ that the kufu (club-house) system seems less developed than in Mekeo would apply very strongly to the Mafulu.

The Kuni superstitious remedies for illnesses, as described by Father Egedi, are quite different from those of Mafulu, and their food restrictions, as enumerated by him, are in some respects substantially distinct from those of the Mafulu, though some of them are more or less similar.

According to him Kuni women, though they may not enter the village $k u f u$ or club-house, are allowed upon its platform, which is not the case with the Mafulu emone; and eldest sons of Kuni influential people may not enter into the $k u f u$ until their parents have given a specific feast, which custom is apparently not identical with that of the Mafulu above described by me, and which applies to all sons of all members of the village, and not merely to those of influential people.

The Kuni houses differ from those of the Mafulu, being more or less round or oval in apparent

1 Geographical Journal, Vol. XXVII., p. 235.

2 P. 236. 
shape, even though the floor is rectangular. Also according to Father Egedi, Kuni $k u f u$ are of several various sorts, and some of them are constructed in specific ways, and have specific carved and painted decorations, some of which are imitative of animals and objects held in veneration; and these different types of club-house, which include one used only by elderly bachelors and widowers, have specific namesall of which is quite different from what is found in Mafulu. Among these club-houses Father Egedi includes one built at feast times higher up the ridge, outside the village, for guests' accommodation, which, though apparently somewhat similar in purpose to the guests' houses at a Mafulu feast, differs from them in form. Indeed, as regards building construction, the only point of strong similarity between the Kuni and the Mafulu which I can trace is the long fireplace extending from front to back of the building, which with the Kuni is apparently very like that of the Mafulu.

Father Egedi's statement as to Kuni cannibalism, that speaking generally it appears to be confined to the bodies of people killed in war or in private vendetta, and that, though other cases are recorded, they are regarded as a violation of a custom and are detested, might be equally well said of the Mafulu; though I did not actually hear of any known record there of the other cases mentioned. Again his statement that the actual killer must not share in the feast holds good with the Mafulu; but I believe that this idea exists elsewhere also. 
Concerning the Kuni implements I can only refer to Dr. Seligmann's statement, ${ }^{1}$ that they do not appear to use bows and shields-which, if correct, is a point of difference between them and the Mafulu-and to a few other things referred to by Father Egedi in his articles. From his descriptions I should imagine that the Kuni pig-bone implements and their bamboo cutting knives are similar, and that their wooden vegetable dishes are somewhat similar to those of the Mafulu. But the Kuni have cooking pots (which they get from the coast), and use forks and spoons and various other implements and utensils which are not found in Mafulu, and their mode of producing fire is quite different from the Mafulu mode.

I recognise that the above comparative notes on Kuni culture are only of a very fragmentary character ; but Father Egedi expresses the general opinion that, though the language of the Kuni people is Melanesian, their habits and customs "may be considered as making one with those of the Mafulu people."

On the whole question of Kuni relationship it can, I think, hardly be doubted that the Kuni have some characteristics which are clearly those of the Mafulu and other central mountain tribes, and others which are obviously those of the Papuo-Melanesians of the adjacent plains and the roast beyond; and the only question seems to be the nature and origin of the Kuni relationship to these two types of people. It may be, as suggested by Father Egedi, that they are actually a cross between these two mixed types; or, if

1 Geographical Journal, Vol. XXVII., p. 235. 
296 THE MAFULU MOUNTAIN PEOPLE cн. xix the suggestion in my concluding chapter as to the possible presence in these Mafulu and other mountain people of Negrito blood be correct, it may be that the Kuni people are merely another result of the general Negrito-Papuo-Melanesian intercrossing, in which the Papuan and Melanesian elements have been more predominant than they have been with the Mafulu. 


\section{CHAPTER XX}

CONCLUSION

What is the origin of these Mafulu people, with their short stature, small and somewhat rounded heads, slight but active build, sooty brown skin, and frizzly hair, predominantly brown in colour, and with their comparatively primitive ideas of organisation, and simple arts and crafts?

The question is one of no mere local interest, as the answer to it will probably be the answer to a similar question concerning most, and perhaps all, of the other Papuan-speaking people of the mountainous interior of the Central District of British New Guinea, and may even be a key to the past early history of the entire island.

It has, I think, been hitherto believed that all these mountain people had a mixed Papuan and Melanesian ancestry; but it was impossible to be among them, as I was, for some time without being impressed by the difference in appearance between them and the people of the adjacent coast and plains, and suspecting that, though they had Papuan and Melanesian blood in 
their veins, there was also some third element there. And the name which obtruded itself upon my mind, whilst in Mafulu, was Negrito.

The dark skin and the comparatively rounded heads, and, I think, some shortness of stature are found elsewhere in British New Guinea; though shortness of stature and rounded heads are unusual, and, I believe, only local, and I do not know whether even the Papuan skin is ever quite so dark as that of the Mafulu people. But the almost universal shortness of stature, the comparatively slight, but strong and active, build and the brown colour of the hair seemed entirely different from anything that I had ever seen or read of as regards either the Papuans or the Melanesians; and all of these, coupled with the tendency to roundness of head, were consistent with a partial negrito ancestry.

Then on my return to England I learnt that dwarf people had been found by the recent expedition into Dutch New Guinea organised by the British Ornithologists' Union. Dr. Haddon has expressed the opinion that these dwarf people and some dwarf people previously found by Dr. Rudolph Pöch in German New Guinea are all negritoes, or negritoes crossed with Papuans. ${ }^{1}$

Dr. Keith, to whom I submitted all my notes upon the measurements and physique of the Mafulu people, and who measured and examined the three skulls which I brought home, wrote to me as follows :-

"I have examined the observations you have made on the Mafulu. From your paper one can form, for 
the first time, a picture of the physical characters of this tribe; but, when I proceed to assign the tribe to its proper race, I am at once met by difficulties. In my opinion the short stature, the pigmented skin, and the small heads inclined to brachycephaly indicate a strong negrito element, which we know is widely distributed in the far east, and certainly, as we should expect, occurs in certain districts of New Guinea. In the three crania there were characters which one could assign to Papuan, as well as to a Melanesian stock. .. A brown or reddish tinge is seen not infrequently in the hair of negritoes. You will see that I am inclined to look on the Mafulu as showing a very considerable degree of negrito blood, and to regard the more primitive tribes of New Guinea as being of this nature. If that were so, the Mafulu might be regarded as belonging to the older population of New Guinea, both Papuan and Melanesian having added something to their civilisation, as well as their physical characters."

Dr. Keith then is inclined to agree with my suggestion concerning the origin of the Mafulu; and Dr. Haddon, having seen my notes upon physique, said that he endorsed the views expressed by Dr. Keith. And if the view suggested be correct as regards the: Mafulu or Fuyuge people, I am prepared to say that from what I have heard of the other mountain Papuan-speaking people of that part of New Guinea, including the Oru Lopiku (Kovio), Boboi and Ambo people, I am convinced that it must be correct as regards them 
also, though the relative predominance of the three strains may well vary with these different people.

I am hardly qualified to enter into the discussion as to the relationship, if any, existing between the principal hitherto known dwarf races, the Pygmies of Central Africa, the Semang of the Malay Peninsula, the Andamanese and the Aetas of the Philippine Islands, or to deal with the question whether or not all or some of them are to be grouped together as forming a distinct and related type, or are to be regarded as unconnected in the sense that each of them is merely a local variation, sharing a common ancestry with some other taller negroid race.

As, however, my suggestion of a partial negrito origin of the Mafulu people necessarily brings me into contact with this wider question, and the latter is still one upon which opinions differ, I may perhaps briefly tabulate some of the chief physical characters of the Andamanese, the Semang, the Aetas, the dwarf people recently found in Dutch New Guinea and the Mafulu. I think I may omit the African pygmies from my tables.

\section{Stature.}

Andamanese $\quad \cdots 4^{\prime} 10_{2}^{\prime \prime}$ This is the figure given by Mr. Portman (Journal of Anthropological Institute, vol. 25, p. 366) and by Dr. Haddon (Races of Man and their Distribution, p. 9), and is very near the $4^{\prime} \mathrm{rO}_{4}^{3 \prime \prime}$ given by $\mathrm{Mr}$. Man (The Andaman 1slanders, p. 5), and adopted by Messrs. Skeat and Blagden (Pagan Races of the Malay Peninsula, p. 573).

Semang $\quad . . \quad \cdots 4^{\prime} 10^{\frac{3}{4}}$ 'Skeat and Blagden (Pagan Races, \&.c., p. 573) and Haddon (Races of Man, Ec., p. 9). 
Aetas ... ... ‥ $4^{\prime} 10^{\prime \prime}$ This is Dr. Haddon's figure (Races of Man, \&c., p. 9), and it is within half an inch of the $4^{\prime} \mathrm{ro}_{2}^{\prime \prime}$ given by Dr. Semper (Journal of Anthropology for October, 1870, p. 135). Dr. Meyer gives a number of varying measurements (see Journal of Anthropological Institute, vol. 25, p. 174), and Reed gives the average of 48 males, some of whom were not pure types, only $4^{\prime} 9^{\prime \prime}$ (Negritos of Zambales, p. 32).

Dutch New Guinea $4^{\prime} 9^{\prime \prime}$ Captain Rawling (Geographical Journal, vol. 38, dwarfs. p. 245).

Mafulu... $\quad \ldots \quad \ldots 5^{\prime} \mathrm{I}^{\prime \prime}$ It is merely suggested by me that they are partly negrito, which, if correct, would explain the somewhat higher stature.

\section{General Physique.}

Andamanese ... ... Well proportioned, and with: good muscular develop ment (Man, Journal of An!hropological Institute, vol. I2, pp. 72 and 73 ).

Semang $\quad . . \quad \ldots \quad \ldots \quad$ Sturdily built (Haddon, Races of Man, \&.c., p. 9).

Aetas $\quad \ldots \quad \ldots \quad \ldots$ Well formed and sprightly (Earle, Papuans, p. 123), and with limbs which, corresponding to their stature, are uncommonly slender, but well formed (Semper, Journal of Anthropology for October, 1870, p. 135). Well-built little men with broad chests, symmetrical limbs, and well-developed muscles (Reed, Negritos of Zambalis, p. 34).

Dutch New Guinea Of sturdy build (Rawling, Geographical Journal, vol. 38 , dwarfs. p. 24I).

Mafulu $\quad \ldots \quad \ldots \quad \ldots \quad$ Fairly strong and muscular, but rather slender and slight in development.

\section{Cephalic Index.}

Andamanese $\quad \ldots \quad 82$ This is Dr. Haddon's figure (Races of Man, \&cc., p. 9). Messrs. Skeat and Blagden say they are decidedly brachycephalic (Pagan Races, \&્c., p. 573).

Semang $\quad \ldots \quad \ldots \quad 78.9$ Dr. Haddon's figure (Races of Man, \&.c., p. 9). Skeat and Blagden describe them as brachycephalic to mesatecephalic (Pagan Races, \&c., p. 34).

Aetas ... $\quad \ldots \quad \ldots \quad 80 \quad$ Dr. Haddon's figure (Races of Man, $\&^{\circ} c_{.}$, p. 9). Skeat and Blagden describe them as decidedly brachycephalic (Pagan Races, \& c., p. 573). Reed gives 82 as the average (Negritos of Zambales, p. 34).

Dutch New Guinea $80 \cdot 2$ This figure is calculated by me from the actual length dwarfs ... ... and breadth given by Captain Rawling (Geographical Journal, vol. 38 , p. 245).

Mafulu... $\quad \ldots \quad \ldots \quad 80$ 


\section{Nasal Index.}

Andamanese $\quad \ldots$ ?

Semang $\quad . . . \quad$... IOI Calculated by me from average of actual measurements of 5 people given by Skeat and Blagden (Pagan Races, \&ce, p. 577).

Aetas ... $\quad \ldots \quad \ldots \quad$ ? $\quad$ Reed records highly varying indices, the bulk of which were hyperplatyrhine $(87 \cdot 9-108 \cdot 8)$, and nearly all the others of which were ultraplatyrhine ( 109 and over) (Negritos of Zambales, pp. 34, 35).

Dutch New Guinea 80.9 Calculated by me from Captain Rawling's actual dwarfs.

$\begin{array}{llll}\text { Mafulu... } & \ldots & \ldots & 84: 3\end{array}$

\section{figures.}

\section{Colour of Skin.}

Descriptions of this are so general, and so much depends in each case upon the relative meanings attached by each writer to the terms used by him, that I prefer to depend as regards the Andamanese, Semang, and Aetas upon Dr. Haddon's descriptions, which are doubtless based upon his comparison of those given in previous literature.

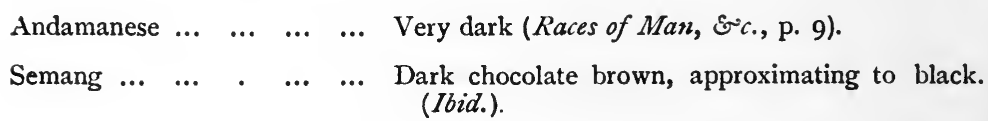
Aetas $\quad \ldots \quad \ldots \quad \ldots \quad \ldots \quad \ldots \quad$ Dark sooty brown (Ibid.).

Dutch New Guinea dwarfs ... Brown (Rawling, Geographical Journal, vol. $3^{8}$, p. 245).

$\begin{array}{lllllll}\text { Mafulu } & \ldots & \ldots & \ldots & \ldots & \text { Dark sooty brown. }\end{array}$

\section{Texture of Hair.}

This is frizzly in all cases, as with other negroids, the word "woolly" often used being, I imagine, intended to imply frizzly. 


\section{Colour of Hair.}

This being a point which seems to me to be rather interesting, I propose to quote various descriptions.

Andamanese ... - Varies from sooty black to dark brown, old gold, red and light brown; and, though these may be the colours of individual hairs, the general appearance is sooty black or yellowish-brown.

Varies between black, greyishblack and sooty, the last perhaps predominating.

Black, with a reddish tinge.

Semang $\ldots \quad$... $\quad \ldots$ Brownish-black, not a bluishblack like that of the Malays.

Brownish-black.

Aetas $\quad \ldots \quad \ldots \quad \ldots \quad$ Brown-black, shining.

Rich dark brown.

Varying from a dark seal-brown to black.

Dirty black colour, in some instances sun-burned at top to a reddish-brown. [The italics are mine.]

Black, sometimes tinged with red.

Dutch New Guinea Black.

dwarfs.

The hair of some of the pygmies was decidedly dark brown.

Hair of 3 men (out of 24) distinctly not Jlack, a sort of dirty rusty brown or rusty black colour ; all others black. haired.

Mafulu ... $\quad . . \quad$... Generally dark brown, often quite dark, approaching to black, and sometimes perhaps quite black. But frequently lighter, and often not what we in Europe should call dark.
Portman (History of our Relations with the Andamanese, p. 30).

Man (The Andaman Islanders, p. II).

Haddon (Kaces of Man, \&sc., p. 9).

Skeat and Blagden (Pagan Races, \&c., p. 46).

Haddon (Races of Man, Ecc., p. 9).

Semper (Journal of $A n$ thropology for October, 1870, p. 135).

Writer of article on Semper's work (Id.).

Meyer (Journal of Anthropological Institute, vol. 25, p. 174).

Reed (Negritos of Zam bales, p. 35).

Haddon (Races of Man, \&sc., p. 9).

Rawling (Geographical Journal, vol. $3^{8}$, p. 245).

Statement made to me by Mr. Walter Goodfellow.

Extract supplied to me by Dr. Wollaston from his Diary. 
I think that the above tables indicate that, though there are differences, there are elements of similarity between (I) the Mafulu people, (2) the Dutch New Guinea dwarfs, and (3) one or more of the Andamanese, Semang and Aetas; but in my comparison of the Mafulu and the dwarfs of Dutch New Guinea with the other previously known dwarf races I would specially draw attention to their similarity in shortness of stature and (as regards most of the Mafulu and a few of the Dutch New Guinea people) colour of hair ; and this impels me to venture to say a few words on the larger question.

I have searched through much existing literature concerning the various hitherto discovered dwarf races of the world with reference to the question whether, even assuming that these people have an original primary ancestry from which the taller negroid races also are descended, they must be regarded as having become a related type, separate and distinct from the latter, as now existing, or whether they must all be treated as merely separate local variations, each of them having failed to develop, or retrograded, and in other respects become different in type from taller negroid races among or near to whom they are found. And I am struck by the fact that, though the natural tendency to local variation in stature, shape of head, colour and other matters is brought forward in support of the latter theory, no one seems, in connection with the general question, to have noted the fact that, whilst the hair colour of negroes, Papuans and Melanesians is black, the hair of all these various dwarf people 
seems to be predominantly brown, and that this variation explanation, if regarded as applying to these dwarf races separately and independently of one another, involves a remarkable coinciding double variation (in stature and predominant colour of hair) exhibited by all these dwarf people as compared with the taller negroids.

On the other hand, if there has been an original separation of descendants of common primary ancestors of all the negroid races, which, through variation, has resulted in two main types, one predominantly fullsized and always black-haired, and the other always short and predominantly brown-haired, and the pygmies (negritoes and negrilloes) are to be regarded as being all descendants of the latter type, who have since for some reason become geographically separated, there would appear to be nothing remarkable in the double variation.

But in that case we are, I take it, justified in regarding the dwarf races as being a separate type, to be distinguished from the taller races; and, if that be so, there appears to be substantial ground for thinking that the Dutch New Guinea dwarf people and the Mafulu people are in part descended from people of that type.

I may also draw attention (for what they are worth as points of detail) to the facts already noted, that the Semang and Andamanese, who bury their ordinary folk under ground, adopt tree burial, and apparently, as regards the Semang, platform burial not on trees also, as a more honourable method of disposing of the bodies 
of important people and chiefs; and that as regards these matters the Mafulu custom is similar.

Also the very simple ideas of the Mafulu, as compared with Papuans and Melanesians, in matters of social organization, implements, arts and crafts, religion and other things may well, I think, be associated with a primitive negrito origin.

If the Mafulu people may be properly regarded as having a negrito ancestry, distinct in type from that of either the Papuans or the Melanesians, the negrito element would presumably be the earlier one, Papuan and Melanesian infusion having occurred subsequently. Indeed it may well be believed that the negrito element is derived from an original ancestry who were probably the earlier inhabitants of New Guinea. 


\section{APPENDIX I}

\section{A Grammar of the Fuynge Language}

Translated and Edited by Sidney H. Ray, M.A., from the Manuscript of the Rev. Father Egedi, S.C.

\section{Phonology.}

I. Alphabet. Vowels : $a, e, i, o, u$.

Consonants: $k, g ; t, d ; p, b, f, v ; m, n ; r, l ; s ; y$. The vowels are pronounced as in Italian, the consonants as in English. The sound of the Italian $c$ is also found, but is rare.

It is sometimes difficult to distinguish between $o$ and $u$. Ex. ombo(le) or umbo(le), belly.

$G, b$, and $d$, are often preceded by a nasal, sometimes constant (and then marked in the vocabulary), sometimes variable according to the pronunciation of individuals. For the nasals $m$ is employed before $p$ and $b$, and $n$ before other consonants.

The $i$ and $y$ are very difficult to distinguish, especially when they follow one another. Ex. iye, or ye, or ie, tree; iangolo or yangolo, ear. Father Egidi wrote $j$ for $y$.

The $l$ and $r$ are very difficult to determine. Ex. aliete or ariete, to salute; naul $i$ and naur $i$, my eye. In the vocabulary $l$ is used generally.

The $s$ is often $t s . \quad E x . t s i v u$ and $s i v u$; $s u(l e)$ and $t s u(l e)$, grass. Also in the future suffix $t$ or $t s$. Ex. nati or natsi, I will eat.

\section{Elision.}

A great number of Fuyuge words terminate in an open syllable of which the vowel is generally $e$. This 
syllable is usually omitted at the end of a phrase, and nearly always when the following word commences with a consonant. But if the following word begins with a vowel the final $e$ only falls away. Thus the complete form of a word is rarely used, except to avoid confusion, or for the sake of emphasis. The following are examples :

ovo(le), pig: ovol ovoge, boar, ovo momombe, sow.

ifa(ne), beautiful : ifa $t a$, very fine, ifan' $a k a$, less fine.

$d a(l e)$, who? nu da? who art thou? dal aua? who is this?

$i(n d e)$, to give : ne $i$, give me, ne ind" $u$, give it to me. knife.

$-a(l e)$, with: andal' a? with what? indir' al' ongai, cut with the

$a(l e)$, here : a mo ma? must I put it here? al itatsi, he will sleep here.

$u(n e)$, and : kitoval' $u$ kene, black parroquet and white, $a m b^{\prime} u n^{\prime}$ ale, banana and sugar cane.

Note (I). The $b$ in an elision sometimes changes to $p$. Ex. obe, bud, $o p^{\prime}$ indie, to bud.

(2). Sometimes two syllables are elided: Ex. taume, tame, from which comes ovo ta, a tame pig, and ovo taum' if a, the tame pig is good.

(3). Words which do not end in $e$, rarely elide a final vowel, and never the last syllable. Ex. $k u k u$, tobacco, kuk' oko nei, give me a little tobacco ; $n a, \mathrm{I}, n u$, thee, ongo at the foot of, $n a n^{\prime}$ ong ando, I am at thy feet ; umbubi, wash, umbub' $u$, wash him.

(4). Some verbs in $-r i$ or $-l i$ however often omit this syllable. Ex. ivo(ri), to wipe, na ga kodig' ivo, I have wiped the plates; tsimi(li), to lick, ama tsimi, lick the salt ; itu(lili) to split, of itu, split the wood.

In the grammar and vocabulary the syllable which may be elided is enclosed in a bracket, and in compound words and phrases the elision is marked with an apostrophe, as in the preceding examples.

III. Vowel Changes.

I. A final $o$ sometimes changes to $u$ if the word following begins with a vowel.

Ex. oko, some, a little, $k u k^{\prime} o k u$ ind" uno, give him some tobacco to smoke.

2. An initial 0 , on the other hand, sometimes changes to $u$ when the preceding word begins with $a$.

Ex. onso, under; na ungo ando, remain at my feet. 
3. The final $a$ of the word $n a$, I, becomes $e$ when it is followed by the verb indi in the imperative.

Ex. ne $i$, ne inde, give me, but nuga na indi, thou hast given me.

\section{Nouns.}

I. Gender.

There is no modification or grammatical difference to mark gender.

Sex is indicated by separate words in the case of human beings: an(e) man, me(le) boy, ena (ne) brother, amu(le) woman, ame(le) girl, eta(de) sister.

For manimals the words avoge, male, or momobe, female, follow the noun: ovol' avoge, boar, ovo' momobe, sow.

Dr. Strong notes that the sex of birds is sometimes denoted by the adjective ifa(ne), good, i.e., "ornamented," for the male bird, and ifan' $u l$ " amu, the "wife of the ornamented" for the female: uruv' ifa, the male hornbill; uruv' ifan' ul' amu, the female hornbill.

II. Number.

Only nouns indicating persons have been found with plurals. These are formed by changing the final $e$ to $i$. Sometimes the $e$ is changed to $a$; this may indicate the dual.

Ex. amu(le) woman, plur. amuli and amula; so(le), young man, plur. soli and sola; me $(l e)$, child, plur. meli and mela.

Note (I). The word $a(n e)$, man, has a double plural in two different meanings : ani, the men; ake(da), the married men.

(2). The shortened form of the word is often used in the plural. This naturally is the same as the singular.

\section{CASE.}

I. There is no modification of the noun to express case, but the equivalents of cases are shown by suffixes. The vocative alone often takes a final $a$ as in the interrogative form.

Ex. Tayova, a tsia! Tayo, come here!

The subject, direct object, and indirect object are however easily recognised by their position in the sentence. The subject comes first, followed by the direct object, then the indirect object if there be one, 
with the verb at the end. If there are complements they immediately precede the word which governs them.

Ex. naga kuku nu inde, I tobacco to thee gave; Baiv $u$ mega nembe u fod' al ema, Baiva's child bird his bow-with killed; nuni ake $m u$ letsi gatsi, thou men their village-to will-go.

2. The genitive is expressed by means of the possessive adjective.

Ex. ovo'u ma, hair of the pig, lit. pig his hair.

3. Persons belonging to a place sometimes omit the adjective.

Ex. A Kotsi, a man of Kotsi ; An'Alol', a man of Alole ; Alol' amu, a woman of Alole; Ambov'amu, a woman of Ambove; Tseluku ul $a k e d a$, men of Tseluku.

4. Position in a place, or motion to or from a place is shown in the following ways. When the noun has a shortened form -tsi is suffixed. If there is no short form the final $e$ of the noun is changed to $i$ and $-t s i$ is added.

Ex. nani etsi ando, I am in the house; nuni bulitsi gatsi, thou wilt go to the garden; naga Mambutsi l'a tela, I have come here from Mambo.

Note (I). Some proper names of places do not take the suffix $-t s i$. Ex. amul' Alol' itatsi, the woman will sleep at Alole.

(2). Other proper names, especially those of mountains and the villages built on them, take the suffix -tu (upon) instead of -tsi. Ex. Falitu gatsi, I will go to Faliba, lit. I will go upon Faliba.

\section{Interrogative Nouns.}

The noun in Fuyuge has a special form to indicate the interrogative. If the noun ends in $e$, this vowel is changed to $a$. If already ending in $a$, the $a$ takes a strong accent. To any other vowel ending $a$ is added.

Ex. ovo(le), pig: interrog. ovola? is it a pig?

bulomakao, cow, \&c. : interrog. bulomakaoa? is it a cow?

$k u k u$, tobacco: interrog. kukua? is it tobacco?

$k u p a$, sweet potato: interrog. kupà? is it a sweet potato? 
V. Demonstrative Nouns.

These are similar to the Interrogative Nouns and are formed by the addition of the syllables -aua, -ana, or -ala instead of $a$. This form is both affirmative and interrogative.

Ex. oyand" aua? is it a flower? or, it is a flower.

Tayov' aua, it is Tayo; kuku aua, it is tobacco; an' ala, it is a man; Ambov' ana, it is Ambo.

\section{Adjectives.}

I. Adjectives have no Gender. In the expression of Case, Interrogative and Demonstrative forms they are the same as Nouns.

Ex. a baibe, amu baibe, man tall, woman tall ; uli baibitsi mau, pot big-in put it, put it in the big pot; ifana? is it good? ifan' ala, it is good.

\section{Adjectives of Quality.}

I. Number.

Number is expressed as with nouns by changing $e$ to $i$. Some adjectives in $-a$ add $i$. There are no adjectives with the plural in $-a$. Some adjectives in $-a(n e)$ have the plural $-a i$.

Ex. kakava(ne), strong, plur. kakavani; safa(le), plur. safa(li) ; isosonga, idle, plur. isosongai; aka(ne), small, plur. akai.

2. Agreement.

The adjective always follows the noun which it qualifies, and takes the suffix of the noun.

Ex. a sesada, fence long; emo gai, house old; kodige kisiakatsi, plate little-in: indiv' amoja(le), knife blunt-with; koua baibitu, box big-on.

Sometimes the pronoun $u(n e)$, his, is placed between the noun and the adjective.

The meaning of this is uncertain, but it appears to be more emphatic, as e.g. "the road which is good," "the house which is bad."

Ex. enamb' un' if a, the good road, em' u koi, the bad house. 
The adjective used as predicate immediately follows the noun, without a substantive verb.

Ex. an' ala gududuba, that man (is) stingy ; nuni sesada, thou (art) tall; amu safali, the women (are) weak.

Note.-When the subject is represented by a pronoun of the first or second person dual or plural, the predicate remains singular.

Ex. dini kakava(ne), we (are) strong; yani kapape, you two (are) weak; but, muni isosongai, they (are) idle.

When the predicate expresses a negation the word expressing the quality is followed by the adverb ua(ne), not.

Ex. sesad' $u a, o n o v^{\prime} a k a$, it is not long, it is short.

\section{Comparison.}

There is no special form for comparisons. Two positive statements are made, or a superlative may be used.

Ex. My house is larger than yours may be translated: naul' $e$ baibe, nul' a kisiaka, my house is large, yours is small, or nul'e baibe, naul' a baibe ta, your house is large, mine is large much.

Equality is expressed by the suffix $-u m b a$ or -yakala.

Ex. naul' e, nul' 'em' umba, my house is like your house; nuni sesada, nauyekala, you are tall like me.

A superlative is expressed by the prefix ande, or the suffix -ta. But if the adjective in the superlative expresses a lessening of the quality then $-a k a(n e)$ is suffixed.

Ex. baibe, large, ande baibe, larger; if a, fine, ifata, finer; but ono(ve), short, onov'aka, shorter.

The prefix ande is used only with adjectives which express an idea of extension.

When the adjective expresses an actual state rather than a passive, it is preceded by the sign of past tense, the particle $g a$.

Ex. ani g'ifa, the breeches are (have become) good; ena ga ko, the road (is) bad. 


\section{Demonstrative Adjectives.}

The demonstrative adjectives in Fuyuge are represented by the suffixes -ana, this, -ala, this, here, -vala that, there. The same expressions translate the French "le voici," "le voilà."

Ex. indiv'ana, this knife; em'ala, this house; enavala, that road.

There is no article, but the expression $u$ mane is used in reference to any thing which has been previously spoken about.

Ex. enamb' ifa, or enamb' 'un' ifa, it (is) a good road; but enamb' $u$ man' if a, the road (which has been mentioned) is good.

\section{Interrogative Adjectives.}

For these. See Pronouns.

\section{Indefinite Adjectives.}

The indefinite adjectives are $o k o$, some, a little, part of ; tale(le), several, many ; korio, several ; gegeto, a few, several ; alu(ve), all ; urambe, another; none. together, one with the other; dovavemunge? domamai? how many?

Note.-When oko is followed by a word beginning with $i$, it becomes o.ku.

Ex. Kuku oko nei, give me some tobacco; nemb' oko ematsi, they will spear the birds; bodol oko tsia, take one of his hands ; indiv' oko ya, take a knife; kuk' sko ua, (there is) no tobacco; indiv' oku $i$, give him a knife; ake talel ando, there are many men; kupa korio inde, give several potatoes; me' gegeto indiatsi, some children will come; aked' aluvi etsi ando, all the men are in the village ; nau mel' $a l u$, all my children; indiv' urambe $y a$, take another knife; Pitsoke non' ade, the Pitsoke strike one another; oye non' ongete, the dogs keep beside each other; kokol' ul' ombo dovavemunge? how many eggs? nu sise domamai? how many dog's teeth?

VI. Possessive Adjectives. See Possessive Pronouns.

\section{Numerals.}

I. There are only two numerals : $f i d a(n e)$, one, and gegeto, two. Gegeto is also used for a small number, and gegetom'inda, is little used for three. For more 
than three, gegeto, meaning "a few," or tale(le), "many" is used.

II. There are no ordinals and the only distributive is fida fida, one by one.

\section{Pronouns.}

\section{Personal Pronouns. Simple.}

Singular.

Ist Person na, nave, nani, I, me 2nd ", nu, nove, nuni, thou, thee $3^{\text {rd } ~ ", ~ u(n e), ~ o v e, ~ u n i, ~ h e, ~ s h e, ~ i t, ~ h i m, ~ h e r ~}$
Dual.

$d a, d a n i$, we, or us two ya, yani, you two tu, tuni, they, or them two

$$
\begin{array}{ll}
\text { Ist Person } & \text { Plural, dini, we, us } \\
\text { 2nd ", } & y i, y i n i, \text { you } \\
\text { 3rd ", mu, muni, they, them }
\end{array}
$$

I. The first form $n a, n u, u(n e)$, etc., is used either as subject or object of the verb, the meaning being only indicated by the position of the word.

Ex. na kuku nu inditsi, I will give thee tobacco; na un' adatsi, I will strike him; ya di ong' ando, you two are beside us.

When used before the imperative of the verb indi, to give, na becomes $n e$.

Ex. ne $i$, ne inde, give me.

The forms nave and ove are rarely used. The commonest use is with the words ete, to say, ende, also.

Ex. nav' elete, I said; ov' elete, he said; nav' ende, nov' ende, $o v$ 'ende, I also, thou also, he also.

3. The forms nani, nuni, etc., are employed when the verb is understood, or to indicate opposition or emphasis.

Ex. da gatsi? dini; who will go? we (will); nuni kakape ta, nani kakava, you are weak, but I am strong; nani a baibe, I am a great man.

4. The dual is generally observed by the natives. Adjectives used with the dual pronoun take the singular form.

Ex. dani sosonga, we (are) idle. 
5. The dual is often employed with two subjects one of which is plural.

Ex. Kakao tu, tsimani u ganga, Kakao they two, with the policemen, have started.

When dani is used alone it is generally inclusive of the person addressed, and means " I and thou." If the third person is intended the name is used : dani Okomi' u da gatsi, we two Okomi with we will go. Yani is used in a similar way, when one of the persons referred to is not present : ya, Dun'u yani natsi, you two Dune with you will go. The use of the conjunction $u(n e)$ with the second member of the subject does not appear to be constant.

6. The pronoun of the third person singular $u(n e)$ when it is the direct object of the verb usually follows, and often takes the form -unde. him.

Ex. kodigitsi mau, put it in the dish; nag' al unde, I have seen

\section{Personal Pronouns. Compound.}

From the pronouns $n a, n u$, etc., are derived by means of the suffix -muku, alone, the forms namuku, numuku, etc., with the meanings, "I alone, without company," etc.

The suffix -mule, is equivalent to self, namule, numule, etc., myself, thyself, etc.

From nani, nuni, etc., come the forms: naniende, or nanienge, etc., meaning myself in person, etc.; nanieke, nunieke, etc., from -eke, alone; naniova, etc., it is my business, nanibila, I by myself, without help. Nani endebila is more emphatic than nanibila.

Ex. numuku andola? art thou quite alone? da gatsi? uniende; who will go? he himself; $n u$ da? nanicnge; who art thou? it is myself; amed" unieke ando, the chief is alone; ake muniova, it is the men's business; dinieke al' andetsi, we will stay here alone; isong' unibila, his own rainbow appears.

\section{Possessive Pronouns.}

I. These are formed from the simple forms of the personal pronouns by suffixing -ula(ne) literally "his thing."
Singular.
Dual.
Plural.
I. naula $(n e)$
1. daula(ne)
2. nula(ne)
2. yaula(ne)
3. ula(ne)
3. tula(le)
1. diula(ne)
2. $y u l a(n e)$
3. mula(ne) 
They translate the English mine, thine, etc. Sometimes in compounds the final $n$ becomes $n d$.

Ex. nauland aua, here is mine. la.

2. The adjectival forms appear without the syllable

\begin{tabular}{lll} 
Singular. & \multicolumn{1}{c}{ Dual. } & \multicolumn{1}{c}{ Plural. } \\
I. $n a u(l e)$ & 1. $\operatorname{dau}(l e)$ & 1. $\operatorname{diu}(l e)$ \\
2. $m u(l e)$ & 2. $y a u(l e)$ & 2. $y u(l e)$ \\
3. $u(l e)$ & 3. $\operatorname{tu}(l e)$ & 3. $m u(l e)$
\end{tabular}

These adjectives precede the noun which they govern. With personal nouns the forms naula, etc., are sometimes used.

Ex. nau me and naula me, my son; diu vase and diula vase, our guest.

Note.-The form nulu is heard in the phrase nulu babe, thy father.

The suffix mule is also used in the sense of "own."

Ex. numul u' $\imath$ to, $n$ ' alo, your own name, which I know; namul' $u l i$, my own name. These suggest that the true possessive is simply $u l(e)$ or $u l a(n e)$.

\section{Interrogative Pronouns.}

I. These are: $D a(l e)$ ? dau(ne)? who, which? anda(le)? what? unau? which? They are used also as adjectives.

Ex. Nu da? who art thou? dau ga ne? who has eaten it? anda l' elete? what did he say? Ivi: unau? Ivi : which one?

2. When the verb is preceded by the particle $g a$, $d a u(n e)$ must be used instead of $d a(l e)$.

V. Indefinite Pronouns.

These are the same as the Indefinite Adjectives.

\section{Relative Pronouns.}

The suffix $m u(n e)$ or $u(n e)$ takes the place of a relative pronoun.

Ex. A yaigegemune, the man who descends; audati itedemu bulitsi jalo tolom elota, in the garden which they are cutting now when the food is ripe; ovo jamun' imbade, the meat taken from the pig; fal' itamun' akeda, the men who have dug the ground. 


\section{VERBS.}

I. Conjugation.

The Fuyuge verb is conjugated by modifications of the terminal syllables, or by a particle added to the subject.

\section{The Particle, Ga.}

The particle $g a$ (often $g$ ' before a vowel) is generally used with the past tense, and is rarely absent in the positive form of the verb. But it may be used also with the present and future. With the present it seems to indicate reference to a preceding action in the sense of "being on the point of," "ready to." With the future it has almost the sense of "go."

Ex. Ake ga nembe na, the men have eaten the bird; amu gianga, the women are gone; "naga bulitsi gatsi, I am going to go away to the garden; naga sue, I am going away.

Note (r). Ga always immediately follows the subject, except with the past of the verb ange(ge), to go, which always has ganga.

(2). When the subject is not a pronoun, the pronoun of the 3rd pers. sing. is often expressed.

(3). $G a$ never appears to be used in a negative expression.

Ex. Naga ipitsial' uruv' ema, I have killed with the gun a toucan; mel' u' etsi g'anga, the child to his village has gone; Okon' ug' $n e m b$ ' ema, Okome has killed a bird; ake kupa me na, the men have not eaten the potatoes.

\section{Person and Number.}

These are not expressed by the verb in Fuyuge.

\section{Tense and Mode.}

I. There are three principal tenses, present, past and future. The present is found in the indicative and imperative modes, the past in the indicative only, and the future in the indicative and subjunctive. Besides these, there is a method of expressing the infinitive, a passive participle, and two forms of verbal adjectives. 


\section{Paradigm of tenses and modes.}

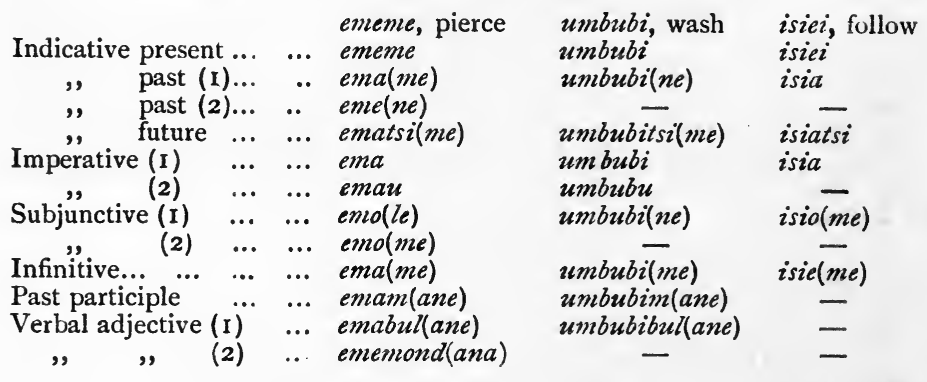

If the Imperative be regarded as the stem, there appear to be three Conjugations, but Dr. Strong gives four based on past tense, thus: I. Verbs with monosyllabic roots, 2. Verbs with roots in $a$, 3. Verbs with roots in $i, 4$. Verbs with roots in $e$.

His examples are:-

\begin{tabular}{|c|c|c|c|c|c|c|}
\hline Present & $\cdots$ & I. & $\begin{array}{l}\text { nene, eat } \\
\text { nene }\end{array}$ & $\begin{array}{l}\text { 2. itede, cut } \\
\text { itede }\end{array}$ & $\begin{array}{l}\text { 3. ongai, break } 4 \text {. } \\
\text { ongai }\end{array}$ & $\begin{array}{l}\text { bole, leave } \\
\text { bolo }\end{array}$ \\
\hline ast & .. & $\ldots$ & na & ita & ongai & bole \\
\hline Future... & $\ldots$ & ... & natsi & itatsi & ongaitsi & bolatsi \\
\hline erative & $\ldots$ & $\ldots$ & $n a$ & ide & ongai & bo(le) \\
\hline Subjunctive & e... & $\ldots$ & no & ito & ongai & bolo \\
\hline Infinitive & & $\ldots$ & namubabe & itamubabe & ongaimubabe & bolamubabe \\
\hline Yast partici & iple & $\cdots$ & namane & itaname & ongaimane & bolamane \\
\hline & & $\ldots$ & nabulc & itedondona & ongaibula(ne) & bolabula(ne) \\
\hline
\end{tabular}

3. Notes on the foregoing paradigms.

a. Indicative present.

Most verbs double the last syllable of the stem, which in the first conjugation always ends in $e$. There are, however, some exceptions, especially among verbs in $i$, and those which have a verbal suffix. The syllable -te when doubled is always -tede.

Ex. $N a g^{\prime}$ alili, I see; nani e gadi, I build (tie up) the house; nani okid' atede, I light the fire.

\section{b. Indicative past.}

The difference between the two forms, both of which are preceded by the particle $g a$, is not yet clearly made out. The ending $e$ seems to refer to the time when the action finished, whilst $-a$ has a more general signification.

Ex. Naga ne, I have eaten, naga kupa na, I ate the potatoes. There is another form which replaces the final syllable of the present tense by $-u a$. Verbs in $-i$ add $-u a$ to the final syllable. But it is uncertain whether this expresses the near past, or includes an idea of movement.

Ex. na bul' elelua, I have just worked in the garden; nu a gadi ua, you have just tied up the fence. 
c. Indicative future.

If the syllables preceding the suffix - $t s i$ also contain $-t s i$, the suffix becomes - ti. In monosyllabic verbs especially, a second form of the future is often found, which retains the doubling of the present tense.

Ex. etsiati, will come; nenetsi, will eat; yeyetsi, will take. For ga with the future, see below.

d. Imperative.

The first form of the imperative has less force than the second. In the first conjugation the second form always terminates in -au, even when the first form is irregular. The last syllable of the imperative is often lost, especially when the ending is -li.

Ex. aitodede, runs, imperat. aitode and aitodau; itulili, ward off, imperat. itu ; bole, leaves, imperat. bole, bo, and bolau ; ameme, puts, imperat. $a$ and $a m a$.

The imperative is only used for the second person. In the first and third (sometimes even in the second) it is replaced by the subjunctive.

Ex. di ango, let us go; to n'alo, speak, that I may know; go di go, go that we may go.

e. Subjunctive.

The two forms of the subjunctive are distinguished only in composition, and have not yet been clearly understood. The last syllable besides is rarely heard except in questions, and refers then to the interrogative form. The subjunctive without a conjunction is used in simple phrases consisting only of subject and object.

Ex. $k u k u$ gadi, di no, roll the tobacco (make cigarette), that we may smoke (eat).

$f$. Infinitive.

The forms given as infinitive are uncertain. They may be verbal nouns. They are used in phrases such as: nam' $u$ babe, father of eating, for 'a great eater': tsimilim' $u$ babe, father of licking, cf. andaval $u$ babe, father of crying, one who causes crying.

g. Past Participle.

This does not easily lose the final syllable when it ends a sentence. In other cases, when it is followed by the word it qualifies it loses -ane, if the qualified word begins with a vowel, and -ne in other cases.

Ex. 'iy' ongaimane, the cut tree, indiv' ongaima ya, or ongaim' indi' $y a$, take the broken knife, g'usangaman' $u l^{\prime}$ ande, the thing of death.

The past participle of some verbs has not yet been ascertained.

$h$. Verbal Adjectives.

The exact difference between the two forms is not accurately ascertained. The first seems to indicate an instrument, and is 
equivalent to the phrase "used for," the second appears to indicate habitual rather than momentary use. When qualifying persons -onde is used for -ondana.

Ex. indi kupa fifitabula, knife for scraping potatoes; ai safatsilibula, a yam which has rotted; kulule iy' adedondona, a hammer for striking wood; nuni oyatonde, you are only joking; nani falazea me nonde, I don't eat bread.

In composition -ande, or at least -nde, is lost when the word qualified follows.

Ex. ai filibulanda, a yam for planting, filibula' ai ne $i$, give me the yam for planting ; ambe nenondana, the eatable banana, nenond' ambe $y a$, take the eatable banana.

\section{Negation.}

The negative of the verb is formed by the particle $m e$ or $m i$ preceding. In the imperative it also precedes, but when emphasis is laid upon the negation $m i$ follows. The difference between $m e$ and $m i$ is not clear, but me appears to be used only before verbs beginning with a consonant, and $m i$ with other verbs.

A negative participle or infinitive does not appear. For the verbal adjective the suffix $-u a(n e)$ is used.

Ex. Na mi alele, I do not understand; nani matsine mi engatsi, I will not put on the (shell) bracelet; mi unde, do not fear; kolose $m i$, do not play; me $y a$, do not take ; nenond' an' $u a$, what is not eaten.

\section{Interrogative.}

The interrogative is only employed with reference to the verb itself, not to the complements. It changes with the conjugation and varies for present, past and future tense.

\begin{tabular}{|c|c|c|c|}
\hline $\begin{array}{l}\text { Present. } \\
\text { ememoma? } \\
\text { umbubinta? }\end{array}$ & $\begin{array}{l}\text { Past } \mathrm{I} \text {. } \\
\text { emama? } \\
\text { umbibia? }\end{array}$ & $\begin{array}{l}\text { Past } 2 . \\
\text { emena? } \\
\text { umbubina? }\end{array}$ & $\begin{array}{l}\text { Future I. } \\
\text { emola? } \\
\text { umbubiia? }\end{array}$ \\
\hline
\end{tabular}

The present in the first conjugation keeps the reduplication of the stem, and changes the final $e$ to -oma. The second conjugation simply adds $-m a$. The interrogative in the past simply changes the $e$ of 
the positive indicative to $a$ in both forms. The future is formed in the same way from the subjunctive with a stress upon the final $a$ in the first conjugation.

Ex. Nuga malele yera? have you taken the book? uga nemb' emama? has he killed the bird? nu aiti golà? would you start to-morrow? kupa g'ilama? are the potatoes cooked?

Note (I). The future interrogative replies to the question, "Can I . . ."? or "Should I . . ."?

(2). The interrogative of the near past $(c f . p .318,3, b)$ is formed by substituting -una for -ua.

Ex. nug $\mathrm{em}^{\prime}$ aliluna? Have you just come to see the village?

(3). The form of the second future as umbibia is rarely heard, except with the verb alili, see, from which comes 'Aria? see?

(4). The negative interrogative is formed like the simple negative by $m e$ or $m i$ preceding the verb.

The questions "What should I do?" "What should I say," "How should I begin it?" are translated by the expression do(le). . maiti, from do(le)? where?

Ex. dotamaiti? how should I say? dol' imaiti? what should I do? do yela maiti? how shall I call?

\section{ViI. Substantive Verb.}

I. In the present tense there is no substantive verb. The predicate and subject are combined as in the examples already given (cf. p. 3 I 2, 2). But when the present indicates a state in opposition to one preceding it, $g a$ is used before the adjective, or if in opposition to a future state, the verb ando follows.

Ex. Kuku ga ko, the tobacco is bad; balava ga $u a$, the bread is finished; indi ga kouatu, the knife is on the box: ambe gifa, the banana is good; ambe gos' ando, the banana is (still) green (not ripe).

The past is more difficult to express. It always requires an adverb of time.

Ex. Mele maleke ifa, audati ga ko, the child formerly was good, now he is bad.

3. For other tenses the verb is translated only by the auxiliaries -elele and -angege, for which cf. p. 322, 7 . 


\section{Auxiliary Verbs.}

I. The particle ga may be used to make any expression whatever attributive.

Ex. Yu g'ua, the water is finished (i.e., is not) ; malele ga kouatsi, the book is in the box.

In such examples there is almost the sense of a past action, as if it were "The water (has become) nothing," "the book has been put (is already in) the box."

2. The verbs ete, tede, to say, or to do, and elele, to become, are often used to form a noun stem into a verb. Ete and tede give the sense of sounding, elele gives the sense of using whatever the noun expresses.

Ex.

fioli, flute, fioliete, to play the flute. ule, thunder, ulonete, to thunder. andavale, crying, andav' ete, to weep. yuve, water, yuv' elele, to bathe. ivule, dye, ivul' elele, to paint one's self. bule, earth, bul' elele, to cultivate.

3. The Tenses, etc., of these verbs are found as follows :

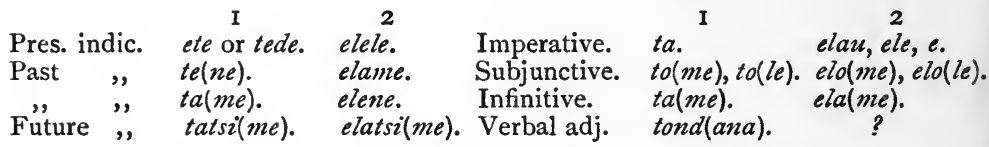

4. The negative is formed regularly by $m i$.

Ex. nani yu mi elatsi, I shall not bathe; degu mi e, don't get dirty.

5. The interrogative is regular.

Pres. or past, tena? or tama? elena? or elama? Fut. toma? and tola? eloma? and elola?

6. The auxiliaries ete, tede, elele, should be distinguished from the regular verb, tede or ta, to make. The latter is a distinct verb used when the result of the action is to produce a new thing.

Ex. Sambari tatsi, will make a wall ; ombo tatsi, will make a sieve.

7. The verbs elele and angege, both meaning " to become," may be regarded as auxiliary verbs when they are used with adjectives, often taking the place of a substantive verb. In this use elele is never, and 
angege very rarely used in the past tense, the particle ga taking their place.

Both are regular except in the imperative, which has respectively ela and elau, ange and angau.

Ex. Ifan' eloma? will he become handsome? ifa mi elatsi? he will not be handsome? indi $g^{\prime}$ ifa, the knife is good; yuv' uan angatsi, the water will cease (become nothing); mel $g^{\prime}$ ' $u s^{\prime}$ anga, or me $g^{\prime}$ use, the child is dead.

\section{Verbal Suffixes.}

I. The suffix $-i$, added to a noun stem, forms generally a neuter verb.

Ex. $a b e$, work, $a b i$, to work; iso(ne), smoke, isoni, to give forth smoke; kese, a clean vegetable, kesi, to clean vegetables.

2. The suffix -tede, added to a noun stem, forms usually an active verb.

Ex. foye, ashes, foitede, to cook in ashes; gurube, neck, gurutede, to hang at the neck.

3. The suffix of manner defining the verb, is formed by adding the adjective with the final syllable changed to $-i$.

Note (I). The suffix of manner is always added to the infinitive form of the preceding verb.

(2). In the negative these compound verbs are considered a single word.

Ex. te, say, ifane, good, tam' ifani, to say well.

$i$, do, koye, bad, $i$ 'koi, to do badly.

ilele, cook, akane, small, ilam'akani, to half-cook.

4. The suffix -matede appears to have a causative signification.

Ex. ga koda (perhaps the past of kodeaie), pierced, komatede, to pierce (of a man); ga siuda, extinguished, siumatede, to extinguish.

Note. This suffix appears in some examples as a separate verb in the same sense.

Ex. $y u v^{\prime}$ olola mata, warm up the water; indi koi matatsi, the knife will become bad.

The negative is not known.

5. The suffixes -meme and -ngo are added to neuter 
verbs. The first has an active meaning, the second is passive.

Ex. $y u$, to be upright, yuma, to put upright, yungo, to be upright. yari (?), yarima, to hang, yaringo, to be hanging.

Note (I). Meme is regularly conjugated; -ngo is imperfectly known.

(2). Negative forms are me yumatsi, will not place upright, $m i$ yaringo, not hanging.

6. The auxiliary verbs, except $g a$, may perhaps be included among the suffixes (see p. 322, VIII.).

X. Verbal Prefixes.

The prefix $y a$-renders a neuter verb active or causative.

Ex. yaigege, to go down, yeyaigege, to carry down.

faikadede, to come back, yefaika(dede), to give back. $y u$, to stand up, yeyu, to set up.

XI. Irregular Verbs.

I. Many verbs are irregular in the imperative. Ex.

angege, imperat. ange, go. isie, imperat. isia, follow.

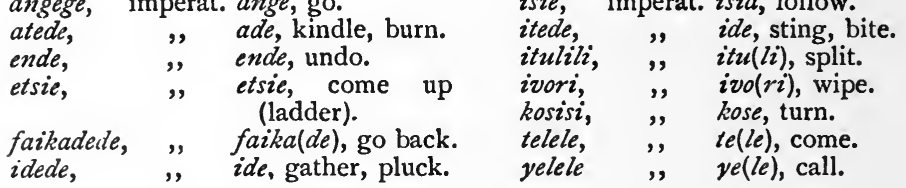

2. Other irregular verbs are the following. Only those forms known are entered.

Aitodede, to run: imperat. attode, infin. aitode(me).

ando and ande, to be there : fut. andetsi, imperat. ande, subj. ando, and ande.

bole, to leave : past, $b o(l e)$, imperat. $b o(l e)$.

ete, to tell : past, ete and elete, imperat. eta and ta.

faduatsiete, to ache (head) : fut. faduatatsi.

$i e i$, to throw: fut. iatsi, imperat. $i a$.

indi, to give: imperat. $i(n d e)$, subj. $i(n d i)$.

ingale, to carry (on shoulder): past, ingala and inge, imperat. inga, subj. ingo.

itede and ito, to lay down: past, ito and ita, near past, itova, imperat. ito. 
songe, to go: pres. and past, se, near past, sova, imperat. so(nge), subj. so, interrog. sona?

sue, to walk, go: pres. sue, fut. susuetsi.

utsisi, to draw : fut. utsisi, imperat. ude.

Note (I). The verbs ando and ito are not yet accurately understood.

(2). The verb ete has a double conjugation, the initial $e$ being retained or omitted at will. The past elete is used in reporting the words of another person.

(3). The verb faduatsiete is a type of several verbs which end in ete, preceded by the syllable $t s i$. All these appear to lose $t s i$ in the future, although some have both forms.

Ex. kiovatsiete, to cry (of black parrot) : fut. kiovatatsi and kiovatsitatsi.

puatsiete, to make a cracking noise: fut. puatatsi and puatsiatsi.

(4). The verb sue in the meaning "go away" always has $g a$.

Ex. nu ga sua? na ga sua, are you going away? I am going away.

The verb angege, to go, in the past tense has the particle $g a$ prefixed to the verb instead of suffixed to the pronoun.

Ex. na nul etsi ganga, I went to your village.

\section{Notes on Some Verbs.}

I. Tede and $i$.

'There is a difference in the meaning of the verbs tede, (ete) and $i$, both used for "do" or "make." The first is used when the object by which one obtains the action is indicated, the second is used when the action only is expressed, and might then be translated by the phrase " to go to work, to set about."

Ex. olon'ete, to snore, make a sound with the olo(ne), hole, i.e., the nostrils, ung'ul'olo. na (melauk') $i$ koitsi, I shall do the thing wrong.

2. Gege, angege, engege, songe.

All of these have the general meaning of "go." Their differences are not yet clearly understood. Engege appears to mean "go up." Songe is specially employed when the following phrase indicates a final 
proposition, or an answer to the questions "Where do you come from ?" or "Where are you going?"

Ex. nuni o' gega, thou hast passed down there; di engo, let us go up; na song' em' aritsi, I am going to see the village; $n u$ do sona? where have you been? (or, where do you come from?); na bulitsi sova, I have been in the garden (or, I have come from the garden).

\section{Idede.}

This verb has a general meaning besides the special one "to gather."

Ex. fang' idede, to set a trap; di yu molots' idoma? should we make a water-pipe?

4. Ameme.

This verb has the general meaning of passing, or making anything pass, through an opening. The object which has the opening dues not take suffixes.

Ex. kupa ulin' ama, put the potatoes in the pot; na ul' olol' amene, I passed it through the hole; iso nu emana? andavete, does the smoke irritate you? you are weeping.

\section{Adverbs.}

I. Adverbs generally precede the verb which they modify. The exceptions are the interrogative na? (is it not so?) which always comes at the end of the sentence, and -ta (at first), which follows the verb.

Ex. aiti balava natsi, to-morrow bread I shall eat; aiti nu inditsi $n a$ ? to-morrow I will give it you, shall I not? kuku neta, I eat the tobacco at first.

Note.-This $t a$ appears to be almost a conjunction, and the phrase might be translated "when I shall have smoked( eaten) the tobacco."

II. Adverbs of Place.

$d o(l e) ?$ where.

$a(l e)$, here.

valle), there.

ombatsi, underneath.

gisa(le), far.

ime(li)? far.

kugume, near. $t s i$, inside.

val enga. outside.

$t u$, on, over

ibe(le), down there.

$o(m e)$, up there.

yo(le), there above. 


\section{Adverbs of Time.}

The adverbs of time are not very definite. For example audati, " to-day, now," means also " in a few days" or "a few days ago." The latter meaning is also attributed to arima, and the former to aiti.

\section{aida? when?}

vomarima, day before yesterday.

arima, yesterday.

male(ke), formerly.

malieke, formerly.

audati, to-day, now.

aiti(me), to-morrow.

vomaiti, day after to-morrow.

talele, often, for ever. dedi, just now, later (near).

ido(ve), not yet (with fut.) immediately. utsienga, later on, in the future.

utsimata, ,, ,, , utsinenga, ,",", ," kelavalage, for a time.

$-t a$, at first.

$v o(y e)$, again.

\section{Adverbs of Quantity.}

dovavemunge? how much ? how many? domainai? how much? how many?

avevemunge, as much, so much.

tale(le), many. as many, so many.

$a p a(l e)$, enough.

kisiaka, few, little. oko, few, little.

$-t a$, very.

ande, very.

boboi, entirely, quite.

gegeto, few.

Note. When $a p a$ is used with a numeral it precedes it. Ex. apa gegeto, two are sufficient.

V. Adverbs of Affirmation, Negation and INTERROGATION.

$e$, yes.

akai(ge), truly.

g'akai, truly.

me! what! certainly!

ila! who knows? ua(ne), not, no.

$n d ?$ is it not (French, n'est ce pas?).

ous ! not at all, by no means.

andal'ai(me)? why?

Note. $M e$, óuo, and ila are almost interjections.

\section{Adverbs of Manner and Likeness.}

The adverbs of manner are often replaced by noun suffixes attached to the verb, with the final $i$. (See Verbal Suffixes, p. 323).

unoi, together.

akaumai(nge), further, beyond, besides.

uneke, only.

dedi, slowly.

ende, also.

elele, quickly.

fidefide, continually.

kela, without reason, gratis.

Note. When ende modifies a verb with subject in the third person, it is preceded by the pronoun ove. Ex. nau fud' ov' ende fufuli, my bones (they) also ache. 


\section{Prepositions and Postpositions.}

\section{Prepositions.}

Only two prepositions are found in Fuyuge. These are ise, near, and $g a$, by.

Ex. aked' is' okid' ando, the men are near the fire; ganda? ga ma I by what do you swear? by the thread.

Note. $G a$, in the sense of "by," is much used, and corresponds to a kind of oath.

\section{Postpositions.}

I. All the postpositions are used as suffixes to the words which they govern. When the noun to which they are suffixed has a double form, the postposition is added to the short form.

Ex. uli-tsi from uli(ne), pot: fatsi from $f a(l e)$, ground.

There are however some exceptions.

2. When the postposition begins with a consonant, the final $e$ of a noun changes to $i$.

Ex. kodigi-tsi from kodige, plate; bulitsi from bule, garden.

3. The postpositions are often used as nouns.

Ex. balava $u$ tsi ido asi, the inside of the loaf is still raw.

\section{List of Postpositions.}

-ai(me), because of, for : ovol' aim' andavete, I weep for the pig.

-a(le), with, by (instrumental): isong' al oki ya -andal' $a$ ? isong' ale, take the fire with the tongs-with what? with the tongs; amul' al' ul'ese, the woman with her child; uli sond' al' ale, a pot with a handle.

-ata, to, adherent to, along : yo' ata yarima, hang it on the rattan; enamb' ata malele yatsi, I will take it along the road.

-fendateme, near (within bounds): Sivu Alo fendatem' ando, Sivu is near Alo. 
-noi, with (?) : yini danoi gatsi, you will go with us two.

-ongo, before, at the side of (with an idea of inferiority): na nu ongo ando, I am before thee (at thy service); non' ongo, one beside the other.

-enga, from the side of, towards: nani Ambov'enga g'anga, I have been (gone) towards Ambove.

-kaine, towards: dedi yi kaine tsiati, later on I will come towards you.

teti, under: sosoeteti ando, he is under the bed.

$t s i$, to (movement, and time, rest), at, at the place of (Fr. chez): nani etsi andota, ubulitsi ganga, I am in the house, he has gone into the garden; naga Mambutsil a tela, I am come here from Mambo; kouatsi ma, put it in the box; tutsi etsiati, he will come in the night; $n u$ datsi sona? who has he been with?

-tu, upon (to or at places on mountains) : kulumitu $m a$, put it on the table; Falitu ganga, he is gone to Faliba.

Note. Ale in the sense of "with" is used when the second substantive is considered as an accessory to the first. Ex. an' al amu, a married man (man with a wife); uli sondal' ale, pot with a handle. There are not yet enough examples to distinguish the two forms.

IV. Prepositional Phrases.

u mome, above: kurum' $u$ mome yarime, hang it over the table; ubane, behind ; mel' an' u ban' ando, the child is behind the man; ul' umbo(le), in the middle of; Veke ul umbol ando, he is at Vee.

\section{Conjunctions.}

I. Copulative.

$-u(n e)$, and, with ; naga kitoval' u kene' ema, I killed a black and white parrot.

Une is generally only used to connect two nouns, and is placed between the two. But sometimes it comes after the second, especially when meaning "with," and the first noun is then followed by the 
personal pronoun. There are a few doubtful examples of une joining two phrases: ake tale mu, Augustin' un' ando, many men are with Augustin.

\section{Adversative.}

-ta, yet, but: nuni safa' ta nani kakava, you are weak but I am strong.

$T a$, meaning "but," precedes the phrase which it governs: nuni natsi, ta nani fema, you will eat, but I do not.

\section{Sequence.}

$-t a$, when (when a fact is accomplished, or will certainly happen), lest: aked' indiota, dinoi gatsi, when the men arrive, we will go together.

$T a$ in this sense follows the verb, which is in the past if the action depends on the person who speaks or is spoken to, in other cases in the subjunctive : kuku neta, etsi gatsi, when I (or you) have eaten, I will (or you will) go to the village; mulamula angetota, gadiu, lest the medicine fall, tie it up.

-tamai, when (uncertain event): oki finolitamai, na natatsi, when the fire blazes, warn me.

Tamai always requires the subjunctive.

-mai, if: Augusto bubulimai, dimuku e gaditsi, If Augusto delays, we ourselves will build the house.

-umba, so, like: an' umba ne $i$, give me (one) like that.

mamu(la)! admiration.

ile! sadness.

fanimo(le), commiseration.

fanikoe! commiseration.

$-e$ (suffix), commiseration.

\section{INTERJECTIONS.}

\section{segoa! joy at another's misfortune.}

biu! contempt.

alaila! a command for silence.

faiamela! expresses the recognition of an error.

\section{Notes on Dependent Clauses.}

I. A final proposition with the future is expressed in four ways.

$a$. By the infinitive preceding the verb which it governs: na mul' em' arim' an gatsi, I will go to see thy village, lit., I thy village to-see will-go. 
b. By the simple future preceded by the verb: na songe, Tsekan' aritsi, I go, I shall see Tseka.

c. By the future preceding the verb: ake Mambutsi itatsi ' $m$ ' ando, the men remain to sleep at Mambo.

a. By the suffix -du(le): Pe' Egidi yol' itadul andemai, puatsitatsi, If Père Egidi stays to sleep up there, he will fire a gun; ake Baidane (gatsi) ame boladu, the men will go to Baidane to leave the girl ; muto yetadu, Labao gatsi; I will go to Yule Is to take the sheep, (muto, Fr. mouton). The use of the verb "to go" is not certain.

2. A dependent sentence with the past is expressed in two ways.

$a$. By the simple past : na so, fang' arn, I went to see the trap.

$b$. By the suffix $-u a$, with the omission of the verb: Tsekan' alilua, I went to see Tseka, which might also be translated: na sova, Tsekan' ari.

3. Causative sentences appear to be governed by the same rules as the preceding.

Ex. ame nu arim' undede, the girl is afraid to see you; andal' $u n^{\prime}$ arim' ete, what has he seen to talk about.

4. Conditional sentences precede the principal and have their verb in the subjunctive with the conjunction -mai or -tamai. (See p. 330, III.).

5. A dependent sentence expressing time also precedes the principal sentence. It has its verb in the subjunctive or indicative, followed by the conjunction -ta or sometimes -tamai. (See p. 33O, III.). 


\section{APPENDIX II}

\section{Note on the Afoa Language}

By Dr. W. M. Strong

THE vocabulary recorded below was obtained from a Fuyuge native who spoke the Afoa language. $\mathrm{He}$ had travelled with me to the Afoa-speaking villages on Mount Pitsoko and I could assure myself that he spoke the language fluently. In spite of the vocabulary having been obtained through a Fuyuge native there is very little similarity between this and the Fuyuge vocabulary. It should be noted that the words for "I" and for "thou" are substantially the same in the two languages.

I also obtained a short vocabulary from a native who came down the coast to me, and found that this was substantially the same as the Pitsoko vocabulary. The native had come from a village which appeared to be situated on the slopes of Mount Davidson and on the inland side of it. According to native accounts the Afoa language is spoken in numerous villages which stretch from Mount Davidson to the head of the St. Joseph River in the Mafulu district. All the Afoa villages are situated north of the St. Joseph and its main branches.

[Dr. Strong gives only the pronoun: mui, thou; and the numerals : koane, one; atolowai, two; atolowai-itima, three; atolowai-atolowai, four; atolowaiatolowai-itima, five. 
The Pronouns given by Father Egidi for Tauata ("Anthropos," II. I907, pp. IOO9-IOI 5) are :-

Singular.

Ist Person, nai, na. and Person, nui, nu. 3rd Person, omei, ome.
Plural.

Ist Person, nanei, nane. 2nd Person, nunei, nune 3rd Person, otei, ote.
Dual.

Ist Person, nonei, none. 2nd Person, nuvei, nuve. 3rd Person, olei(?).

\section{The Possessives are :-}

Singular.

Ist Person, ne, neve. and Person, ni, nie. 3rd Person, ote, otene.
Plural.

Ist Person, nane,nanene. and Person, nune. 3rd Person, otene.
Dual.

Ist Person, none. 2nd Person, nuvene. 3rd Person, olene.

The Interrogatives are: te? who? te? teile? what thing ? te? tue? which?

The Numerals, according to Father Egidi, are, kone, one; atolo(ai), two; atoloai-laina, three; talele, memene, many ; konekone. few.

S. H. R.] 


\section{APPENDIX III}

Note on the Kovio Language.

By Dr. W. M. Strong.

Substantially the same language is spoken in the whole of the neighbourhood of Mount Yule. I have travelled all around this mountain and the same interpreter was able to make himself understood everywhere. The vocabulary recorded below was collected by means of the Motuan from a native of Lopiko in the Inava valley. I have also collected short vocabularies from the village of Inavarene in the same valley, and from the Kwoifa district of the upper part of the Lakekamu river. These vocabularies show close similarities with that of Lopiko. The natives around the Pic Eleia also speak much the same language.

The vocabulary of the language bears no resemblance to any other language I am acquainted with. It is peculiar in that a word often ends in a consonant preceded by a short vowel. There is also an unusual consonant sound in the language. This sound seems to vary between a " $c h$ " and a " $t$ ch" sound.

The pronouns are as follows ;-

$$
\begin{aligned}
\text { First person : } n a . \\
\text { Second person : } n i . \\
\text { Third person : } p i \text {. }
\end{aligned}
$$

These were obtained without much difficulty as well as the corresponding possessives nemai, nimai, and 
pimai ; but plurals could not be obtained. Possibly the above are both singular and plural. The possessive precedes the noun, e.g., nemai tupumagi, my house. ${ }^{1}$ A binary system of counting is shown in the following numerals :-

One: uniuni.

Two : karaala.

Three: naralavievi napuevi.

Four: naralavievi naralavievi.

Five: naralavievi naralavievi napuevi.

Ten : kowa.

Eleven: kowa uniuni.

Twelve : kowa karaala.

Twenty : kowakowa.

Seven, eight, and nine were also translated by saying naralavievi for each two, and napueve for one over. The numeral follows the noun, e.g., inai karaala, two spears. ${ }^{2}$

${ }^{1}$ The Rev. Father Egedi's Vocabulary of Oru Lopiko gives the pronouns thus :

\section{Singular.}

Ist Person, na, naro. and Person, ni, niro. 3rd Person, pi, piro.

\section{Plural.}

Ist Person, dae, daro. 2nd Person, ali, alero. 3rd Person, valo, valoro.

The Possessives are formed with ma: nema, nima, pima, daema, lima, valoma.

The Interrogatives are : tsia? who? itara? vaina? what thing?

2 These numerals differ from the Oru Lopiko of Father Egidi. (S.H.R.) konepu, one ; kalotolo, two; konekhalavi, three; maimitara, many ; onionipu, few. 


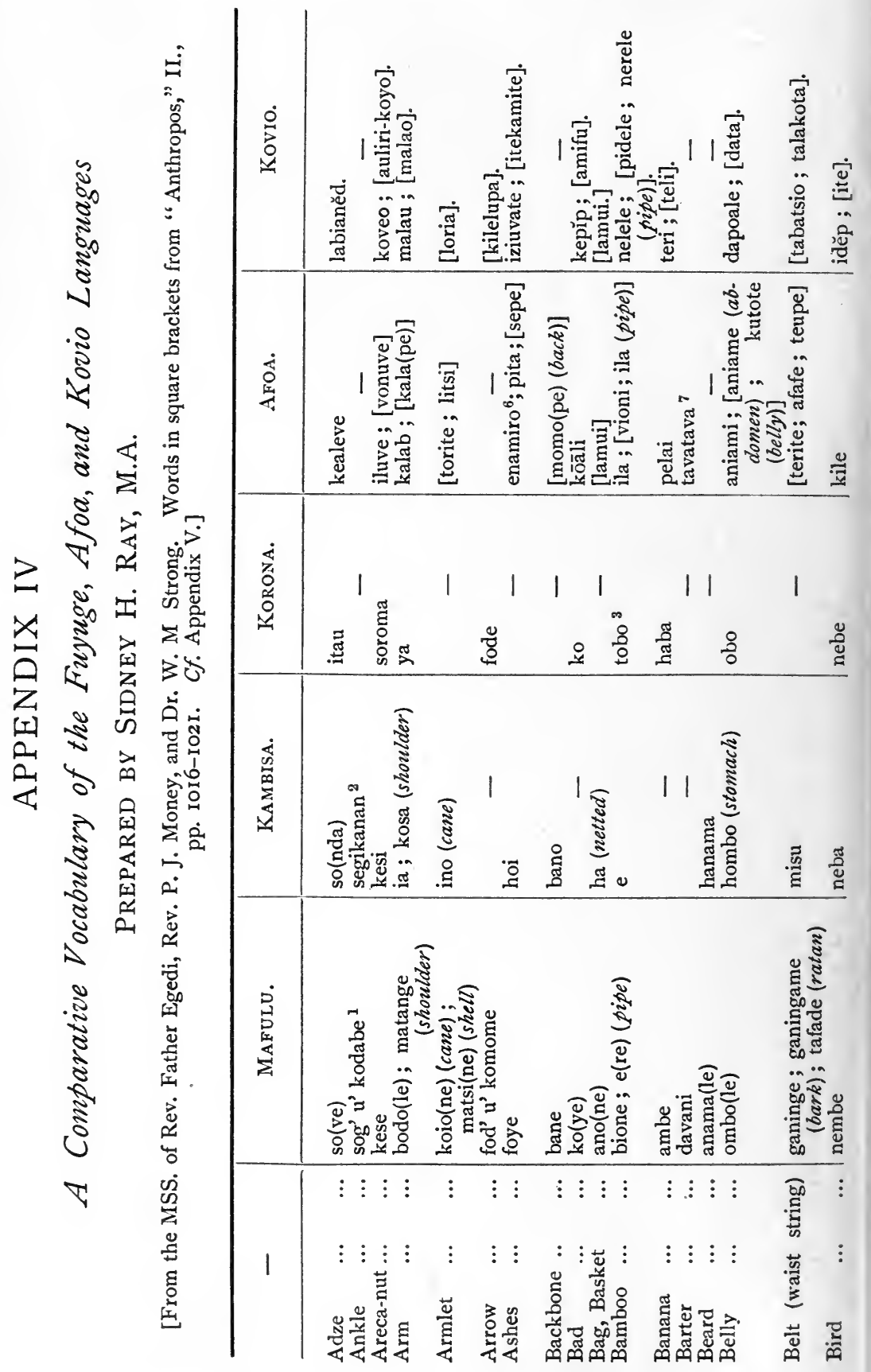




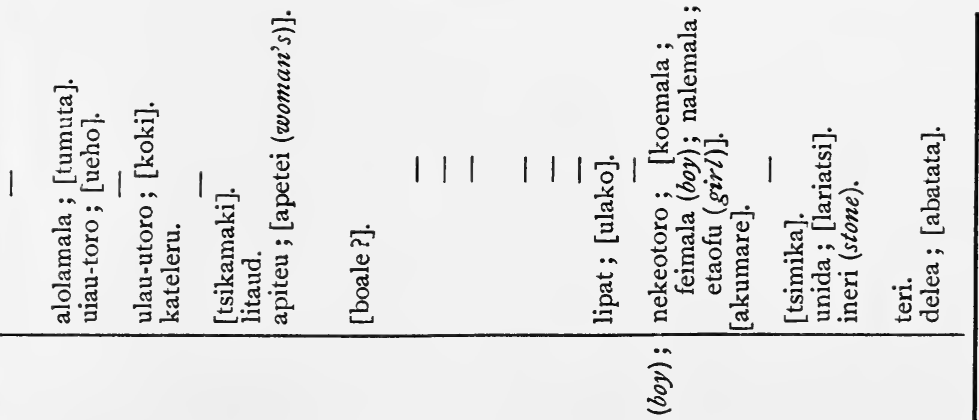

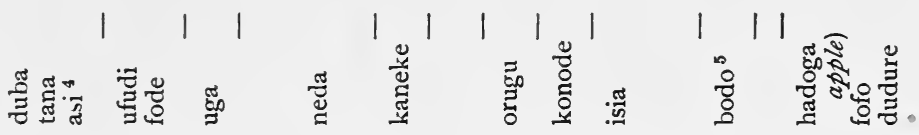

일

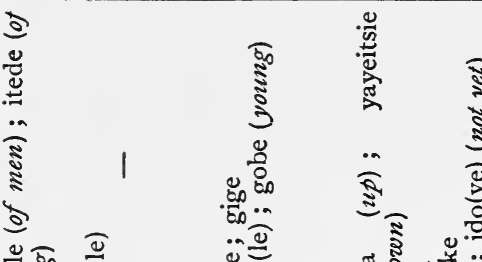

(1)

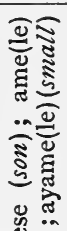

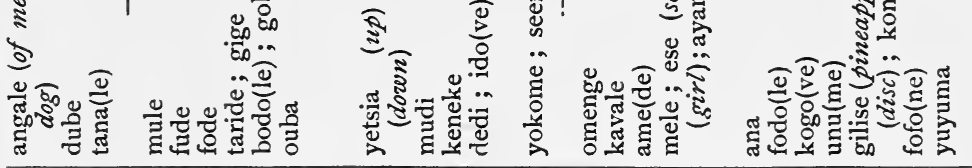

$\vdots \quad \vdots \vdots: \vdots: \vdots \vdots: \vdots \vdots$ 


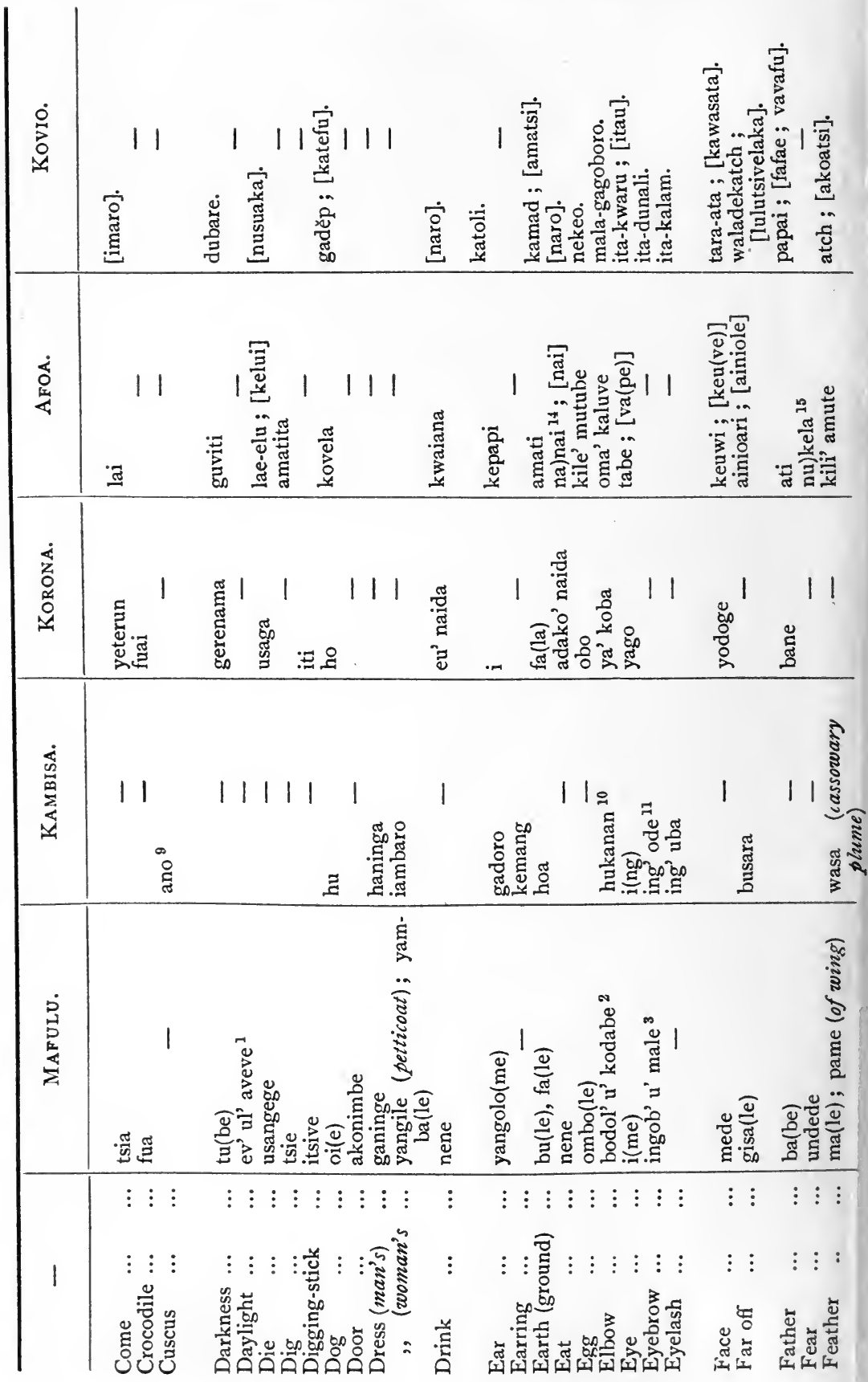




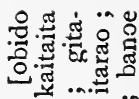

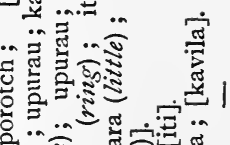

을

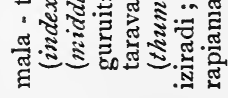

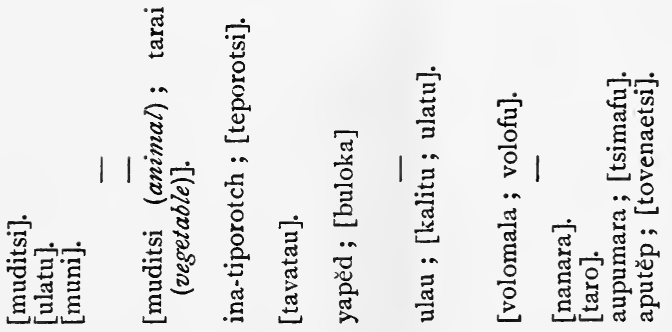

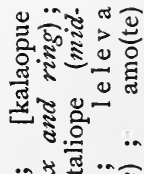

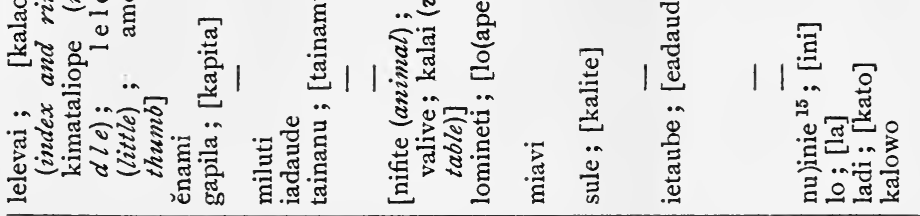

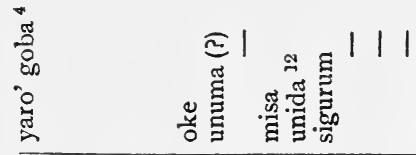

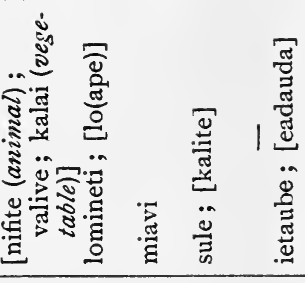

章章

पु

象

音

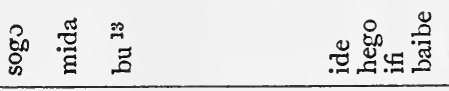

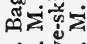

论敨论

윽 표 익

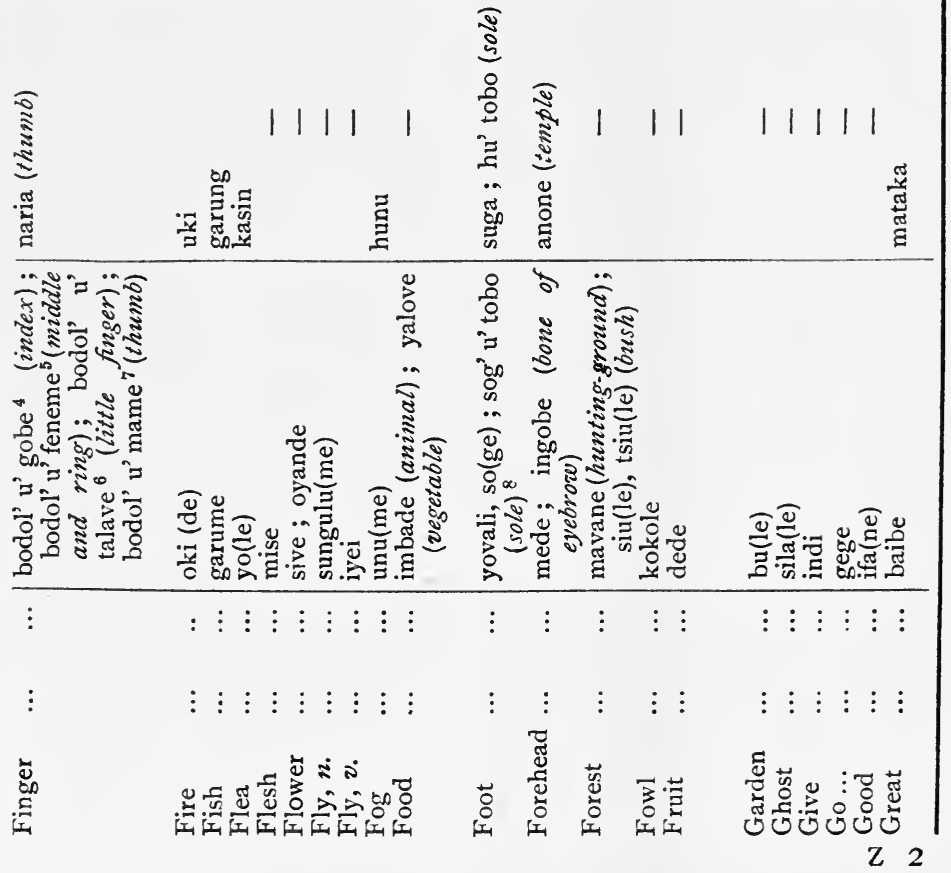

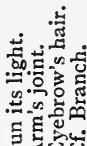


THE MAFULU MOUNTAIN PEOPLE

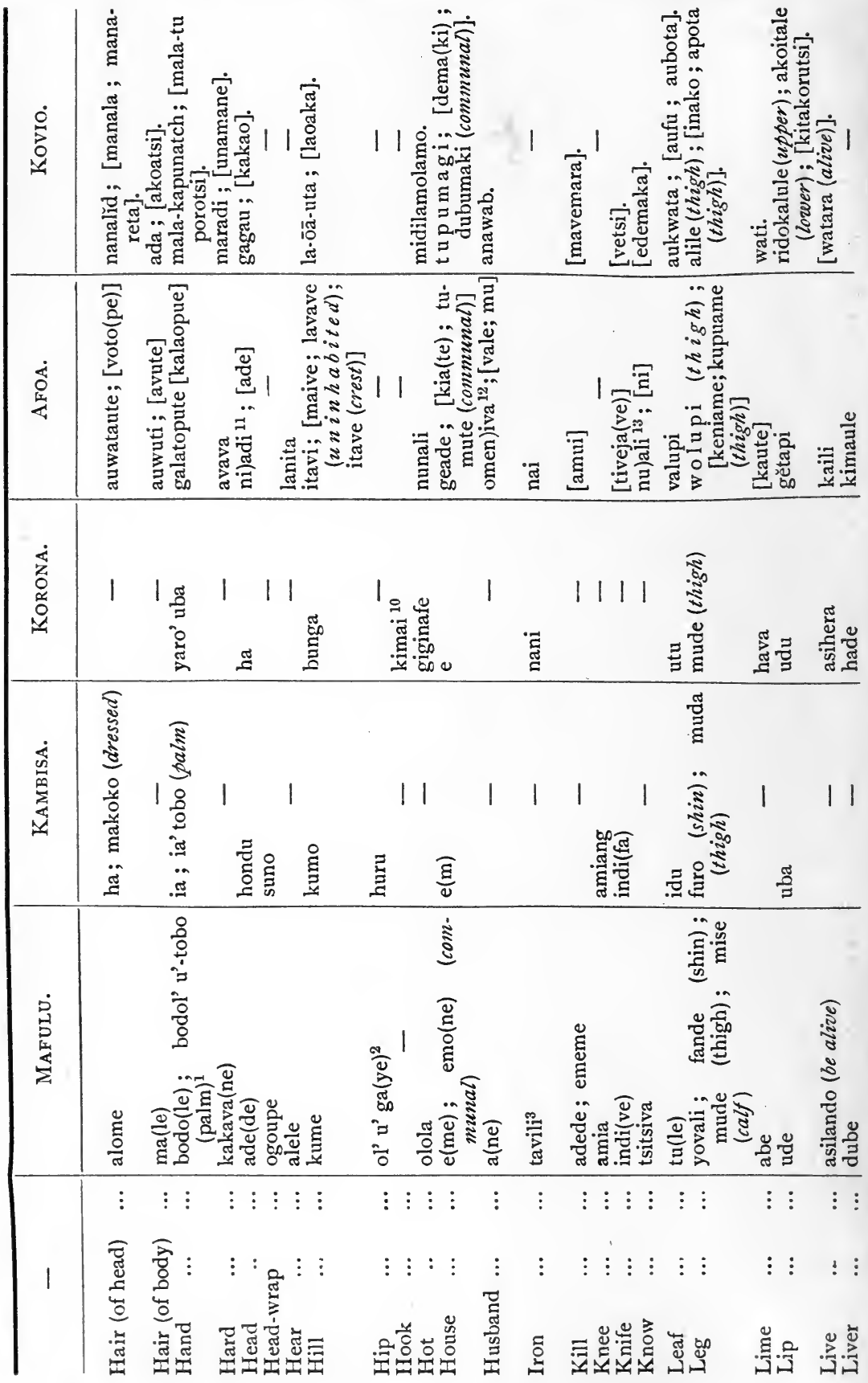


$\rightarrow \quad 1$

离

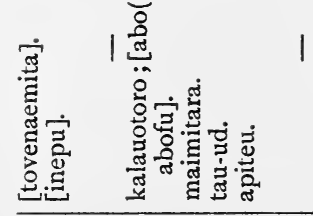

氖

寈: 荡

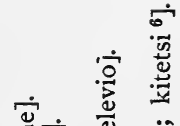

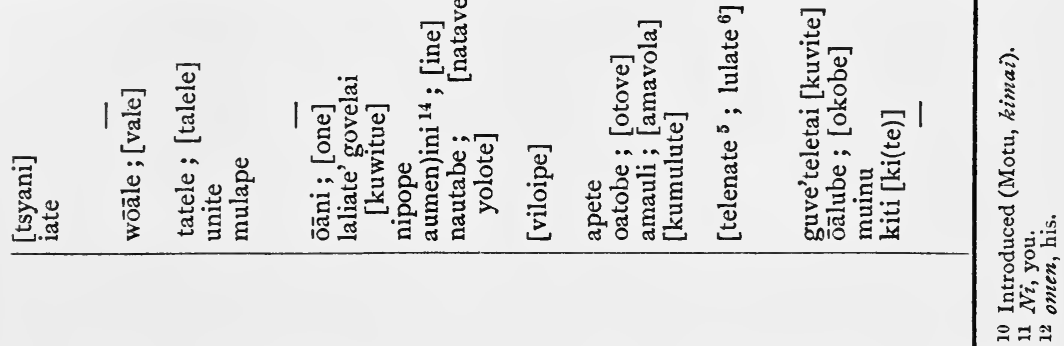

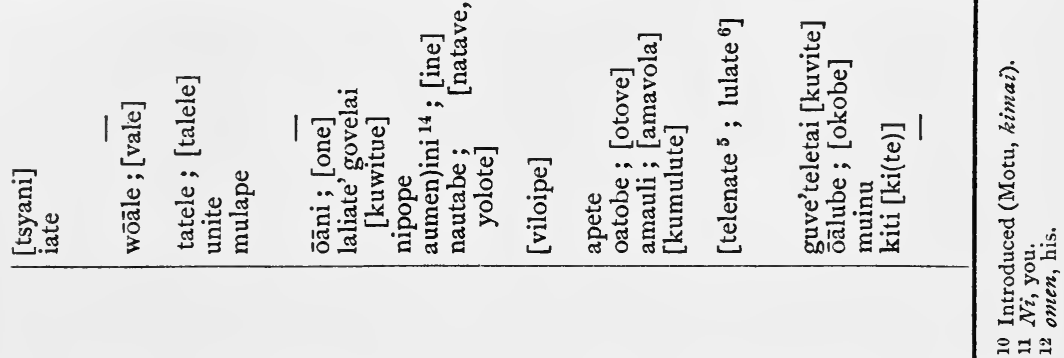

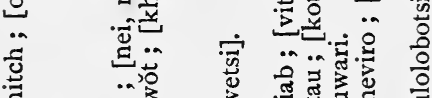

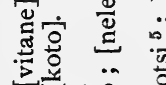

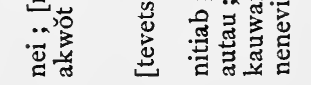

s.

$\stackrel{2}{*}$

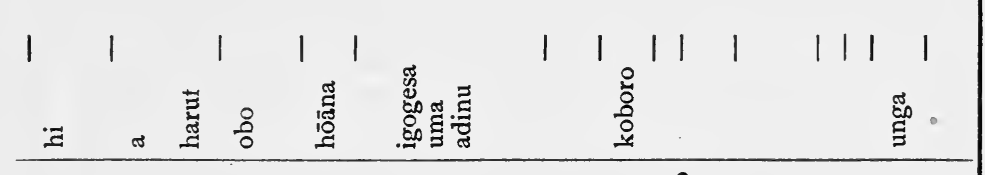

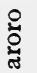

尺コテ

111111111

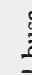

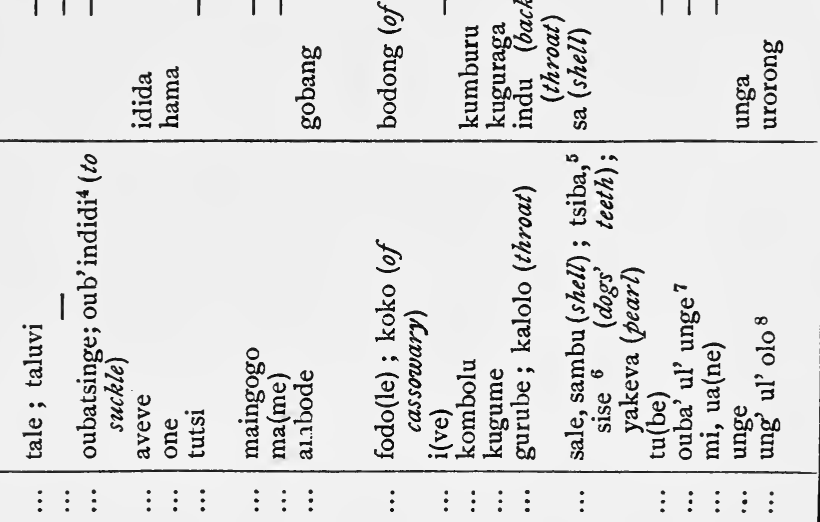

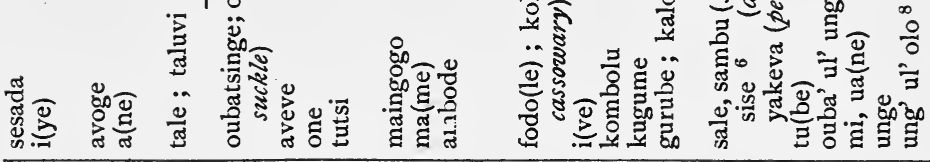

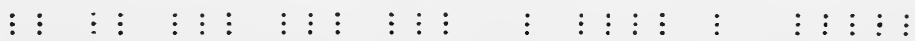

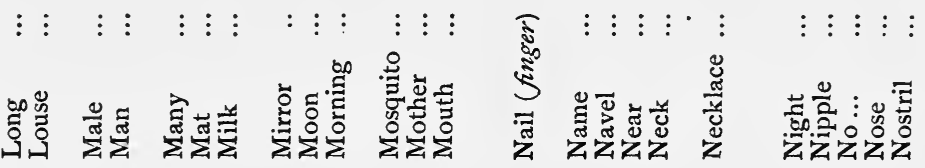




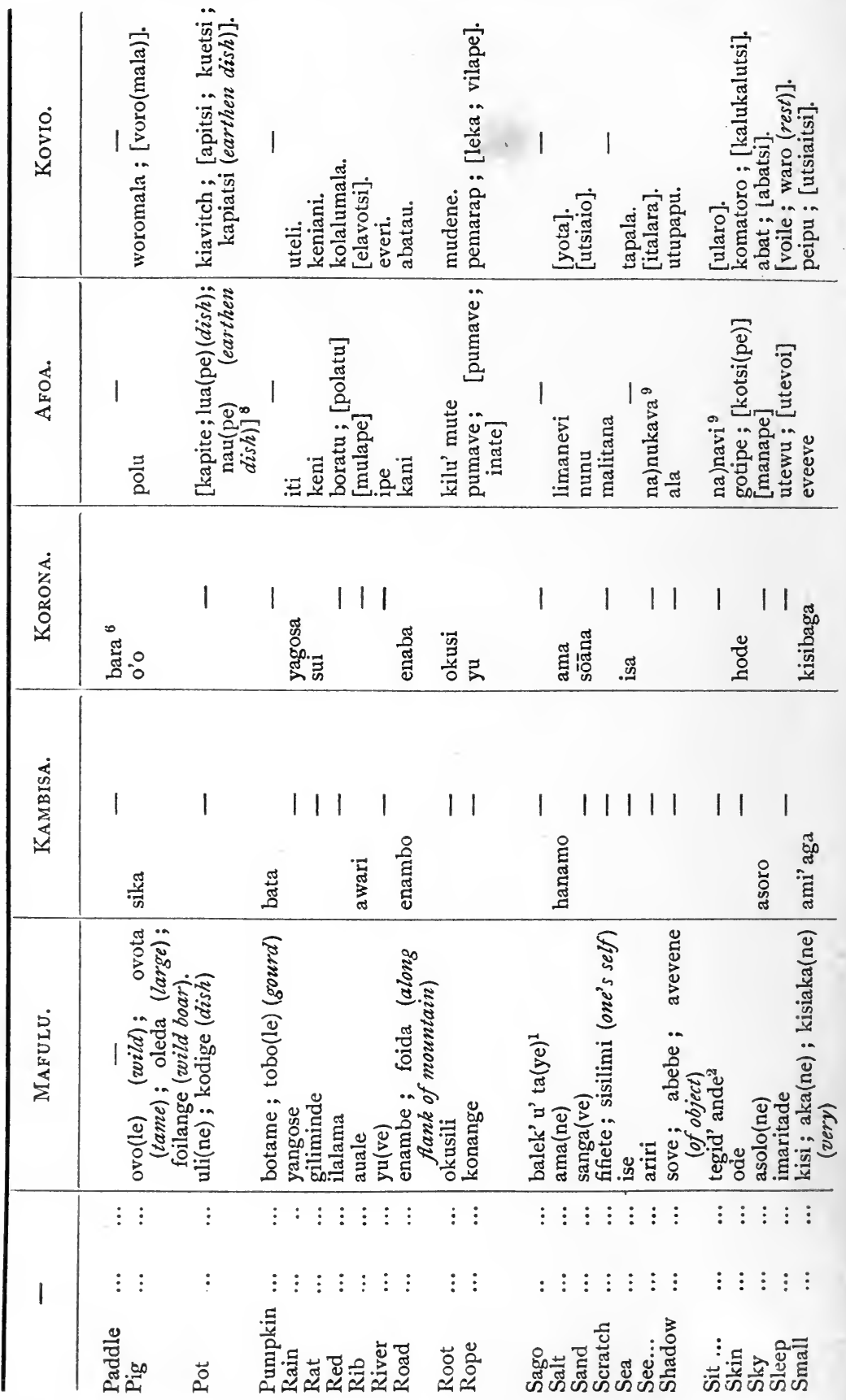




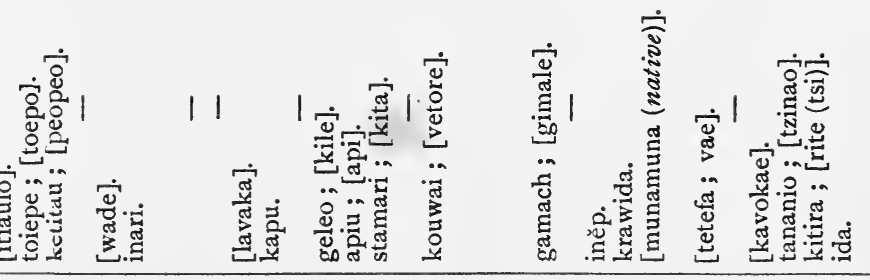

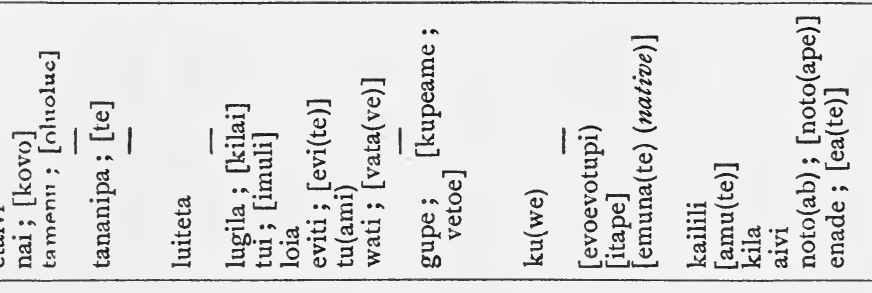

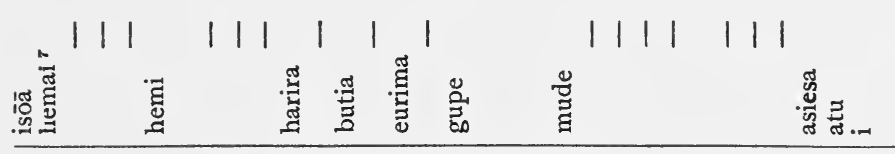

$1111 \ldots 11111$

11111

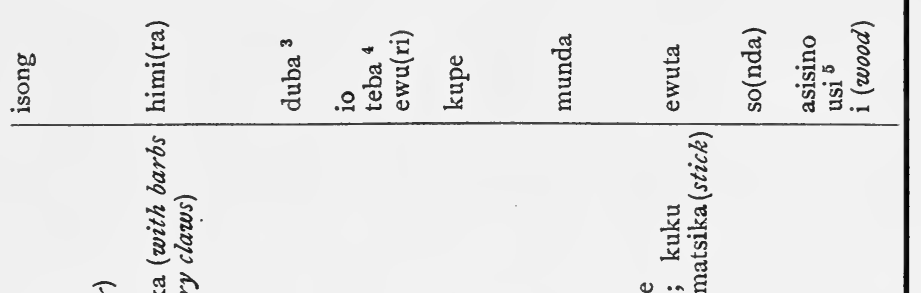

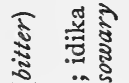

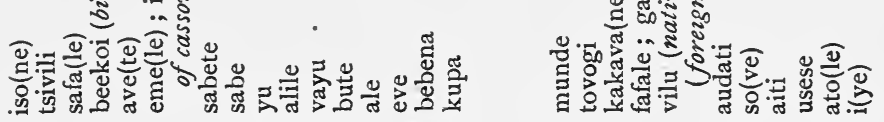

范莒

岸

兽

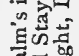

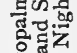

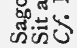

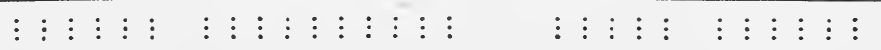

$\rightarrow \infty$

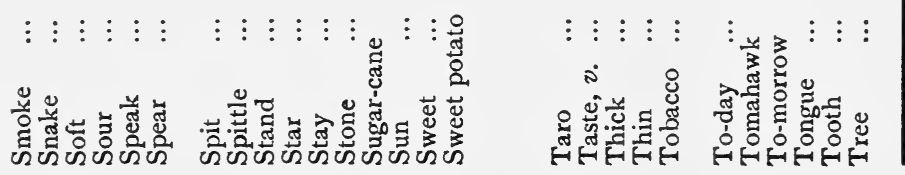


344 THE MAFULU MOUNTAIN PEOPLE

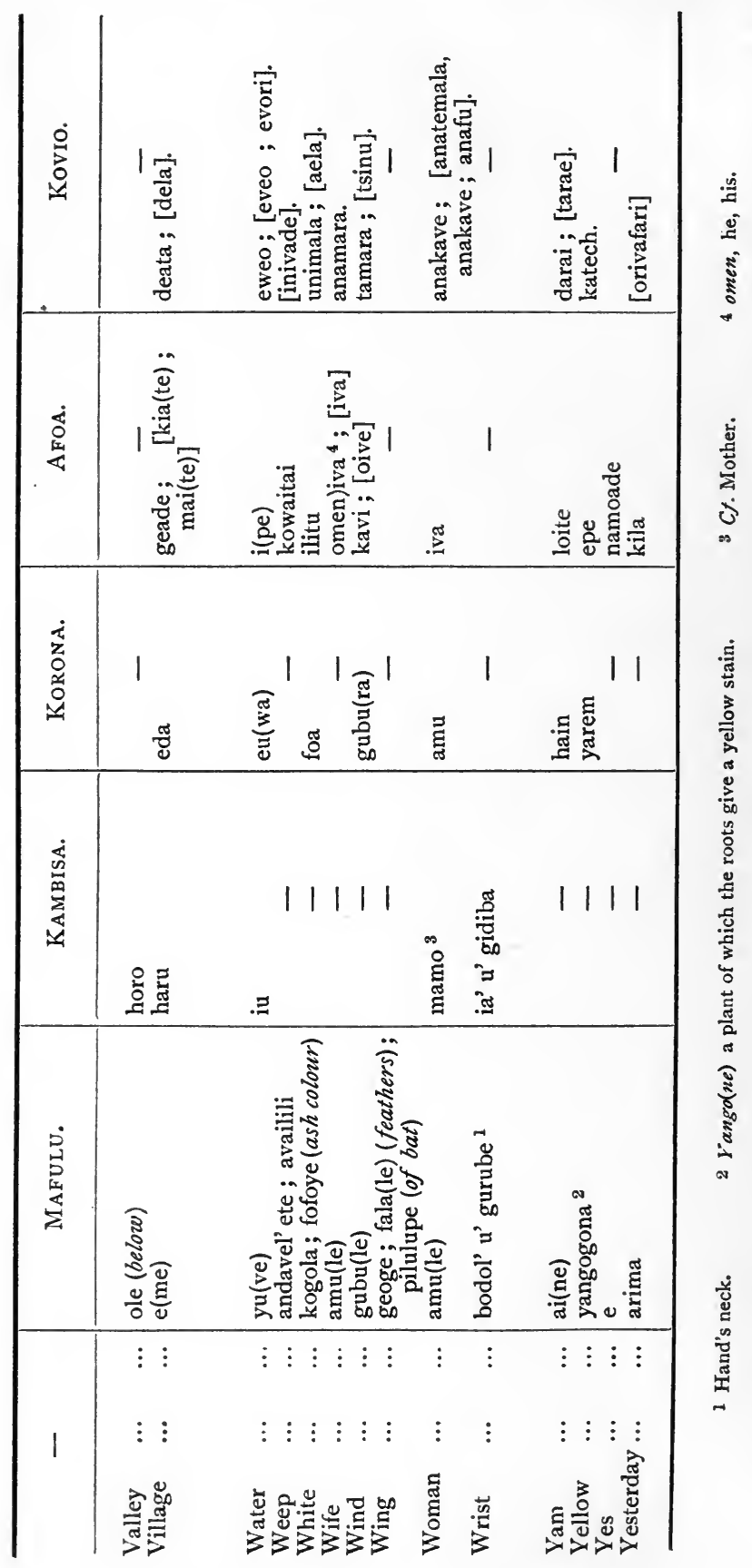




\section{APPENDIX V}

Notes on the Papuan Languages spoken about the Head Waters of the St. Joseph River, Central Papua

By Sidney H. Ray, M.A.

The grammars and vocabularies collected by the Rev. Father Egedi, the Rev. E. P. Money and Dr. W. M. Strong illustrate the languages spoken in the higher hill country extending from the district about Mount Yule to Mount Albert Edward and the Upper Vanapa River. They form three distinct groups. I. Fuyuge, comprising the dialects of Mafulu, Kambisa, Korona and Sikube.

2. AfoA or Ambo, including Tauata.

3. Kovio, including Oru Lopiko.

\section{Classification.}

I. Fuyuge:-The first specimen of any lanugage of the Fuyuge group was collected by the Rev. James Chalmers in 1879 . This was called by him Kabana, and was printed in a collection of vocabularies in I 888. ${ }^{1}$ From a note on the original MS., the vocabulary was assumed to be the dialect of a village on Mount Victoria (cailed by Chalmers Mount Owen Stanley). ${ }^{2}$ But as Sir William MacGregor pointed

${ }^{1}$ British New Guinea Vocabularies. London: The Society for Promoting Christian Knowledge.

${ }_{2}$ A Comparative Vocabulary of the Dialects of British New Guinea. Compilęd by Sidney H. Ray. London, I895. 
out, ${ }^{1}$ there are no villages on that mountain, hence Chalmers, in assigning a locality to the vocabulary some time after its collection, must have been mistaken. The language of Chalmers' Kabana is nearly the same as that of a vocabulary collected by Mr. A. Giulianetti at the village of Sikube in the Upper Vetapa or Vanapa valley, north of Mount Lilley. This was published in $\mathrm{I} 898 .^{2}$

A few words from the village of Kambisa, in Sirima (Chirima) valley were published in the Annual Report on British New Guinea for $1905-6,{ }^{3}$ and I have since been favoured by the compiler, the Rev. P. J. Money, with a fuller list. The Rev. Father Egedi published in 1907 a vocabulary of Fuyuge along with his account of the Tauata or Afoa tribe. ${ }^{4}$ Dr. Strong collected a vocabulary from the natives of Korona, a village situated close to the head of Galley Reach. This was collected with the help of a Motu-speaking native, and contains a few apparently Melanesian words. Dr. Strong was spontaneously told that these had been introduced from the coast in quite recent times. (Cf. \& III.)

The words in the comparative vocabulary are taken from an extensive collection in Mafulu by the Rev. Father Egedi. They represent the same dialect as the Grammar in Appendix I.

That Mafulu, Kambisa, and Korona, with Sikube and Kabana, represent the same language is plain.

The Kabana pronoun nahu, I, the Sikube na(nio) I, $n u(n i)$ thou, and the Kambisa $n a, I$, $n u$, thou, $h u$, he, agree with the Fuyuge na, na(ni), I, nu, $n u(n i)$ thou, $u$, he. The Kabana nauera, mine, is the Fuyuge naula. The Kambisa nara-ndo, mine, nura-ndo, thine, hura-ndo his, also show a suffix ndo corresponding to Mafulu ne in naula(ne), mine, nula(ne) thine,

1 Annual Report on British New Guinea. 1896-7, p. 13.

2 Annual Report on British New Guinea. 1897-8, p. 35.

3 British New Guinea. Annual Report for the Year ending 30 th June, 1906. p. 93 .

4 Anthropos II, Heft 6. pp. 1016-1021. 
$u l a(n e)$ his, and in the vocabulary the Kambisa suffix $n d a$ corresponds to the Korona de in the word for "chest." There is, however, no evidence that the Korona de is equivalent to the Mafulu ne. The word given in Sikube for "woman," amuri, is the Fuyuge plural amuli, "women."

A few other likenesses appear, as e.g., Kambisa suffix $n g$ represents Mafulu me, ne; Kambisa $f a$, the Fuyuge ve; Kambisa $a$, Korona la, Mafulu le.

The following extract shows the likeness of the vocabulary. ${ }^{1}$

\begin{tabular}{|c|c|c|c|c|c|}
\hline Adze & $\begin{array}{c}\text { Mafulu. } \\
\text { so }\end{array}$ & $\begin{array}{c}\text { Kambisa. } \\
\text { so }\end{array}$ & $\begin{array}{c}\text { Sikube. } \\
\text { cho }\end{array}$ & $\begin{array}{c}\text { Kabana. } \\
-\end{array}$ & $\begin{array}{c}\text { Korona. } \\
\text { itaut }\end{array}$ \\
\hline Arm, hand & - & ia & $i a$ & ia & $y a$ \\
\hline Belly $\quad \ldots$ & ombo & hombo & - & habe & obo \\
\hline Bird ... ... & nembe & $n e b a$ & membe & - & nebe \\
\hline Cassowa ry & & & & & \\
\hline plume ... & - & wasa & vasa & 一 & $二$ \\
\hline Child, son & me, ese & isa & me & ese & isia \\
\hline Club $\quad \ldots$ & gilise & hadufa & actufa, girishia & - & hadoga \\
\hline $\operatorname{Dog} \ldots \quad \ldots$ & $o i$ & $h u$ & $h u, f u$ & hoa & ho \\
\hline Ear ... ... & yangolo & gadoro & gaderu & gadero & $i$ \\
\hline Eye ... ... & $i$ & $i$ & $i$ & $e$ & yago \\
\hline Forest $\ldots$ & - & - & $b u=g a r d e n$ & - & $b u$ \\
\hline Father $\quad . .$. & $b a$. & - & - & $b a$ & $b a$ \\
\hline Fire ... ... & $o k i$ & $u k i$ & okia & okia & oke \\
\hline Foot $\quad \ldots$ & soge & suga & suku & suge & sogo \\
\hline Go $\ldots, \ldots$ & gege & - & henga & inga & hego \\
\hline Ground ... & $b u, f a$ & hoa & $b u=$ garden & $\frac{-}{x}$ & $f a$ \\
\hline IIair, head & ade & $h a$ & ha & $h a$ & ha \\
\hline House $\quad \ldots$ & $e$ & $e^{e}$ & - & $e$ & $e$ \\
\hline Knife & indi & indi & indi & - & - \\
\hline Leaf... . ... & $t u$ & $i d u$ & $i t u$ & $i d u$ & utu \\
\hline Lip, mouth & ude & $u b a$ & ude & ude & uau \\
\hline Moon $\quad .$. & one & hama & - & hama & hoana \\
\hline Navel & kombolu & kumburu & - & haber $a=$ belly & koboro \\
\hline Nose & unge & unga & hunge & unųa & unga \\
\hline Pig ... & ovo & - & $o b u$ & - & o'o \\
\hline Rain & vangose & - & iangushe & iangose & vagosa \\
\hline Smoke & iso & iso & ishio & - & isoa \\
\hline Stone $\quad \ldots$ & bute & io & - & io & butia \\
\hline Sun, day... & eve & ezwuri & - & evurima & eucrima \\
\hline Sugar-cane & - & $t e b a$ & tebe & - & - \\
\hline Taro $\quad .$. & munde & munda & mude & - & muae \\
\hline Thigh ... & mude & muda & mude & - & mude \\
\hline Tongue ... & usese & asisino & asese & asese & asiesa \\
\hline Tooth ... & ato & $u s i$ & $a d o$ & ado & $a t u$ \\
\hline Village $\ldots$ & $e$ & haru & $e$ & - & $e d a$ \\
\hline Water ... & $y u$ & $i u$ & $i u$ & $i u$ & $e u$ \\
\hline Woman ... & amu & $?$ mamo $=$ mother & amu & $a m u$ & amu \\
\hline
\end{tabular}

1 In comparing I have omitted the non-essential syllable. 
The numerals show similar agreements. These will be illustrated in the next section.

2. Afon.-The Afoa vocabulary was collected by Dr. Strong in the villages on Mount Pitsoko from a Fuyuge native who spoke Afoa fluently. Dr. Strong also obtained a short vocabulary from a native who came from a village apparently on the slopes of Mount Davidson. The language is substantially the same as the Tauata or Tauatape of which Rev. Father Egedi has published a Vocabulary and Grammar. ${ }^{1}$ There are, however, a few slight differences which seem to confirm Father Egedi's statement that there is probably a difference of pronunciation in the various Afoa villages. ${ }^{2}$ Father Egedi writes: $p, v, k, t, l, t s$ where Dr. Strong has: $b, w, g, d, r, t$. The latter also has final $i$ for $e, \bar{o} \bar{a}$ for $a$ or $o$, $i a$ for $e a, u$ for $o i$, $a i$ for $e i$. Sometimes $b$ represents $m$ or $v$. Some of Dr. Strong's words show marks of Afoa grammar, as, e.g., the words for eat, see, sit, give, head, husband or wife, mother, are: na nai, I eat; na nu kava, I thee see; na navi, I sit; nu inie, thou givest; ni adi, your head; omen iva, his wife or her husband; aumen ini, his mother. The Tauata words are added to the Afoa Vocabulary in square brackets.

3. Kovio.- - The language called Kovio by Dr. Strong is substantially the same as the Oru Lopiko of Rev. Father Egedi. ${ }^{3}$ The same or a similar language is said to be found in four places, viz.-

I. Lopiko in the Inava valley.

2. Inavarene in the Inava valley.

3. Kwoifa district on upper Lakekamu River.

4. Villages round Pic Eleiá.

Details of these dialects are not given.

1. Anthropos, II. Heft 6, pp. 1009-1021.

2 Op. cit., p. 1009. ${ }^{3}$ Op. cit., pp. I016-IO2I. 


\section{Comparison.}

The three groups of languages illustrated in these vocabularies present the usual Papuan characteristics of great differences. A certain amount of resemblance may be found in some of the pronouns, and possibly in a few other words, but generally speaking the languages are not only quite unconnected with each other, but are also distinct from the known Papuan languages surrounding them.

$$
\text { I. Thou. He. We. You. They'. }
$$

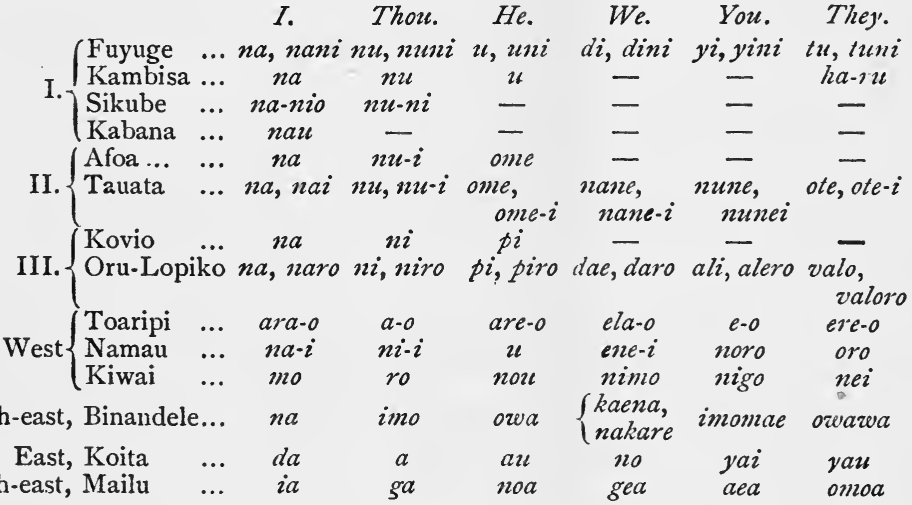

It is interesting here to note the agreement in the forms of the first and second persons singular, with a wide difference in the other pronouns. Similar words for these two pronouns occur in other Papuan languages as e.g., Kai (Finschhafen) no, Kelana Kai $n a i$, "I," and Bongu and Bogadjim (Astrolabe Bay), $n i$, Kelana Kai ne, " thou."

The widespread use of a suffix, used when the pronoun is emphatic, is noteworthy. The possessive case also is formed as in some other Papuan languages by a suffix added to the root of the pronoun. $C f$.-

\begin{tabular}{|c|c|c|c|c|c|c|c|}
\hline Fuyuge & $\cdots$ & $\begin{array}{c}M y . \\
\left\{\begin{array}{l}\text { nau }(l e) \\
\text { naula }(\text { ne })\end{array}\right.\end{array}$ & $\begin{array}{c}\text { Thy. } \\
\text { nu(le) } \\
\text { nula }(n e)\end{array}$ & $\begin{array}{c}\text { His. } \\
u(l e) \\
u l a(n e)\end{array}$ & $\begin{array}{c}\text { Our. } \\
\operatorname{diu}(l e) \\
\operatorname{diula}(n e)\end{array}$ & $\begin{array}{c}\text { Your. } \\
y u(l e) \\
\text { yula(ne) }\end{array}$ & $\begin{array}{c}\text { Their. } \\
\text { ta(le) } \\
\text { tala(ne) }\end{array}$ \\
\hline Kambisa & & narando & nurando & hurando & - & - & haruando \\
\hline $\begin{array}{l}\text { Tauata .. . } \\
\text { Kovio }\end{array}$ & ... & neve & nie & omene & nanene & nuvene & otene \\
\hline $\begin{array}{l}\text { Kovio ... } \\
\text { Oru-Lopiko }\end{array}$ & & $\begin{array}{l}\text { nemai } \\
\text { nema }\end{array}$ & $\begin{array}{l}\text { nimai } \\
\text { nima }\end{array}$ & $\underset{\text { pimaimai }}{\text { pima }}$ & daema & $\overline{\text { alimg }}$ & $\overline{-}$ \\
\hline Toaripi & $\ldots$ & arave & ave & areve & elave & eve & $\begin{array}{c}\text { valoma } \\
\text { ereve }\end{array}$ \\
\hline Binandele & $\ldots$ & nato & ito & $\begin{array}{l}\text { ounda, } \\
\text { ozwanda }\end{array}$ & kaenato & itomane & omida \\
\hline
\end{tabular}


Sometimes the simple form of the pronoun is prefixed to the noun in Tauata to indicate the possessive, as in Namau and Koita. Tauata na ate, Koita di omote, Namau, na uku, "my head."

The numerals also show great differences. As far as "three" they appear as follows :

Fuynge. Korona. Sikube. Afoa. Tauata. Kovio. Oru Lopiko.

I. fida(ne) fida(ne) fidana koane kone uniuni konepu

2. gegeto gegeda iuara atolowai atoloai karaala kalotolo

3. gegeto gegeda- iuara- atolowai- atoloai- naralavievi- konekhalavi

m'inaa fidane minda itime laina napuevi

Some of these words have other meanings. Thus Fuyuge 2, gegeto is given also as "few." In Tauata I, kone duplicated as konekone, is "few," whilst onioni, means "alone." In Oru Lopiko I, konepu compares with onionipu, "few."

These numerals are all different from Mailu, Koita, Binandele, Toaripi and Namau.

Mailu. Koita. Binandele. Toaripi.

I. omu ... kobua, igagu da farakeka

2. ava ... abu tote orakoria

3. aiseri... abi-gaga tamonde oroisoria morere-monou netowa-naobi

The vocabulary shows very few agreements, and there is very little evidence in support of a connection of any one of these dialects with its neighbours. The following correspondences may be purely accidental.

Bamboo. Afoa, ila; Namau, ina.

Banana. Korona, haba; Iworo, sabari.

Barter. Afoa, tavatava; Toaripi, tavatava.

Belly. Oru Lop., data ; Sogeri, Koiari, detu.

Black. Fuyuge, dube, duba ; Neneba, aduve ; Koiari, Koita, dubu.

Blood. Fuyuge, tana; Koiari, Koita, tago.

Bone. Fuyuge, fude, \&c.; Tharipi, uti.

Child. Fuyuge, me(le); Binandele, mai; Berepo, me.

Fuyuge, isia; Kambisa, isa ; Ubere, esi ; Neneba, eche.

Coconut. Kambisa, bao ; Koiari, bagha.
Crocodile. Fuyuge, fua, fuai; Koiari, fuie.

Dig. Fuyuge, etsia; Toaripi, isei.

Dog. Fuyuge, oi, ho ; Agi, Ubere, o ; Koiari, \&c., to.

Eat, Drink. Fuyuge, na, nene; Nàmau, na.

Fire. Tauata, ena; Koiari, vene; Koita, veni.

Foot. Fuyuge, \&c., soge, suga; Amara, joka.

Male. Tauata, mu; Toaripi, mo. Oru Lopiko, vitapu; Toaripi, vita.

Man. Fuyuge $a(n e)$; Neneba, ana; Koiari, Koita, ata.

Mother. Oru Lopiko, Kovio, nei, Uberi, neia ; Koita, neina; Tauata; ine; Koiari, ine.

Pig. Kambisa, sika; Musa River, siko. 
Fuyuge, avo; Koiari, ofo; Koita, oho. Rope. Fuyuge, konange; Gosisi, goda ; Koiari, Koita, gote.

Salt. Fuyuge, ama(ne); Neneba, Iworo, amani.

Taro. Fuyuge, \&c., munde, muda; Neneba, muda.
Tree. Fuyuge, i, iye ; Kovio, ida ; Koiari, Koita, idi.

Water. Fuyuge, \&c., $y u$; Afoa, $i(p e)$; Neneba, ei ; Ubere, e.

Woman. Fuyuge, amu; Iworo, Neneba, amuro, wife.

\section{Papuan and Melanesian.}

Three Melanesian languages are spoken in the country around the lower courses of the St. Joseph and Aroa rivers, and are thus in immediate contact with the Papuan languages spoken about the upper waters. These Melanesian languages are the Mekeo, Kuni and Pokau. It is, therefore, of some importance to note whether any apparently non-Melanesian elements in these languages may be traced to the influence of the neighbouring Papuan tongues.

In Grammar the only non-Melanesian characteristic which appears is the preceding of the substantive by the genitive, but in the vocabularies a few correspondences are found.

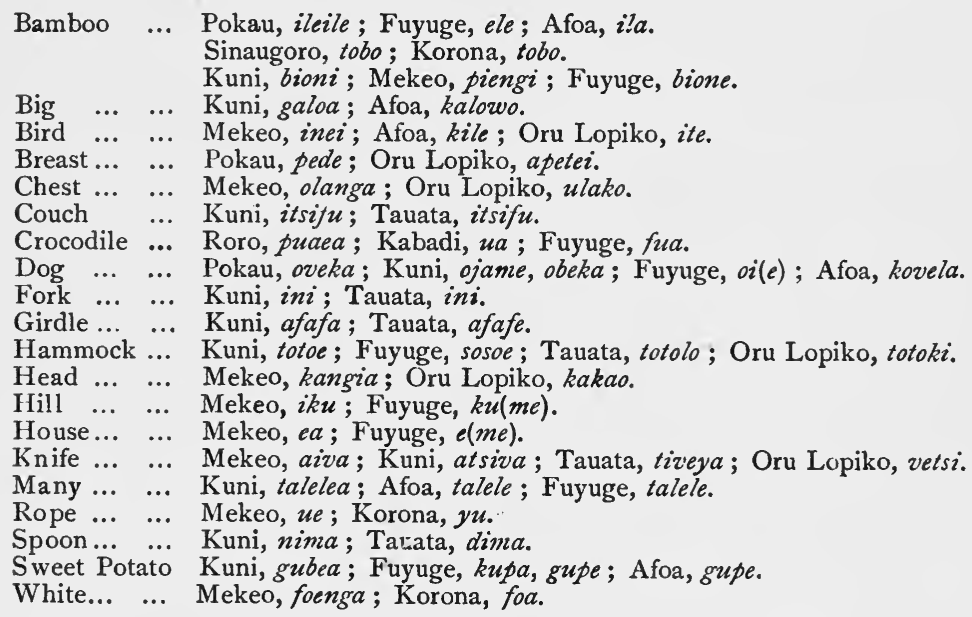

But there are many apparently non-Melanesian words in Mekeo, Kuni and Pokau, which are different in each language, and cannot be traced to the neigh- 
bouring Papuan. The inference is that such words may be remnants of other Papuan tongues spoken in the St. Joseph and Aroa Basins, which have been absorbed by the immigrant Melanesian speech.

Only three Melanesian words in the list appear to have been adopted by the Papuans. These are: Tauata nau (pe), earthen dish, which is Kuni, Motu, Pokau, \&c., nau; Fuyuge asi boat, Pokau and Motu asi ; and Fuyuge bara, paddle, the Motu, Kabadi bara, Mekeo fanga, oar. The Fuyuge kokole fowl is also probably the Mekeo kokolo. 


\section{INDEX}

Abortion, see Killing-Infanticide Aduala River :

Houses on, type of, 109

Situation of, 4 and $n$

Wier on, 193

Aduala valley, 4

Aetas (Philippine Islands), $300 \mathrm{ff}$.

Afoa, see Ambo

$A$-gata, meaning of word, 89

Agriculture, $194 \mathrm{ff}$.

Alabula (Loloipa) river, $4 n, 22 n^{1}$

Albert Edward, Mt., 4 and $n, 9$

Alo community, 87

Amalala, feasts at, 154-6, 249

Ambo :

Name, variations of, 5

Origin of, 299

Ambo (Afoa) language :

Area of, 4,8

Note on, 234, 332-3; vocabulary, $235,336-44,348-9$

Amo-Kau, chief, 87

Ancestor-worship non-existent, 9I, 271

Andamanese, $257 n^{2}$, $300 \mathrm{ff}$, 305

Angabunga river, see St. Joseph

Anum' Iva, Chief, 86

Aristocracy, 94, 96-7

Armlets, 52-3

Art and design :

Armlets and wrist bands, 52-3

Bags, 73-4, 207-8

Bark cloth, 202-3

Belts (bark), 30 (plaited), 30, 32

Buildings, absence in, 99

Dancing aprons, 57-8

ribbons, 59

Feather ornaments, 59-6I frames, $6 \mathrm{r}-2$

Forehead ornaments, 50

Gourds (lime), 66

Perineal bands, 27-8

Primitive nature of, $89,90,99,200-$ I I

Smoking pipes, $7 \mathrm{I}$

Auga community, 98, 259

BABIES, see Infants

Bags, carrying :

Charms, for, 285

Colouring of, 208

Kinds of, 72-4
Bags, carrying :

Manufacture of, 207

Personal, for courtship tobacco, I 7 I

Baiva, chief, 86

Bamboo:

Boiling done in stems of, $32,65-7$

Bows made of, 184

Bridges made of, I 12

Drink obtained from, 65

Jew's-harps made of, 213

Knives made of, 44, 69-70

Smoking-pipes made of, $7 \mathrm{I}$

Storage vessels made of, $67-8$

Banks Is., $266 n$

Bark :

Belt made of, 29

Remedial use of, 242

String made from, 207

Bark cloth :

Capes made of, 34, 201

Caps made of, 29, 201

Colouring of, 202-3

Corpse-wrappings of, 256

Dancing aprons made of, 57,201

Dancing ribbons made of, 59,201

Fire-making with fluff of, 72

Manufacture of, 20I-2

Mourning strings made of, 35,201

Ornamental strings made of, 46,201

Perineal bands made of, 26,201

Remedial use of, $24 \mathrm{I}$

Staining of, 202-3

Barton, Capt., map of explorations by, I, 4, I3; cited, 6

Beads, 44-5, 50, 56

Belts, see under Dress

Betel-nut :

Chewing of, 66, 288

Ornamental use of, 44-5

Bilage, meaning of word, 88

Birds :

Dancing imitative of, 220-I

Hunting of, I9I

Tame, 76-7

Boboi :

Kovio suggested as general name for Oru Lopiku and, 7

Language of, 6

Origin of, 299

Oru Lopiku boundary of, 2

Body-staining among Mafulu people, $4 I-2,220$ 
Boring drills, 7 I-2 and $n$

Boundaries, respect for, 83, I18, 122

Bridges, types of, I I I-I 2

British New Guinea Annual Report cited-(I889), I12 $n^{2} ;$ (I894), II $n^{2}$; (1896), $346 n^{1}$; (1897), I I $n^{1}$, I2 $n 2,346 n^{2}$; (I900), $4 n$, $247 n^{2}, 257 n^{1}$; (1906), $8 n^{2}, 14 n^{3}$, $346 n^{3}$; (I909), I I I

British Ornithologists' Union expedition, see Dutch New Guinea

Bull-roarers, I I, I62

Burial customs:

Chirima people, of, ro

Mafulu people, of :

Platform, 256, 258, 263

Sepulture, 246

Tree, 257 and $n^{1}, 258,263$

Semang and Andamanese people, of, $257 n^{2}, 305$

Burial platforms :

Construction of, 256

Cutting down of, I44

Feast, the big, ceremonial in connection with, 136

Bush land, ownership of, I I7-18, 120

\section{Cane :}

Arrows made of, 184

Belts made of, 30,31

Fishing nets made with, I92-3

Headdress frames made of, $61-2$

Tug-of-war played with, 226

Cannibalism :

Kuni custom as to, 294 ; purification after the feast, $282 n^{3}$

Mafulu custom as to, I79, I83

Carriers, $42,75 n^{2}$

Carrying bags, see Bags

Cats cradles, absence of, 225

Cephalic index :

Dwarf peoples compared as to, $30 \mathrm{I}$

Mafulu, comparative tables as to, $18-20$

Ceremonies (see also Feasts) :

Abdication of chiefs, at, 95

Attacks, ceremonial, I 57, 255

Birth, on, 157

Chieftainship, on devolution of, I65-6

Death, as to, 243-6 ; chief's, $252 \mathrm{ff}$.

Drum and dance, conferring right to, I64-5

Emone, before admission to, 163-4; on building of, $166-7$

Fishing, preliminary to, 193

Haunted spots, for, 274-5

Hunting, preliminary to, $187-8$

Magic men, performed by, on chief's illness, $253-4$

Marriage, I72-3
Ceremonies:

Mourning removal, of, $25^{1-2}, 262-3$

Nose-piercing, for, $37-40$

Perineal band, on assumption of, 1 58-62

Pig-buying at feasts, 232-25I

Purification, I52-4, I62, I64-5, 250, $252,262-3$

Yam-planting, at, 196-7

Chabot, Father, cited, I77

Chalmers, Rev. James, cited, I87.n, I97; Kabana language collected by, $238,345^{-6}$

Character and temperament of Mafulu people, 24-5

Charms:

Bags for, 74

Belief in, 285

Fighting, I8 $\mathrm{r}$

Fishing, 193

Hunting, I 88

Illness, against, 240, 242

Love, 278, 285

Spirits associated with, 27I, 275

Chiefs of Mafulu people :

Abdication of, 95

Birth ceremony for, 157

Bones of, ceremonial use of, 125, 135-6, I 50

Burial of, $256 \mathrm{ff}$.

Clan system in relation to, $84-5$

Death of, 252-5, 277

Devolution of chieftainship, ceremoney on, 165-6

Dress of, not special, 36

Etiquette regarding, 79

Feather ornament special to, 60-2, I 38

Functions of, 92, II4

Funeral of, 256, 259-60

Headdresses of, 143-4, 146

Marriage necessary for, 95

Minors, case of, 86, 96

Mourning for, 260; removal ceremony, 262-3

Nose-piercing chiefly found among, 40

Perineal band ceremony for children of, $16 \mathrm{I}$

Polygyny among, I69

Predominance of, how determined, 88

Residences of, 88, 92, II 7

Sub-chiefs, 93, 96-7

Succession of, $94-5$; food taboo prior to, 289

Usurpation of office of, 96

War chief, no, 94

Wives of, graves of, 263

Children of Mafulu people (see also Infants) :

Adoptions of orphans, 124 
Children of Mafulu people (cont.) :

Burial custom for, IO

Emone admission ceremony for, I63-4

Etiquette for, 79

Excrement of, sorcery connected with, 280-I

Games of, 225-6

Girls, restriction on, as to emone, I64

Hunting, part in, 187,188

Inheritance by - of chieftainship, 96 ; of property, II I-2I, I23

Mourning for death of, 247 and $n^{2}$

Ornaments of, $45,46,5 \mathrm{I}-3$

Perineal band ceremony for, $158-62$

Chirima people :

Boring implement of, $72 n$

Counting system of, $227 n$

Description of, 9-13

Language of, 235, 237, 336-46

Situation of, 4

Circumcision not practised, 44

Clans of Mafulu people :

Aristocracy of, 94, 96-7

Badges not adopted by, 89

Connection in, word signifying, $84 n$, $85,88,9 \mathrm{I}$

Exogamy of, 85, 92

Membership of, how denoted, 85

Names for, non-existent, 85 ,

Offences against, I 15

Predominance among, 88

Totemism, absence of, 90-I, 2 I I

Villages in relation to, 83-5 and $n$

Warfare between, see Warfare

Clauser, Father, cited, I I6, 220-I ; photographs given by, I 54

Coast people :

Comparison of Mafulu with, 297

Contact with, $210-1$ I

Codrington, Dr., cited, 198, $266 n$, $28 \mathrm{I}$

Colour of Mafulu people, 22, 298-9, 302

Communications in Mafulu district, I IO-I3

Communities of Mafulu people :

Boundaries between, 83

Clan system in relation to, 84-5 (see also Clans)

Connection in, word signifying, 88

Exchange and barter between, 232-3

Funeral feast and big feast invitation, restricted to one of, 250

Property possessed by, I I 7

Separateness of, 82-3

Villages comprising, number of, 83

Comparative table of physical characteristics, 300-4
Cooking among Mafulu people :

Methods of-for sweet potatoes, $38-9$; boiling, 67-8; roasting, 66-7; stone cooking, 67

Nose-piercing patients, for, 38

Women, by, $38,63-4$, I 45

Counting :

Method of, 227, 229-3I

Recording, no visible means of, 2 Io, 231

System of, 227

Cowrie shells, see under Decoration

Cranial capacity compared with that of Europeans, 2I

Cranial index tables, I8-20

Creepers :

Fibre of, used for belts, $31-2$ and $n^{2}$

Obstruction of paths by, I IO

Superstitions regarding, 9I, 273

Croton leaves :

Decorative use of, 131, 133, 136, I67

Invitations accompanied by, I 32

Nose-piercing, used after, 39 and $n^{1}$

"Sweetheart of the yam," I96

Currency, 23I-2

Cuscus tails, 48-9

DAILY LIFE of Mafulu people, 63-4

Dancing :

Aprons worn for, 57-8, 220

Belts worn for, 33

Body-staining for, 42, 220

Decorations for, quantity of, 220

Feast, at the big-preliminary $143-4$; real dance, $145^{-6}$

Food taboo in connection with, 288

Funeral feasts, at, 249 ; chiefs', 26I

Headdresses and back ornaments worn for, 6I, 219, 222

Nature of, 218-20; theory as to birdimitation, 220-4

Perineal band ceremony, at, 159

Preliminary, before big feast, I3 I

Ribbons worn for, 59, 220

Right of, ceremony as to, 164, 289

Roro-cassowary dance, $225 n$

View-platforms for, I 29-30

Dauncey, Rev. Mr., $39 n^{2}$

Davidson, Mt. :

Language of natives of, 238, 332

Situation of, 8, 238-9

de Boismenu, Monseigneur, 87 ; cited, 9

Death, ceremonies connected with, 243-6 ; chiefs', $252 \mathrm{ff}$.

Decoration, personal :

Armlets, 52-3

Bark cloth strings, 46-7

Beads, 44-5, 50, 56

Betel-nuts, 44-5

Cane ornaments, 44-5

A A 2 
Decoration, personal (cont):

Combs, 47

Cuscus tails, 48-9

Dancing, for, see under Dancing

Discontinuance of, during convalescence, 34

Dogs' teeth, 44-5, 50, 158 ; boring of, 71

Ear-rings, $48-9$

Emone admission ceremony, for, $\mathrm{I}_{3}$

Feathers :

Back ornaments, 6i

Chiefs' special, 138, 262

Combs, with, 48

Frames for supporting, 6I-2

Headdresses, 59-62, 143-4, 146

Perineal band ceremony, at, I 59, I6 I

Forehead, for, 49-50

Headdresses, 59-62, 143-4, 146

Leg-bands, 53-6

Nose, for, 50 ; price of, 232

Pearl discs, 5I

Perineal band ceremony, for, $158-9$, $16 \mathrm{I}$

Pigs' tails, 45-6 and $n, 49,52$

Sale of, 233

Shells :

\section{Boring of, $7 \mathrm{I}$}

Cowrie, 44-5, 50

Mourning necklace of, 5 1-2, 246,260

Pearl ornaments, $5^{1}$

Wrist-bands, 53

Skulls and bones as, I3 I, I35, I46

Wrist-bands, 52-53

Decoration of objects :

Bags, of, 73

Croton leaves as, 167

Gourds and spatulæ, of, 66

Hammocks, of, 206

Pipes, of, 7 I

Dendrobium, 32 and $n^{2} 47,49$

Depilation among Mafulu people, 36-7

Desnoes, Father, cited, $160 n^{1}$

Deva-deva, $15 n, 28$

Dilava village, 2, 28, 292

Diseases, 240

Dishes and plates, 68-9

Disputes, rarity of, 83, II 4-I 5, I22

Divination, 27 7-9

Dogs, domestic :

Chirima people, of, 12

Description of, 76

Hunting with, 187

Dogs' teeth :

Currency, as, 232

Ornament, as, 44-5, 50, 158 ; boring of, $7 \mathrm{I}$

Domestic animals, 76-8. (And see names of kinds.)

Doura district, I 3
Dress of Mafulu people :

Belts, abdominal, 29-34: of dogs' teeth, $15^{8}$

Capes, 34-5

Caps, 29

Dancing aprons, 57-8

Mourning strings, 35,260

Mourning vests of widows, 35, 209, 260

Perineal band :

Assumption ceremony, $15^{8-62}$; food taboo in relation to, 289

Chief's, sick, ceremony connected with, 253-4, 277

Description of, $26-9$; padding, 9

Etiquette in connection with, 78-9

Scantiness of, 27, 28, 36

Drink, 65

Drumming :

Big feast, at, 143-4

Ceremony conferring right of, I64-5 ; food taboo prior to, 289

Funeral feast, at, 248

Drums, description and making of, 212-13

Dutch New Guinea, dwarf people of :

Belts of, $33 n$

Dancing and singing of, $224 n$

Network by, $204 n$

Origin of, 298

Physique of, $22 n^{3}, 24,300 \mathrm{ff}$.

Dwarf peoples :

Aetas (Philippines), $300 \mathrm{ff}$.

Dutch New Guinea, of, see Dutch

German New Guinea of, 298

Semang and Andamanese, $257 n^{2}$, $300 \mathrm{ff}$, 305

Tabulated comparison of, $300 \mathrm{ff}$.

EAR-PIERCING among Mafulu people, 40-I

Ear-rings, 48-9

Eating (see also Food) :

Etiquette regarding, for unmarried men, 79

Utensils and customs for, 68-9

Eels, I92

Egedi, Rev. Father, S. C., Fuyuge Grammar by, 234, 307-31 ; Mafulu vocabulary of, 235, 336-44 ; Tauata vocabulary, 235, 333; Oru Lopiku vocabulary, $335 n n$; cited, 2, 6, I $28 n, 166 n, 225 n, 227 n$, $282 n^{3}, 288 n, 291 n^{2}$; on the Kuni people, $290 \mathrm{ff}$.

Eleia, Mt., 2; languages of natives round, 334

Emone:

Admission to, 293 ; ceremony before, I63-4 


\section{INDE $X$}

Emone (cont.) :

Building of, 129 and $n^{1}$; ceremony on, 166-7 ; special erection, 93

Ceremonial attacks on, 140,157

Chiefs' bones hung in, 258, 259

Clan system in relation to, 84-5

Croton leaves hung on, 132, I67

Description of, $100 \mathrm{ff}$.

Etiquette regarding, 78-9

Houses, ordinary, compared with, 108-9

Numbers of, 94, 100

Occupants of, 63

Pig-measuring poles tied to, 149

Platform of, IOI

Situation of, 88

Storage of fruit in, 102, I 28

Subsidiary, 93

Upkeep of, 92-3

Women not allowed in, 293

Etiquette among Mafulu people, 78-81

European goods :

Agricultural implements, 195-6

Clothes, no demand for, 36

Varieties of, 76

Exchange and barter, 232-3

Eyes of Mafulu people, 21

Facial characteristics, $17 \mathrm{ff}$.

Family life of Mafulu people, 64

Faribe village, illustration of grave at, 259

Feast, funeral, 247-50 ; chiefs', 260-1

Feast, the big:

Building and repairing for, $129-30$

Ceremonial of, $137 \mathrm{ff}$.

Ceremonies introduced into, 147

Cutting down of chief's burial platform, I 44

Dancing previous to, I3I ; preliminary dancing at, $143-4$; real dance, $145^{-6}$

Decorations for, I38 ; sale of, 233

Desertion of village after, $15^{2-3}$

Food distributed at, $144-5,147-8$

Guests at :

Accommodation for, 130

Composition of, 126, 137

Invitation of, I 26 ; formal, 132

Luggage of, 137

Reception and entry of, $137-42$

Men's part in, 138 , I42-5I

Occasion of, infrequent, 125

Organisation of, $125 \mathrm{ft}$.

Origin of, question as to, 125

Photographs of, 154-6

Pig-killing and distribution at, 148-52

Posts, decorated, for, I30-1, 133-6

Preliminary festivity prior to, I 3 I
Feast, the big :

Preparations for, $126 \mathrm{ff}$.

Purification after, $152-4$

Singing at, 146

Site of, $125-6$

Skulls and hones smeared with pig's blood, 150

Women's part in, $136-43,145,148$

Feast to ratify peace, 183

Feasts (see also Ceremonies) :

Fasting before, 31, 66

Nose-piercing ceremony in connection with, 40

Pigs, village, provided for, 40 ; custom as to eating, 78

Feathers, see under Decoration

Feet, counting with, 228-3 I

Fibre, belts made with, 30-2 and nn

Fillodean, Father, I

Fire-making, 72

Fire-places, 102

Fishing, I92-4 ; supplication at, 193, 286

Flowers, wearing of, 62

Flutes, 214-15

Fly River mouth natives, $224 n$

Food :

Beans, 199

Cooking of, see Cooking

Eating of, see Eating

Flesh, varieties of, 65

Fruit, see that heading

Inedible portions of :

Ceremony connected with, on chief's illness, 253-4, 277

Sorcery in connection with, 279-80

Preparation of, for big feast, $126-8$

Storage of, 102, 127-8

Sugar-cane :

Big feast, for, 126-127, I 34

Planting of, 199

Sweet potatoes :

Cooking of, 38

Cultivation of, 195

Pigs fed on, I 26, I99

Special diet of, $38,4 \mathrm{I}$

Types of, 65 and $n$

Taboos regarding, 90, 287-9 ; opTaro: tional, as mourning, 247 and $n^{1}$

Big feast, for, I 26-7, I 30 , 135

Planting of, 198 and $n$

Types of, $65 n$

Utensils for, 68-70

Yam :

Big feast, for, 126-7, 130; selection and hanging of, 133,135

Cultivation of, 196-7

Superstitious importance of, 197

Types of, $65 n$ 
Forks, 68-70

Fruit :

Banana :

Big feast, for, I 26-7, I 34

Planting of, 198-9

Staple of food, as, 65

Malage :

Big feast, for, 126-8, 147

Cultivation of, 200

Genus of, $128 n$

Preparation and storage of, 128, I35

Pandanus, 65 ; stain obtained from, $4 \mathrm{I}, 42,203$

Pandanus ine :

Big feast, for, I26-8, I35, 147-8

Funerals :

Cultivation of, 199-200

Chiefs', 256, 259-60; feast after, $260-1$

Desertion of village after, $26 \mathrm{I}-\mathbf{2}$

Ordinary, 246; feast after, 247-50

Fuyuge language, 345 ff.; grammar, $234,307-31$

Fuyuge people :

Area of, 3-4, 7-8

Boundary of, 2, 3, 5, 7-9, 13-4, 236-7

Mafulu name as connoting, 3

\section{Galley Reach, 346}

Game :

Kinds of, 186

Rights as to, I I 7

Games, 225-6

Gardens :

Cooking in, 67

Eating in, 65

Houses in, II 8

Ownership of, I I8 ; joint, I20-I

Two kinds of, 200

Work in, allocation of, 63

Geological formation of Mafulu country, I5

Geographical nomenclature among Mafulu people, 85

German New Guinea, dwarf people of, 298

Gestures of assent and dissent, 80-I

Ghosts :

Belief in, $266 \mathrm{ff}$.

Pig-killing to scare away, 250, 268, 270

Shouting to scare away, 244, 246, $255,260,268-70$

Spirits in relation to, $275-6,284$

Gito-iola, Chief, 86

Giulianetti, A., 346 ; cited, $247 n^{2}$

Goodfellow, Walter, quoted, $23 n$; cited, $224 n$
Gourds for storage purposes, 66,68

Government, no system of, I I4

Haddon, Dr., quoted, 13; cited, $22 n, 109 n^{1}, 182 n, 225 n, 298$, 299

Hair of Mafulu people :

Character and colour of, 22 and $n n^{2}, 3,292,303$

Depilation of men, 36-7

Hair-cutting among Mafulu people, 44, 279-80

Hair-dressing :

Chirima upper valley people, of, 9- Io

Mafulu people, of, $42-4$

Hammocks :

Hanging of, 106

Manufacture of, 204-6

Use of, general among Mafulu, 74-5 and $n^{1}$

Haunted spots, 274-5

Healers, reputed, 240-2

Hood Peninsular custom cited, I62

Houses, Chirima, roof-projection of, IO ; at Mt. Scratchly, I3

Houses, Kuni, 293-4

Houses, Mafulu :

Description of, 108-10

Duration of, II 7

Fire-places in, I 2-I3

Gardens, in, I 8

Property in, rule as to, II 7

Repairing of, 129

Roof-projection of, 10, 108 and $n$

Sites of, ownership of, I I 7

Hunting :

Ceremony preliminary to, $187-8$

Game hunted, 186

Individual, 189

Methods of, I 87-9I

Weapons for, I86-7

IDO-IDO ;

Bridge near, 112 and $n^{1}$

Ceremonial dart-throwing at, $158 n$

Dress of women at, 28

Illness :

Capes worn after, 34

Nature of, and remedies for, 240-2

Sorcery as producing, 240, $279 \mathrm{ff}$.

Imbele, $84 n, 85,88,91$

Implements, Kuni, 295

Implements, Mafulu :

Adzes, 68, 76

Bark cloth beater, 177, 202

Forks, 68-70

Knives, bamboo, 44, 69-70

Inava valley, vocabulary of, 235,334

Inavaurene, 6, 235

Incantations, 286 
Infants of Mafulu people (See also Children) :

Adoption of, 178

Bags for carrying, 73

Betrothal of, 170

Birth of :

Ceremonies connected with, 157, I 78,282

Food taboo prior to, 288

Deformation of, not practised, 44

Guardianship of, 123-4

Inheritance by, 123

Killing of, $176-8$

Inheritance, $:$ I 19 ff. :

Children, by, I19-2I, I 23

Disputes as to, rarity of, $\mathrm{I} 22$

Females barred from, I19, 120, I22, 123

Widow's allowances, I I9

Initiation. 110 ceremony of, 162

Iu-Baibe, Chief, 87

JARIA, Chief, 86, 87

Jew's-harp, 2I 3-I4

Judicial system non-existent, I I4, 122

Kabadi District, 5, 7, 13

Kabadi people, I4

Kabana language, 238, 345-7, 349

Kamaweka, connotation of term, 6

Kambisa, see Chirima

Kea river, 3, $4 n$

Keith, Dr., cited, 20-I ; quoted, 298-9

Kemp Welch river, $257 n^{2}$

Killing :

Dying, of the, possibility of, I 76

Infanticide, I 76-8

Penalty for, II 5

Penalty of, for adultery, 173, 176

Quarrels, in, rare, 176

Kiwai natives, $224 n$

Knives, 44, 69-70

Knutsford, Mt., natives of, 13

Koiari people :

Area of, 7

Hair of, $22 n^{2}$

Koita people :

Childbirth custom among, 282

Consanguinity restrictions among, $169 n$

Heni ceremony among, 124, 160

Mourning removal ceremony among, $25^{2} n$

Property system of, I I $7 n$

Succession among, 95

Taboo among :

Ceremonial of, $129 n^{1}$

Food, as to, $273 n^{2}$; for mourning, $247 n^{1}$

Sign of, $274 n$

Wedding decoration of, $46 n$
Korona, I 3 ; vocabulary of, $235,336-44$, 346 ; Dr. Strong's notes quoted, 237

Kovio :

Connotation of term, 5,7

Origin of people, 299

Kovio language, 234-5, 237-8, 334-5, 348-9

Kuni :

Boundary of, 2, 4

Bridge over St. Joseph river, I 12

Dogs obtained from, 76

Scenery of, 15

Villages of :

Height of, 98

Situation of, $\operatorname{I09} n^{1}$

Kuni language, 5, 82, 290, 295, 35I-2 ; pronunciation peculiarities of, 2, 5, and $n$

Kuni people :

Birth ceremony among, I $57 n$

Burial of live infants practised by, 178

Cannibalism among, 294

Comparison of, with Mafulu, $290 \mathrm{ff}$.

Customs of, 5, 292-3

Dancing of, 223

Dress of women of, 28

Fruit-preserving by, I $28 n$

Funeral ceremony among, 293

Hair-dressing of, 42

Houses of, 293-4

Implements of, 295

Intervillage relationship of, 292

Kufu system among, 293

Physical characteristics of, 22, 290-2

Pigs suckled by women among, I 77

Purificatory bathing among, $282 n^{3}$

Remedies of, 293

Restlessness of, I 5

Shouting of messages among, I 13

Umbilical cords worn by mothers among, 62

War chiefs, 293

Kwoifa district, vocabulary of, 334

LAKEKAMU river district, vocabulary of, 235, 334

Language of Mafulu people :

Comparative table of, $346-7$

Fuyuge Grammar, 234, 307-3 I

Notes on, by Dr. Strong, quoted, 237

Vocabulary of, by Father Egedi, 235, 336-44

Lapeka people :

Dress of women of, 28

Physical features of, 29I and $n^{2}$

Leg-bands, 53-6

Lilley, Mt., 237, 346

Lips of Mafulu people, 2 I 
Loloipa river, see Alabula

Lopiko, 334

MACGREgOR, Sir Wm., I $86 n$; cited, I I, I 2-I 3, $257 n^{2}, 345^{-6}$; quoted, $224 n$

Macgregor bears, I86 and $n$

Mafulu, connotation of term, 2-3, I 5-16

Magic men :

Belief in, 266

Ceremony performed by, on chief's illness, 253-4, 277

Charms procured from, I 7 I, 285

Illness caused by, alleged, 279 ff.

Lesser, 278, 283-4

Mekeosorcerers compared with, 276-7

Rain diviners, 278-9

Water as protection against, 28 I

Maiming in token of mourning, 247 and $n^{2}$

Malala village, illustration of grave at, 258

Mambare river, 9; weapons of tribes on, II $n^{1}$

Mambule community, 2, 216-17

Man, Mr., cited, $258 n$

Map, explanation of, I

Marriage :

Adultery, I 73-4, I 76

Age for, 168

Ceremony of, 172

Chiefs under compulsion of, 95

Courting, I70-2

Exogamy, clan and village, 85, 168

Infant betrothal, 170

Kuni custom as to, 292

No special relationship of, between communities, I68, $250 n^{1}$

Polygyny, I69, I 72

Prohibitive rules of consanguinity, I 69 and $n$

Purchase of wives, 91, 172; price, I73; repayment claimed on elopement, I74

Runaway, 173

Severance of tie of, I 74

Unfaithfulness subsequent to, I73

Widow, no devolution of, I 74

Masks not used, I62

Massim :

Funeral feasts of, 250

Omens among, $285 n$

Matrilineal descent and mother right, absence of, 124

Mekeo language, $35^{\mathrm{I}-2}$

Mekeo Nara, 7

Mekeo people:

Bark cloth beaters of, 202

Betel-chewing among, 66

Biofa tribe of, $222 n$
Mekeo people (cont.) :

Birth ceremony among, ${ }_{5} 8 n$

Boring drill of, 7 I

Boundary difficulties among, 83

Chieftainship among :

Devolution, feast and ceremony at, $165 n, 166 n$

Joint, 95

Combs of, 47,48

Counting system and method of, $227 n, 230$

Dancing among, 218-20

Dress of women of, 28

Ear-rings of, $49 n$

Fear of mountain people entertained by, $210 n$

Feathers worn by, 48; head-dresses, 59

Fishing methods of, 192, $193 n$

Food taboos among, $288 n$

Games of, 225

Garden system among, 200

Hair-dressing of, 42

Hammocks of, 204

Hinterland of, 5

Inawae clan of, 222 and $n$

Intercourse between villages of, 89

Kabadi people an offshoot of, I4

Laziness of men of, 64

Mourning removal ceremony among, 251 I $252 n$

Musical capacity of, 212

Perineal band ceremony among, I24, 160 and $n^{1}$

Physical characteristics of, 21, 22

Pig-killings among, 150

Shells ornaments of, 50-I

Sorcerers of, 276-7

Superstition of, 2I 3

Temperament of, 25

Villages and emone of, compared with Mafulu, 99-100

otherwise mentioned, $40 n^{2}, 46 n$

Melanesian languages, 5 and $n, 35^{\mathrm{I}-2}$

Melanesian tendency of features, instances of, 23

Men of Mafulu people :

Adultery of, 173-4

Bachelors :

Eating taboo on, 79

Food taboo on, 287-8

Dancing of, previous to big feast, $\mathbf{I} 3 \mathbf{I}$

Dress and ornaments made by, 26, $30-5,52,57,59,6 \mathrm{I}$

Dress of :

Belts, abdominal, 29-34

Capes, 34-5

Caps, 29

Dancing ribbons, 59

Mourning strings, 35

Perineal band, 26-9 
Men of Mafulu people (cont.) :

Etiquette for, 79-8I

Hairdressing of, 42-4

Inheritance only in male line, 94-5 and $n, 124$; by widowers, 123

Nose-piercing among, 37-40

Ornaments of, 44-53

Work of, in agriculture, etc., 63-4, 195-200

Mission of the Sacred Heart :

Maps lent by, I-2, $4 n, 8-9$; linguistic notes in relation to, $238-9$

Tree-clearing by, 273-4

mentioned, 86-7

Monckton, Mr., map of explorations

by, I, 4, I3; Report of expedition

of, cited, 9-1 I, $72 n, 227 n$

Money, Rev. P. J., cited, 9 ; vocabulary collected by, 235, 336-44, 346

Mortar, ancient stone, 75-6

Motu superstition cited, 197

Motumotu (Toaripi) hunting practice, $187 n$

Mourning :

Black staining for, 42 ; insignia of, 246-7

Chiefs, for, 260

Intermittent wearing of, $246-7$

Kuni custom as to, 293

Maiming in token of, 247 and $n^{2}$

Mud-smearing as, 244, 255

Network vests as, $35,209,260$

Removal ceremony, 25I-2; after chief's death, 262-3

Shell necklaces as, 5I-2

String necklaces as, 35, 246, 260; alternative for, 247 ; removal of, $25 \mathrm{I}$ and $n$

Various methods of, 246-7

Musgrave, Mt., natives of, I3

Music :

Capacity for, among Mafulu people, 212

Example of, 216-I7

Instruments of, $212 \mathrm{ff}$.

NASAL index of Mafulu people, 18,302

Necklaces, 50-2

Negrillo, see Negrito

Negrito strain in Mafulu, 296, 298 ff., 306

Netting :

Chirima people's, ro

Dutch New Guinea dwarfs', 204 n

Mafulu network, 204-6

Strings used for, 203

Nets :

Fishing, for, 192-4, 203-4

Hunting, for, I88, I9I, 203
Network :

Bags made of, 72-4

Hammocks, for, 74-5, 20r, 204-6

Mourning vests of, 35, 209, 260

Northern New Guinea, Mafulu relations with, 9

Nose-piercing among Mafulu people, 37-40; food taboo prior to, 289

Noses of Mafulu people, I7; Semitic, $2 \mathrm{I}, 22 n^{1}$; statistical tables, I8, 21

Numbers, no visible means of recording, 210 (see also Counting)

Numerals, 227-9

OMENS, 9I, 285-6

Origin of Mafulu people, question as to, $297 \mathrm{ff}$. ; older population of New Guinea, 299, 306

Oriropetana village, 222

Ornaments, see Decoration

Oru Lopiku :

Boboi boundary of, 2, 6

Kovio suggested as general name for Boboi and, 7

Origin of, 299

Vocabulary of, 235-6, $335 n n$

Pandanus, see under Fruit

Papuan language :

Ambo, of, 6

Area of, 2-3

Boboi, of, 6

Papuan physique, $21-2$ and $n^{1}, 24$

Paths, I IO-II

Penalties, II 5

Perineal band, see under Dress

Physique :

Chirima people, of, 9

Inavaurene people, of, $19 n$

Mafulu people, of, I $7 \mathrm{ff}$, 30 I

Pic Eleia, 2; languages of natives round, 334

Pig-bone forks, 68, 70

Pig-killer :

Hunting ceremony performed by, I 87,285

Status of, 97 and $n, \mathrm{I} 66,284-5$

otherwise mentioned, I43, 149, 152, I 59

Pig-tail ornaments, 45-6 and $n, 49,52$

Pigs, village ;

Big feast, for :

Breeding and fattening, 126-7

Counting, 229-3I

Killing, collection and distribution, I 48-52

Preliminary feast, distribution at, I3I

Chieftainship devolution ceremony, killing and cutting at, 165-6.

Compensation, as, for adultery, I74 
Pigs, village (cont.) :

Cookery of, 67

Drum and dance ceremony, buying and killing at, 165

Eating of, restrictions as to, I27, I 54

Emone admission ceremony, killing at, 163

Enclosures for, 109

Feeding of, 64

Feasts, killed for, 40

Food for, 126, 199

Funeral feast, killing and distribution at, 249-50 ; chief's, 26 I

Ghost-scaring by killing of, 250, 268, 270

Infanticide in connection with, I 77

Marriage price, as part of, I73

Mourning removal ceremony, killing and buying at, 25I ; chief's, 263

Owner's funeral, killing at, 120

Ownership of, 77-8 ani $n$

Peace-making feast, killing at, $\mathbf{I} 83$

Perineal band ceremony, buying and killing at, $159-60,162$

Price of, 232

Suckling of, by women, 177

Pigs, wild :

Cookery of, 67

Emone building feast, distribution at, I67

Hunting of, 189

Purification ceremonies, for, I 52-4, 162, 250, 252, 262

Taboo connected with, $287-8$

Village pigs becoming, 78

Pipes, smoking, 7 I

Pitsoko (Pizoko), Mt., 8 ; vocabulary from, 238,332

Pöch, Dr. Rudolph, 298

Pokau district, 5

Pokau language, 35 I-2

Pokau people:

Dancing of, 223

Lapeka people related to, 291 $n^{2}$

Nose-piercing custom among, $39 n^{2}$

Portman, Mr., cited, $258 n$

Potatoes, sweet, see under Food

Pottery not used among Mafulu, 75

Property :

Bush land, II7-18, 120

Gardens, I 8

Houses, II 7

Infants, of, 123

Inheritance of, see that heading

Joint, I 20-I

Nature of, I 17

Respect for, 25, I1 5

Women, of, 123

Puberty, no ceremony on attainment of, 162
Pumpkins, 66, 68

Pygmy, see Negrito

Qat, $266 n$

Rain Divination, 278-9

Ray, Sidney H., comparative vocabulary prepared by, 235-7, 336-44 ; Father Egedi's Grammar translated by, 234, 307-3I ; notes by, on Papuan languages of Central Papua, 236-9, 345-52

Religious ideas :

Ghosts, see that heading

Haunted spots, 274-5

Spirits other than human, see that heading

Tsidibe, 264-6 and $n$

Roofs :

Emone, of, 100, 103-4, 106-7

Projecting ends to, ro, 100-I, 108 and $n$; illustration of, $106-7$

Roro people :

Chief of the knife among, $97 n$

Dancing among, $225 n$

Dress of women of, 28

Invitation custom of, $132 n$

Kabadi people allied to, I4

Marea of, 99 ; ceremonial attack on, $158 n$

Mourning removal ceremony among, $252 n$

Perineal band ceremony among, I24, 160 and $n^{2}$

Physical characteristics of, 21, 22

Right and left as regarded by, 93

Sorcerers of, lesser, 278

Superstition of, 213

Temperament of, 25

otherwise mentioned, $40 n^{2}, 46 n$

Rubiana Lagoon district of Solomon Is., $\log n$

ST. JOSEPH (Angabunga) river :

Bridge over, I 12 and $n 1$

Language of natives north of, 332

Mapping of, $4 n$

otherwise mentioned, 2, 7, 8

Sakai people of Malay Peninsula, $33 n$

Salube village, 98

Scenery :

Kuni, I $4 n^{3}$, I 5

Mafulu, 14 and $n^{3}-15$ and $n$

Scratchley, Mt., 4 ; natives of $12-13$

Seligmann, Dr., language notes in possession of, 234, 237 ; cited, 6 and $n, 7,9,12,13,18,22 n^{2}$, $40 n^{1}, 46 n, 95 n, 97 n, \mathrm{II} 7 n, \mathrm{I} 29 n^{1}$, $132 n, 160$ and $n n, 162,169 n$, $223 n, 227 n, 247 n^{1}, 250,252 n$, $257 n^{2}, 273 n^{2}, 274 n, 278,282 n^{2}$, $290 n$, 29I $n n^{1}, 3,292-3$ and $n n$ 
Seluku village :

Burial platform at, 258

Feast at, I 56

Gabi tree at, 259

Semang, $257 n^{2}$, $300 \mathrm{ff}$, 305

Seria village, $225 n$

Sexual relations, I72, I75, I76. (See also Marriage)

Shells, see under Decoration

Shouting of messages, I I3, I33, 244

Sikube village :

Language of, 346

Situation of, 237, 239

Singing :

Big feast, in connection with, $132-5$, I 46

Birth ceremony, at, $158 n$

Character of songs, $215^{-17}$

Funeral song, 244-6, 255, 259

Lullaby, 216

Nature of, 2 I 5

Warfare, in, I82, I8 3

Sivu community :

Villages included in, 86 and $n$

Voitele village of, illustration of emone at, 259

War-song of, 216-I7

Skulls :

Measurements of, I7-2I

Views of, 23

Skulls and bones, decorative use of, I3 I, I 35, 146

Smoking pipes, $7 \mathrm{I}$

Snakes :

Food, as, 65

Hunting of, I87, I9I

Nose-piercing, connection with, 39 and $n^{2}$

Stomachic troubles, supposed connection with, 24 I

Sorcery, see Magic men

Spatulæ, 66

Spirits other than human, 266, 27I-6 ; ghosts in relation to, $275-6,283-4$

Stains, substances producing, 4I, 202-3

Stapf, Dr., cited, $30 n, 3 \mathrm{I} n, 32 n n$, $39 n^{1}, 47 n, 68 n$, I $28 n$, $198 n$, $273 n^{1}$

Stature of Mafulu people, 17-20, $290 n$, 301

Stealing, 25, I I 5-16

Stone Wigg Mt., 9

Storage of food, I02, I27-8

String :

Necklaces of, see under Mourning

Netting, for, 203

Strong, Dr. W. M., map of explorations by, I, 4, I3; Notes by, on Afoa and Kovio languages, 234-5,
332, 334; on Mafulu and Korona languages, 237, 346; cited, 7, I3, I4 $n^{3}$, I8 $n$

Superstitions, see Ceremonies, Charms, Ghosts, Incantations, Magic men, Omens, Religious Ideas, Spirits

Surgery, 242

TABOos, 90; food, -287-9

Taro, see under Food

Tattooing not practised by Mafulu people, 36

Tauata district, language of, 235,238 , 333

Theft, 25, II 5-I6

Thomson, J. P., cited, $257 n^{2}$

Tobacco, 127, I45; in courtship, I 7 I

Toes of Mafulu people :

Counting with, 228-3 I

Peculiarity of, 22, I I I

Toothache, 24I-2

Torres Straits Islands, dancing in, $225 n$

Totemism, no traces of, 90-I, 2 I I

Toys, 225

Trade :

Coast people, with, 2IO-II

Nature of, 232-3

Traps, I 89-9I

Trees :

Burial in, 257 and $n^{1}, 25^{8}$

Spirits, associated with, 273 and $n n,-4,284$

Tsidibe, 264-6 and $n$

Tubetube, $285 n$

Tullalave village, illustration of grave at, 259

UFAFA RIVER, 2

Ukalama river, 2

VANAPA RIVER :

Koiari boundary, as, 7

Suspension bridge over, I I $2 n^{2}$

Valley of, 4

Vanapa watershed, platform burial in, $257 n^{2}$

Victoria, Mt. (Mt. Owen-Stanley), 238, 345

Villages of Mafulu people :

Amalgamation of, 86-8

Clan system in, 83-5 and $n$

Communities composed of : No native word for, 85 Size of, 83

Desertion of, after big feast, $152-4$; after chief's funeral, 26I-2

Emone, see that heading

Enclosure of, graves in, 246

Fortification of, 98-9 and $n$ 
Villages of Mafulu people (cont.) :

Geographical nomenclature of, 85

House-property in, rule as to, I I 7

Houses of, described, I08-10

Pigs of, see Pigs, village

Purification of-after big feast, I 524 ; after perineal band ceremony, 162; after emone admission ceremony, I64; after drum and dance ceremony, 165; after funeral feast, 250-I, 262 ; after mourning removal ceremonies, 252,263

Repairing of, I 29

Sites of, partly determined by presence of Gabi tree, 257

Situation and arrangement of, 98100

Size of, 99

Splitting up of, 85-7, 96

Visiting, etiquette regarding; 80

Voitele village, illustration of emone at, 259

\section{WARFARE :}

Causes of :

Adultery, 9I, I74, I80

Magic, alleged, 255, 283

Murder, 91, I80

Conclusion of, 183

Duration of, I 83

Kuni war chiefs, 293

Leadership in, 182

Method of, I8I-3

Prohibition of, 180

Weapons in, $182-5$

Women's part in, I83

Weapons of Chirima and Lower

Mambare river people, II and $n^{1}$

Weapons of Mafulu people :

Adzes, I85

Bows and arrows, $\mathrm{I} 84$; for bird. shooting, 186-7

Clubs, I84

Shields, I 85

Spears, $183-4$

Weights and measures non-existent, $23 \mathrm{I}$

Wharton mountains, 9

Wollaston, Dr., quoted, $23 n$

Women of Mafulu people :

Abortion procured by, 3I, I76-7

Chiefs' wives, graves of, 263

Childbirth, see Infants--Birth

Cooking done by, 38, 63-4, I45

Dancing of, before big feast, 13 I, I $36-7$
Women of Mafulu people :

Dress and ornaments made by, 26, $31,33-5,54-7,59$

Dress of :

Belts, abdominal, 3I, 33, 34

Capes, 34-5

Dancing aprons, $57-8$

Dancing ribbons, 59

Mourning strings, 35

Perineal bands, 27, 28

Widows' vests, 35, 209, 260

Dying and dead attended by, $243 \mathrm{ff}$., 252,255

Fishing not done by, 192

Hairdressing of, 43-4

Inheritance by, not permitted, II9, I 23

Inheritance from, 123

Loads carried by, $63,72-4,137$

Maiming of, in mourning, 247, and $n^{2}$

Mothers, guardianship of infants

- devolving on, I23

Nose-piercing among, 37-40

Ornaments of, $44-6,49-53$

Physique of, 17

Pigs suckled by, I77

Purification of villages performed by,

152

Sterility of, attempts to produce, I77

Succession to chieftainship never through female relationship, 95

Umbilical cords not worn by, 62

Warfare, part in, 183

Widows :

Allowances to, II 9

Inheritance by, not permitted, II 9

Return of, to own people, I74

Wives :

Adultery of, $173-4,176$

Polygyny, system of, 169, 172

Runaway, I74

Work of, in agriculture, 63, 195-6, 198-200

Women of Mount Scratchley, dress of, 12

Wood used for dishes, 68 and $n$

Wounding, penalty for, I 15

Wounds, treatment of, 242

Wristbands, 52-3

Writing, no system of, 210

YAMS, see under Food

Yodda valley, mortar found in, $76 n$

Yule, Mount, 5, I 2 ; languages of neighbourhood of, 334 


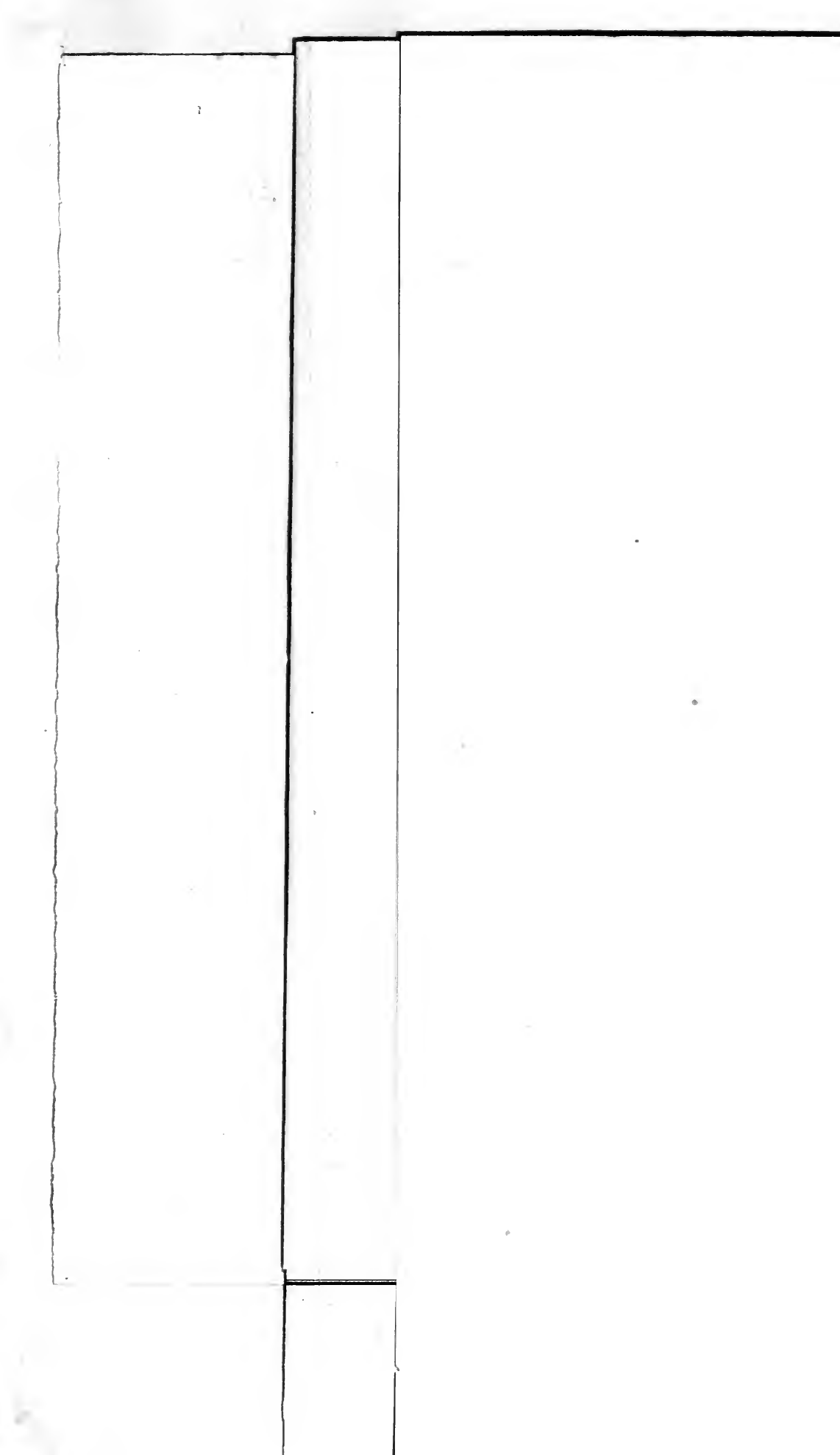







$\begin{array}{ll}\text { GN } & \text { Williamson, Robert } \\ 671 & \text { Wood, } 1856-1932 \\ \text { N5W6 } & \text { The Mafulu mountain } \\ & \text { people of British } \\ & \text { New Guinea. } \\ & \text { Macmillan (1912) }\end{array}$

\section{PLEASE DO NOT REMOVE CARDS OR SLIPS FROM THIS POCKET}

UNIVERSITY OF TORONTO LIBRARY 
